Prepared in cooperation with the Nuclear Regulatory Commission

6. Historical and Paleoflood Analyses for Probabilistic FloodHazard Assessments - Approaches and Review Guidelines os
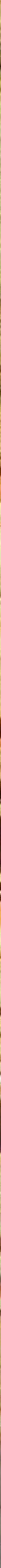
Front cover. Slack-water deposits exposed in Saddle Canyon along the Colorado River in the Grand Canyon, Arizona. Photograph by Tessa M. Harden, U.S. Geological Survey.

\section{Back cover (clockwise from top left):}

Tree scar indicating the stage of a historical flood along Spring Creek in the Black Hills, South Dakota. Photograph by Tessa M. Harden, U.S. Geological Survey.

Ohio River flood stages on the flood wall in Cannelton, Indiana. Photograph by Michelle O'Donnell, Northeastern University. Used with permission.

Subject-matter experts conducting a field review of flood stratigraphy along the Colorado River in the Grand Canyon, Arizona. Photograph by Jessica Flock, Paddle House, Laramie, Wyoming. Used with permission.

Main-stem Colorado River flood deposits interbedded with red tributary deposits in the Grand Canyon, Arizona. Photograph by Jim O'Connor, U.S. Geological Survey.

Flood deposits visible in a terrace exposure along Upper Elk Creek in the Black Hills, South Dakota. Photograph by Tessa M. Harden, U.S. Geological Survey.

Ideal location for the preservation of flood deposits along the Tennessee River near Chattanooga, Tennessee. Photograph by Tessa M. Harden, U.S. Geological Survey. 


\section{Historical and Paleoflood Analyses for Probabilistic Flood-Hazard Assessments- Approaches and Review Guidelines}

By Tessa M. Harden, Karen R. Ryberg, Jim E. O’Connor, Jonathan M. Friedman, and Julie E. Kiang

Prepared in cooperation with the Nuclear Regulatory Commission

Techniques and Methods 4-B6 


\section{U.S. Geological Survey, Reston, Virginia: 2021}

For more information on the USGS - the Federal source for science about the Earth, its natural and living resources, natural hazards, and the environment—visit https://www.usgs.gov or call 1-888-ASK-USGS.

For an overview of USGS information products, including maps, imagery, and publications, visit https://store.usgs.gov/.

Any use of trade, firm, or product names is for descriptive purposes only and does not imply endorsement by the U.S. Government.

Although this information product, for the most part, is in the public domain, it also may contain copyrighted materials as noted in the text. Permission to reproduce copyrighted items must be secured from the copyright owner.

Suggested citation:

Harden, T.M., Ryberg, K.R., O'Connor, J.E., Friedman, J.M., and Kiang, J.E., 2021, Historical and paleoflood analyses for probabilistic flood-hazard assessments-Approaches and review guidelines: U.S. Geological Survey Techniques and Methods, book 4, chap. B6, 91 p., https://doi.org/10.3133/tm4B6.

ISSN 2328-7055 (online) 


\section{Contents}

Abstract

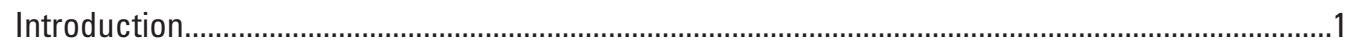

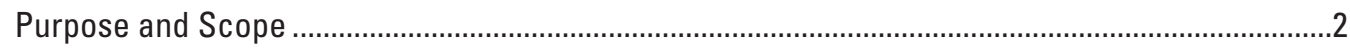

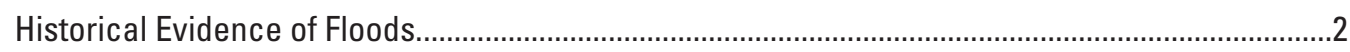

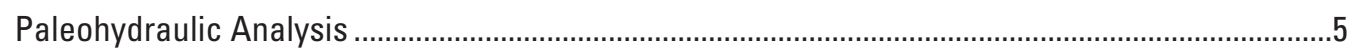

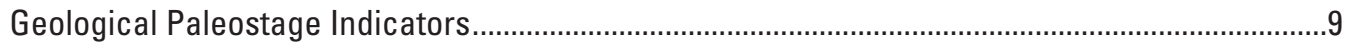

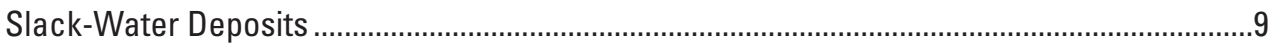

Site Selection and Stratigraphic Analysis of Flood Sequences .......................................

Terrace and Floodplain Deposits...............................................................................................16

Site Selection and Identification of Flood Sequences ...................................................16

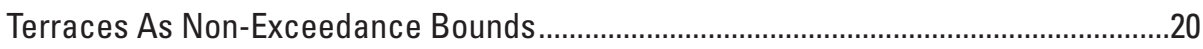

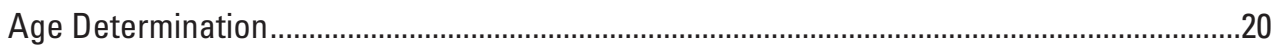

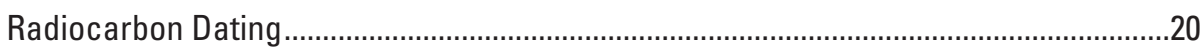

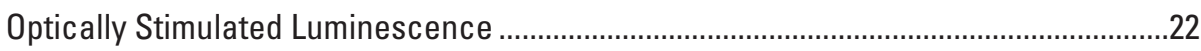

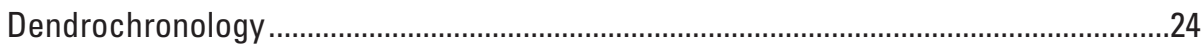

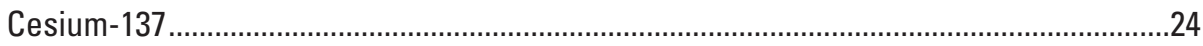

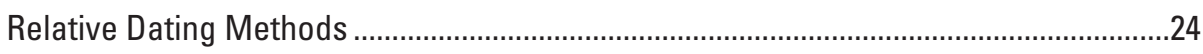

Other Methods for Determining Chronology .............................................................24

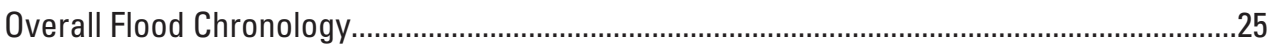

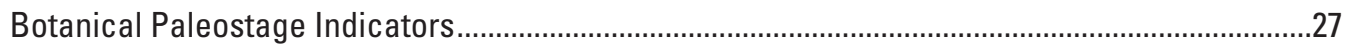

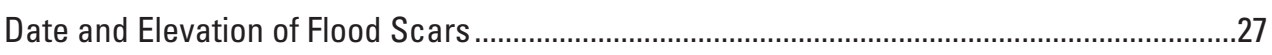

Death Date of Flooded Trees...............................................................................................28

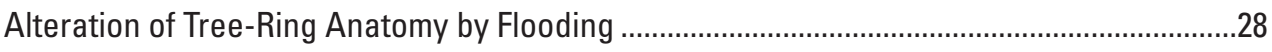

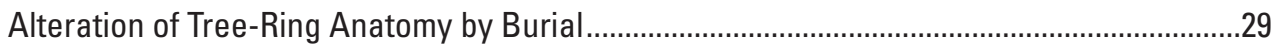

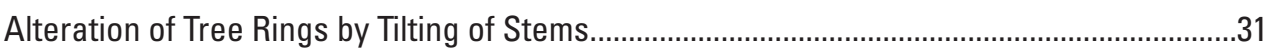

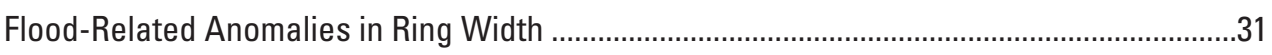

Establishment of Seedlings or Vegetative Sprouts Following Flood Disturbance ...................32

Uncertainties Associated With Paleostage Indicators .....................................................................3

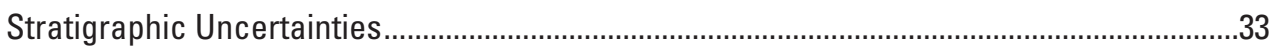

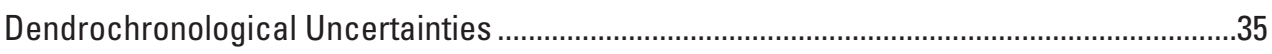

Lake and Other Off-Channel Deposits .....................................................................................36

Site Selection and Identification of Flood Sequences ........................................................36

Stratigraphic Analysis of Lake Deposits and Age Determination ............................................38

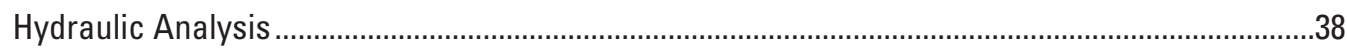

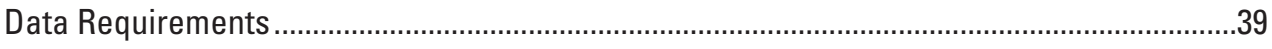

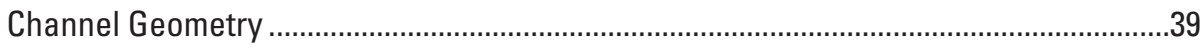

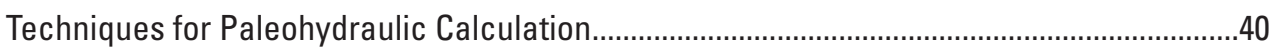

Gradually Varied Flow ............................................................................................ 40

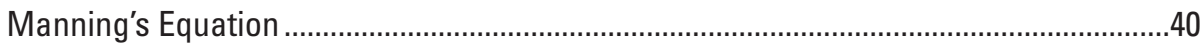

Manning's $n$ Roughness Coefficient ......................................................................

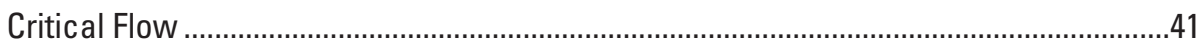

Flow Computation Directly from Sedimentary Deposits ...................................................41

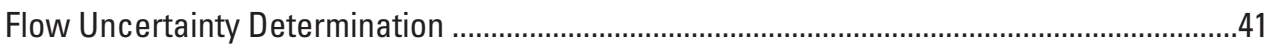




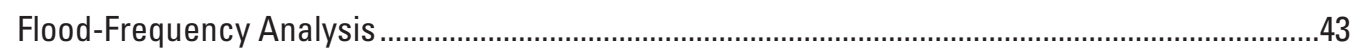

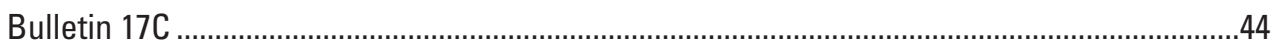

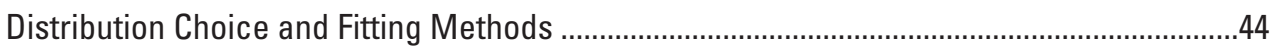

Identification of Perception Thresholds and Non-Exceedance Bounds..................................45

Peak-Streamflow Data Uncertainties and Assumptions ........................................................51

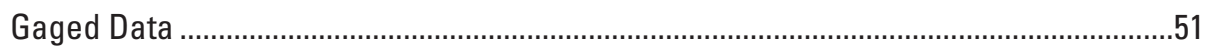

Use of Historical Data in Flood-Frequency Analysis ...................................................52

Examples of Flood-Frequency Analyses Performed with Historical and Paleoflood Data ....53

Uncertainties Not Treated by Bulletin 17C........................................................................53

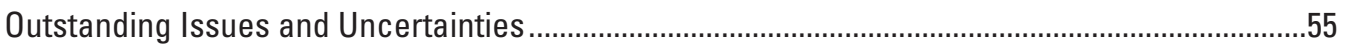

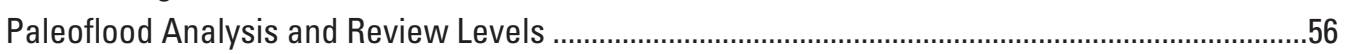

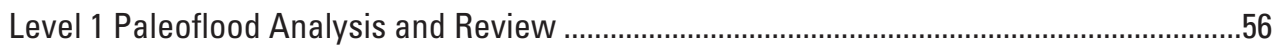

Level 2 Paleoflood Analysis and Review .........................................................................58

Level 3 Paleoflood Analysis and Review .......................................................................62

Documentation and Reporting........................................................................................

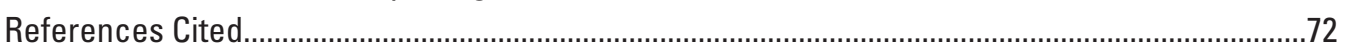

Appendix 1. Development of a Framework for Technical Review of Paleoflood

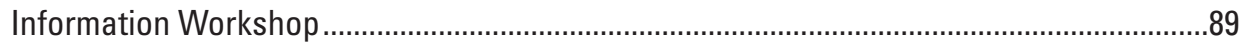

Appendix 2. Incorporating Historical and Paleoflood Information in Probabilistic

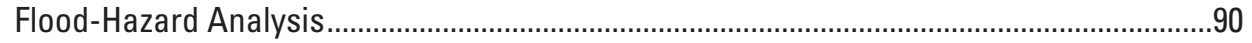

\section{Figures}

1. Photographs showing historical building in The Dalles, Oregon, with etching of the elevation of floodwaters from the 1894 flood on the Columbia River.

2. Photographs showing examples of high-water marks from woody debris, mud line on a fence marking peak water surface elevation, and tree and erosion scars......10

3. Photographs showing paleostage indicators including slack-water deposits, boulder bar, tree scar, erosional features, and silt lines.................................................11

4. Photograph showing flood scour marks on bedrock of Taylor Arroyo, Colorado............12

5. Photograph showing vertical sprouts on a tree along Elk Creek, South Dakota ..............13

6. Photograph showing large driftwood log likely from the 1884 flood on the talus slope along the Colorado River in the Grand Canyon, Arizona .

7. Deposits from individual floods within a sedimentary sequence commonly distinguished by the following criteria-Silt layer capping a flood unit, intervening layers of non-main-stem deposits such as tributary sediments separating mainstem flood deposits or angular cave roof-fall clasts, erosional boundary where a younger flood partially eroded an older flood, bioturbation such as a packrat midden on a previously exposed sediment surface now buried by flood sediment, a change in physical characteristics of flood units such as grain size or color, and evidence of subaerial exposure such as a surface previously occupied by humans.

8. Schematic diagram showing flood slack-water deposits preserved in different environments and at different elevations (stages).....

9. Schematic diagram showing terraces, including an inset terrace and the modern floodplain. 
10. Photograph showing set of relatively younger Holocene terraces inset in relatively older Quaternary valley fill deposits allowing for sensitive stage-discharge relations when determining flood magnitude, in California

11. Photograph showing alluvial fan deposits reworked into a terrace-like feature by the Kern River, California.

12. Photograph showing coarse- and fine-grained reddish fan material above and below grayish fine-grained main-stem French Creek flood deposit, South Dakota........19

13. Photograph showing buried soil between two flood deposits from Kettle Creek, Colorado.

14. Schematic diagram showing a relatively older stable terrace with developed soils, a relatively younger terrace with a well-developed flood overflow channel, the active channel with gravel bars, and a series of slack-water deposits along the channel margin on the bank opposite the terraces

15. Photographs showing optically stimulated luminescence sample collection of fine sediment under a dark cloth in southern California and the typical representative sample size for luminescence analyses of fine silt grains.

16. Photographs showing location of the beer can imbedded in the stratigraphic exposure along the Verde River, Arizona.....

17. Photograph showing scars caused by floating ice impacting plains cottonwood along the Missouri River in the Missouri Breaks region, Montana

18. Photograph showing five annual rings from Oregon white oak along the Columbia River, near Portland, Oregon

19. Photograph showing magnified part of a core showing a flood ring in an oak along the Red River in central Winnipeg, Canada

20. Photograph showing tamarisk stem cross-section cut 2.8 meters below ground surface along the Rio Puerco, New Mexico

21. Photographs showing frontal and cross section views of tilted juniper tree along the Crooked River in Oregon used to date the occurrence of a paleoflood there

22. Photographs showing floating rig used to sample cores from Barlow Lake, Texas .......37

23. Photograph showing core sample from Barlow Lake, Texas.

24. High-resolution scan of a 9- centimeter core showing chemical and sedimentological differences in fluvial and lake deposits, taken from Horseshoe Lake, Illinois.

25. Graphs showing annual exceedance probabilities using systematic, historical, and paleoflood peaks and thresholds for U.S. Geological Survey streamgage 09337500, Escalante River near Escalante, Utah...

26. Schematic diagram showing stratigraphy, multiple dating methods, redundant dating of key units, and elevation of deposits in relation to discharge at Kitty's Corner pit C on Boxelder Creek, South Dakota. 


\section{Tables}

1. Examples of historical flood databases in the United States and Europe .........................8

2. Comparison of three paleohydraulic approaches............................................................8

3. Key uncertainties of paleoflood analysis and strategies for reducing them with respect to four aspects of paleostage indicators

4. Key uncertainties of paleoflood analysis and strategies for reducing them with respect to hydraulic modeling aspects.

5. Key uncertainties of paleoflood analysis and strategies for reducing them with respect to six flood-frequency analysis aspects

6. Key uncertainties of paleoflood analysis and strategies for reducing them with respect to historical flood data and streamgage data

7. Summary table of paleoflood analysis and review levels for probabilistic flood-hazard assessments

8. Suggested documentation for paleoflood analyses

\section{Conversion Factors}

U.S. customary units to International System of Units

\begin{tabular}{|c|c|c|}
\hline Multiply & By & To obtain \\
\hline \multicolumn{3}{|c|}{ Length } \\
\hline foot $(\mathrm{ft})$ & 0.3048 & meter $(\mathrm{m})$ \\
\hline mile (mi) & 1.609 & kilometer $(\mathrm{km})$ \\
\hline \multicolumn{3}{|c|}{ Flow rate } \\
\hline cubic foot per second $\left(\mathrm{ft}^{3} / \mathrm{s}\right)$ & 0.02832 & cubic meter per second $\left(\mathrm{m}^{3} / \mathrm{s}\right)$ \\
\hline
\end{tabular}

International System of Units to U.S. customary units

\begin{tabular}{llll}
\hline & \multicolumn{1}{c}{ Multiply } & \multicolumn{1}{c}{ To obtain } \\
\hline & \multicolumn{1}{c}{ Length } & \\
\hline millimeter $(\mathrm{mm})$ & 0.03937 & inch (in.) & \\
centimeter $(\mathrm{cm})$ & 0.3937 & inch (in.) & \\
meter $(\mathrm{m})$ & 3.281 & foot (ft) & \\
\hline
\end{tabular}




\section{Abbreviations}

\begin{tabular}{|c|c|}
\hline AEP & annual exceedance probability \\
\hline EMA & expected moments algorithm \\
\hline FFA & flood-frequency analysis \\
\hline HHA & hydrologic hazard analysis \\
\hline HWM & high-water mark \\
\hline LP3 & log-Pearson Type III \\
\hline CT & computer tomography \\
\hline HEC-RAS & Hydrologic Engineering Center River Analysis System (USACE) \\
\hline HEC-SSP & Hydrologic Engineering Center Statistical Software Package (USACE) \\
\hline NEB & non-exceedance bound \\
\hline NWIS & USGS National Water Information System \\
\hline OSL & optically stimulated luminescence \\
\hline PeakFO & Peak-Flow Frequency Analysis software (USGS) \\
\hline PFF & peak flow file \\
\hline PFHA & probabilistic flood-hazard assessment \\
\hline PSI & paleostage indicator \\
\hline RIDM & risk informed decision making \\
\hline RTK-GPS & Real-Time Kinematic-Global Positioning System \\
\hline SEFM & Stochastic Event Flood Model \\
\hline SWD & slack-water deposit \\
\hline USACE & U.S. Army Corps of Engineers \\
\hline USGS & U.S. Geological Survey \\
\hline U-Th dating & uranium-thorium dating \\
\hline XRF & X-ray fluorescence \\
\hline $1 \mathrm{D}$ & one-dimensional \\
\hline $2 \mathrm{D}$ & two-dimensional \\
\hline${ }^{12} \mathrm{C}$ & carbon-12 \\
\hline${ }^{14} \mathrm{C}$ & carbon-14 \\
\hline${ }^{137} \mathrm{Cs}$ & cesium-137 \\
\hline $210 \mathrm{~Pb}$ & lead-210 \\
\hline
\end{tabular}





\title{
Historical and Paleoflood Analyses for Probabilistic Flood-Hazard Assessments-Approaches and Review Guidelines
}

\author{
By Tessa M. Harden, Karen R. Ryberg, Jim E. O'Connor, Jonathan M. Friedman, and Julie E. Kiang
}

\section{Abstract}

Paleoflood studies are an effective means of providing specific information on the recurrence and magnitude of rare and large floods. Such information can be combined with systematic flood measurements to better assess the frequency of large floods. Paleoflood data also provide valuable information about the linkages among climate, land use, floodhazard assessments, and channel morphology. This document summarizes methods and techniques for the preparation, gathering, evaluation, and interpretation of paleoflood information, including uncertainties, especially with respect to new statistical approaches available to efficiently use such data. We summarize best practices and strategies for assessing and mitigating uncertainties and provide guidelines on appropriate technical review of paleoflood analyses based on project goals and requirements.

\section{Introduction}

For most flood-hazard assessments, past flood measurements, typically derived from streamflow ${ }^{1}$ measurement stations, underlie flood-frequency analyses. Streamgage records, commonly referred to as systematic data, are the primary basis for flood-frequency analyses and for calibrating rainfall-runoff models used in quantifying the probability of large floods. However, because streamflow measurement records typically are short (commonly less than 100 years in the United States), the recurrence of rare floods with low annual exceedance probabilities (AEP) is difficult to reliably estimate using standard streamflow data, especially for those floods with AEPs less than 0.001. Such rare floods are of particular interest in designing critical infrastructure such as dams and nuclear power plants, where failure can pose catastrophic consequences. Because of typically short observational records, rare and extreme natural hazards - such as large floods, earthquakes, and hurricanes - are challenging design factors because of large uncertainties regarding magnitude and frequency (National Research Council, 2014).
Paleoflood studies are one means of providing specific information on the recurrence and magnitude of rare and large floods. These studies can be combined with systematic records to improve flood-frequency analyses and the calibration of rainfall-runoff models, especially for extreme flood events. Paleoflood hydrology is the reconstruction of the magnitude and date of past floods using geological or botanical evidence (Kochel and Baker, 1982; Kochel and others, 1982; Benito and others, 2020). These indicators can provide information about the time of occurrence, magnitude, and frequency of past flood events, particularly those from time periods or locations lacking direct measurements and observations. Paleoflood studies complement streamgage measurement programs by extending records of flooding beyond the gage record. Increasing the record length is particularly important for assessing the magnitude and frequency of floods with low AEPs, thereby providing more accurate assessments of hazards to critical infrastructure (O'Connor and others, 2014). Paleoflood data also provide valuable information about the relations between climate, land use, flood frequency, and channel morphology that may not be well-represented by the systematic record. For example, Liu and others (2020) used paleoflood records to characterize long-term flood variability related to large-scale atmospheric circulation patterns that could link extreme events with climate models.

Paleoflood data typically derive from geological or botanical records of previously undocumented or poorly recorded floods (Baker, 1987; Kochel and Baker, 1988). In many river environments, geological evidence, such as fine-grained slackwater deposits (SWDs) in bedrock-confined settings (Ely and others, 1993; O'Connor and others, 1994; Hosman and others, 2003; Harden and others, 2011; Greenbaum and others, 2014) or flood sediment deposited in floodplains and terraces (Knox, 1985; Levish and others, 2003; England and others, 2010; Godaire and Bauer, 2013; Toonen and others, 2015; Munoz and others, 2018) can preserve records of floods for hundreds to thousands of years. Botanical evidence of floods, including tree rings (annual growth rings on trees) and tree scars, can provide a flood record spanning hundreds of years (St. George and Nielsen, 2003; Tardif and Bergeron, 1997). 
Paleoflood information provides tangible information on the occurrence and magnitude of large and infrequent floods, which when considered in a statistically appropriate manner, can substantially reduce uncertainties in frequency and magnitude estimates of rare floods (Stedinger and Cohn, 1986; Costa, 1978; Stedinger and Baker, 1987; Frances and others, 1994; Webb and others, 2002; Harden and others, 2011; Lam and others, 2017). The increasing global application of paleoflood studies has prompted development of multiple techniques to efficiently incorporate such information in floodfrequency analyses (Stedinger and Cohn, 1986; Cohn and others, 1997; Levish, 2002; O'Connell and others, 2002; England and others, 2018).

Paleoflood information (derived from geological and botanical records) as well as other non-systematic records of large floods, such as historical data from newspaper accounts and archival records, can be incorporated in flood-frequency analyses. Such data can take the form of flood-magnitude point estimates (single-value estimates without quantitative uncertainty), interval estimates (estimates presented as a plausible range of values, thereby acknowledging the inherent uncertainty in estimating past floods), or perception thresholds (the minimum flood magnitude that could have been detected at a site had it occurred; England and others, 2018).

Guidelines to incorporate historical and paleoflood data in flood-frequency analyses in the United States have been standardized in Bulletin 17C (England and others, 2018). Several software packages are available, which implement the methods described in Bulletin 17C including the U.S. Geological Survey (USGS) Peak-Flow Frequency Analysis software (PeakFQ; Flynn and others, 2006; Veilleux and others, 2014) and the U.S. Army Corps of Engineers (USACE) Hydrologic Engineering Center Statistical Software Package (HEC-SSP; U.S. Army Corps of Engineers, 2019). The USACE Risk Management Center Risk Management CenterBestFit software for flood-frequency analysis performs distribution fitting and Bayesian estimation from a choice of 13 probability distributions and can incorporate historical and paleoflood data (Smith and Doughty, 2020). Guidelines exist in other countries for flood-frequency analyses that incorporate non-systematic data (usually historical, as reviewed in Kjeldsen and others, 2014). For example, Australian methods use several distributions (Log-normal, Gumbel, Generalized Pareto, log Pearson III or Generalized extreme value in TUFLOW FLIKE software; [https://www.tuflow.com/ products/flike/]) and include paleoflood data with Bayesian methods (Ball and others, 2019).

Paleoflood analysis is an increasingly applied tool for improving estimates of the magnitude and frequency of flooding hazards, particularly for assessing the safety and design of critical infrastructure such as nuclear power plants and dams (Swain and others, 2006; England, 2011; O'Connor and others, 2014; Harden and O'Connor, 2017; Kelson and others, 2017a). Standards of practice for conducting and reviewing such studies, however, have been lacking, inhibiting their effective use in regulatory decision-making.

\section{Purpose and Scope}

This report describes typical standards of practice for developing historical and paleoflood data and incorporating such data in flood-frequency analyses. Specifically, we describe methods and techniques for gathering, evaluating, and interpreting historical and paleoflood data, including application of new statistical approaches available to efficiently use such data for flood-frequency analysis. We discuss geological and botanical evidence of floods, geochronologic techniques, hydraulic analysis methods, and flood-frequency analysis. Three levels of paleoflood analysis and review are identified - ranging from scoping or reconnaissance (Level 1) to intermediate (Level 2) to comprehensive (Level 3) - that would be selected to meet project objectives including the risk criteria and management goals of the project. This summary is followed by a discussion of detailed guidance developed to differentiate the level of detail of the study (number of reaches/sites), hydraulic analysis method (for example, single cross sections, 2-dimensional models), probabilistic floodhazard analyses for input into probabilistic risk analysis (for example, flood-frequency analysis), uncertainty propagation acceptable for decision-making, and extent of the technical review.

A paleoflood workshop in 2019 (app. 1) held at the Nuclear Regulatory Commission in Rockville, Maryland, was convened to survey the experience and views of experts in geology, hydrology, botany, dendrochronology, geomorphology, engineering, statistics, and policy at Federal and local agencies and in academia. Broad information and perspectives were gathered at the workshop to guide the structure of this report.

\section{Historical Evidence of Floods}

Historical evidence of floods consists of records and data originating from outside the period of systematic records but derived from human accounts (Ryberg and others, 2020). Examples of historical records that can be used for flood estimates or perception thresholds for a particular site include (1) flood estimates from agencies other than the one within the systematic record; (2) flood marks inscribed in structures or durable features; (3) newspaper accounts that can be translated to flood magnitude point estimates, interval estimates, or perception thresholds (for example, a statement that an 1880 flood was the largest flood since 1869); and (4) historical photographs that show floodwaters in relation to landmarks, such as railroad bridges or historical buildings. 
A common source of historical flood estimates is the USGS peak-flow file (PFF) that is available as part of the USGS National Water Information System (NWIS) at https://nwis.waterdata.usgs.gov/usa/nwis/peak (U.S. Geological Survey, 2020a). Historical peaks are qualified with a peak qualification code of 7 . The USGS uses a series of qualification codes in NWIS to describe data and help with data interpretation. The official definition for code 7 is that the "discharge is an historic peak" (Ryberg and others, 2017, p. 8; U.S. Geological Survey, 2020a). This definition has caused some confusion as a result of the standard dictionary definition of historic, which means "famous or important in history," whereas historical means "concerning history or historical events" (Oxford University Press, 2017). As a result, some USGS staff responsible for applying the qualification codes assigned the largest peak in the PFF a code 7, historic, regardless of where it fell in the record, and nonsystematic peaks that should have been qualified with a code 7 were not. For clarification, peak-flow data that should be qualified with a code 7 are those that provide historical evidence and are outside the systematic period of record. There has been an ongoing effort to correct these misinterpretations for all sites in the PFF; however, the official definition still uses the term "historic" (Ryberg, 2008; Ryberg and others, 2017). Throughout this report, we refer to the nonsystematic peaks recorded by human accounts as "historical."

Historical flood information can play an important role in filling the gap between paleoflood data and the beginning of the systematic record. Furthermore, historical information can have an advantage over most paleoflood data if photographs and first-person accounts for the flood exist. Historical peaks have been considered biased in the systematic record because the only reason they were documented is that they were large floods. The previous Federal guidelines for determining flood-flow frequency known as Bulletin 17B (Interagency Advisory Committee on Water Data, 1982) used a historical weighting procedure to acknowledge this bias when estimating the flood-frequency distribution at a site with historical data. Recently, with the publication of Bulletin 17C (England and others, 2018), improved methodology and a growing interest in hydrologic extremes have led to a recognition and acceptance of historical floods as an important source of data used to reduce uncertainties in flood-frequency analyses (Sutcliffe, 1987; Engeland and others, 2018).

As the ability to use historical data has improved, a concerted effort has been made to gather the information for use in flood-hazard analysis in the United States and abroad. General sources of information for historical floods include (1) hand-written documents such as diaries, personal correspondences, and memoirs; (2) printed sources such as newspapers and technical reports; (3) physical markings on bridges, trees, buildings, rocks, etc. (fig. 1); (4) iconographic sources such as photographs and paintings; and (5) oral histories (Montgomery, 2016). Other more unusual sources have been used, such as analysis of expense records for flood-related bridge repairs in the 1500s (Merz and Blöschl, 2008). For a detailed, in-depth reconstruction of floods from historical archives, see Historical Floods in New England (Thomson and others, 1964) and a survey of hydroclimate, flooding, and runoff in the Red River [of the North] Basin prior to 1870 (Rannie, 1998).

The uncertainty of historical information can be difficult to quantify. Individual observations from personal accounts in letters and newspapers tend to be less certain because of perceptions of the writer and the later (often much later) interpreter, and the purpose of describing the flood (such as historical documentation, selling newspapers, describing a dramatic event, or attempting to draw attention to flood-induced suffering). Researchers examining historical high-water marks have determined that newspapers may have exaggerated flood severity. Talke and others (2014) used recovered tide, highwater, and low-water records for New York Harbor to show that the high-water mark for 1893 was 1.4 meters (m) lower than an estimate previously derived from a newspaper article (Scileppi and Donnelly, 2007). Talke and Jay (2017) updated the New York harbor analysis and downgraded other events previously estimated from newspaper accounts. Orton and others (2016) reported that the difference in interpreting a record as " 13 feet over low water" rather than " 13 feet over low water mark" may have caused storm surge from an 1821 hurricane to be overestimated by $0.4-0.6 \mathrm{~m}$. Additionally, misinterpretation of historical datum and tabulation or transcription errors led to the overstatement of 1723 and 1847 storm tides in Boston Harbor (Talke and others 2018).

Organizational historical sources tend to be more standardized, such as ecclesiastical records and technical reports. Physical marks may seem to be more certain but should be confirmed, as stonework can be moved during building restoration or streets can be renamed (Benito and others, 2015). Flood magnitudes derived from historical data can have large uncertainty but often are exact in terms of dates of floods and have a richness of information that sheds light on consequences of extreme events (Wilhelm, Ballesteros Cánovas, and others, 2018). Flow estimates from historical elevations are subject to many of the same uncertainties as flow estimates from geological and botanical flood evidence; in most cases, such flow estimates probably are best expressed as interval estimates when used in flood-frequency analyses. Additionally, the stage-discharge relation often is assumed not to vary over time. This may be incorrect because of channel changes (Winters and Baldys, 2011) or because of other alterations to the basin. 

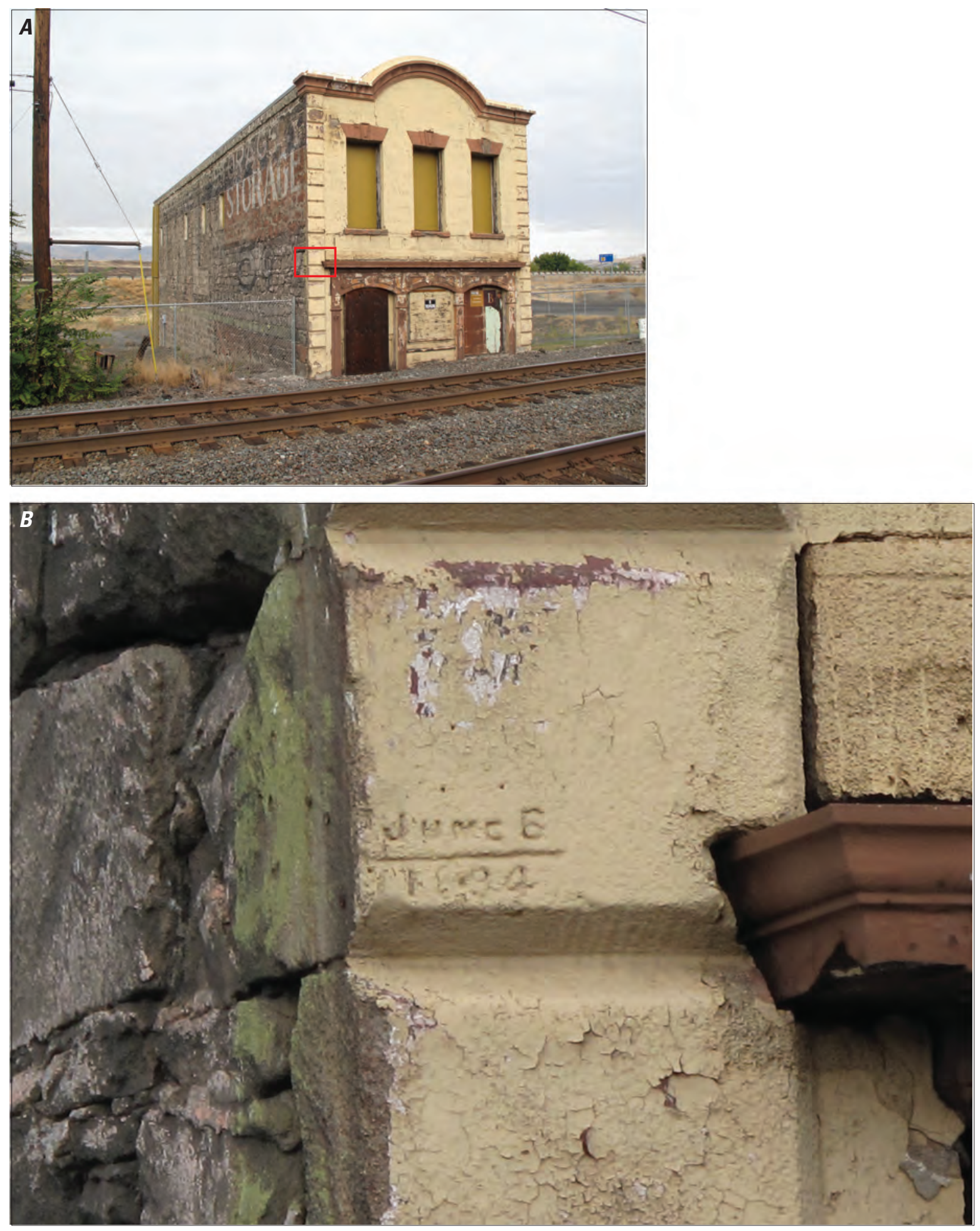

Figure 1. Historical building in The Dalles, Oregon $(A)$, with etching of the elevation of floodwaters from the 1894 flood on the Columbia River (close-up of the rectangular area outlined in $[A])(B)$. Columbia River is about 150 meters beyond the building. Photographs by Jim O'Connor, U.S. Geological Survey. 
Quantifying a historical flood ideally involves (1) multiple collaborative evidence and information sources such as historical newspaper accounts; (2) historical documents from government entities that may no longer exist under the same name or structure, such as the U.S. Army Signal Corps or the U.S. Weather Bureau (https://library.noaa.gov/Collections/ Weather-And-Climate); (3) reports by agencies such as the U.S. Army Corps of Engineers or the U.S. Geological Survey; and (4) libraries or historical society records of photographs and diaries. A historical flood that occurred in Fargo, North Dakota-Moorhead, Minnesota, in 1897 provides a rich example of the types of material that may be available to quantify and qualify a historical peak. See the example 1 sidebar for a description of the process that might be followed to estimate a historical flood.

Gathering historical (and paleoflood) evidence and estimates from across the United States and the world to extend the periods of record available for flood-frequency analysis has been of interest for some time. However, the effort has been piecemeal, and often has been done on a single State or agency basis. Several historical flood databases and other common sources of historical flood data are listed in table 1.

\section{Paleohydraulic Analysis}

Several geological, biological, and archival techniques enable the determination of past flow conditions, or paleohydraulics, for locations with sparse or no documented flood data for time periods before the historical record. These techniques can be categorized into three fundamental approaches (table 2). Regime-based (Baker, 1989, 2014) approaches rely on empirically derived relations between channel morphologic or sedimentologic characteristics and past flow conditions. Regime-based methods are most useful for inferring average flows (Salas and others, 1994). A second approach to estimate past flow is the use of flow-competence criteria. These criteria use theory and empirical evidence to link the largest sediment grain size that a particular discharge can transport with flow strength represented by a velocity, shear stress, or stream power (Jacobson and others, 2016). Flow-competence methods can be used to estimate average flow conditions as well as individual floods (Salas and others, 1994). The last approach, commonly practiced since the 1980s and the main technique addressed in this report, is the analysis of peak-stage evidence left by individual floods as inferred from geological records (such as fine-grained deposits derived from a flood's suspended load) and botanical records (such as flood-related changes in tree-ring characteristics). This approach is the basis for several recent flood-hazard assessments that incorporate paleoflood data (England and others, 2010; Harden and others, 2011; Lam and others, 2017; Kelson, Hall, and others, 2018, Kelson and others, 2020; Harden and others, 2021).

In the United States, most paleoflood studies using peak-stage evidence have been conducted in arid or semi-arid regions of the western United States, likely owing to several factors including (1) the preponderance of stable boundary rivers; (2) the abundance of sandy sediment eroded from less vegetated landscapes and transported in floodwaters during extreme floods; (3) increased deposit preservation owing to the lack of vegetation and reduced bioturbation; (4) the high variability of peaks in the streamflow record (it is not uncommon to have an annual peak in the systematic record an order of magnitude larger than the next highest peak); and 5) the fact that many paleoflood researchers live and work in the Western United States. However, successful paleoflood studies conducted in the more humid Eastern United States have shown the versatility of using peak-stage evidence (Kelson and others 2017b; Harden and O'Connor, 2017; Harden and others, 2021) and other methods described later in the report (Wang and Leigh, 2012; Munoz and others, 2018; Davis and others, 2019).

The approach of using peak-stage evidence to reconstruct flood-frequency has three main components: (1) Using various types of paleostage indicators and geochronology, develop and interpret a stratigraphic, botanical, and historical record of flood stages, including timing, and maximum thresholds for a river of interest; (2) Converting the resulting stage information to estimates of discharge for specific events and perception thresholds; and (3) Appropriately incorporating the discharge and chronology information, including historical and gaged flood records, in a flood-frequency analysis. All aspects of these analyses have uncertainties that need to be considered in the resulting flood-frequency analysis. 


\section{Example 1-1897 Flood Fargo, North Dakota-Moorhead, Minnesota}

A U.S. Geological Survey Water Supply Paper documenting floods in 1950 compared those floods to past floods, including a large flood in 1897 reported by the Fargo Forum and Daily Republican for March 15, 1897, in an article titled “The Coming Flood" by Old Settler:

The present indications are that we will have high water this spring, as high if not higher, than it was in the spring of 1861. If all reports are true, there is more snow on the level now than there was in the spring of 1861. That year the entire valley was flooded from Big Stone Lake to Winnipeg, a distance of more than 300 miles [mi]. There are but four men living in the valley now that witnessed the great flood of ' 61 -the largest body of fresh water in the world at that time ***

R. M. Probesfield is authority for saying that he, a few days ago, measured the snow in his timber, where it was free from drifting-and it measured 5 feet. This measurement is two and one-half feet more snow than we had in 1861. Those facts prove that we will have a greater flood this year than in the history of the valley.

(U.S. Geological Survey, 1952, p. 303).

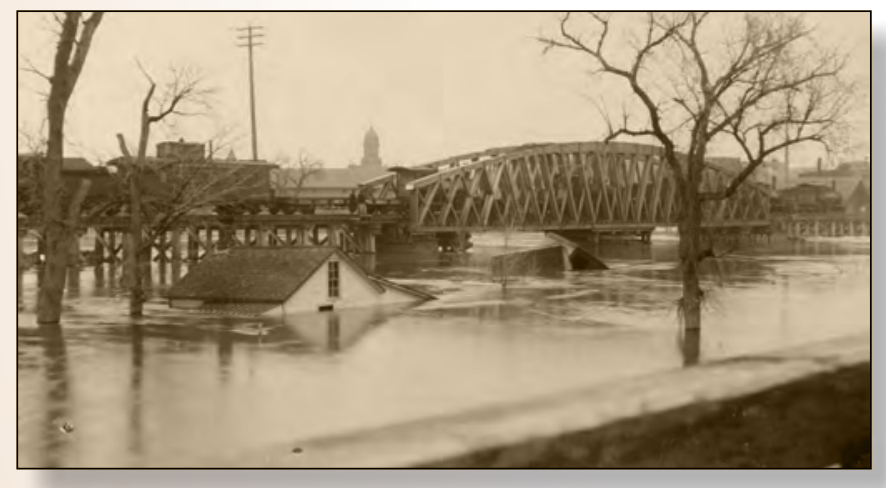

Figure Ex1.1. Northern Pacific Railroad bridge over Red River of the North from Main Avenue bridge, between Fargo, North Dakota, and Moorhead, Minnesota, April 3, 1897. North Dakota State University Archives; used with permission.

The Red River crested early on the morning of April 7, 1897, at Fargo exceeding the known high levels of 1871, 1873, and 1882. The 1897 flood did not seem to exceed the 1861 flood at Fargo, although this is difficult to prove definitively. Downstream from Fargo, the 1897 flood did not exceed the 1861 flood at Winnipeg, Manitoba, Canada, where more historical documentation before 1897 is available (U.S. Geological Survey, 1952).

Numerous historical photos of the 1897 flood and other historical floods are available through Digital Horizons, a consortium of organizations that provides historical content related to North Dakota and Minnesota (Digital Horizons, 2020). A selection of photos from the days leading up to the flood peak and the day of the peak are included here (figs. Ex1.1-Ex1.3). According to documentation accompanying the photograph in figure Ex1.3:

[The] view of the Northern Pacific Railroad bridge and the old south bridge was taken from the foot of

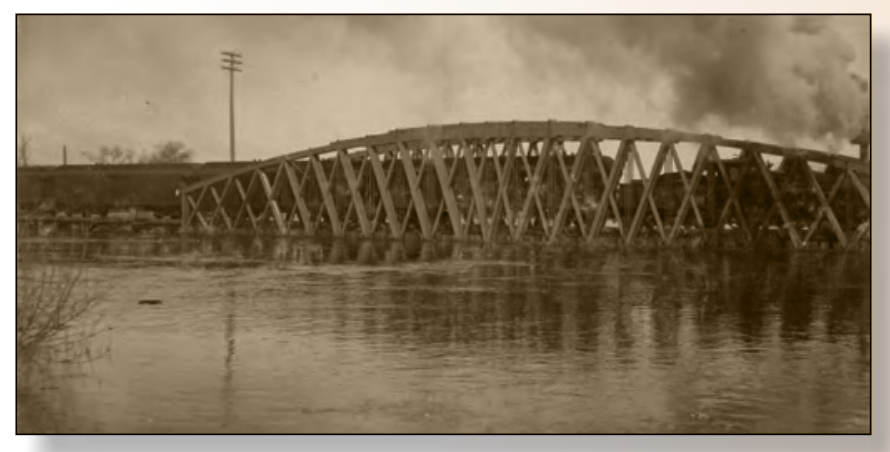

Figure Ex1.2. Northern Pacific Railroad bridge over Red River of the North, between Fargo, North Dakota, and Moorhead, Minnesota, April 5, 1897. North Dakota State University Archives; used with permission.

what is now Center Avenue in Moorhead. The building shown at the lower right was the old steamboat freight house, which stood just across Third Street from what is now the Moorhead Daily News building, but which was then occupied by the Zervas \& Kippels meat market. The objects seen on the south bridge are steam threshing engines placed there to weight down the bridge.

\section{(Digital Horizons, 2020).}

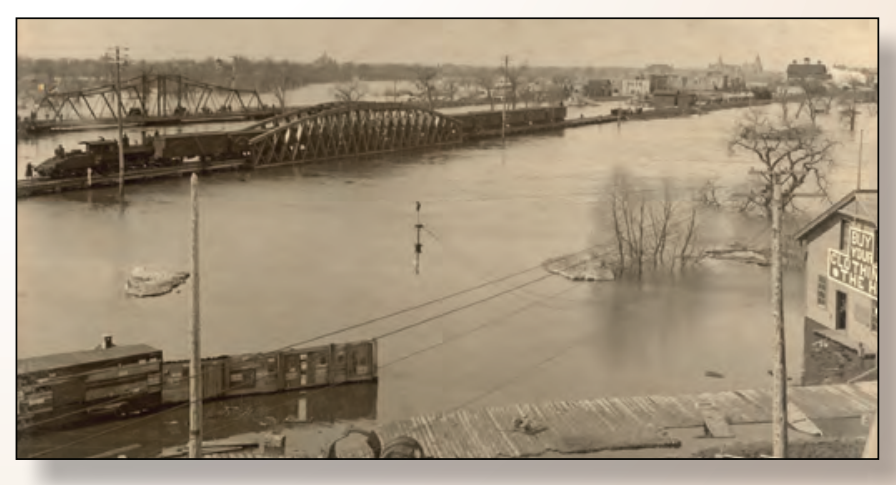

Figure Ex1.3. View from Moorhead, Minnesota, of flooded Red River of the North, with Northern Pacific railroad bridge in middle distance and Old South bridge in far distance, April 7, 1897. North Dakota State University Archives; used with permission. 
Additional historical photographs (Digital Horizons, 2020) show floodwaters in relation to institutional buildings, streets, houses, and other landmarks, some of which may still exist and could aid in estimating additional high-water marks and flood inundation. Photographs showing floodwaters in relation to bridges are particularly useful in that the bridges may exist during the systematic period of record and allow one to compare current and past floods. Bridges are surveyed and surveying may facilitate estimates of water-surface elevation. Additionally, bridges often are iconic landmarks that attract photographers during extraordinary events.

The historical photographs document a large flood in 1897 , but what was the water-surface elevation or stage? We know from the 1952 Water Supply Paper that there was a U.S. Weather Bureau gage at Fargo and the elevation recorded at the gage, adjusted to 1912 datum, was 863.5 feet (ft) above mean sea level (U.S. Geological Survey, 1952, table 7). However, where was the gage in relation to the photographs and the current gage that represents the systematic period of record? A search of microfiche records in the U.S. Geological Survey Dakota Water Science Center in Bismarck, North Dakota, produced a 1930 document stating that the U.S. Weather Bureau gage was on Front Street (fig. Ex1.4; S. Robinson, U.S. Geological Survey, electronic commun., July 7, 2020). Further investigation at the North Dakota State University Archives indicated that Front Street is now Main Avenue (North Dakota State University Archives, 2020). Two bridges in relation to each other during the 1897 flood are shown in fig. Ex1.3, and a photograph of the 1897 flood specifically in relation to the Front Street Bridge is shown in fig. Ex1.5.

Water-surface elevations, or stage values, in the 1800 s generally were accurate because of railroad or other surveys. Archival documents show the existence of a survey benchmark at the railroad bridge in Fargo that provided datum information. However, creating a reliable

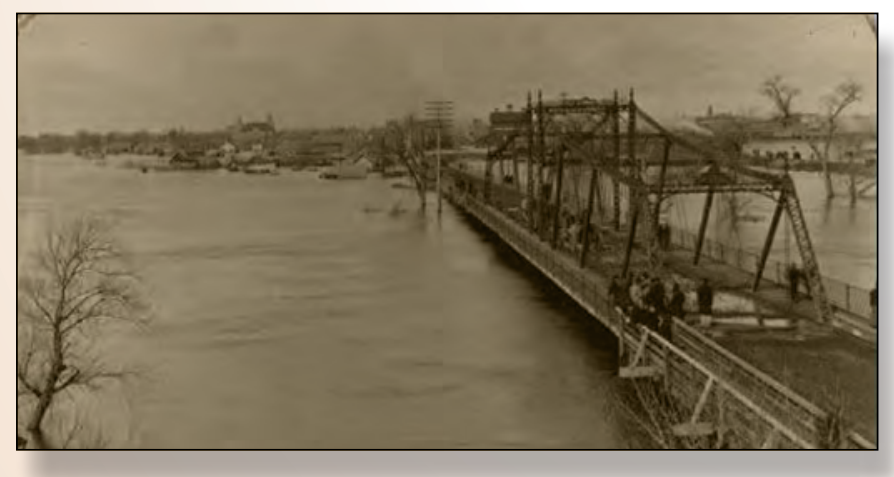

Figure Ex1.5. View from Moorhead, Minnesota, across flooded Red River of the North at Front Street Bridge toward Fargo, North Dakota, 1897. County Historical Society, Bonanzaville, West Fargo, North Dakota; used with permission. rating curve ${ }^{1}$, or the stage-discharge relation that allows one to estimate a streamflow (volume) from an elevation or stage, requires numerous measurements of stage and streamflow over a range of conditions (Wagner and others, 2017). The 1897 peak was for many years much larger than systematically gaged peaks, and a streamflow estimate would have been an extrapolation (extension) of the rating curve to an unverified stage-streamflow estimate.

Eventually, with historical documents and data from observations of additional large floods, Russ Harkness of the U.S. Geological Survey estimated the 1897 flood stage at the current streamgage location and estimated a streamflow (G. Wiche, U.S. Geological Survey, oral commun., July 7, 2020). The water-year summary for current USGS streamgage 05054000 (Red River of the North at Fargo, North Dakota) describes an extreme flood outside the period of systematic record as "flood of April 7, 1897, reached a stage of $39.1 \mathrm{ft}$ present datum, discharge, 25,000 ft3 $3 / \mathrm{s}$ [cubic feet per second] at site $1.5 \mathrm{mi}$ downstream" (U.S. Geological Survey, 2020b).

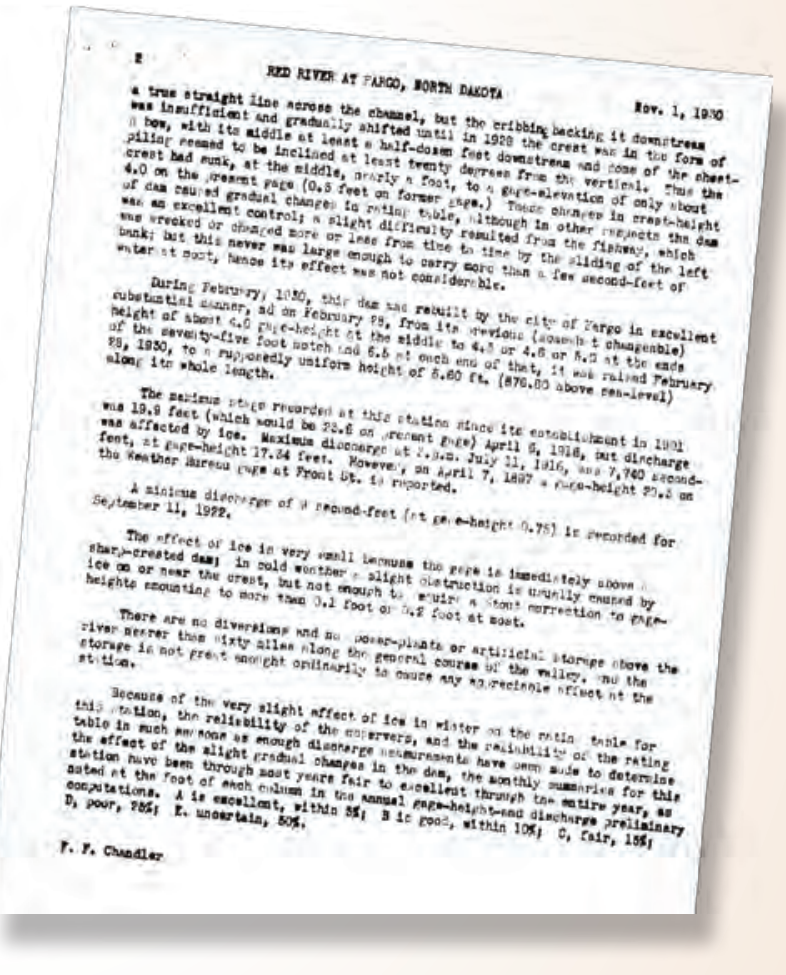

Figure Ex1.4. Information related to U.S. Geological Survey (USGS) streamgage 05054000, Red River of the North at Fargo, North Dakota, 1897. Photograph of microfiche record provided by USGS Dakota Water Science Center.

\footnotetext{
${ }^{1}$ A straight-line rating curve extension may not be appropriate in some instances, especially if a river or stream leaves a confined channel and reaches a wide floodplain. Conventional USGS policy is to not extend a rating past two times the highest confirmed streamflow discharge measurement and, as more extrapolation that occurs, the greater the uncertainty.
} 
Table 1. Examples of historical flood databases in the United States and Europe.

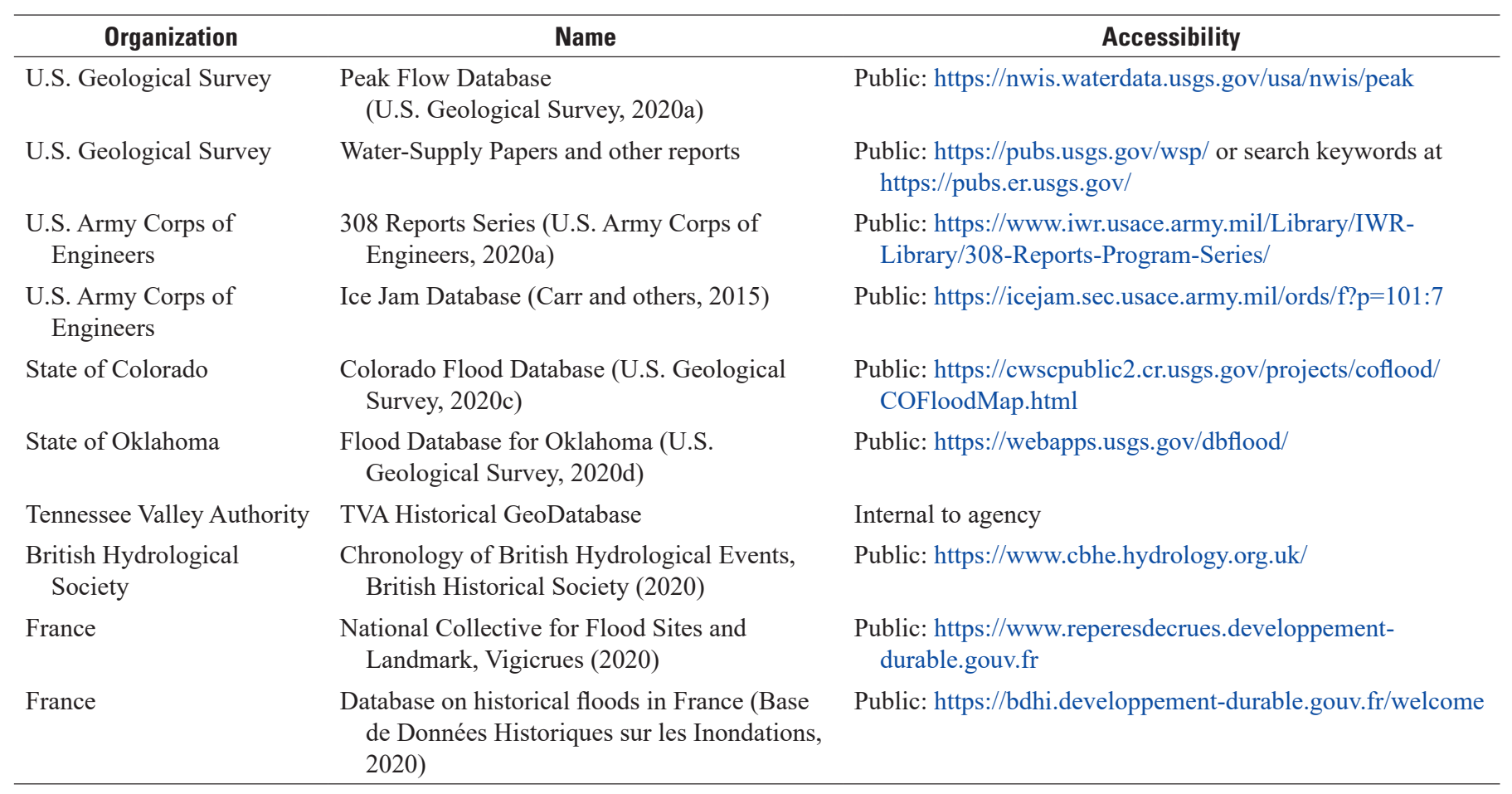

Table 2. Comparison of three paleohydraulic approaches (after Baker, 1989; modified from Jacobson and others, 2016).

[Symbol: \pm , plus or minus]

\begin{tabular}{|c|c|c|c|}
\hline \multirow{2}{*}{ Attribute } & \multicolumn{3}{|c|}{ Approach } \\
\hline & Regime & Flow competence & Slack-water deposits \\
\hline River type & Alluvial (deformable boundaries). & $\begin{array}{l}\text { Alluvial and stable boundary } \\
\text { channels. }\end{array}$ & Stable boundary channels. \\
\hline Scale of analysis & $\begin{array}{l}\text { A reach of river or channel cross sec- } \\
\text { tion. }\end{array}$ & Individual deposit. & $\begin{array}{l}\text { Individual or multiple deposits within a } \\
\text { reach of river. }\end{array}$ \\
\hline $\begin{array}{l}\text { Commonly inferred } \\
\text { properties }\end{array}$ & $\begin{array}{l}\text { Mean annual discharge, "bankfull" } \\
\text { discharge for a channel reach or } \\
\text { cross section. }\end{array}$ & $\begin{array}{l}\text { Shear stress, velocity, and } \\
\text { unit stream power associ- } \\
\text { ated with an individual } \\
\text { deposit. }\end{array}$ & $\begin{array}{l}\text { Rare and high magnitude floods for a } \\
\text { channel reach. }\end{array}$ \\
\hline Major uncertainties & $\begin{array}{l}\text { Empirical and semi-empirical hydrau- } \\
\text { lic geometry relations and channel- } \\
\text { type thresholds typically have large } \\
\text { uncertainties. }\end{array}$ & $\begin{array}{l}\text { Uncertain transport relations; } \\
\text { uncertain inferences re- } \\
\text { garding channel geometry. }\end{array}$ & $\begin{array}{l}\text { Uncertain relations between deposit } \\
\text { elevations and maximum flow stage; } \\
\text { uncertain channel geometry and rough- } \\
\text { ness characteristics. }\end{array}$ \\
\hline Reviews of Approach & Dury, 1976; Williams, 1988. & Maizels, 1983; Komar 1996. & $\begin{array}{l}\text { Kochel and Baker, 1988; Baker, 1989; } \\
\text { Benito and O'Connor, } 2013\end{array}$ \\
\hline Example applications & Dury, 1976; Williams, 1984. & $\begin{array}{l}\text { Costa, 1983; Waythomas and } \\
\text { Jarrett, 1994; Grimm and } \\
\text { others, 1995. }\end{array}$ & $\begin{array}{l}\text { Ely and others, 1993; O'Connor and oth- } \\
\text { ers, 1994; Harden and others, } 2011 .\end{array}$ \\
\hline
\end{tabular}




\section{Geological Paleostage Indicators}

The essential element of any paleoflood assessment is flood evidence. This section focuses on physical evidence of previously undocumented floods. Much of the material in this section and hydraulic analysis section of this document is modified from the reviews of Benito and O'Connor (2013); Jacobson and others (2016); Benito and others (2020) and the Black Hills, South Dakota, paleoflood study of Harden and others (2011).

Paleoflood records can be reliably reconstructed from two basic types of physical evidence: high-water marks (HWMs), and paleostage indicators (PSIs). HWMs include flotsam (fine organic debris, grass, and woody debris; fig. $2 A$ ) and mud, silt, and seed lines (fig. $2 B$ ) that closely mark peak flood stage (Koenig and others, 2016). Multiple HWMs on each side of the channel, such as fresh tree injuries on one bank and corresponding scour marks on the other bank (fig. 2C), commonly are used to estimate peak water-surface elevations. Evidence of HWMs typically survives for a short period of time; weeks in humid climates, but possibly hundreds of years in semi-arid and arid climates (Williams and Costa, 1988; Webb and others, 1988). By contrast, PSIs typically provide evidence of peak flow stages that may be preserved for thousands of years, and are the evidence typically sought to conduct detailed paleoflood analyses. Commonly used PSIs include fine-textured flood sediment SWDs (fig. 3A, 3B), gravel and boulder bars (fig. 3C), silt lines, and erosion features (Baker, 1987; Kochel and Baker, 1988; Webb and Jarrett, 2002), as well as botanical evidence such as scars (fig. $3 D$ ) and atypical growth rings in trees adjacent to rivers and streams as discussed later in this report.

Floods also etch scour marks and trimlines into valleymargin colluvium and soils (fig. $3 E$ ). Scour lines can also be used to estimate peak discharge in bedrock reaches with no soils and little colluvium by eroding a thin layer to expose a fresh rock surface (fig. 4). Such erosional features may mark the largest floods, although their interpretation and dating may be ambiguous (Webb and Jarrett, 2002).

Silt lines are sub-horizontal linear deposits of silt- and clay-sized particles preserved along channel margins that provide clear evidence of maximum flood stage (fig. $3 F$ ). They most commonly are preserved on bedrock canyon walls and channel-margin boulders, especially in areas protected from weather. These lines likely are derived from the suspended load of the flooded stream, left as floodwaters soaked into porous rock (O'Connor and others, 1986).

In high-gradient streams, coarse boulder deposits (fig. 3C) are the most common large-flood deposits. Such deposits are probably from flood bedload and likely provide a minimum peak estimate (Wohl, 2010) of the largest floods.
Boulder bars, like erosional features, provide information on the largest floods but typically do not record numerous floods (Wohl, 2010).

Botanical flood evidence includes flood scars and other flood-related effects on riparian trees. These effects include physical damage to trees, such as tilting and abrasion, which result in sprouting of new stems that grow vertically from the fallen or tilted stem, eccentric ring growth, and scarred stems (fig. 5; Sigafoos, 1964). Floods may also alter growth because of persistent inundation or by sediment burial or exhumation. The resulting change in width or anatomy of individual growth rings have been used effectively for reconstructing regional flood-frequency and magnitude (McCord, 1990, 1996; Yanosky and Jarrett, 2002; Ballesteros-Cánovas, Stoffel, and others, 2015).

\section{Slack-Water Deposits}

The physical characteristics of a river system dictate the type, preservation, and uncertainty of paleoflood records (Benito and O'Connor, 2013). The most complete paleoflood records are obtained from analyses of stratigraphic sequences of fine-grained flood deposits occurring in slack-water and eddy environments. SWDs are fine-grained sedimentary deposits that accumulate from suspension during floods (Baker and others, 2002). Typically, SWDs are preserved in areas with low velocity such as areas of backwater flooding and flow separation. The reduced flow velocities in these areas promote rapid deposition of the high-settling-velocity fraction (sands and silts) of the suspended load. The finest grain sizes with low-settling velocities (clays) typically remain in suspension even in low-velocity environments.

\section{Site Selection and Stratigraphic Analysis of Flood Sequences}

Environments where SWDs are commonly deposited and preserved include (1) areas of channel widening; (2) severe channel bends; (3) the lee side of obstacles where flow separation occurs; (4) alcoves and caves in bedrock walls; (5) backflooded tributary mouths; (6) channel margins below steep canyon walls; and (7) macrochannels in stable confined semialluvial reaches (Kochel and others, 1982; Ely and Baker, 1985; Baker and Kochel, 1988; Benito and others, 2003; Sheffer and others, 2003; Benito and Thorndycraft, 2005; Thorndycraft and others, 2005; Harden and others, 2011; Lam and others, 2017).

Searches for SWDs can be aided by identifying evidence in the field left by recent large floods. Locations of deposits or large woody debris of such recent floods (fig. 6) are likely to match areas of paleoflood deposition, indicating an ideal starting elevation from which to search areas with similar characteristics. 


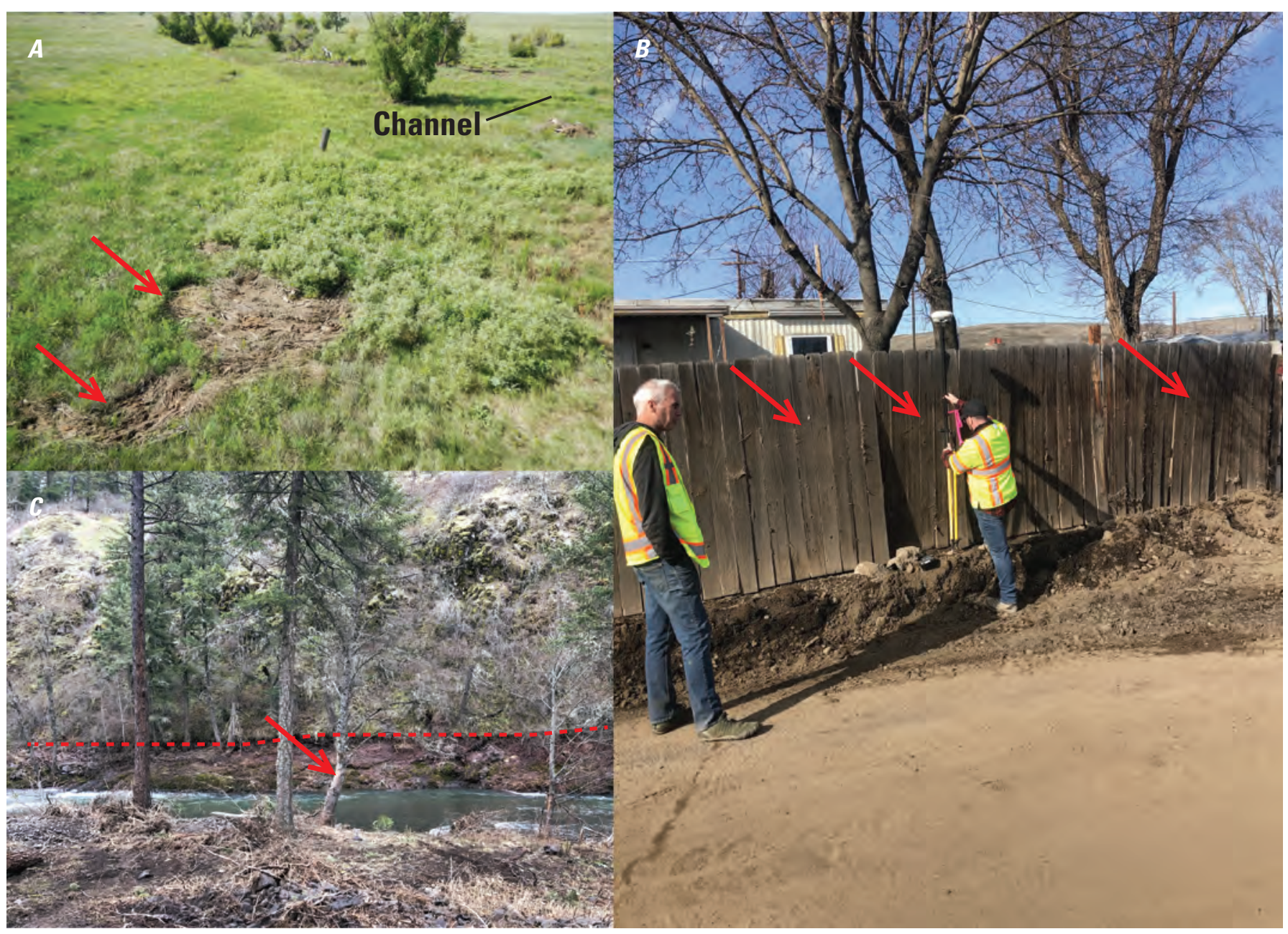

Figure 2. Examples of high-water marks (arrows) from $(A)$ woody debris, $(B)$ mud line on a fence marking peak water surface elevation, and $(C)$ tree and erosion scars (dashed line). Photographs by Tessa M. Harden $(A)$ and Lori Fischer $(B$, C), U.S. Geological Survey. 


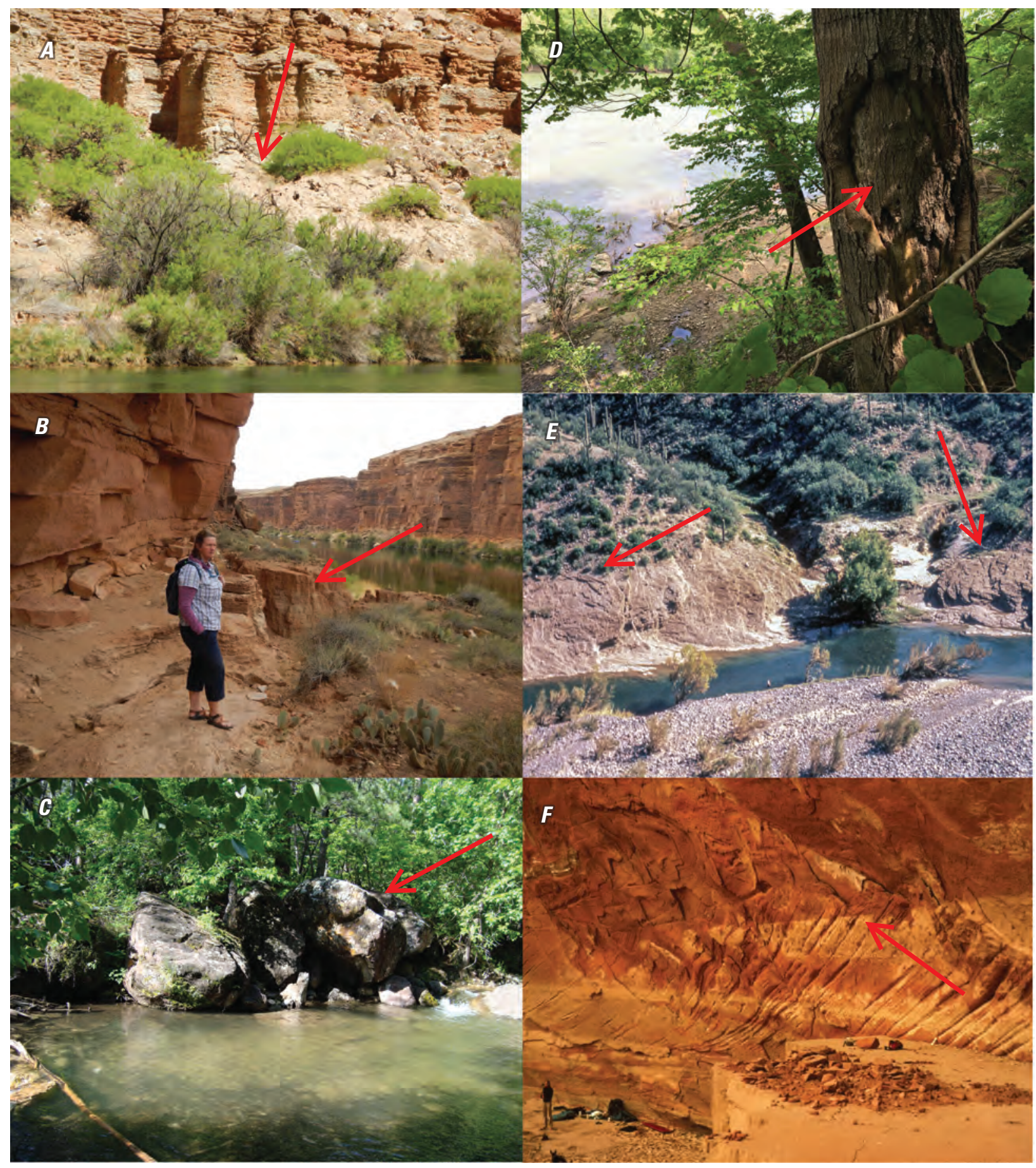

Figure 3. Paleostage indicators (arrows) including $(A, B)$ slack-water deposits, $(C)$ boulder bar, $(D)$ tree scar, $(E)$ erosional features, and $(F)$ silt lines. Photographs by Tessa M. Harden $(A-C)$ and Jim O'Connor $(E, F)$ U.S. Geological Survey; and Keith Kelson (D), U.S. Army Corps of Engineers. 


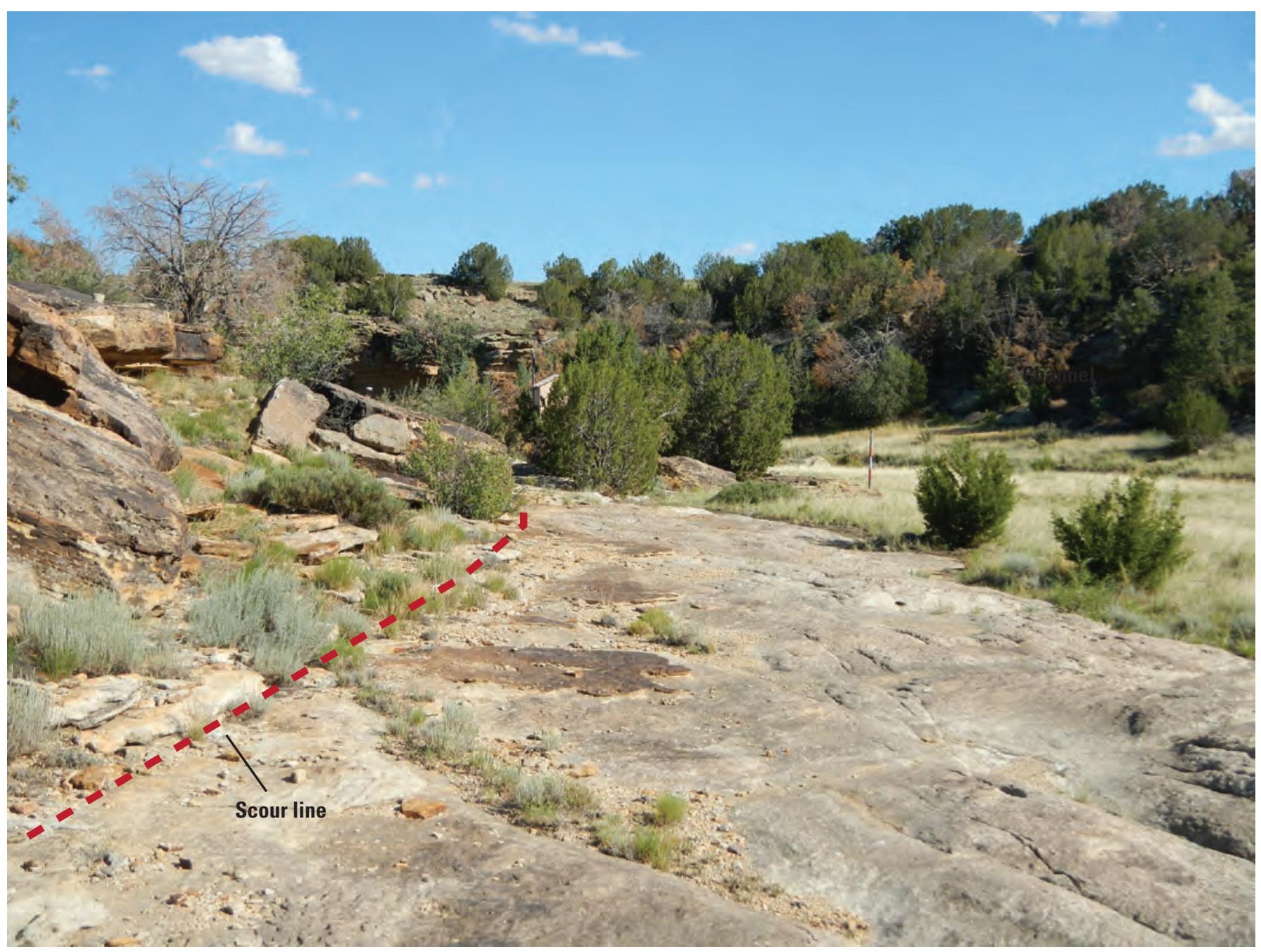

Figure 4. Flood scour marks on bedrock of Taylor Arroyo, Colorado. Loose sediment and vegetation are abundant above the scour line but have been eroded by floodwater below the scour line. Photograph by Tessa M. Harden, U.S. Geological Survey. 


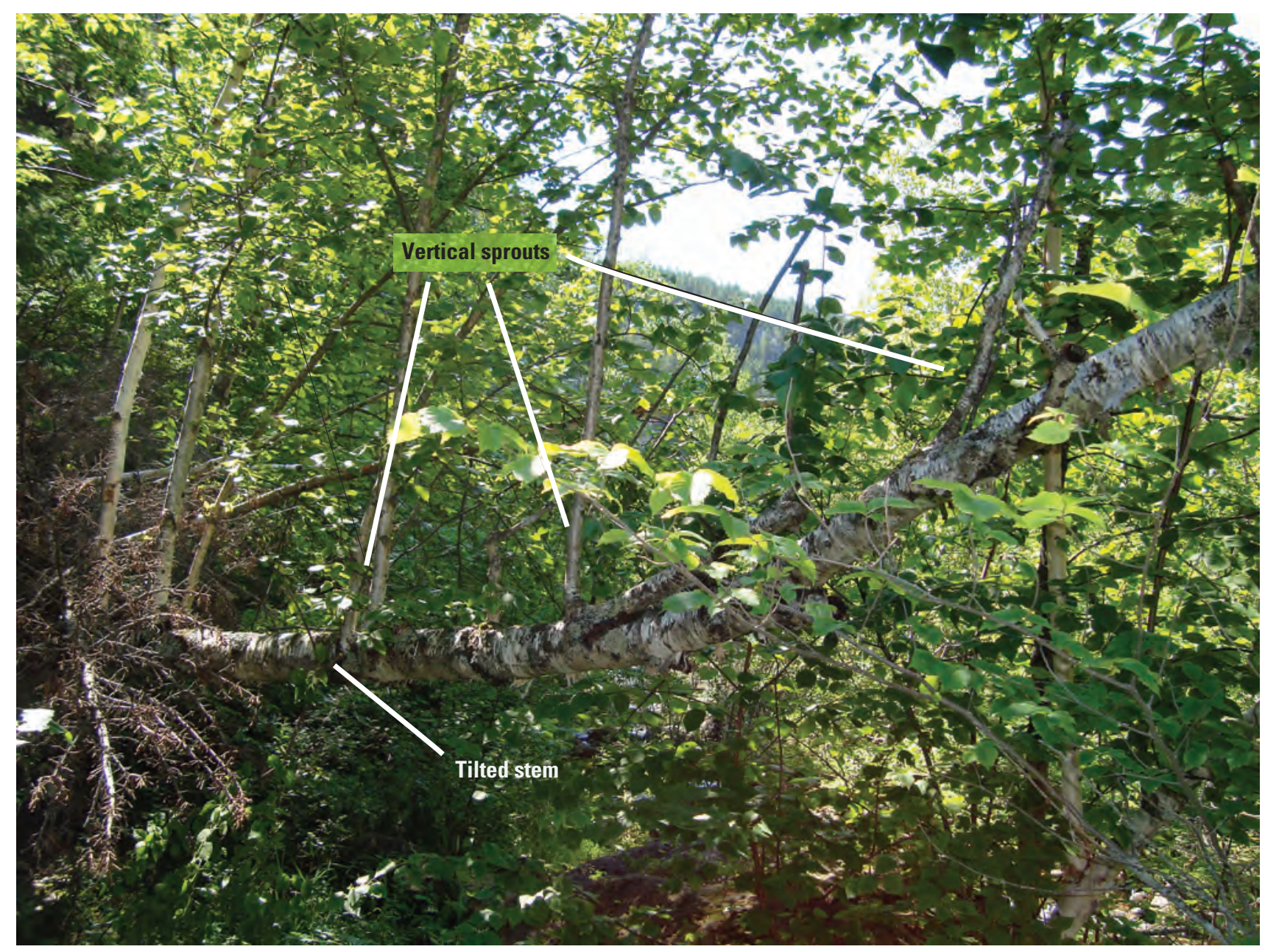

Figure 5. Vertical sprouts on a tree along Elk Creek, South Dakota. Tree was undercut and tilted by a flood. Age of vertical branches marks the time since the flood. Photograph by Tessa M. Harden, U.S. Geological Survey. 


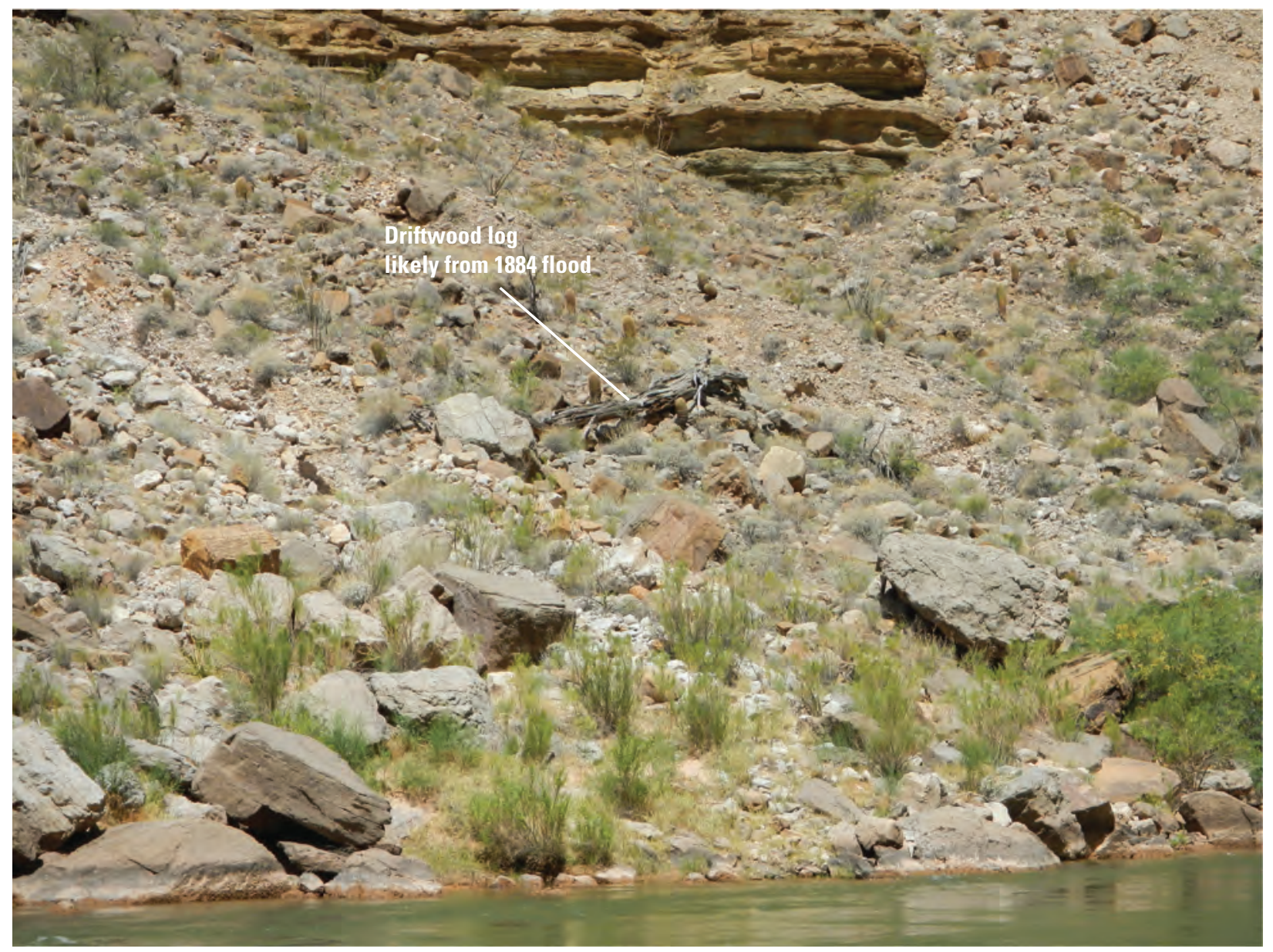

Figure 6. Large driftwood log likely from the 1884 flood on the talus slope along the Colorado River in the Grand Canyon, Arizona. When identifying paleoflood deposits in this reach, the elevation of the driftwood indicates an ideal elevation from which to start. Photograph by Tessa M. Harden, U.S. Geological Survey.

Stratigraphic descriptions of flood sequences emphasize breaks and contacts separating deposits of individual floods from each other and from non-flood deposits such as slopewash or other local material. Descriptions of sedimentary structures and deposit characteristics (such as mineralogy, grain size, and bedding) can help define the depositional environment and sediment source, which are attributes used in deciphering a local flood record. As summarized in Benito and O'Connor (2013), Baker and Kochel (1988), Enzel and others (1994), and Benito and others (2003), deposits from individual floods within a sedimentary sequence commonly are distinguished by the following criteria (fig. 7):

1. Identification of a distinct silt-to-clay layer, often called a silt cap (fig. $7 \mathrm{~A}$ ), at the top of a flood unit, commonly marking final deposition of very fine sediment during the waning stage of a flood.

2. Intervening layers of sediments deposited by non-flood processes (for example, tributary alluvium [fig. $7 B]$ or cave roof-fall [fig. $7 C$ ]) separating deposits of mainstem floods.
3. An erosional boundary where the surface of an older flood unit has been eroded by a younger flood (fig. 7D).

4. Bioturbation (plant and animal activity) indicative of an exposed sedimentary surface after the flood has passed (fig. $7 E$ ).

5. A change in the physical characteristics of the flood deposits, such as sediment grain size (fig. $7 F$ ) or color (fig. $7 G$ ), owing to factors such as differing sediment source or differing energy conditions. This criterion is not always valid by itself and typically needs additional evidence of the flood sediments being exposed for some length of time at or near the surface.

6. Other evidence of subaerial exposure and time between successive sedimentary units, such as the development of soil in fluvial deposits or evidence of surface occupation by humans or animals (fig. $7 H$ ). 


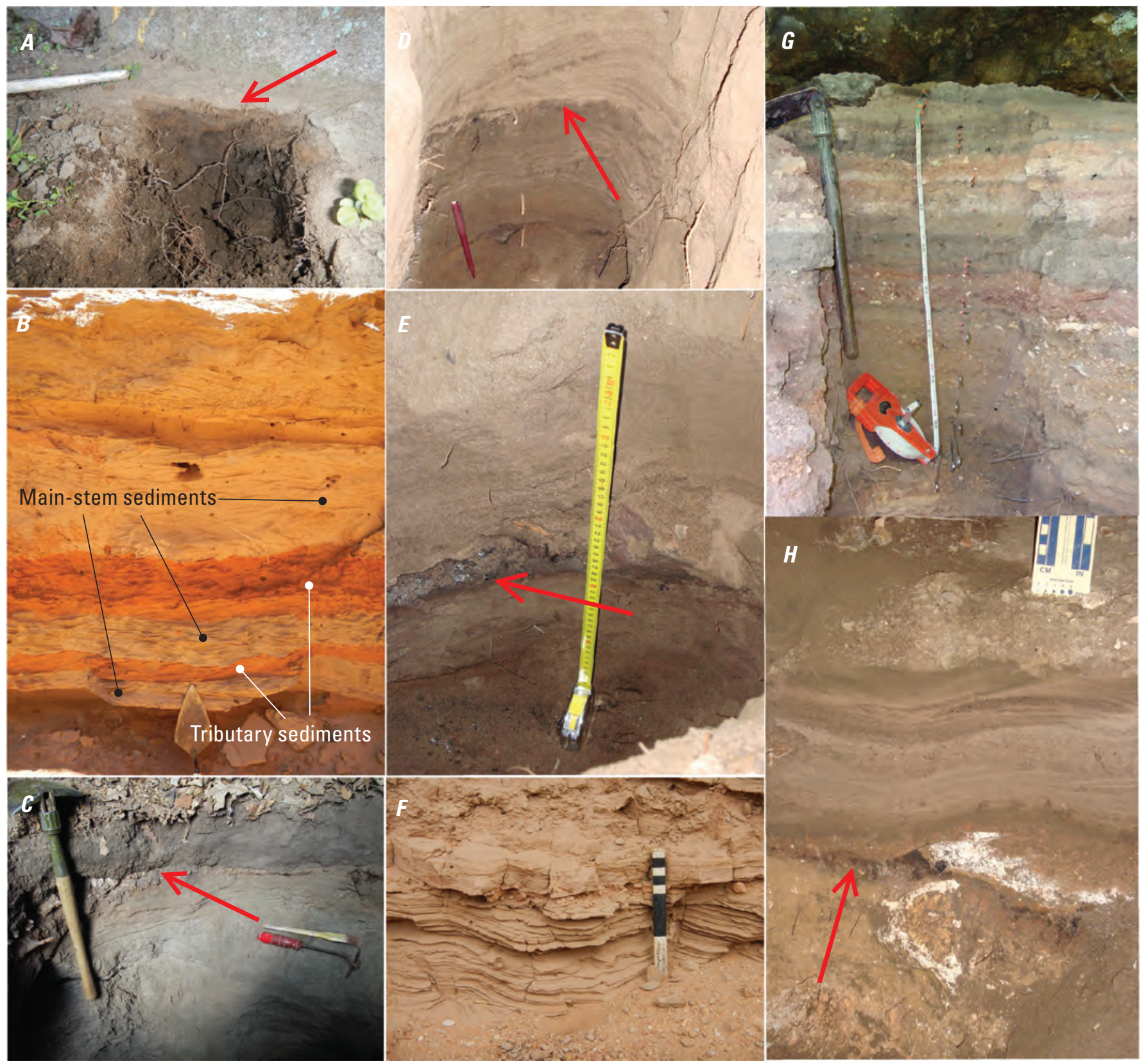

Figure 7. Photographs showing deposits from individual floods within a sedimentary sequence commonly distinguished by the following criteria- $(A)$ Silt layer (arrow) capping a flood unit, $(B)$ intervening layers of non-main-stem deposits such as tributary sediments separating mainstem flood deposits or $(C)$ angular cave roof-fall clasts (arrow), (D) erosional boundary (arrow) where a younger flood partially eroded an older flood, $(E)$ bioturbation such as a packrat midden (arrow) on a previously exposed sediment surface now buried by flood sediment, a change in physical characteristics of flood units such as grain size $(F)$ or color $(G)$, and $(H)$ evidence of subaerial exposure such as a surface previously occupied by humans (arrow). Photographs by Tessa M. Harden $(A, B, D$, $F, G)$ and Jim $O^{\prime}$ Connor $(C, E, H)$, U.S. Geological Survey.

For detailed paleoflood assessments, such stratigraphic analyses commonly are conducted for multiple sites within a study reach (for example, Harden and others, 2011), and for multiple reaches along a river system (for example, Hosman and others, 2003). One approach is to evaluate sites at a range of elevations (with respect to flood magnitude; fig. 8) to improve chances of defining the number of floods reaching different stages. There is no clear consensus on the minimum number of sites to investigate per reach and factors such as site access and conditions, project goals, timelines, and budgets commonly influence the number of study sites. However, more sites typically lead to less uncertainty and more reliable results as well as a more robust chronology of flooding for a wide range of discharge magnitudes. 


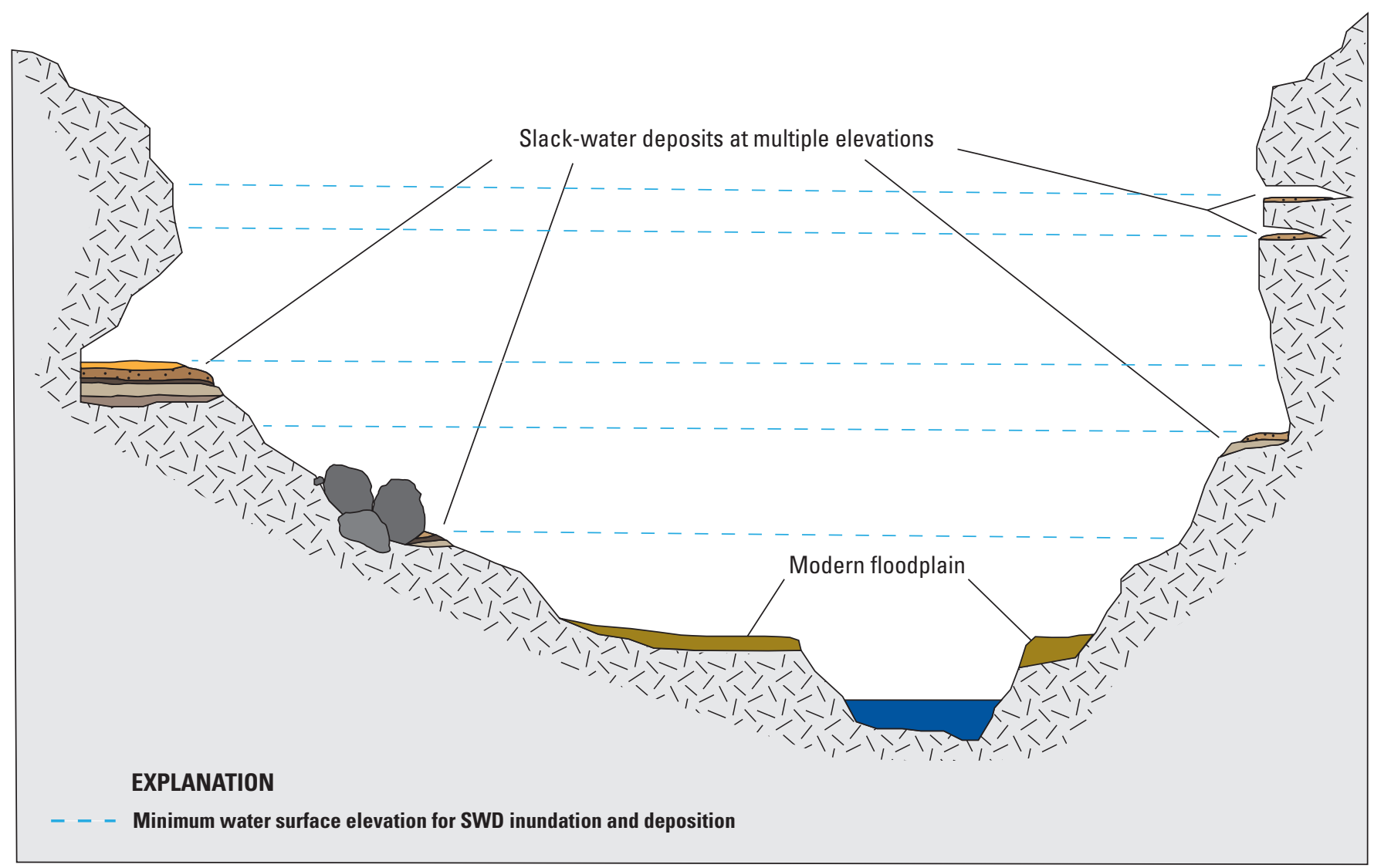

Figure 8. Schematic diagram showing flood slack-water deposits (SWDs) preserved in different environments (cave, channel margins, lee side of boulders) and at different elevations (stages).

\section{Terrace and Floodplain Deposits}

Terraces and floodplains are composed of river alluvium (fine-grained stream-transported sediments) flanking active river channels (fig. 9). Floodplains are sites of recurring overbank deposition adjacent to a channel, whereas terraces are former floodplains abandoned owing to river incision or flow reduction and at a higher elevation than the active floodplain. Some terraces may continue to accrete by overbank deposition during large floods (fig. 9). Because terraces and floodplains are formed of flood deposits, they can provide stratigraphic records of past floods (Jones and others, 2012; Wang and Leigh, 2012; Leigh, 2018). Depending on the environment, such records may go back hundreds to thousands of years (McQueen and others, 1993; Hosman and others, 2003; England and others, 2010; Harden, 2013; Harden and Bauer, 2014). Terraces and floodplains can be more challenging environments in which to identify individual floods compared to SWDs. Terraces commonly are more affected by bioturbation and dynamic channel changes that can rework the sediment and alter soil forming processes - attributes that hinder stratigraphic preservation and interpretation.

\section{Site Selection and Identification of Flood Sequences}

Rivers flanked by multiple terraces may have stratigraphic records of flooding at several different elevations/ stages spanning multiple time intervals. Terraces inset or confined in narrow valleys (figs. 9-10) can be especially favorable for paleoflood analyses because of the potential for sensitive stage-discharge relations associated with the elevations of flood deposits. In some instances, alluvial fan deposits from tributaries, reworked by the river into terrace-like features (fig. 11), can be useful, especially if there is clear distinction between river and fan material (fig. 12). The basic stratigraphic methods are the same for those of SWDs. However, terraces typically are affected by soil-forming processes and commonly have more developed soils than SWDs. Therefore, stratigraphic boundaries often are more subtle and individual floods can be hard to distinguish, especially if they occurred within a short time period. The presence of buried soils in terraces almost always is a clear indication of the boundary between two floods. With respect to floods, buried soils occur when flood sediments are deposited on an existing soil, such as when a large flood inundates an older terrace. The existing soils will be genetically different from the fresh flood 


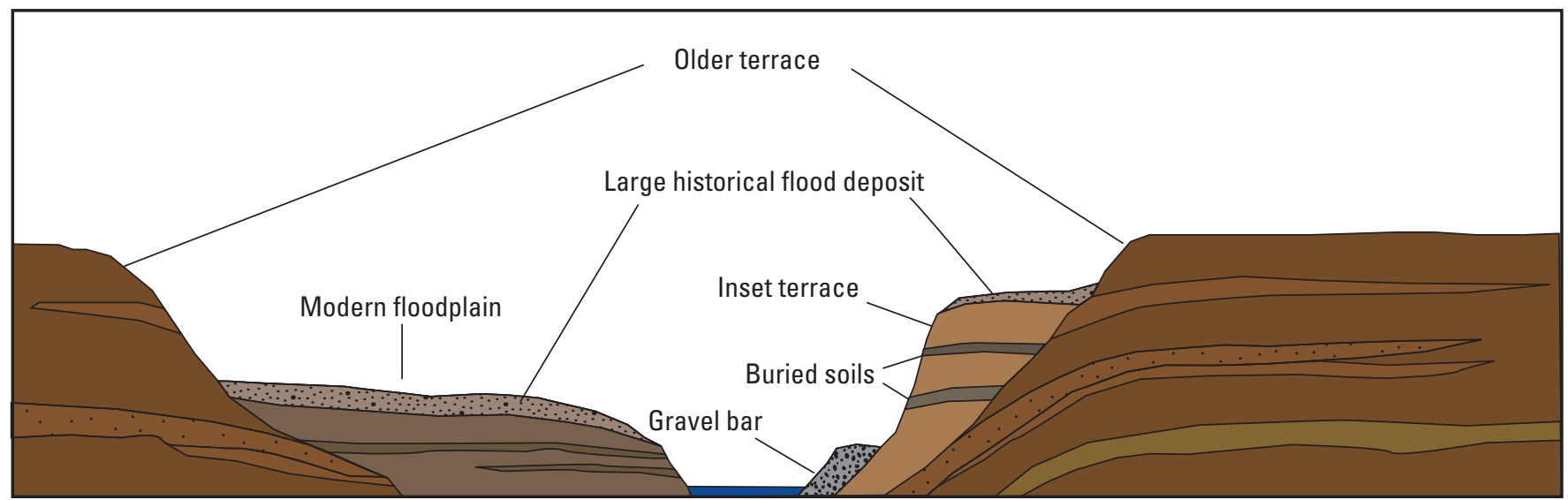

Figure 9. Schematic diagram showing terraces, including an inset terrace and the modern floodplain. A deposit from a large historical flood is shown on the modern floodplain and the lower terrace. Buried soils indicating individual floods also are shown.

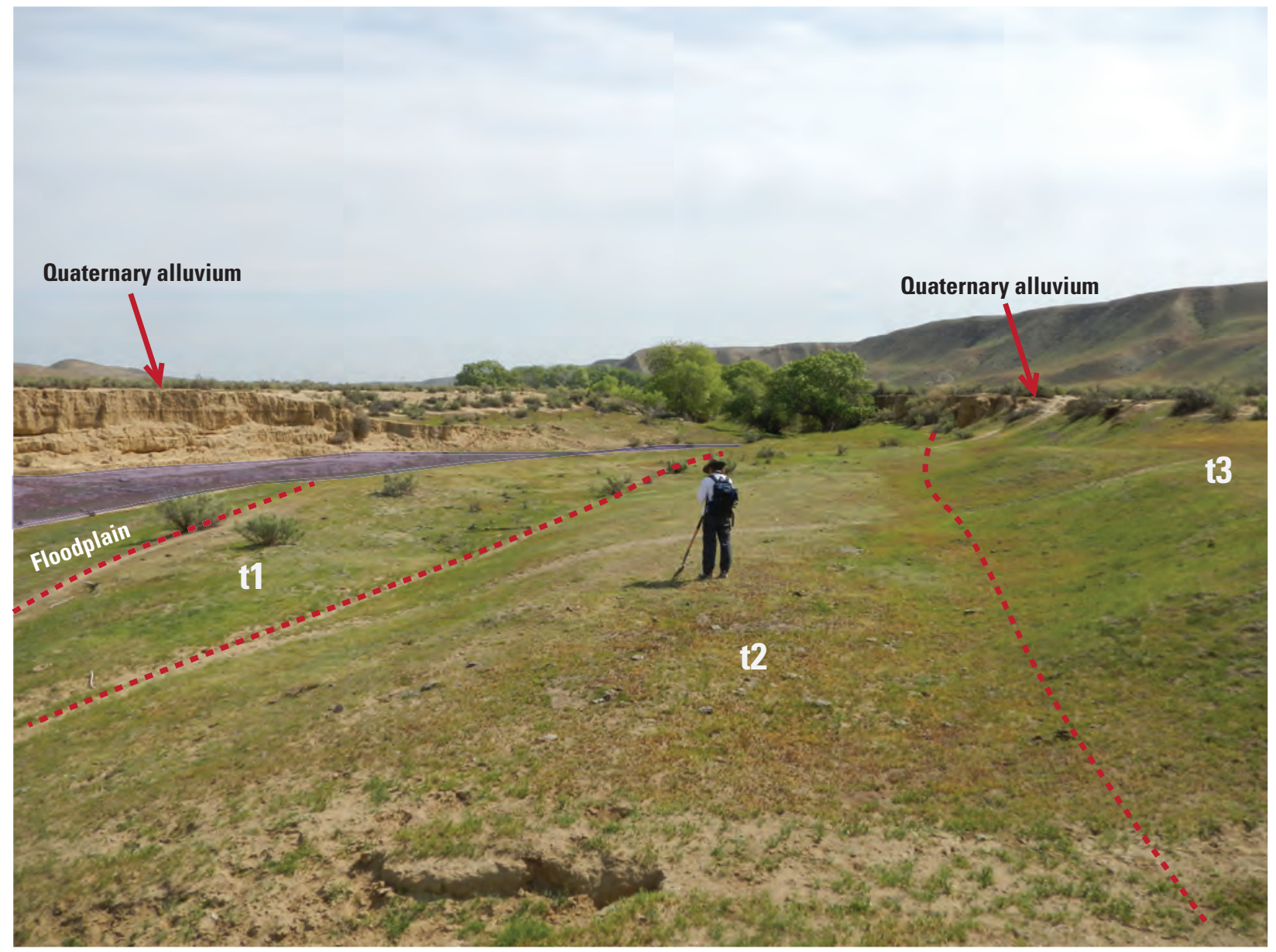

Figure 10. Set of relatively younger Holocene terraces (t1-t3) inset in relatively older Quaternary valley fill deposits (arrows) allowing for sensitive stage-discharge relations when determining flood magnitude, in California. Photograph by Tessa M. Harden, U.S. Geological Survey. 


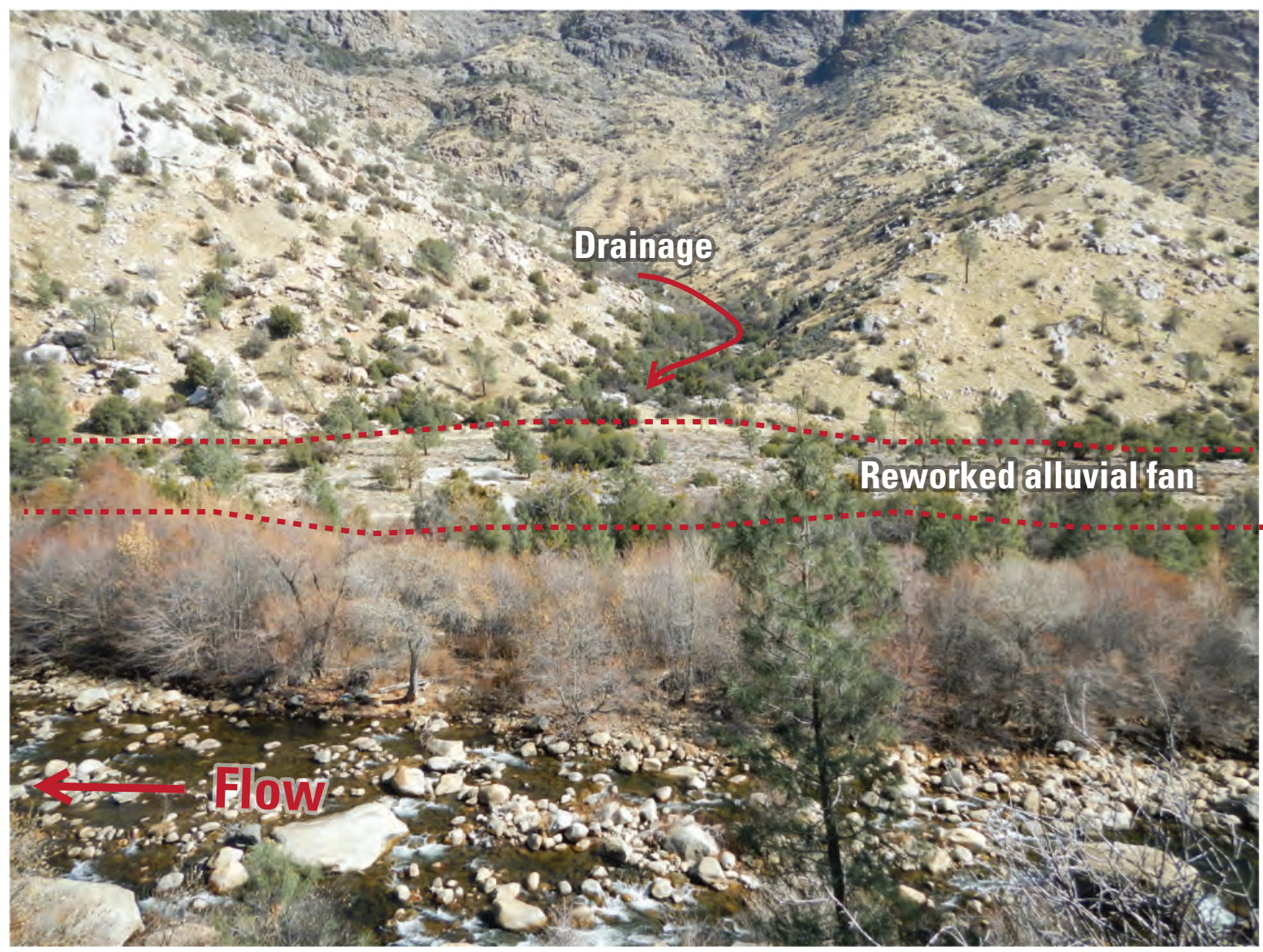

Figure 11. Alluvial fan deposits reworked into a terrace-like feature by the Kern River, California. Photograph by Tessa M. Harden, U.S. Geological Survey. 


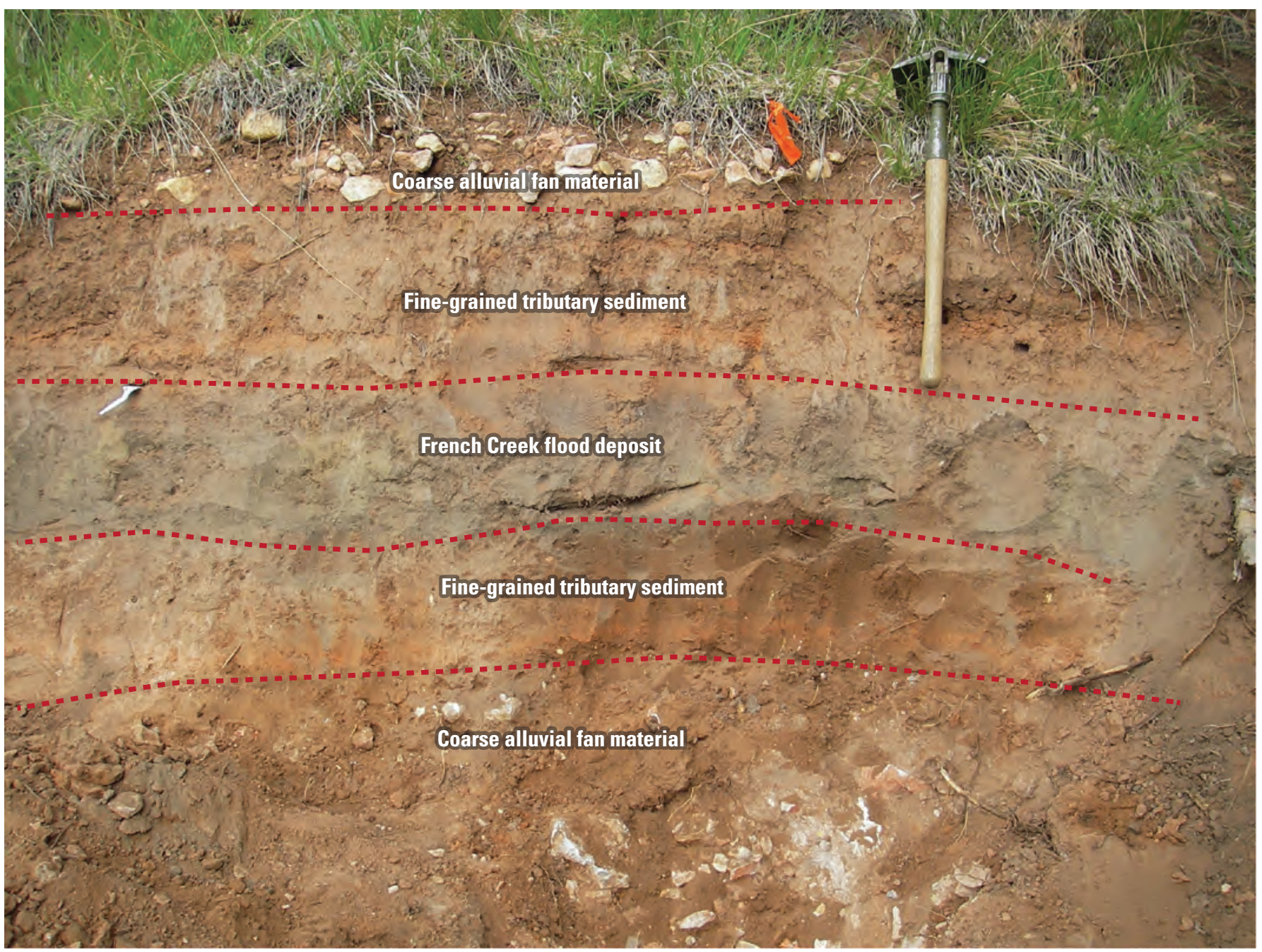

Figure 12. Coarse- and fine-grained reddish fan material above and below grayish fine-grained main-stem French Creek flood deposit, South Dakota. Photograph by Jim O'Connor, U.S. Geological Survey. 
sediments, differing in physical and mineralogical properties (Natural Resources Conservation Service, 2014). In the field, buried soils typically can be identified by relatively dark horizon or organic material (A horizon) that originally was the vegetated terrace surface of the older terrace (fig. 13).

Wang and Leigh (2012) and Leigh (2018) successfully used grain-size measurements and particle sorting in combination with the gaged record to identify time intervals of large floods preserved in low terraces on the Little Tennessee River, North Carolina and Georgia, and relict terraces on the Tennessee River in Alabama (Davis and others, 2019). Although estimating temporal resolution and accurate discharge estimates are challenging, this method can be combined with SWDs to produce a more robust history of flooding (fig. 14).

\section{Terraces As Non-Exceedance Bounds}

Once frequent inundation of terraces by floodwater ceases and fluvial sediment stops regular accumulation, the characteristics of the deposits change over time. When soils begin to form, bedding features and deposit contacts can be blurred or lost by bioturbation from plants and animals, and accumulation of organic material. Terrace surfaces can become heavily populated with mature vegetation that can obscure unit contacts and surface topography. Surface features such as overflow channels become smoother over time and, if a terrace is adjacent to a slope, the terrace will start to develop slope drainage features such as channels and gullies perpendicular to the main channel. These stable terrace surfaces may mark the upper limit of flooding since inundation ceased (fig. 14). If that time duration can be determined, the terrace elevation (and associated discharge) can be used as a flood non-exceedance bound (Levish and others, 1996; England and others, 2006; England and others, 2010; Harden, 2013; Harden and Bauer, 2014). Discharges associated with non-exceedance bounds can have considerable uncertainty because of the difficulty in determining the depth of the floodwaters needed to inundate the stable terrace surface and leave a recognizable trace either from deposition of flood sediments or erosion of the terrace surface (England and others, 2010). The depth of inundation and associated discharge values have been estimated by calculating the critical shear stress for mobilizing surface sediment particles (Godaire and Bauer, 2013) or applying an arbitrary depth (typically $1 \mathrm{~m}$ ) above the terrace surface (England and others, 2010) with the assumption that shear stress values would be high enough to modify the surface sediments of most fine-grained alluvial terraces at that depth (Levish, 2002).

Non-exceedance bounds, if appropriately applied in a flood-frequency analysis, can provide powerful constraints on the flood-frequency distribution. However, caution is needed when inferring the absence of floods from the absence of evidence. The most rigorous non-exceedance bound assessments account for inundation depths required for initiating erosion or deposition of the stable terrace surface by considering the shear stress or stream power exerted by a range of flows, or by comparing with effects of historical floods (England and others, 2006). Even these assessments can have large uncertainties because they typically do not consider soil cohesion and the "armoring" effects of a vegetated surface. The Bureau of Reclamation (Levish and others, 1996; Levish and others, 2003; England and others, 2010; Godaire and Bauer, 2012a,2012b) and U. S. Army Corps of Engineers (Kelson, Hall, and others, 2018; U.S. Army Corps of Engineers, 2020b) commonly apply non-exceedance bound assessments in their paleoflood analyses of flood risk for dam safety operations and other substantive projects.

\section{Age Determination}

A key component to understanding the frequency of large floods preserved in a geological record is determining the length of record and the timing of individual floods. In most cases, development of a paleoflood site chronology requires a combination of geochronologic age-determination methods. Most detailed paleoflood assessments typically develop flood records of durations on the order of thousands of years (O'Connor and others, 1994; Hosman and others, 2003; Harden and others, 2011; Greenbaum and others, 2014; Lam and others, 2017; Harden and others, 2021).

\section{Radiocarbon Dating}

Numerical dating methods aim to establish the timing of individual floods. Such dating may target individual flood deposits or the intervening non-flood deposits in order to establish a minimum or maximum age of an underlying or overlying flood deposit. Radiocarbon dating is the most common numerical age-dating tool used in paleoflood studies. Organic materials such as wood, charcoal, seeds, or leaf fragments are entrained by floods and commonly deposited in conjunction with inorganic sediment in flood sequences. Additionally, flood deposits may cover or be covered by vegetation or organic cultural materials. These types of materials can be radiocarbon dated, thereby providing information on the age of enclosing or bounding flood deposits.

Plants incorporate atmospheric carbon, including the radioactive isotope carbon- $14\left({ }^{14} \mathrm{C}\right)$, through photosynthesis. The systematic loss of ${ }^{14} \mathrm{C}$ from plant tissue by radioactive decay begins immediately at the rate of the ${ }^{14} \mathrm{C}$ half-life of $5,730 \pm 40$ years. Thus, a radiocarbon analysis dates the time of carbon assimilation into plant tissue as measured by the amount of remaining ${ }^{14} \mathrm{C}$ relative to the stable carbon-12 $\left({ }^{12} \mathrm{C}\right)$ isotope. Typically, these measurements are made by accelerator mass spectrometry (Vogel and others, 1984). 


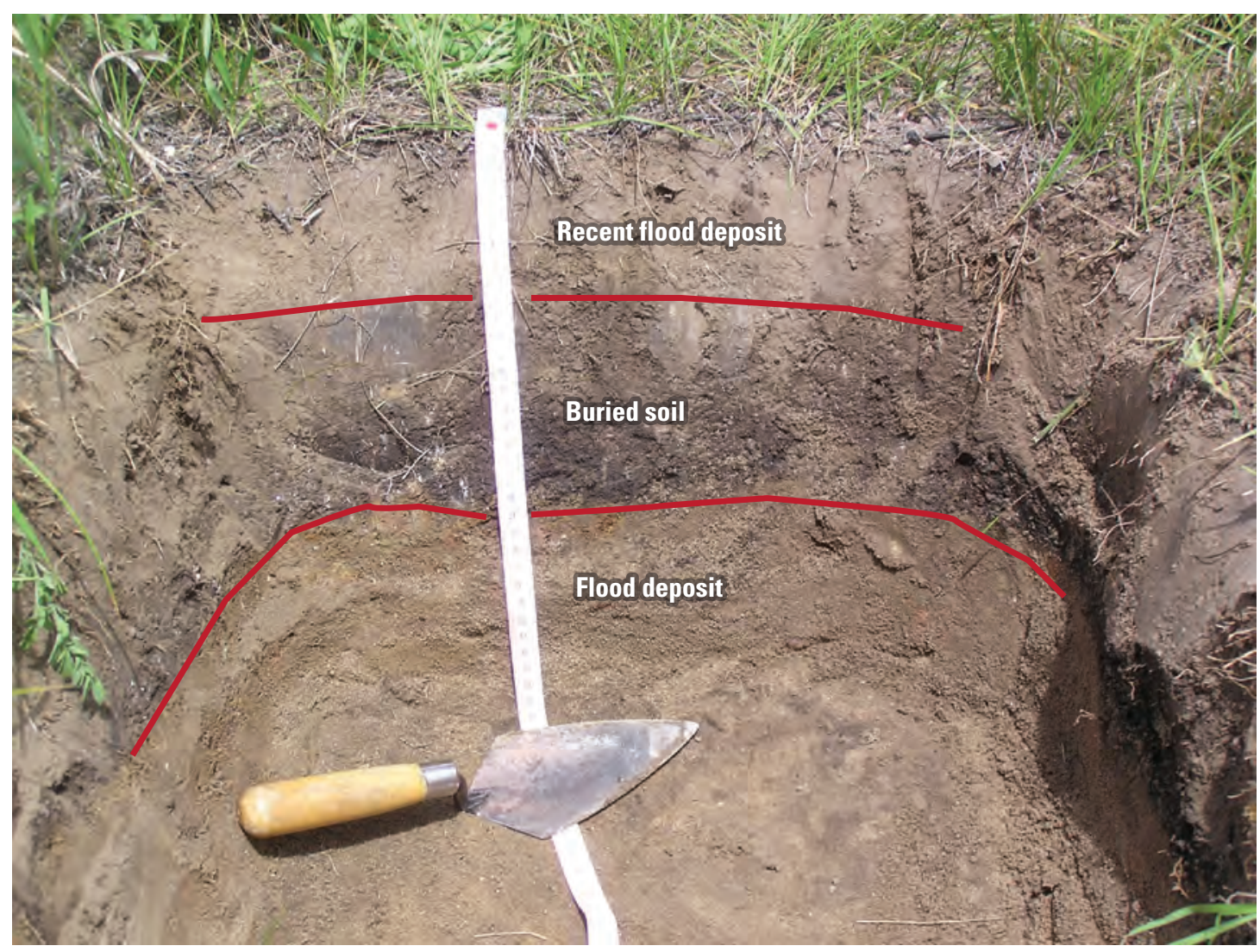

Figure 13. Buried soil between two flood deposits from Kettle Creek, Colorado. Photograph by Jeanne Godaire, Bureau of Reclamation.

Stable terrace showing signs of soil development

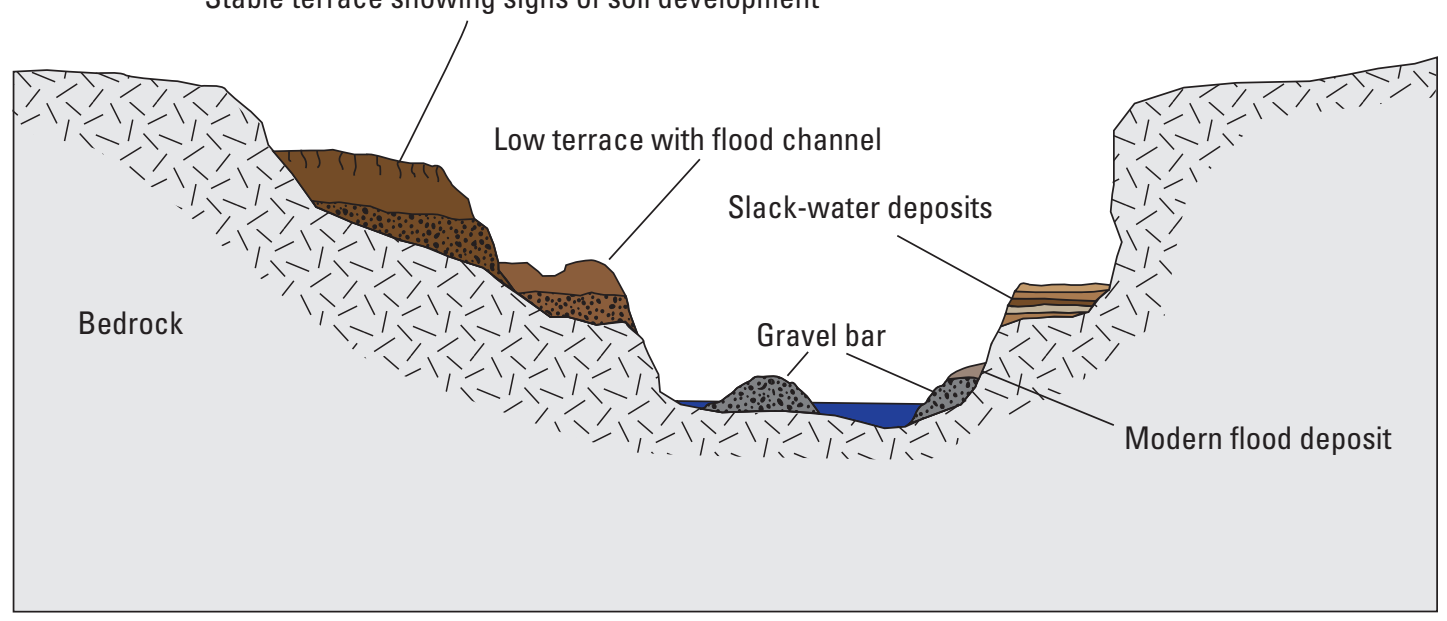

Figure 14. Schematic diagram showing a relatively older stable terrace with developed soils, a relatively younger terrace with a well-developed flood overflow channel, the active channel with gravel bars, and a series of slack-water deposits along the channel margin on the bank opposite the terraces. 
An inherent assumption is that the time of carbon assimilation of organic material associated with a flood deposit closely approximates the time of the flood. In some cases, particularly for durable organic materials, the time of plant death may significantly precede the deposit age. Consequently, the radiocarbon age of organic material within a flood deposit is a maximum limiting age for the flood, and organic materials associated with deposits of accumulated materials between floods provide a maximum limiting age for the overlying flood deposit. To reduce potential errors resulting from dating materials substantially older than the associated flood deposits, ideal samples for radiocarbon analysis are materials not likely to persist long in open environments, such as short-lived plant fragments, pine needles, and leaves. In certain situations, however, the only suitable organic materials are of types that may have persisted for many years, even centuries, before being entrained into a flood deposit. Charcoal and large wood fragments are particularly susceptible to yielding erroneously old ages because of their potential persistence and reworking by multiple floods but, owing to their more common presence in sediment deposits, they often are used in radiocarbon analysis (Blong and Gillespie, 1978). Precise identification in the laboratory of organic material collected in the field also can help in selection of which organic samples would be most successful for radiocarbon analysis (for example, charcoal from a shortlived maple compared to charcoal from a long-lived pine).

In addition to uncertainties resulting from the history and stratigraphic context of a dated sample, analytical and calibration uncertainties affect radiocarbon dates. There is inherent imprecision in measuring the laboratory-calculated age, ranging from \pm 10 years to \pm 50 years (Clague, 2015). In addition to the unavoidable uncertainty in the laboratory-calculated radiocarbon age, the ratio of ${ }^{14} \mathrm{C}$ to ${ }^{12} \mathrm{C}$ in the atmosphere, biosphere, and hydrosphere has varied; consequently, radiocarbon ages based on the historical ratio diverge from true calendar ages even with well-established radiocarbon datasets (for example, Reimer and others, 2009). This uncertainty becomes larger further back in time and in most cases, the uncertainty in the calibrated age ranges is greater than the precision of radiocarbon age ranges (Clague, 2015). For radiocarbon ages less than about 300 years, the resulting uncertainties in the calendar age are especially large because of the large and varying quantities of ${ }^{12} \mathrm{C}$ released into the atmosphere by anthropogenic burning of fossil fuels (Walker, 2005). Samples of organic materials photosynthesizing after A.D. 1950 have particularly high ${ }^{14} \mathrm{C}$ levels because of substantial ${ }^{14} \mathrm{C}$ introduction into the atmosphere by above-ground weapon nuclear testing, distinctly marking post-1950 samples - commonly termed "modern" or "post-bomb." Radiocarbon dating can reliably date organic material younger than about 50,000 years although uncertainty increases at the extreme end of the age range.

\section{Optically Stimulated Luminescence}

Optically stimulated luminescence (OSL; Aitken, 1998; Rhodes, 2011) is a dating technique that indicates time elapsed since the burial of deposits, principally quartz and feldspar minerals. Sediments containing, or proximal to, naturally occurring radioactive isotopes (such as uranium, thorium, and potassium, common in most soils and sediments) are exposed to low levels of radiation (Walker, 2005). OSL dating relies on the accumulation of free electrons derived from the decay of such radioisotopes within structural defects in the crystal lattice of a mineral grain. The longer a mineral grain is exposed to a radiation source, such as being buried in sediment with radioactive isotopes, the more trapped electrons accumulate (Bradley, 1999; Walker, 2005). When a mineral grain is exposed to light, the electrons are stimulated and released from the crystal lattice. Under laboratory conditions, the number of electrons released can be measured and correlated to the amount of time the crystal has been buried, thus giving a burial age. If sediment entrained by a flood is exposed to light ("bleached") before or during entrainment, the electron traps will be emptied, only to begin accumulation when buried within a flood deposit. In such cases, the measured age, as indicated by subsequent electron accumulation, represents the age of the depositing flood. The capacity of the minerals to store electrons in their crystal lattice and the dose rate of the environments typically limit the useful age of OSL samples to no more than $200,000-400,000$ years, although uncertainties are large and may exceed 10 percent for very old ages (Rhodes, 2011; Wallinga and Cunningham, 2014).

Sampling and analysis involve collection and analysis of fine sand-sized sediment from a target deposit, avoiding exposure to light (fig. 15A; Porat, 2006). Multi-grain luminescence measurements are common (fig. 15B); however, developments in OSL instrumentation are reducing the sample size to individual quartz and feldspar grains (Duller and Murray, 2000; Bøtter-Jensen and others, 2000; Jacobs and others, 2015). Analytical protocols have improved the application of OSL dating for alluvial deposits (Murray and Wintle, 2000; Wintle and Murray, 2006), resulting in numerical dating of years to hundreds of thousands of years with age uncertainties within 5-10 percent, even for young deposits ( $<300$ years) (Ballarini and others, 2003; Duller, 2004; Arnold and others, 2009; Wallinga and Cunningham, 2014). 


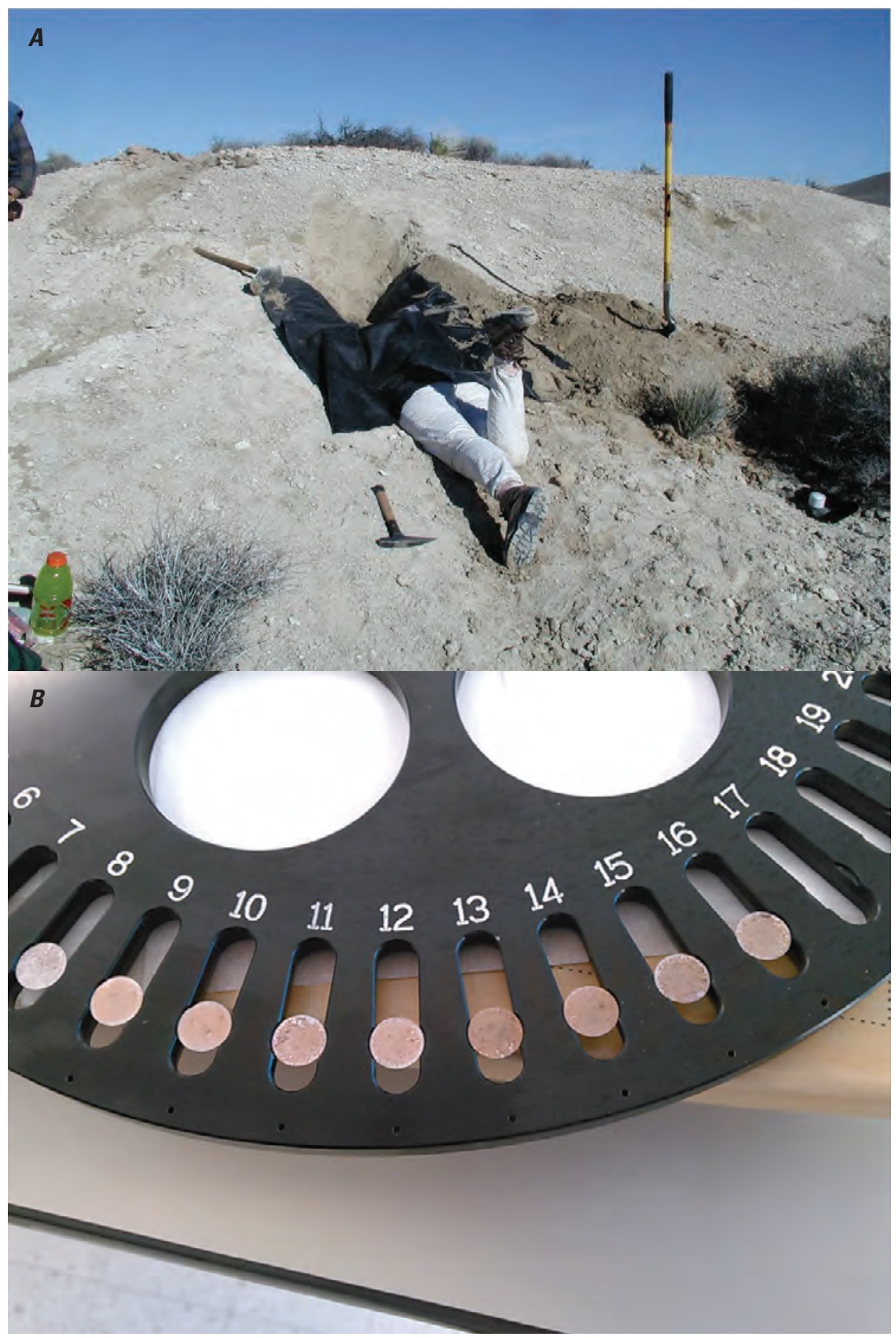

Figure 15. Optically stimulated luminescence (OSL) sample collection of fine sediment under a dark cloth in southern California $(A)$ and the typical representative sample size for luminescence analyses of fine silt grains $(B)$. Each disc is 1 centimeter in diameter. Photographs by Dave Miller $(A)$ and Shannon Mahan $(B)$, U.S. Geological Survey. 
Research has highlighted the importance of selecting suitable sample locations (Rodnight and others, 2006). The technique can be hampered in the following situations: (1) wherein the proper species of quartz are not present in the deposits and (2) for floods where the transported sediment was not bleached or only partially bleached by exposure to light (Harden and others, 2021) because of high turbidity levels from sedimentrich floodwaters, the sediment traveled a short distance, or because the flood occurred at night. If the duration of the exposure is insufficient for full bleaching or resetting, the measured signal will not be a true indicator of the elapsed time since the flood of interest (Bailey and others, 1997). However, under appropriate conditions, OSL dating can be an important tool, especially for deposits (1) containing little or no organic materials or (2) younger than 300 years old, for which calibration issues render radiocarbon dating imprecise.

\section{Dendrochronology}

Tree rings often are used to date sediment-based paleoflood determinations. See section, "Botanical Paleostage Indicators," for more information.

\section{Cesium-137}

Another technique used to date more recent fluvial deposits is cesium-137 $\left({ }^{137} \mathrm{Cs}\right)$ (Ely and others, 1992; Harden and others, 2011). Atmospheric ${ }^{137} \mathrm{Cs}$ was produced during nuclear weapons tests, with smaller amounts from nuclear reactor waste and accidental releases such as at Chernobyl, Ukraine, in 1986. Thus, ${ }^{137}$ Cs production and deposition began about 1945 and peaked about 1963 (Holmes, 1998). The presence of ${ }^{137} \mathrm{Cs}$ in flood deposits signifies a post-late 1940s age and offers a cost-effective method to distinguish modern flood deposits from older deposits, making it a practical method to characterize the chronology of sediments that have accumulated within the last 100 years (Jeter, 2000).

\section{Relative Dating Methods}

Relative age-dating of flood deposits can be helpful in determining the sequence of flood events. One method, stratigraphic superposition, relies on the principle that older deposits will underlie younger deposits in undisturbed stratigraphic settings. Nevertheless, younger flood sediments commonly are inset against older deposits, producing sequences of younger and lower flood deposits buttressed against older and higher deposits. Weathering characteristics such as desert varnish (a dark coating of minerals and oxides found on exposed rock in arid climates), desert pavement (closely packed rock fragments on the surface in arid environments), weathering rinds of clasts (the chemically altered outer layer of a rock), and archeological material can be indicative of relative age in some settings (Dorn, 1994; Knuepfer, 1994; Kohn and others, 2016). Soil development also has been used as a relative agedating technique (Markewich and others, 2017) in paleoflood studies (Ostenaa and others, 2001), especially for stable terrace surfaces in reconnaissance-level studies. Many soil properties (color, thickness, texture, structure, minerology, salt accumulation) change over time (Birkeland, 1984; Holliday, 1988). Knowledge of the rate of change of these properties in a particular study area can sometimes be used to determine the relative age of the deposit.

\section{Other Methods for Determining Chronology}

The largest floods typically have the largest effects on landscapes and leave multiple physical and botanical records. The establishment and growth of riparian vegetation along river corridors are controlled by hydrogeomorphic processes (Everitt, 1968; Bedinger, 1971), including flood magnitude and duration, flow velocity, and sediment transport fluxes (Osterkamp and Hupp, 1984). Resulting botanical conditions provide a context for linking flood sediments and geomorphic surfaces with flood timing and magnitude. Along rivers, caves, rock shelters, and terraces are commonly the sites of recurrent human occupation. At such sites, archaeological features may be used to infer floods and date flood episodes. More modern human artifacts, such as beer cans and other datable trash (fig. 16; House and Baker, 2001; Sabol and others, 2021), pottery (Benito and others, 2003) and even socks (Harden and others, 2011) have provided numerical age constraints on flood deposits.

Cave deposits of speleothems (for example, a stalactite or stalagmite) have shown potential for documenting and dating paleofloods (Denniston and Luetscher, 2017). In appropriate cave environments, floods are recorded by detrital layers trapped within speleothems. Reconstructing cave chronologies has been done primarily using uranium-thorium (U-Th) dating techniques, albeit with high degrees of uncertainty (Carolin and others, 2013; Moseley and others, 2015). In some instances, U-Th dating has been aided by identifying annual banding in speleothems through fluorescence or mineralogy as well as through seasonal cycles of oxygen isotope ratios or carbon (Dasgupta and others, 2010; Frappier and others, 2014). 


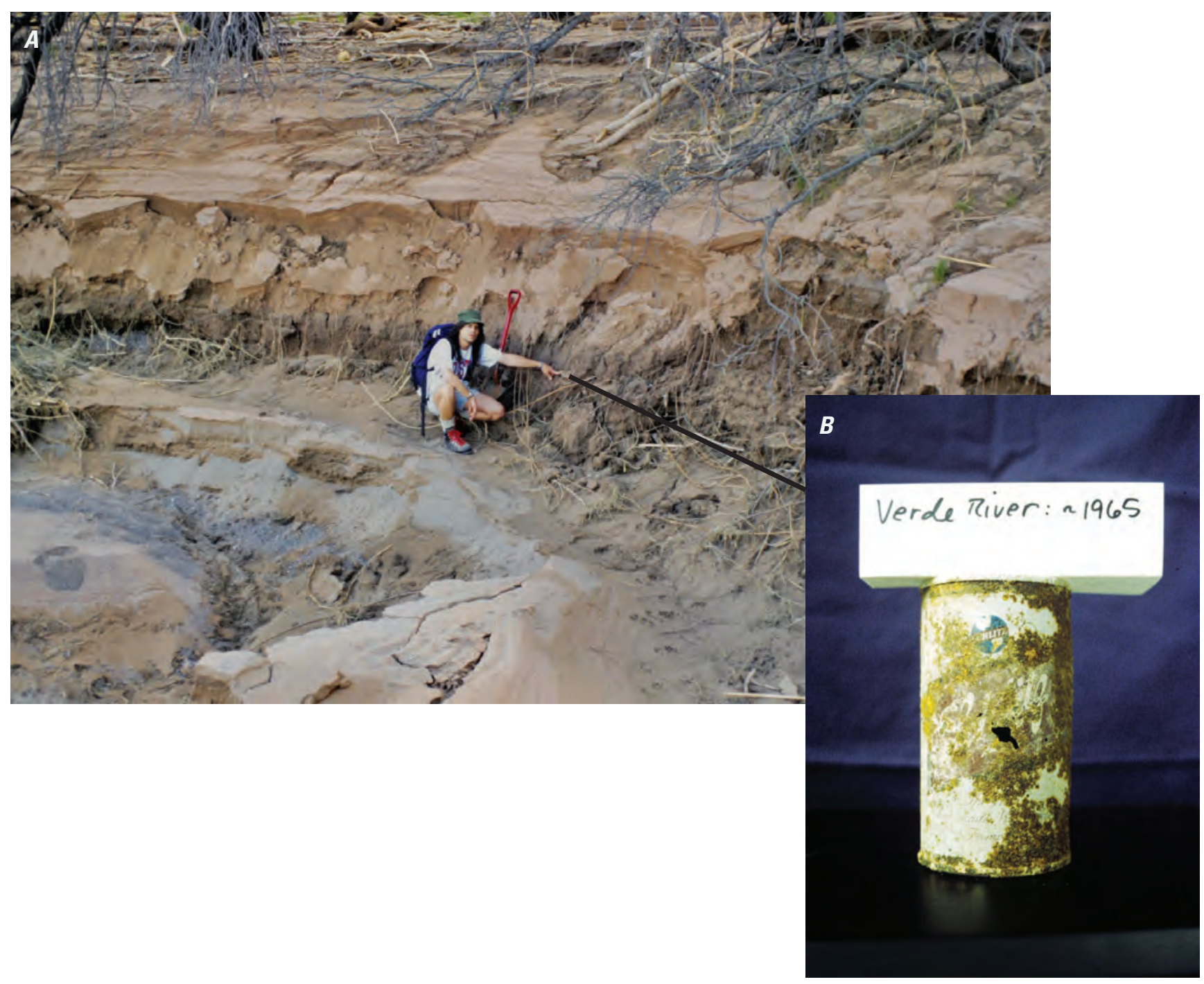

Figure 16. Location of the beer can $(A)$ imbedded in the stratigraphic exposure $(B)$ along the Verde River, Arizona. Diagnostic features of the can, such as the opening and label, can be used to date the flood deposit. In this case, the can indicated that this flood deposit is likely from a 1965 flood. Photographs by Kyle House, U.S. Geological Survey.

\section{Overall Flood Chronology}

Integrating the stratigraphy and chronology of multiple paleoflood study sites, although at times challenging, enables the determination of an overall flood chronology for a river reach (see example 2 sidebar). Rarely does a single site yield complete information. Commonly, one or two sites have lengthy and well-dated records of multiple large floods. The records from such sites typically are the primary information sources for associated flood-frequency analyses (Harden and others, 2021). Such "benchmark" sites generally are augmented by more fragmentary records at other sites, such as sites at higher elevations preserving records of larger floods (Harden and others, 2011). Correlation of flood deposits among sites is a critical step, necessary to avoid under- or over-counting of floods. Such correlations typically are based on deposit elevation, age, and physical characteristics of the sediment such as minerology, grain size, color, or thickness. Uncertainties in the resulting correlations are common but can be carried through into flood-frequency assessments. 


\section{Example 2-Tennessee River Flood Chronology}

Establishing an overall flood chronology for each river, or river reach, is an essential component of a paleoflood analysis. An overall flood chronology correlates flood deposits at all sites based on the stratigraphy, sediment characteristics, age, elevation, and associated discharge. A flood chronology supported by several sites also adds confidence to the final flood-frequency analysis and overall results of the paleoflood chronology. The overall flood chronology for the Tennessee River near Chattanooga, Tennessee, is shown in figure Ex2.1 (from Harden and others, 2021). Eight individual paleofloods (P1-P8) are identified from 39 flood deposits at 15 sites. The 15 sites represent a wide range of flood stages and depositional environments over a 12-mi stretch of the Tennessee River. In the field, the initial site selection was based on the elevation of high-water mark evidence of the 1867 historical flood previously documented by the Tennessee Valley
Authority $(1940,1961)$. In figure Ex2.1, the deposits at the Turkey Blind and Jeff-nSteph sites all correspond to

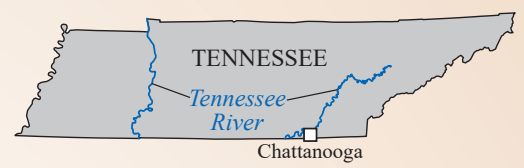
discharges of about 460,000 cubic feet per second, close to the discharge of the $1867 \mathrm{flood}$. The benchmark sites on this reach are Red Flower, based on the presence of the largest flood in the record, and the Jeff-n-Steph site, based on the long record of large floods (the highest site in elevation with the most complete record of floods). Only the four flood deposits outlined in black were combined with the historical and systematic record for the final flood-frequency analysis. The other four paleofloods were either too low in elevation (P4, P5, and P6), and, therefore, well-represented by the systematic record, or too old to confidently extend the record of individual floods (P1).

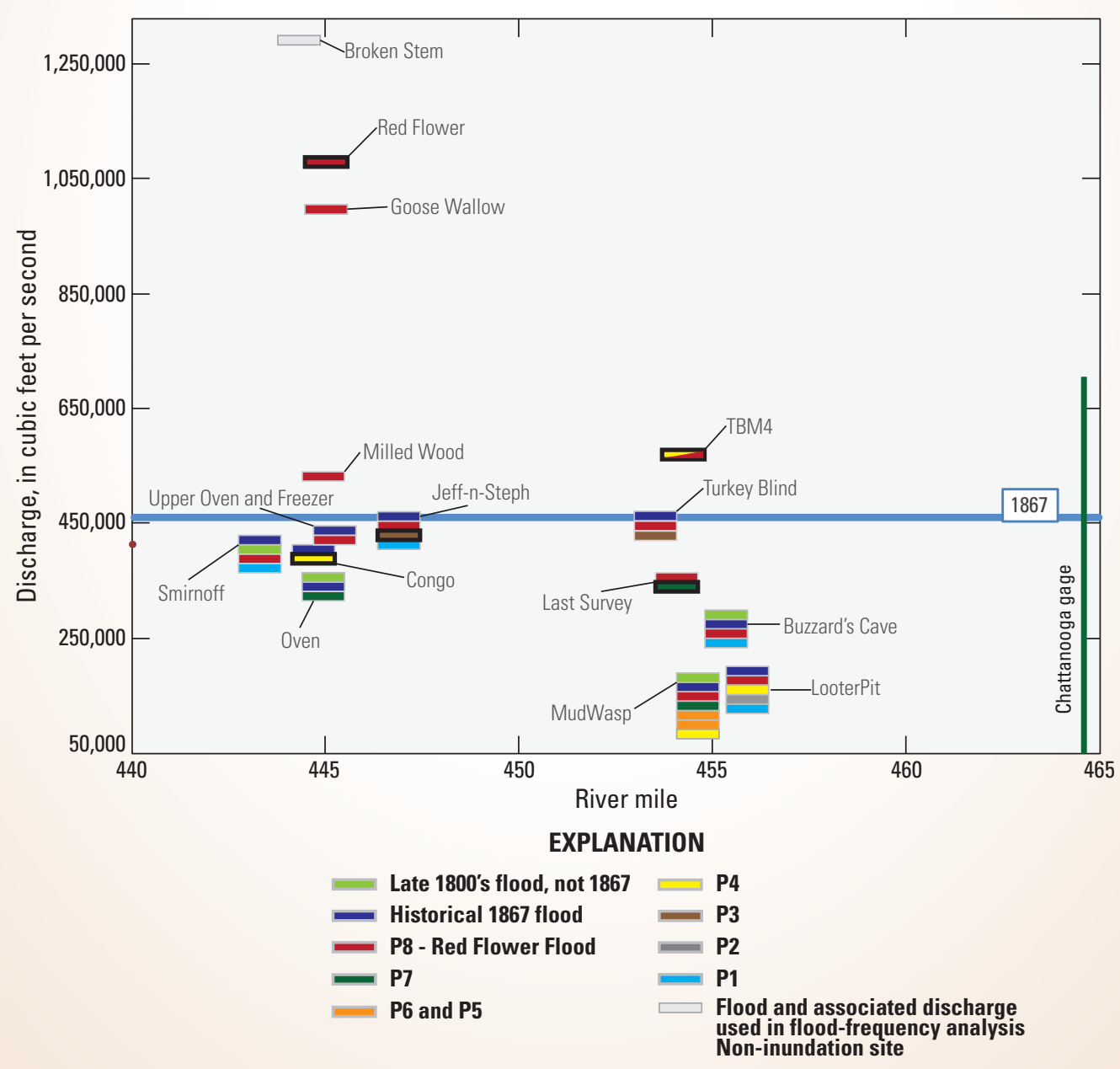

Figure Ex2.1. Overall flood chronology of Tennessee River below Chattanooga, Tennessee, correlating flood deposits at 15 sites. Boxes with same color are deposits left from the same floods. Site TBM4 has two colors because it is unclear which flood that deposit represents. Sites are shown relative to discharge magnitude. Historical 1867 flood magnitude is shown as horizonal line. 


\section{Botanical Paleostage Indicators}

Botanical evidence of large floods is available mostly in records preserved by trees and their growth rings. Several characteristics of tree rings make them useful for documenting the occurrence and magnitude of paleofloods. Many species, especially in temperate regions, form one ring per year allowing annual temporal resolution of disturbance. Flooding, impact of debris, and sediment deposition cause predictable changes to ring width and ring anatomy. Some of these changes are localized on the trunks of trees as scars, adventitious roots, or multiple stems growing from a parent trunk allowing estimates of flood stage. Living trees often are cored in order to examine their growth rings. However, timbers from historical building and archaeological sites and subfossil logs buried in river alluvium can be used cored and may extend records hundreds to thousands of years (St. George and Nielsen, 2003).

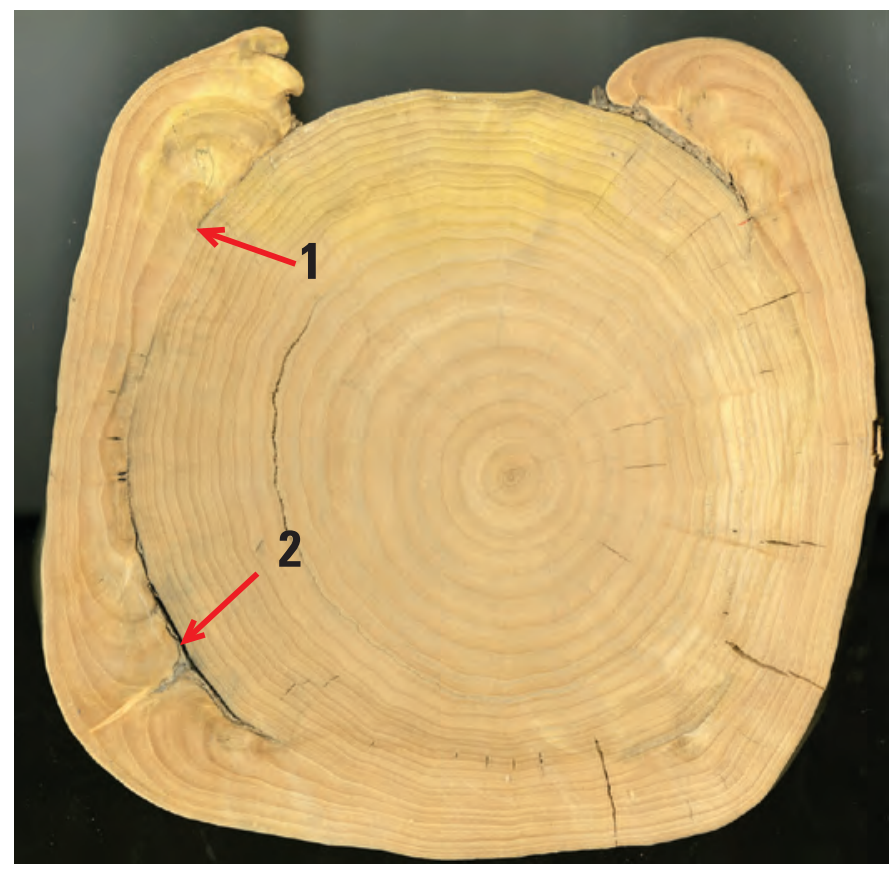

Figure 17. Scars caused by floating ice impacting plains cottonwood (Populus deltoides ssp monilifera) along the Missouri River in the Missouri Breaks region, Montana. Arrow 1 points to the lateral limit of the original injury; counting rings from this point to the bark indicates that the injury occurred 7 years prior to harvest of the tree. Arrow 2 indicates a location where the scar has completely covered a flood injury, making it invisible from the outside of the tree. Photograph by Jonathan Friedman, U.S. Geological Survey.
The type of flood evidence available from tree rings depends partly on watershed characteristics. In large, relatively humid watersheds, flood durations often exceed a few weeks, causing anatomical changes in developing tree rings. In small, steep, or arid watersheds, flood durations typically are shorter, flow variability is greater (Wolman and Gerson, 1978), and floods are more likely to produce scars following abrasion injury from floating debris. Tree rings are examined in cross sections of trunks or roots, wedges cut from scars, or cores collected with an increment borer. Use of tree rings in paleoflood analysis is reviewed by Alestalo (1971), Shroder (1980), Hupp (1988), Stoffel and Bollschweiler (2008), St. George (2010), Díez-Herrero and others (2013), Merigliano and others (2013), and Ballesteros-Cánovas, Stoffel, and others (2015). The following sections describe the different ways in which botanical evidence acts as a PSI to infer paleoflood date and magnitude.

\section{Date and Elevation of Flood Scars}

When floating ice, flood-transported boulders, or wood collides with a tree, bark may be damaged or removed, and the tree produces a characteristic scar to cover the injury (fig. 17; Shroder, 1980; Tardif and Bergeron, 1997; Gibson and others, 2019). Examining the rings in the scar reveals the year and sometimes the season of damage (Gottesfeld and Johnson Gottesfeld, 1990), and the elevation of the top of the scar is an approximate stage of the flood that carried the debris. Measurements from multiple scars allow analysis of the frequencies of different flood stages (Harrison and Reid, 1967; Hupp, 1988; McCord, 1996; Fanok and Wohl, 1997). Because the annual rings within scars are geometrically complex, they often cannot be analyzed accurately from core samples. They typically are collected by cutting a cross section of the stem (fig. 17), or if this is too invasive, by cutting a partial cross section or wedge that includes all years within the scar tissue.

Flood scars useful for paleoflood analysis can be collected from any long-lived species with distinct annual rings. Scarred trees may preserve flood data for centuries; McCord (1996) used flood scars to reconstruct flooding along a Utah stream back to year 1471. Use of flood scars to document paleofloods may be complicated because of the limited locations on the floodplain where moving debris might encounter a 
tree (Gottesfeld and Johnson Gottesfeld, 1990), because large floods may have removed scarred trees or because old scars may heal over and become difficult to detect (fig. 17).

\section{Death Date of Flooded Trees}

When extended flooding kills a tree, there is no formation of a scar. This prevents estimation of flood magnitude, but the year of the flood may be determined by matching the pattern of interannual variation in ring width of the dead tree with those of living trees (Stokes and Smiley, 1968). Rot of outermost rings in the dead tree may result in underestimation of the year of death. Yamaguchi and others (1997) used samples from stems and roots to date flooding mortality of western red cedar (Thuja plicata) due to subsidence caused by the 1700 Cascadia earthquake.

\section{Alteration of Tree-Ring Anatomy by Flooding}

Prolonged flooding for weeks or longer may affect the typical seasonal transition of tree ring structure. A core taken from a tree or a slice through an entire annual ring perpendicular to the direction of stem growth (fig. 18) viewed under magnification shows abundant hollow circles or polygons of varying size. These shapes are cross sections of structures called xylem vessels in broad-leaved trees or tracheids in conifers, which transport water up the stem from the roots to the leaves. The cross-sectional area of vessels or tracheids is limited by the tendency of the water column they contain to break under high tension during drought or freeze-thaw cycles (Pockman and Sperry, 2000). Narrower vessels or tracheids can sustain higher tensions, whereas wider ones transport water more rapidly. Therefore, vessels and tracheids normally are larger in the spring, when water is more abundant (Panshin and de Zeeuw, 1980), than in the summer, when water is scarcer. Flooding

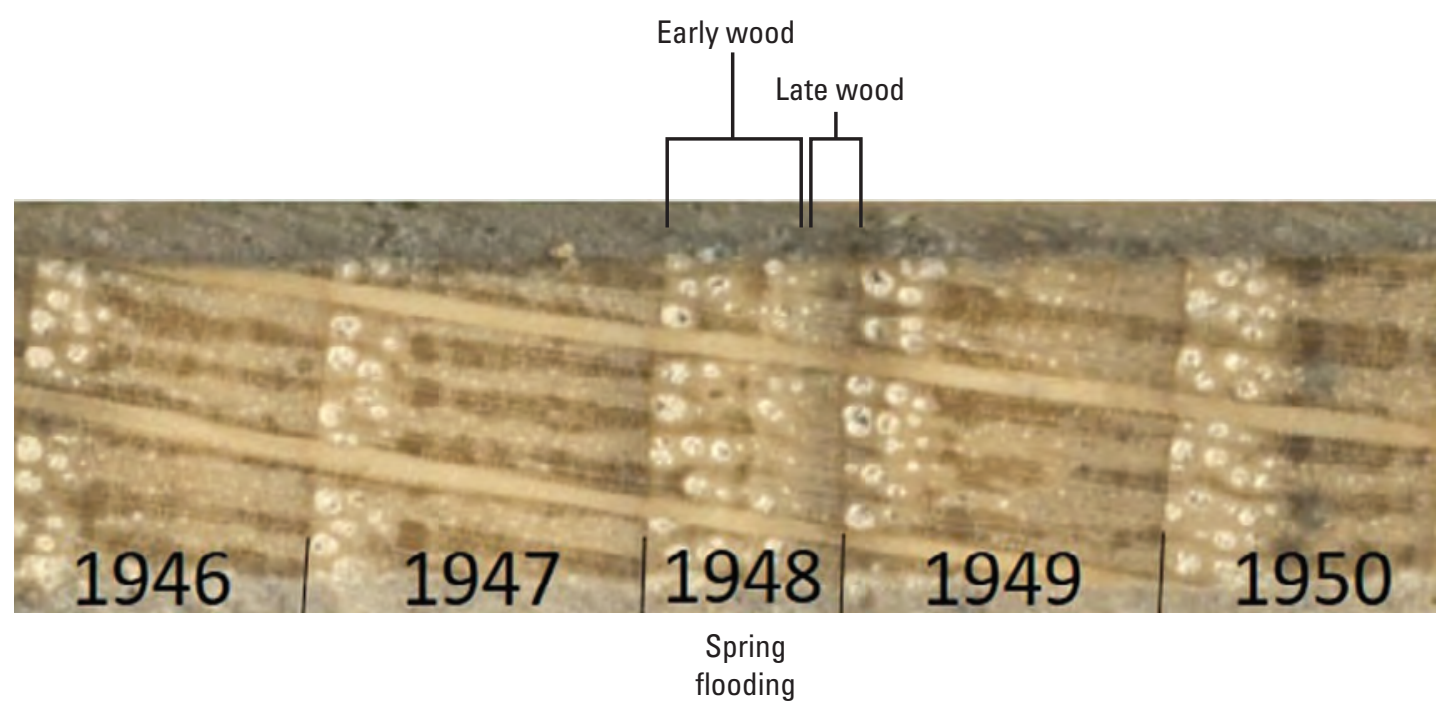

Figure 18. Five annual rings from Oregon white oak (Quercus garryana) along the Columbia River, near Portland, Oregon. Time progresses from left to right. Each annual ring begins with large early-wood vessels seen as lighter circles and ends with small late-wood vessels appearing as dark material with less apparent circles. The 1948 ring shows extended production of early-wood vessels as a result of spring flooding. Photograph by Richard Thaxton, U.S. Geological Survey. 
may alter this normal seasonal progression, allowing identification of flood rings (Wertz and others, 2013). This can be seen in the 1948 ring in fig. 18, which shows extended production of large early-wood vessels owing to spring flooding.

The anatomical characteristics of flood rings vary among species and by season of formation (Yanosky, 1983; Hupp, 1988; St. George and Nielsen, 2003). Flood rings are most obvious in ring-porous trees like oak (Quercus spp.) and ash (Fraxinus spp.) that show a sudden transition from large early-wood vessels to small late-wood vessels in normal (non-flood) years (St. George, 2010; Yanosky, 1983). Flooding of oak trees in late winter while trees are still dormant may have little effect on ring anatomy (Wertz and others, 2013). Flooding of oak trees in spring after leaf buds begin to swell causes reduced diameter of early-wood vessels (fig. 19) and extension of early-wood vessels into the late-wood (fig. 18) (Astrade and Bégin, 1997; Wertz and others, 2013; Copini and others, 2016). Summer flooding of ash causes enlargement of late-wood vessels without affecting size of earlywood vessels (Yanosky, 1983).

Where observation of flood rings is qualitative, it is difficult to use them to quantify flood magnitude. However, vessel diameter in Quercus can be used as a proxy for paleoflood magnitude (St. George and others, 2002; Therrell and others, 2017). Furthermore, because flood rings are more pronounced below the high-water surface (St. George and others, 2002; Copini and others, 2016), it may be possible to compare multiple sections cut at different heights to estimate paleoflood stage, but this has not yet been accomplished. The spatial extent of flooding can be determined by sampling trees distributed across the floodplain (Yanosky, 1983; St. George and Nielsen, 2003; Therrell and Bialecki, 2015), and the number or elevation of affected trees can be used as an index of flood magnitude. Where flood durations are shorter than a few weeks (such as in steep, small, or arid watersheds [Wolman and Gerson, 1978]), formation of flood rings is unlikely. The ability to distinguish flood rings from ring abnormalities caused by other factors, including frost and insect outbreaks, also is important (Sutton and Tardif, 2005).

\section{Alteration of Tree-Ring Anatomy by Burial}

Sediment deposited by a flood can bury some lower parts of a tree stem. Sediment burial causes anatomical changes to the rings in the stem, allowing dating of the flow event that deposited the sediment. This effect has been used to date sediment deposition using green ash (Fraxinus pennsylvanica) in Washington D.C. (Sigafoos, 1964), balsam poplar (Populus balsamifera) in British Columbia (Nanson and Beach, 1977), willow (Salix sp.) in northern Russia (Rubtsov and Salmina, 1983), tamarisk (Tamarix ramosissima) in Texas (Dean and others, 2011) and Colorado (Manners and others, 2014), and

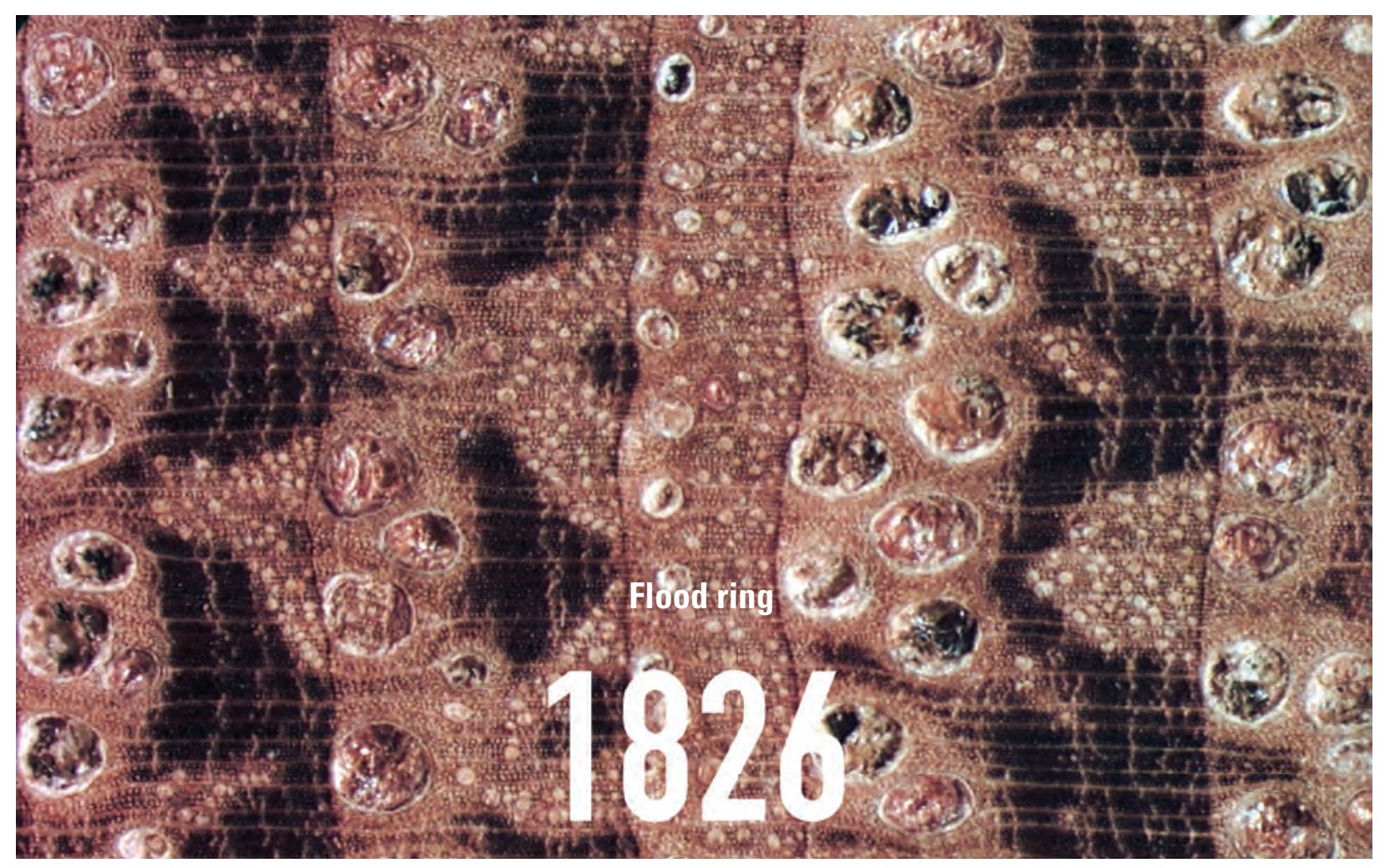

Figure 19. Magnified part of a core showing a flood ring in an oak along the Red River in central Winnipeg, Canada. Image shows rings formed from 1824 (on left) to part of 1828 (on right). Ring formed in 1826 shows flood-induced reduction in the diameter of early-wood vessels. Photograph by Scott St. George, University of Minnesota; used with permission. 


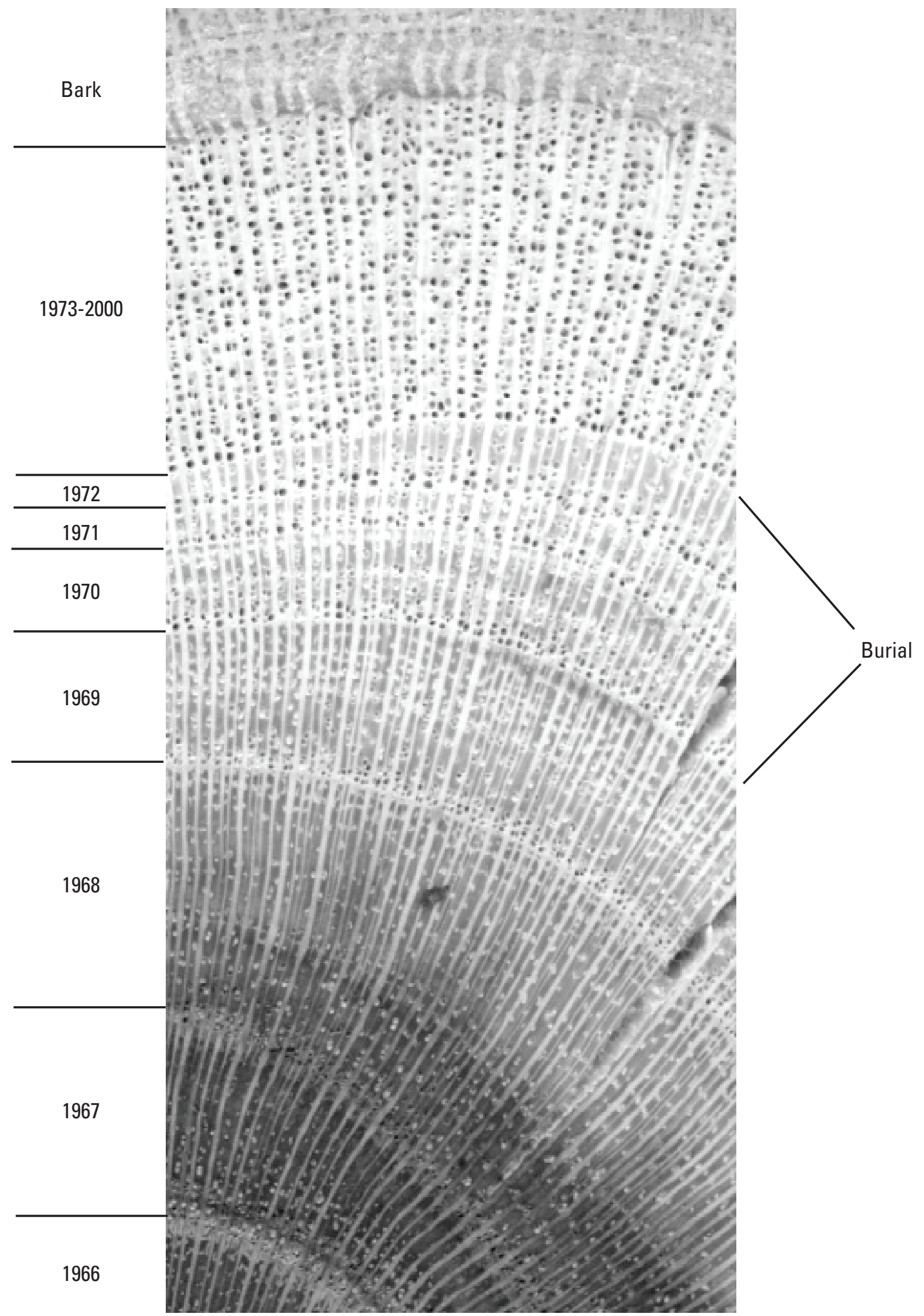

Figure 20. Tamarisk (Tamarix ramosissima) stem cross-section cut 2.8 meters below ground surface along the Rio Puerco, New Mexico. Following initial burial of 68 centimeters during a 1969 flood, ring-width decreased, vessel size increased, and annual transitions became less distinct. After a second flood burial by 41 centimeters in 1972, annual transitions became indistinguishable. Photograph by Jonathan Friedman, U.S. Geological Survey. 
tamarisk and sandbar willow (Salix exigua) in New Mexico (fig. 20; Friedman and others, 2005, 2015). When a stem is buried, subsequent annual rings in the buried section resemble the rings of roots; rings narrow, vessels within the rings enlarge, and boundaries between rings become less distinct (Friedman and others, 2005). These effects are limited to the buried section of the stem, and do not extend above ground level. Aerial exposure of roots caused by erosion at the base of a tree causes the opposite effect; that is, development of stem characteristics in the former root (Sigafoos, 1964).

The elevations of stratigraphic flood units exposed in a trench may be projected to nearby trees. The trees can then be excavated and sectioned just above each contact elevation, and the date of burial can be determined for each section. These data can be used to date sedimentary beds thicker than about 30 centimeters $(\mathrm{cm})$ with annual or subannual precision (Friedman and others, 2005). When trees are excavated to date flood deposits, the considerable time necessary to excavate a tree can be leveraged by choosing trees located along a floodplain trench and growing through the sedimentary units of interest. Because the annual transitions often become unreadable in deeply buried stems, it may be necessary to cross-date buried sections of the stem with higher unburied sections (Friedman and others, 2005). Additional complications of this method include the difficulty of excavating large trees, rot in buried stems, the subtle effects of multiple shallow burials, and the individualistic response of different stems. For example, the effect of burial on ring anatomy may be more pronounced on small stems than on large stems (Friedman and others, 2005).

Flood deposition also may be dated by determining the year and elevation of germination of a tree from buried stems (Sigafoos, 1964; Helley and LaMarche, 1968; Hupp and Simon, 1991; Strunk, 1997). To determine the time and net amount of sediment deposited since establishment, a buried stem is excavated to the establishment surface and the annual rings at that surface are counted (Alestalo, 1971; Hupp, 1988). Three anatomical characteristics can be used to identify the establishment level of a tree. First, the establishment level often is indicated in the field by the presence of large lateral roots. Second, because stems have central pith, whereas roots have none, the establishment level often can be determined in the laboratory by locating the lowest cross section that includes pith (Gutsell and Johnson, 2002). Third, the establishment level always is the oldest cross section of the tree. If the tree is alive, the establishment year can be determined by counting back from the present (Hereford, 1984; Scott and others, 1997). If the tree is dead, the establishment year may be determined by cross-dating with living trees (Karlstrom, 1988). The establishment date provides a maximum age of the overlying sediment deposit and a minimum age of the underlying deposit. Shortcomings of this method include the difficulty of locating the wood produced in the first year of life, which may be small, buried, rotten, or consumed by herbivores (Everitt, 1968; Jacoby and others, 2008). Additionally, precision is reduced if a substantial period of time elapsed between deposition of the overlying and underlying sediments.

\section{Alteration of Tree Rings by Tilting of Stems}

Flow shear stress or boulder movement during extreme floods can tilt stems in the downstream direction (RuizVillanueva and others, 2010), and the angle of tilt can be related to flood magnitude (Ballesteros-Cánovas, MárquezPeñaranda, and others, 2015). Tilting reduces the light available to the tree and changes the direction of the gravitational force with respect to the central axis of the stem. The tree responds by asymmetrically adding wood to the stem cross section in order to bend the stem back toward vertical. The resulting stem cross section is radially symmetric in rings formed prior to the flood and asymmetrical afterwards. The year of the flood, therefore, can be determined by dating rings back to the onset of asymmetry (fig. 21; Sigafoos, 1964; Hupp, 1988; Merigliano and others, 2013). By taking, at a minimum, two cores in the direction of the tilt and in opposing directions, the anomalies can be observed and counted (Stoffel and Bollschweiler, 2008). The tilted tree also responds chemically to the change in direction of gravitational forces in order to prevent the stem from breaking or bending downward. Conifers form compression wood with a heightened ratio of lignin to cellulose on the underside of the stem, whereas broad-leaved trees form tension wood with a reduced ratio of lignin to cellulose on the top side of the tree (Stoffel and Bollschweiler, 2008). The resulting chemical asymmetry also could be used to date the flood event.

\section{Flood-Related Anomalies in Ring Width}

The width of individual tree rings may record the occurrence of past floods even without injury (scarring), burial, or tilt. Relatively large rings indicate favorable growing conditions. Annual growth increment can be influenced by many factors, including temperature; availability of water, light or nutrients; lack of oxygen in the soil (soil anoxia); death of competitors; disease; or injury (Sigafoos, 1964; Stokes and Smiley, 1968; Hupp, 1988). Because flooding may influence most of these factors, linking annual growth to flooding can be complex. Flooding may increase (Reily and Johnson, 1982; Dudek and others, 1998) or suppress (Martens, 1993; Astrade and Bégin, 1997) annual ring width. Mechanisms of growth suppression by floods include development of soil anoxia from prolonged inundation and physical damage to the tree. Mechanisms of growth enhancement by floods include reduction of drought, elimination of competitors, and fertilization. Where growth is chronically limited by water shortage, tree rings record droughts better than floods (Meko and others, 2015; Schook and others, 2016). Ring-width may be more sensitive to floods where growth is limited by water excess. For example, where bald cypress is subjected to months of flooding by stagnant water, soil anoxia reduces annual growth (Keim and Amos, 2012), and larger floods can cause a stronger width reduction. 


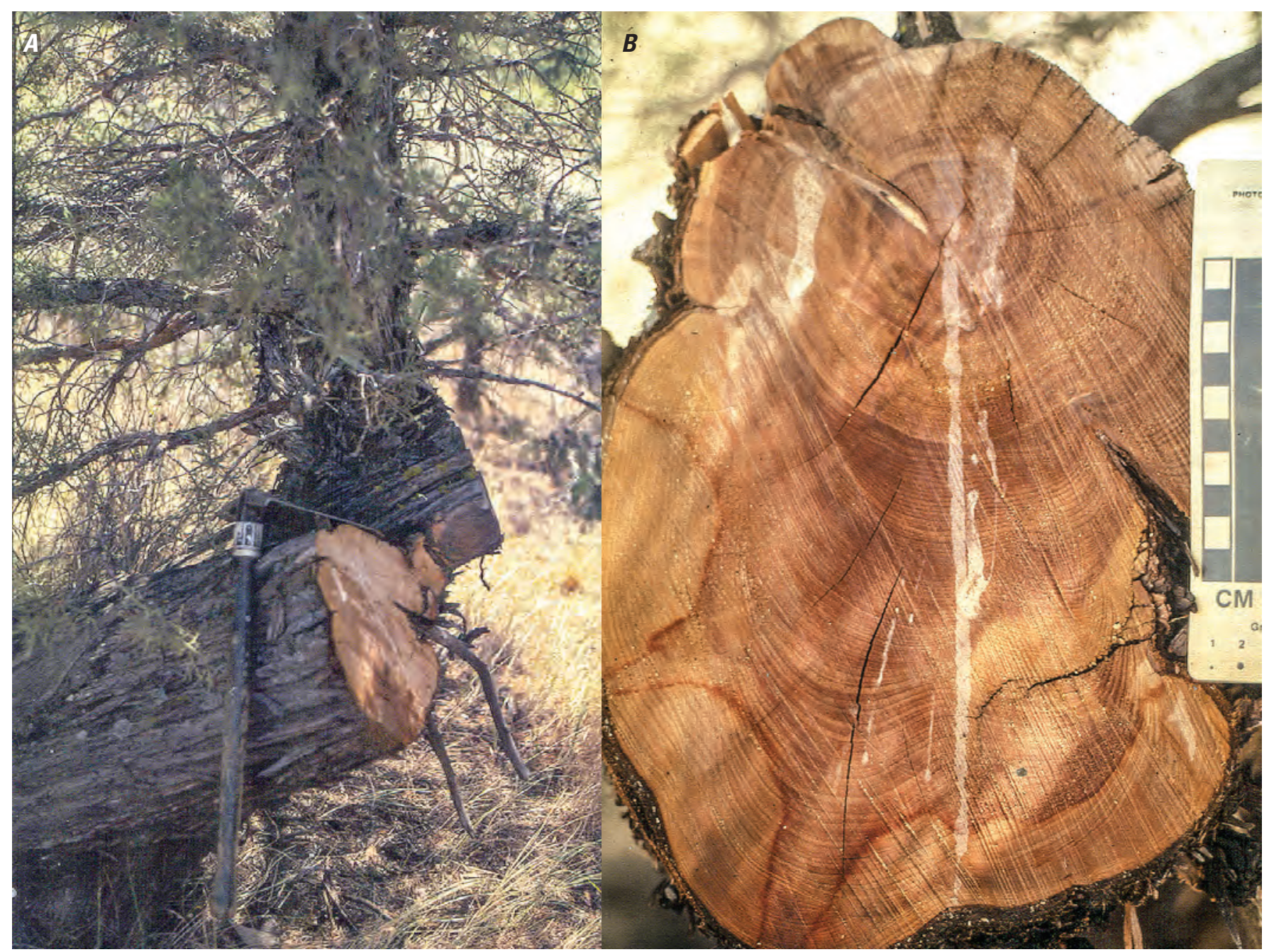

Figure 21. Frontal $(A)$ and cross section $(B)$ views of tilted juniper tree along the Crooked River in Oregon used to date the occurrence of a paleoflood there. Prior to the flood, the tree was vertical, and growth was symmetrical. The tree responded to flood by tilting with asymmetrical growth. The onset of asymmetry occurred in 1861, a year of many recorded large floods in the Pacific Northwest. Photograph by Jim O'Connor, U.S. Geological Survey.

To investigate the occurrence of paleofloods, ring widths in a set of riparian trees can be cross-dated and digitized, and mean annual ring width during the period of streamgaging can be correlated with flood magnitude or duration. This correlation then can be used to estimate flood timing and magnitude prior to systematic flow records. Because of the complex relation between flooding and ring width, use of ring width to document paleofloods must be based on an understanding of the local relation between growth and flooding. For this reason, ring-width data from trees selected for other purposes are unlikely to be useful for documenting paleofloods. Other proxies now are available from tree rings that could be useful in paleoflood reconstruction, including wood density and stable isotopes of carbon, oxygen, and hydrogen (Waterhouse and others, 2000; McCarroll and Loader, 2004; Friedman and others, 2019).

\section{Establishment of Seedlings or Vegetative Sprouts Following Flood Disturbance}

Floods disturb and clear patches of the floodplain, creating opportunities for establishment of riparian trees as seedlings or sprouts from damaged stems or roots (Sigafoos, 1964; Jacoby and others, 2008). If such flooding was catastrophic and removed or killed all prior trees, the age of the present trees is a minimum estimate of the number of years since the flood that created the disturbance (Sigafoos, 1964; Everitt, 1968; Merigliano and others, 2013). Because larger floods tend to disturb larger areas (Miller and Friedman, 2009) than smaller floods, the area occupied by forest established in a given year is an estimate of flood magnitude in or prior to that year. Paleofloods can be discovered by determining establishment years of a representative sample of trees across the floodplain (Merigliano and others, 2013), and then finding 
years or decades with anomalously large areas of forest establishment (Everitt, 1968; Friedman and Lee, 2002). When applying this approach, the selected river reach must be large enough to be representative of the entire floodplain and relatively free from levees or riprap that restrict channel migration (Edmondson and others, 2014). Trees can be selected systematically or at randomly selected points to minimize sample bias (Merigliano and others, 2013). Difficulties encountered using this method include a delayed establishment following a disturbance (Friedman and Lee, 2002), formation of a new floodplain by processes other than flooding (for example, fires; Scott and others, 1996), the time necessary for a stem to grow up to the height above ground where the core was collected (Schook and others, 2017), and imperfect preservation of old trees because of mortality from multiple factors including river migration (Merigliano and others, 2013).

\section{Uncertainties Associated With Paleostage Indicators}

In appropriate circumstances, physical and botanical evidence of flooding enables estimates of the number of floods, their maximum stages, and their timing. However, these estimates have associated uncertainties that may affect resulting flood-frequency analyses and hydrologic hazard analyses. Table 3 summarizes key uncertainties associated with aspects of paleostage indicators, the likely consequences of these uncertainties, approaches to quantification and evaluation of the uncertainties, the effects of the uncertainties on flood-frequency analysis, and strategies to help reduce such uncertainties.

The assumptions and uncertainties in stratigraphic, geomorphological and botanical PSIs mainly relate to (1) the fidelity of the paleostage evidence to the actual maximum flood stage, (2) the reliability of the stratigraphic or botanical record in accounting for all floods above an identified stage for a given period, and (3) the reliability of the chronologic information in adequately defining the timing and duration of floods and stratigraphic/botanical records. The magnitude and direction of PSI uncertainties varies among the different types of paleostage indicators, but they generally produce biases tending toward underestimates of the number of floods and their maximum stages and overestimates of record lengths (table 3). Such uncertainty and bias are minimized by careful site selection, using multiple sites of stratigraphic and botanical analysis, careful and detailed stratigraphic and botanical analyses, and extensive chronology, including multiple age dating techniques and multiple analyses of key sites and deposits.

Site selection can be improved by conducting a desktop survey of topography and soils/geology of the study area prior to conducting any field work. Modeling various flows such as large historical floods or substantial flows in the gaged record to estimate surface inundation prior to field campaigns can be helpful when locating potential sites (Kelson, Pearce, and Kinder, 2018) as is coordinating with local hydrologic experts familiar with the study area. Landowners can sometimes provide evidence of past peak flow elevations of notable floods to help determine stage information for large floods. This information can then be used to help determine the elevation range when initially selecting paleoflood sites.

\section{Stratigraphic Uncertainties}

Uncertainty of the agreement between measured stratigraphic elevation and the actual flood stage of the event is difficult to validate (Jarrett and England, 2002). Stable boundaries and evidence of stability owing to lack of aggradation and degradation helps to reduce uncertainty due to geomorphic river change over time (Benito and O'Connor, 2013). Confined river systems also provide sensitive stage-discharge relations that reduce uncertainty in flood-discharge estimates. For terraces and floodplains, the original elevation of the flood deposits might be altered by vegetation, drainage, or human modifications.

Uncertainties in the stratigraphic record can be caused by indistinct boundaries between flood deposits. Interpretation errors in identifying the breaks between floods can result in the overestimation or underestimation of the number of floods. Because stratigraphic analysis requires evidence of time between flood deposits, floods that occur close together in time may be counted as a single flood. Floods also may not leave a deposit or barely exceed the last deposit elevation and may not be recorded. Preservation bias, by which younger deposits are more readily found than older deposits, also can cause gaps in the stratigraphic record owing to local depositional or erosional environment. Bedrock or confined river systems can provide better preservation of stratigraphic and geomorphic records of paleofloods and reduce the risk of erosion or deposition unrelated to floods that might cause reworking of the flood deposit and blur unit contacts (Kochel and others, 1982; Stoffel and Bollschweiler, 2008).

Uncertainty in the stratigraphic record, involving the paleoflood stage and count, can be reduced through examination of multiple sites and by focusing analyses on the largest floods, and in a time frame that has the most complete record in order to reduce these biases (Hosman and others, 2003; Harden and others, 2011; Harden and others, 2021).

Chronologic information for sediment deposits is gained using relative age dating techniques such as soil development and superposition, and numerical age dating techniques such as radiocarbon analysis and OSL. Relative and numerical age dating techniques can have large uncertainties. However, in flood-frequency analysis, the precise age of the flood deposits is much less critical than knowing how many floods exceeded a certain threshold in a specific period of time (Blainey and others, 2002; Harden and others, 2021). Uncertainty in flood chronology is reduced if multiple age dating techniques are used and the flood stratigraphic sequence is well-defined (Jarrett and Tomlinson, 2000; Harden and others 2011, 2021). 
Table 3. Key uncertainties of paleoflood analysis and strategies for reducing them with respect to four aspects of paleostage indicators.

[Relation to peak flood stage: AEPs, annual exceedance probabilities; FFA, flood-frequency analysis; PSI, paleostage indicator. Geochronology: ${ }^{14} \mathrm{C}$, carbon-14; NEBs, non-exceedance bounds; OSL, optically stimulated luminescence]

\begin{tabular}{|c|c|c|c|c|}
\hline & \multicolumn{4}{|c|}{ Paleostage Indicators } \\
\hline & $\begin{array}{c}\text { Relation to peak flood } \\
\text { stage }\end{array}$ & $\begin{array}{l}\text { Incomplete or uncertain } \\
\text { stratigraphic record }\end{array}$ & Botanical (tree) record & Geochronology \\
\hline $\begin{array}{l}\text { Approaches to } \\
\text { quantification } \\
\text { and evaluation of } \\
\text { uncertainty }\end{array}$ & $\begin{array}{l}\text { Bracket discharge } \\
\text { estimates; evalu- } \\
\text { ate historical flood } \\
\text { deposits relative to } \\
\text { known peak stages; } \\
\text { do sensitivity analysis } \\
\text { in FFA. }\end{array}$ & $\begin{array}{l}\text { Multiple sites and eleva- } \\
\text { tions. Sensitivity analy- } \\
\text { sis in flood-frequency } \\
\text { analysis. }\end{array}$ & $\begin{array}{l}\text { Use early-wood vessel area } \\
\text { or proportion of trees } \\
\text { affected to quantify flood } \\
\text { magnitude from flood } \\
\text { rings. Use scar eleva- } \\
\text { tion to estimate flood } \\
\text { elevation. }\end{array}$ & $\begin{array}{l}\text { Numerical uncertainty range } \\
\text { comes with laboratory } \\
\text { result. Sensitivity analy- } \\
\text { sis associated with plau- } \\
\text { sible age ranges. Multiple } \\
\text { analyses of single deposits. } \\
\text { Selection of methods based } \\
\text { on expected ages, availabil- } \\
\text { ity of usable organics, risk } \\
\text { of differential bleaching, and } \\
\text { post-depositional sediment } \\
\text { mixing. Examine wood of } \\
\text { dead trees to extend record. }\end{array}$ \\
\hline $\begin{array}{l}\text { Uncertainty reduc- } \\
\text { tion strategies }\end{array}$ & $\begin{array}{l}\text { Use evidence of large } \\
\text { historical floods to } \\
\text { help determine the } \\
\text { relation between PSIs } \\
\text { and peaks. Examine } \\
\text { PSIs at multiple el- } \\
\text { evations per reach. }\end{array}$ & $\begin{array}{l}\text { Increase number of sites } \\
\text { examined. Do detailed } \\
\text { stratigraphic analysis. }\end{array}$ & $\begin{array}{l}\text { Examine multiple trees } \\
\text { from multiple sites. }\end{array}$ & $\begin{array}{l}\text { Apply multiple dating meth- } \\
\text { ods, use multiple dates and } \\
\text { redundancy on key units and } \\
\text { selective material choices } \\
\text { for radiometric and OSL } \\
\text { dating. }\end{array}$ \\
\hline
\end{tabular}




\section{Dendrochronological Uncertainties}

Paleoflood observations derived from tree rings typically have narrow interval estimates with respect to time and wider estimates with respect to discharge. Although tropical species often do not produce annual rings, most temperate zone species produce one ring per year. If samples are cross-dated to verify occurrence of any false and missing rings, then the date of an event observed within a ring is known to be within the year that ring was produced. Because growth can be observed within a ring before or after formation of a flood scar, the flood that formed it may be dated to within one to several months. Where paleoflood determinations are based on the establishment of seedlings on flood deposits, the interval estimate may be 1 decade or more depending on the delay between the flood and subsequent tree establishment and the time necessary for the tree to grow to the height at which it was cored (Schook and others, 2017). For acceptable statistical analysis, National Centers for Environmental Information (2020) recommend 20 trees per site, with consideration of climate signal and study purpose. Two samples (bores) per tree are recommended to cross-date within the tree. For most methods, increasing the number of trees sampled and sampling undisturbed trees for reference or cross-dating are useful in reducing uncertainty of flood estimates (Stoffel and Bollschweiler, 2008). Uncertainty also is caused by the opportunity for trees to be damaged or ring width to be affected by factors unrelated to floods, including lightning, fire, disease, animals, and falling debris. Confusion from non-flood botanical PSIs can be minimized by collecting samples from multiple trees for each event and by limiting collection of scars to locations where flood damage is likely to occur, such as the upstream or stream-facing sides of trees adjacent to the channel (Ballesteros-Cánovas, Stoffel, and others, 2015).

Interval estimates for flood magnitude vary with the treering technique applied (table 3). Relating the actual flood stage to the elevation of a PSI can be uncertain. The top of a flood scar can provide a precise estimate of flood stage, although it may underestimate the peak stage because the injury may have happened before or after the peak. However, this source of error has been shown to be small (Gottesfeld, 1996; Ballesteros and others, 2011). Conversely the elevation of the scar may overestimate the peak stage (Yanosky and Jarrett, 2002) because of impact by debris protruding above the water surface or because of the local increase in water surface on the upstream side of a tree caused by momentum runup where velocity is high. For this reason, error in estimated flood stage may be greater in samples collected at the outside of bends (Ballesteros-Cánovas, Stoffel, and others, 2015; BallesterosCánovas and others, 2016). Collection of multiple scars per flood event allows quantification of that error and reduces uncertainty.
Change in tree-ring anatomy caused by burial provides a precise estimate of the top of flood deposition, but then the depth of flow depositing that sediment must be estimated by a hydraulic model. Flood rings typically provide a less precise estimate of flood magnitude than burial or scars. Flow magnitude can be estimated by the proportion of trees showing a flood ring, the height along the stem to which the effect is observed, or the magnitude of the change in vessel diameter. Where flood magnitude is estimated from ring width, the interval estimate depends partly on the strength of the correlation between ring width and flow during the period of gage operation. Such correlations typically are non-linear and generally weak because of the many factors other than floods that can influence ring width. When paleofloods are indicated by a large area of forest of a particular age, inferences about flood magnitude depend on collecting a representative sample of trees and on quantifying the relation between flood magnitude and rates of channel change (Merigliano and others, 2013).

Uncertainties in capturing the entire botanical record of floods and correctly establishing the dating of events include tree longevity and likelihood for a PSI to be observed. Tree longevity is a major limit on the length of record for paleoflood estimates from tree rings (table 3 ). Therefore, correct quantification requires collection of data on the age of trees recording paleofloods as well as the age of the oldest trees present at the site capable of recording paleofloods. Riparian trees generally range in age from decades to several hundreds of years. Because dead trees can be cross-dated with living ones, the time period of inquiry can be extended using dead trees preserved on the ground, in log buildings (St. George and Nielsen, 2003), underground (Stambaugh and Guyette, 2009), or underwater (Gennaretti and others, 2014). The uncertainty associated with cross-dating is reduced using skeleton plots (Stokes and Smiley, 1968) and algorithms for detecting errors (Holmes, 1983). Schneuwly-Bollschweiler and others (2013) demonstrated the use of a data-noise index and spatial distribution indices to optimize tree selection for reduction of uncertainty.

Creation and likelihood of observation of botanical PSIs is limited by a site, flood characteristics, and time since the flood events. For flood scars, the flood magnitude must be large enough to entrain the debris that causes the physical injury leading to flood scars. However, injuries forming scars in trees tend to heal over or cause tree death, which can result in near disappearance of the paleoflood signal before the death of nearby uninjured trees. Internal scars might be located by careful inspection of the trunk for signs of disturbance and focusing on likely surfaces based on geomorphology and hydraulics of the site (Stoffel and Bollschweiler, 2008). A single core through the scar may not include all the rings necessary to date the injury; additional cores or collection of full or partial stem cross sections may be necessary to reduce the uncertainty of the scar timing. 
For detection of flood evidence in the micro-anatomy of tree rings (flood rings), flood duration must be long enough to cause the necessary physiological changes. A study of oak trees along the Mississippi River determined that this duration is at least 10 days (Therrell and Bialecki, 2015). Tree rings may tend to record paleofloods in some seasons but not others. For example, flood scars may be more likely in late winter when ice is present, whereas flood rings will not form if the flood occurs in the dormant season (St. George and Nielsen, 2002). To use buried tree rings to date stratigraphic flood units, a minimal sediment deposit of about $30 \mathrm{~cm}$ is required to cause alteration of the tree rings (Friedman and others, 2015).

\section{Lake and Other Off-Channel Deposits}

Lakes, wetlands, and closed basins also may preserve stratigraphic records of floods (Knox and Daniels, 2002; Zhu and others, 2005; Jones and others, 2012; Munoz and others, 2015; Toonen and others, 2015, Olivia and others, 2016). Such sites may be especially useful in broad, low-relief landscapes adjacent to rivers where the traditional PSI approach is less effective because of the lack of sensitivity to stage-discharge relations. Floodplain lakes and wetlands may accumulate deposits when inundated by sediment-laden floodwater (Toonen and others, 2015). Flood layers in these floodplain depressions typically are coarser and contain fewer organic materials than the surrounding sediment. These layers can be preserved in the deep undisturbed areas of the basin and can provide long records of flooding (Toonen and others, 2015; Munoz and others, 2018).

\section{Site Selection and Identification of Flood Sequences}

Lake deposit sites commonly are on river-flanking floodplains, and include oxbow lakes, sinkhole depressions, scour holes, and paleochannels (Jones and others, 2012, Toonen and others, 2012; Gutiérrez and others, 2017; Munoz and others, 2018). Typically, only floods above a certain stage will be able to enter the basin, providing a defined stage threshold associated with the deposits. For example, the elevation of a natural levee surrounding an oxbow lake would define such a threshold.

Deposits in such sites, especially ones that are continuously wet, often are extracted and examined by coring (fig. 22). This requires stratigraphic and sedimentologic techniques that differ from SWDs to define individual flood deposits. Typical methods include examining density differences, magnetic susceptibility, grain size, and geochemical/mineralogical composition of the layers in core samples from the sediment trap. As described in Wilhelm, Canovas, and others (2018), specific methods include the following:

1. Laser diffraction or particle size analyzer for grain-size analysis. This method is time consuming and is destructive to the core sample, but it can be used to identify an increase in grain size (fig. 23) associated with increased discharge magnitude during flood events (Parris and others, 2010; Wilhelm, Canovas, and others, 2018).

2. Multi-sensor core loggers, resolution greater than or equal to 2 millimeters ( $\mathrm{mm}$ ), to measure density and magnetic susceptibility.

3. Micro-X-ray fluorescence (XRF) core scanners for elemental composition. These scanners provide micrometer-scale resolution, which makes detection of very thin flood layers possible (Cuven and others, 2010; Wilhelm, Canovas, and others, 2018). XRF measurements use geochemical signatures as a proxy for grain size, which, in turn, is a proxy for discharge. For example, assuming a geochemical difference between coarsegrained overbank deposits and fine-grained lake deposits, the ratio between zirconium (or silicon) — which is associated with relatively coarse material—and titanium (or iron, aluminum, potassium, and rubidium) - which is associated with relatively fine material — can be used to identify flood units (Jones and others, 2012; Schillereff and others, 2014; Schillereff, 2015).

4. Medical- or industrial-type three-dimensional computer tomography (CT) scans enable the detection of highdensity flood layers on sub-millimeter scale in organicrich background sediments.

5. Induced coupled plasma or X-ray diffraction have been used in combination with CT and XRF scans for detailed geochemical or mineralogical analysis.

Method selection is site specific and depends on surrounding environmental characteristics including local geology, site location, and type of sediment trap. For example, $\mathrm{X}$-rays may be the best option at sites with sizeable density differences between the flood deposit and adjacent sediments (Wilhelm, Canovas, and others, 2018). At a site with a geochemical difference between relatively coarse-grained overbank deposits and fine-grained lake deposits, the ratio between certain elements is linked with soil type and can be used to identify flood units by using XRF measurements (Jones and others, 2012; Schillereff and others, 2014; Schillereff, 2015; Wilhelm, Ballesteros Cánovas, and others, 2018). 


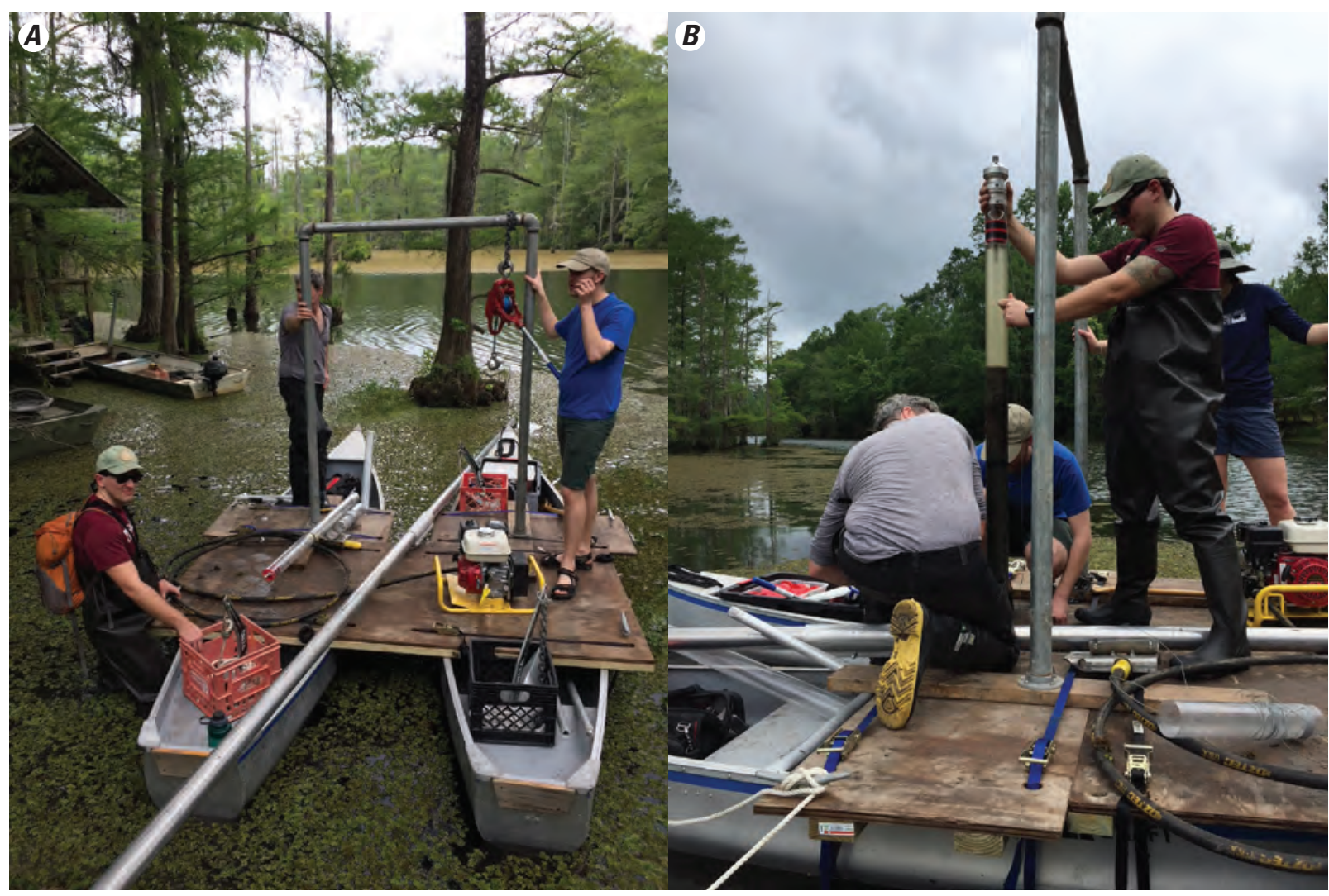

Figure 22. Floating rig used to sample cores from Barlow Lake (an oxbow of the Neches River), Texas. Photographs by Samuel Munoz, Northeastern University, used with permission. 


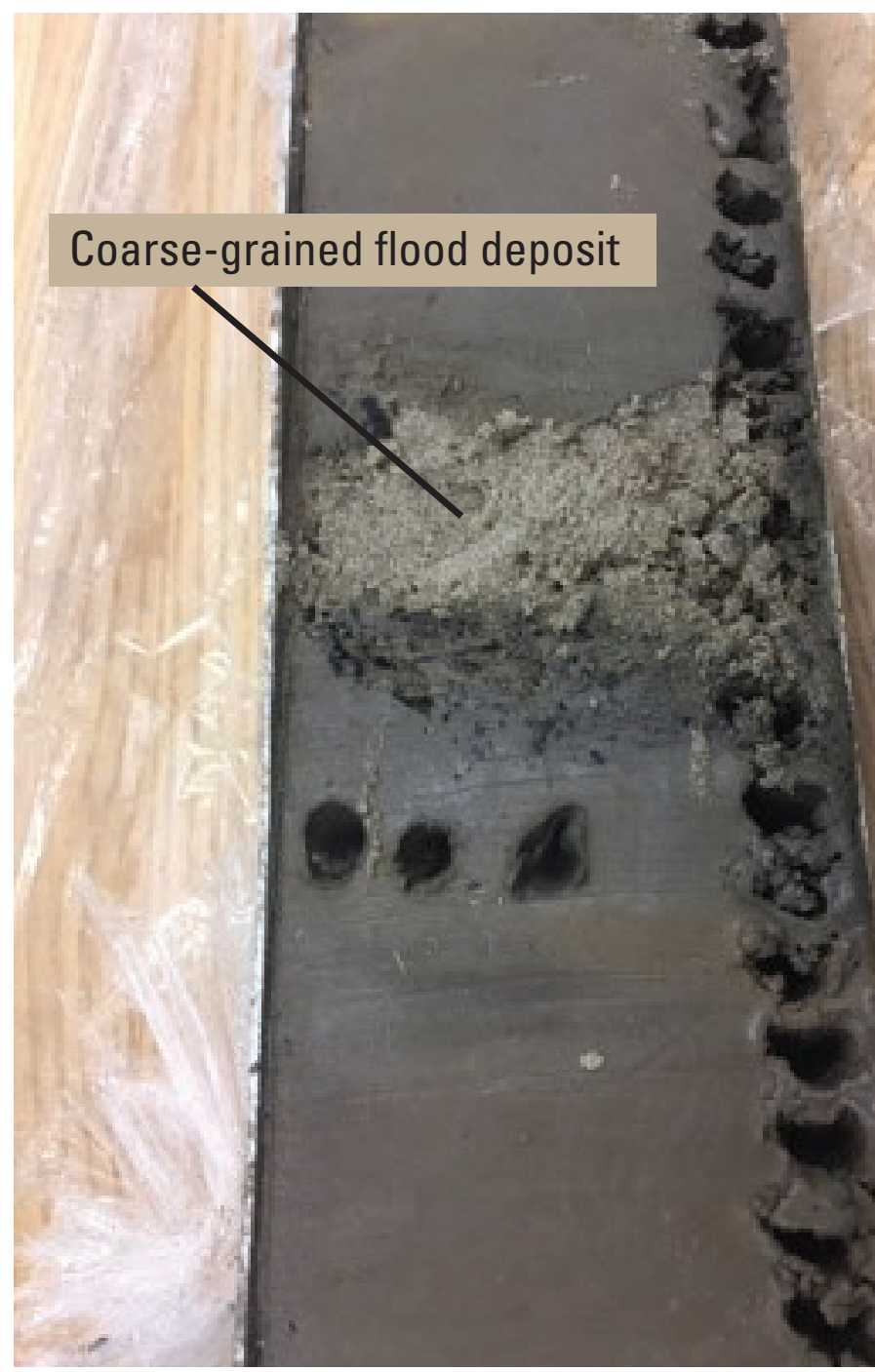

Figure 23. Core sample from Barlow Lake, Texas. Coarse-grained deposit highlighted in photograph is evidence of a large flood. Photograph by Samuel Munoz, Northeastern University, used with permission.

\section{Stratigraphic Analysis of Lake Deposits and Age Determination}

Stratigraphic analysis of lake deposits typically involves the interpretation of core samples (fig. 24). For analysis of slack-water and terrace/floodplain deposits, the objective is to determine the number of deposits left by individual floods. However, the lack of exposure of the stratigraphy provided by a core (compared to a trench or excavation of a SWD accumulation or terrace) requires more dependence on proxy measurements of core properties. In lake sediments, uncertainties are related to (1) the sediment availability from the basin and affected by reduced mobility of sediments if floods occur too rapidly in succession, (2) whether the sediment deposits preferentially in the basin rather than running off to the lake during large scale floods, and (3) the effects of human land use on sediment supply (Wilhelm, Ballesteros Cánovas, and others, 2018).

Most flood sequences from lakes and basins are dated by the same approaches used for slack-water and terrace deposits, including radiocarbon dating and OSL. Cesium-137 $\left({ }^{137} \mathrm{CS}\right)$ and lead-210 $\left({ }^{210} \mathrm{~Pb}\right)$ also have been used for dating young deposits (Aalto and Nittrouer, 2012; Wang and Leigh, 2012). If annual layers, or varves, are present and distinguishable in the sediment, they can be counted to determine flood ages. Pollen analysis of various units can help define the period of flooding by the presence or absence of time-indicator species such as maize, rye, or pine (Toonen and others, 2015).

More recently, variations in the geomagnetic field indicated by the orientation of magnetic particles in the sediment when those particles were deposited have been explored as an option to date flood sequences (Barletta and others, 2010; Wilhelm, Canovas, and others, 2018). Geomagnetic variations along the core samples are compared to the geomagnetic variations by the Earth's geomagnetic field. Much like tree-rings, these unique features serve as chrono-markers that can reduce uncertainties in age (Wilhelm, Canovas, and others, 2018).

\section{Hydraulic Analysis}

A key aspect of any quantitative paleoflood study is the estimation of flood magnitudes associated with PSIs. In most analyses, discharge estimates derive from the assumption that the position of the paleostage or historical flood evidencewhether it be a flood deposit, tree scar, or flood mark on a building - is related to the peak of the flood. The elevation of a flood deposit gives a minimum estimate for the peak stage of the emplacing flood (Baker, 1987; Kochel and Baker, 1988). In SWDs, the highest deposits left by a specific flood may closely approximate the peak stage (Webb and others, 2002), although maximum flood stages may exceed the highest deposits in many cases (Harden and others, 2011). Estimates of the peak discharge are obtained by relating stage evidence given by the elevation of the paleoflood deposit to channel geometry by hydraulic calculations. These calculations typically are based on modern channel and valley topography, roughness, and slope. This approach requires assessment of the assumption that changes in channel geometry have been sufficiently small during the time represented by the stratigraphic record to not substantially affect calculations of flow rate associated with specific deposit elevations. This assumption likely is valid in stable bedrock reaches but seldom holds for alluvial reaches with mobile channels, particularly for time periods of hundreds to thousands of years. 


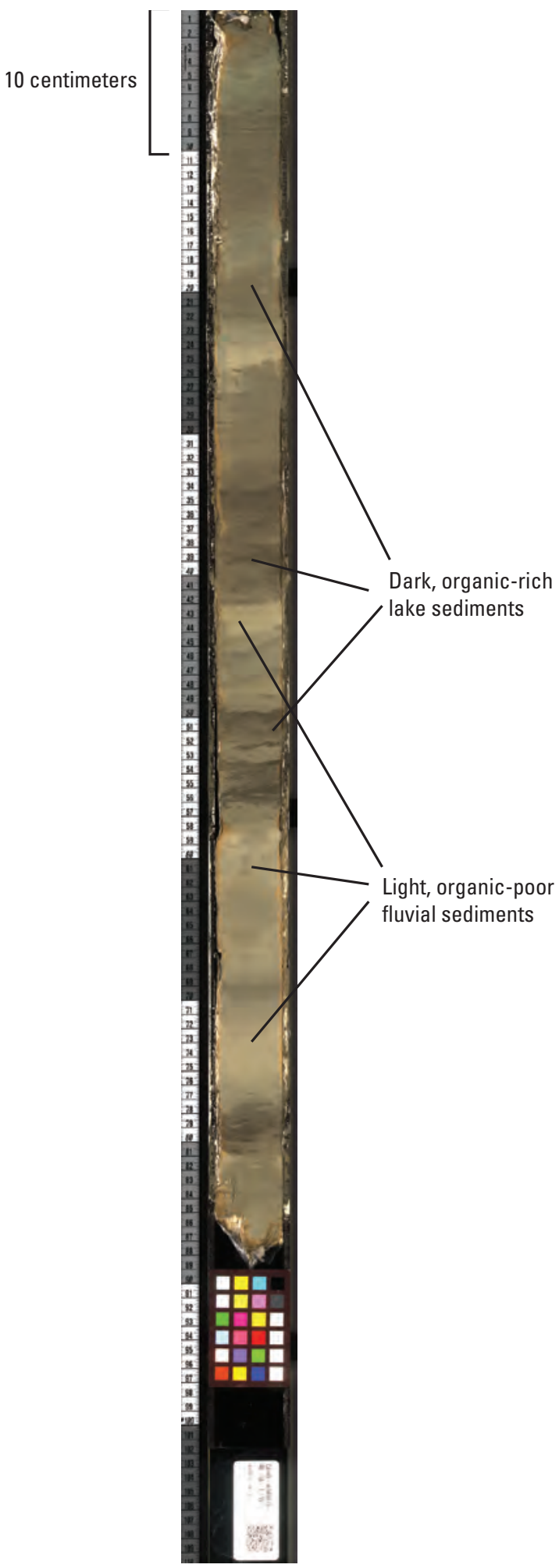

Figure 24. High-resolution scan of a 9- centimeter core showing chemical and sedimentological differences in fluvial and lake deposits, taken from Horseshoe Lake (an oxbow of the Mississippi River), Illinois. Dark deposits generally are organic-rich lake deposits and light deposits are mineral-rich fluvial deposits indicating high flow events. Photograph by Samuel Munoz, Northeastern University, used with permission.
The hydraulic analysis method used to estimate flood discharge associated with flood evidence depends on the type of paleoflood evidence, project objective, and the desired accuracy of the overall analysis. Several common methods of hydraulic analysis used for paleoflood investigations are described in the following sections.

\section{Data Requirements}

Critical elements needed for any hydraulic calculation are accurate channel and floodplain geometry and precise elevation of the flood evidence relative to the channel. Roughness (and other energy-loss factors) also are important for most hydraulic analysis techniques and are discussed in more detail in section, "Manning's $n$ Roughness Coefficient."

\section{Channel Geometry}

The most influential parameter in the relation between discharge and flood stage is channel geometry, including longitudinal slope (O’Connor and others, 1986). Channel geometry can be obtained either by (1a) direct survey of channel cross sections by Real-Time Kinematic-Global Positioning System (RTK-GPS), (1b) total station, or (1c) other accurate survey methods, or (2) by remotely sensing data such as lidar or photogrammetry. Horizonal and vertical accuracy can vary greatly for different methods but more accurate channel geometry generally will lead to more accurate discharge estimates. In many cases, vertical accuracy of less than $0.5 \mathrm{~m}$ is considered ideal, but this figure can vary. Horizontal accuracy is less critical on the floodplain, where changes generally are gradual. Typically, PSI elevations are measured directly in the field by RTK-GPS or other precise survey techniques.

For paleoflood applications, the channel geometry at the time of the flood - possibly thousands of years ago - is of interest. For floods in bedrock-bound fluvial systems and occurring within the Holocene epoch of the last 11,700 years, the present valley geometry commonly is assumed to adequately represent the channel conditions at the time of flooding (for example, Ely and Baker, 1985; O'Connor and others, 1986; Benito and others, 2003; Thorndycraft and others, 2005; Harden and others, 2011; Greenbaum and others, 2014). However, an assessment of this assumption (including evaluation of evidence for recent aggradation or degradation, large-scale mass movements in the reach of interest, and anthropogenic channel modifications) is important for the overall uncertainty analysis. Hydraulic analysis of paleofloods in river channels where flow-boundary geometry is uncertain requires specific consideration of plausible ranges of channel geometry at the time of flooding. This is particularly true for alluvial or bedrock rivers where there may have been incision, widening, aggradation, or lateral migration since the paleostage evidence was emplaced. 


\section{Techniques for Paleohydraulic Calculation}

Several methods are widely used to estimate flood discharge associated with specific stage and channel conditions (O'Connor and Webb, 1988; Webb and Jarrett, 2002; Kutija, 2003; Lang and others, 2004). As outlined below, they range from simple hydraulic equations, such as Manning's equation, to one-dimensional or multidimensional hydraulic modeling. The approach used for a particular site depends on local hydraulic conditions and data availability and requires an understanding of flood hydraulics and suitability of model application. For example, for locations with limited geometry data, a simple hydraulic analysis using a single or few cross sections might be more suitable than a more complex twodimensional (2D) model. However, in locations with complicated channel geometries and detailed topography data, a 2D model may be the best choice.

\section{Gradually Varied Flow}

The most common paleoflood analysis situation is that of gradually varied flow (O'Connor and Webb, 1988; Webb and Jarrett, 2002). River channels typically are irregular in shape and surface roughness, leading to nonuniform flow conditions. A one-dimensional (1D) solution to the energy equation generally is used to compute the water-surface profile in the direction of flow.

The simplest gradually varied flow analyses assume a steady state (constant discharge) for which flow depth varies with distance but not with time (Chow, 1959). For such situations, calculations of water-surface profiles are based on solving the conservation of mass and energy equations in their 1D forms. The step-backwater method, or standard step method (Chow, 1959; Henderson, 1966), for gradually varied water-surface profile computation is the typical approach used to relate a water surface to discharge (O'Connor and Webb, 1988). This solution to the energy balance between adjacent cross sections is used to compute water-surface elevation stepping up the channel from a downstream boundary condition.

Available public-domain computer codes, such as the USACE Hydrologic Engineering Center River Analysis System (HEC-RAS; U.S. Army Corps of Engineers, 2016) software, allow for calculation of water-surface profiles for specified discharges and energy-loss coefficients. From these calculations, water-surface elevations are computed at specific cross sections for a given discharge. Model runs at multiple discharges can be used to develop synthetic stage-discharge rating curves at sites of interest, which can be used to estimate paleoflood discharge from the elevation of a deposit or other high-water evidence.

Many of the limitations of traditional 1D hydraulic models for paleoflood studies (Cunge and others, 1980; Bates and De Roo, 2000) have been overcome through the application of 2D hydrodynamic models (Denlinger and others, 2002; Ballesteros-Cánovas and others, 2010; Turzewski and others, 2019). Advances in modeling approaches, computational software, and high-resolution topographic data acquisition now make such models more practical for applied paleoflood studies. 2D models including SRH2D (Lai, 2008, 2009) and HEC-RAS 2D (Brunner, 2016a) have been used extensively for paleoflood studies by the Bureau of Reclamation (Bauer and Klinger, 2010) and the USACE (Kelson and others, 2017b). These 2D models typically leverage high-resolution digital elevation data derived from terrestrial or airborne lidar to produce better estimates of flow stage and velocity associated with large flows, particularly in environments of substantial secondary and cross-valley flow currents (Denlinger and others, 2002). Two-dimensional models have been used to estimate shear stress on stable terrace surfaces used as non-exceedance bounds, which can be helpful for estimating the depth of flow needed to cause erosion of the surface and, therefore, leave a record of inundation (Levish and others, 2003; Godaire and Bauer, 2012a).

\section{Manning's Equation}

Manning's equation (Chow, 1959) was developed to evaluate uniform flow conditions (whereby flow properties do not change in the downstream direction) of straight channels with uniform slope and regular width. This equation typically is applied to a representative cross section, and generally is applied for reconnaissance-level investigations because of its many assumptions and large uncertainty. Manning's equation for Imperial units, based on discharge, $Q$, in cubic feet per second (or cubic meters per second in the International System of Units, SI), is (Chow, 1959):

$$
Q=\frac{k}{n} A R \frac{2}{3} \sqrt{S_{f}},
$$

where

$R \quad$ is the hydraulic radius (cross-sectional area divided by the wetted perimeter in the units of feet for U.S. customary units and meters for International System [SI] units),

$A$ is the cross-section area (in square feet for U.S. customary units and square meters for SI units),

$S_{f} \quad$ is the friction slope (dimensionless),

$n \quad$ is the Manning's roughness coefficient (in units of second per cubed root of feet, s/ $\mathrm{ft}^{1 / 3}$, in U.S. customary units and second per cubed root of meters, $\mathrm{s} / \mathrm{m}^{1 / 3}$, in SI units), and

$k \quad$ is the units conversion factor (1.49 for U.S. customary units and 1.0 for SI units).

Where overbank flow occurs, Manning's equation is computed separately for each overbank subarea. This approach has produced discharge estimates based on heights of tree scars and gravel bars (Jarrett, 1985; Rico and others, 2001). 


\section{Manning's $n$ Roughness Coefficient}

Most hydraulic computations involving flow in open channels require an evaluation of the roughness characteristics of the channel (Barnes, 1967). Roughness is the bulk parameter that not only accounts for energy loss attributable to friction with bed particles, but also includes the influences of vegetation, channel morphology, and obstructions to flow. In most hydraulic analyses, from simple calculations for single cross sections to multidimensional hydraulic models, roughness is expressed as Manning's $n$ roughness coefficient. In natural channels, Manning's $n$ values typically range from 0.02 for bedrock channel bottoms to 0.15 for heavily forested overbank areas. Higher values $(0.20+)$ for thickly vegetated overbank areas are not uncommon is some parts of the United States (Aldridge and Garrett, 1973; Conyers and Fonstad, 2005). See Barnes (1967) and Arcement and Schneider (1989) for examples of Manning's $n$ values for natural channels and overbank areas.

\section{Critical Flow}

Another specific flow condition is critical flow (indicated by Froude number equal to 1), which occurs when flow is constricted or subject to substantial slope increase and passes through a state of minimum specific energy as it moves though a channel contraction or slope break. Unlike supercritical (which rarely occurs in natural rivers - see Jarrett, 1984; Grant, 1997; Costa and Jarrett, 2008) or subcritical flow (for which the solution is based partly on channel slope and roughness), critical flow has only a single solution for depth for a specific discharge and channel geometry. If critical-flow conditions can be inferred and associated with paleostage evidence, they can provide robust discharge estimates (Webb and Jarrett, 2002) because the controlling parameter is channel geometry and is independent of slope and roughness. Critical flow is more common in stable bedrock channels. A common situation in bedrock fluvial systems is flood sediment accumulation upstream from constrictions, where flow is controlled by the reduction in width, promoting upstream hydraulic ponding and deposition of the suspended sediment and bedload. In these situations, the maximum-stage evidence can be related to discharge by assuming critical flow in the channel contraction, based on the assumption that the elevations of the flood deposits in the controlled reach upstream indicate the total energy of the flow (for example, O'Connor and others, 2001). Criticalflow conditions, although uncommon, can occur in steep mountain streams with alternating pools and steep reaches that result in longitudinal accelerations and decelerations through the critical threshold (Grant, 1997). The critical-flow method requires the field selection of sections fulfilling the conditions of critical flow that can be verified by flow modeling. Because of the specific conditions required to use the critical-flow method, this method has been used primarily in reconnaissance or scoping-level studies.

\section{Flow Computation Directly from Sedimentary Deposits}

An alternative approach to estimating flood discharge, which does not consider channel geometry and other hydraulic variables, is based on the thickness and grain size of flood deposits. This approach may be adopted for conditions where the elevation of flood deposits is not likely to closely represent the flood stage, such as in lake deposits and low-lying off-channel deposits, where water surface elevation cannot be directly related to the elevation of the flood sediments. Two methods to estimate peak flow have been developed (Wilhelm, Ballesteros Cánovas, and others, 2018). One method is based on the assumption that larger floods leave thicker deposits, whereas the other method assumes the larger the flood, the coarser the sediment in the deposit. Unlike the hydraulic analyses, there is no systematic methodology to estimate flood magnitude using a specific proxy; instead, end-member modeling (for example, Van Hateren and others, 2017) is used to characterize flood magnitudes and age-depth models (for example, Blaauw and Heegaard, 2012) to describe flood frequency (Toonen and others, 2015; Wilhelm, Ballesteros Cánovas, and others, 2018). However, the relation between grain size or deposit thickness and flood magnitude is not consistent from site to site within the same reach or between sites in different depositional environments (Jenny and others, 2014; Kämpf and others, 2014; Wilhelm, Ballesteros Cánovas, and others, 2018). Other complicating factors such as changing sedimentation rates through time caused by climate and human activities and the complex interaction of the two may limit the feasibility of these proxy-for-proxy methods of estimating flow for use in traditional flood-frequency analyses for low-AEP events. These analyses do, however, yield peak-overthreshold (values that exceed a certain threshold) recurrence time estimates for specific flood magnitudes (Toonen and others, 2015).

\section{Flow Uncertainty Determination}

Uncertainties related to hydraulic modeling are dominated by three major factors: (1) the appropriateness of the choice of hydraulic model or calculation approach; (2) uncertainty in hydraulic model parameters such as flow roughness coefficients and boundary conditions; and (3) the relation between the modeled topography to that of the topography at the time the paleostage or historical flood evidence was emplaced (table 4). Most of these uncertainties can be systematically evaluated and incorporated in multiple flood scenarios by means of sensitivity testing (Harden and others, 2021). For flood-frequency applications using paleoflood data, uncertainty in flow magnitude is more important than uncertainty in dating (Strupczewski and others, 2014), so characterizing and minimizing this uncertainty is essential, particularly for highlevel decision-making. 
Table 4. Key uncertainties of paleoflood analysis and strategies for reducing them with respect to hydraulic modeling aspects.

[Model selection: 1D, one-dimensional; 2D, two-dimensional; 3D, three-dimensional. Energy-loss coefficients: HMWs, high-water marks. Abbreviation: PSI, paleostage indicator]

\begin{tabular}{|c|c|c|c|}
\hline & \multicolumn{3}{|c|}{ Hydraulic modeling } \\
\hline & Model selection & Channel geometry & Energy-loss coefficients \\
\hline $\begin{array}{l}\text { Major issues (key } \\
\text { uncertainties) }\end{array}$ & $\begin{array}{l}\text { Different model computation algorithms } \\
\text { may produce different stage-discharge } \\
\text { relations for PSIs owing to assump- } \\
\text { tions and methods. Simple models } \\
\text { require assumption of normal or criti- } \\
\text { cal flow. 1D models assume gradu- } \\
\text { ally varied flow in a single preferred } \\
\text { direction with slow variation across } \\
\text { the river. 2D models capture more } \\
\text { complex circulation, but still cannot } \\
\text { resolve vertical flow variations. }\end{array}$ & $\begin{array}{l}\text { Channel geometry at time of PSI } \\
\text { emplacement may be differ } \\
\text { from the geometry (typically } \\
\text { modern) used as basis for hy- } \\
\text { draulic calculations. Lack of } \\
\text { accurate and detailed bathym- } \\
\text { etry and topography. Datum } \\
\text { inconsistences, particularly } \\
\text { between joined topographic } \\
\text { datasets. }\end{array}$ & $\begin{array}{l}\text { Unknown values for model param- } \\
\text { eters such as Manning's n; expan- } \\
\text { sion/contraction loss coefficients. } \\
\text { If model is calibrated to smaller } \\
\text { flows and energy-loss, coefficients } \\
\text { change with flow depth. }\end{array}$ \\
\hline $\begin{array}{l}\text { Likely conse- } \\
\text { quences }\end{array}$ & $\begin{array}{l}\text { In most cases, differences are likely to be } \\
\text { small, although single-cross-section } \\
\text { uniform-flow estimates can vary sig- } \\
\text { nificantly from calculations accounting } \\
\text { for non-uniform flow. Difference be- } \\
\text { tween accuracy of model dimensions } \\
\text { depends on complexity of flow. }\end{array}$ & $\begin{array}{l}\text { Variable, depending on degree } \\
\text { of channel change. In cases of } \\
\text { incising or eroding channels, } \\
\text { will produce overestimates of } \\
\text { flood discharges associated } \\
\text { with PSIs. }\end{array}$ & $\begin{array}{l}\text { Produce uncertainty in stage- } \\
\text { discharge relations for specific } \\
\text { PSIs, resulting in discharge un- } \\
\text { certainty. }\end{array}$ \\
\hline $\begin{array}{l}\text { Approaches to } \\
\text { quantification } \\
\text { and evaluation } \\
\text { of uncertainty }\end{array}$ & $\begin{array}{l}\text { Compare multiple model results if fea- } \\
\text { sible or appropriate for level of study. } \\
\text { Compare with similar existing models } \\
\text { if available. }\end{array}$ & $\begin{array}{l}\text { Sensitivity analysis in hydraulic } \\
\text { model. Inspection of model } \\
\text { results (larger uncertainties } \\
\text { at cross sections that required } \\
\text { additional iterations, are spaced } \\
\text { too far apart, sudden Froude } \\
\text { number changes) }\end{array}$ & $\begin{array}{l}\text { Sensitivity analysis in hydraulic } \\
\text { model. }\end{array}$ \\
\hline $\begin{array}{l}\text { Effects on flood- } \\
\text { frequency } \\
\text { analysis }\end{array}$ & $\begin{array}{l}\text { Variable and dependent on assumptions } \\
\text { and choice of model. }\end{array}$ & $\begin{array}{l}\text { Variable, depending on degree } \\
\text { of channel change, including } \\
\text { volume increases from erosion } \\
\text { and decreases from deposition. }\end{array}$ & Variable. \\
\hline
\end{tabular}


The uncertainties expected in using Manning's equation at a single section or the critical depth approach are not discussed in detail here but have been estimated as \pm 25 percent of streamflow at 0.01 AEP (Jarrett and England, 2002). That level of uncertainty may be appropriate in reconnaissance-level studies where large uncertainties are acceptable.

Selection of the type of hydraulic model used for a study may be based on availably of data, project resources and timelines, and computational capacity. One-dimensional hydraulic models generally are faster to build and run than 2D models, but unreliable when it comes to sudden longitudinal changes in velocity or width, such as at a channel constriction. Twodimensional models, however, require detailed topographic data to converge and may have varying assumptions (Bodoque and others, 2015).

Uncertainty in hydraulic model results can be linked to selections of cross section and mesh design that challenge assumptions of the models. For gradually varied flow assumptions in 1D, streams must neither be so steep as to void the assumption of gradually varied flow nor so flat that the large overbank areas have ponded areas or flow reversals. Uncertainties will be larger if velocity or flow regime changes suddenly, causing hydraulic jumps (Bodoque and others, 2015). Cross sections must be placed perpendicular to flow and close enough to each other to prevent model instability, but not so close that they cause wave steepening. Uncertainty is reduced if spacing between cross sections $(\Delta x)$ is smaller than Samuel's equation (Brunner, 2016b), which is a function of longitudinal surface slope, $S_{o}$, and bank full depth, $D$ :

$$
\Delta x \leq \frac{0.15 D}{S_{o}} .
$$

In a case study looking at varied cross-section spacing taken out of topography from lidar, Ali and others (2015) confirmed that spacing according to Samuel's equation results in similar depth at close-spaced cross sections, which increases model stability.

Manning's $n$ is difficult to define and depends on many factors. Flow models are sensitive to its determination, with some models estimating 50 percent error in roughness causing a 40 percent error in peak discharge estimates (Ballesteros and others, 2011). Low-flow models are more sensitive to Manning's $n$ than extreme flows represented by some paleoflood stages. However, data regarding roughness at such high flows are scarce. Roughness also is flow-dependent and can change at higher flows owing to the flattening of grassy vegetation or inundation in forested areas at the edge of the floodplain. Manning's $n$ also varies spatially across the channel and floodplains because of the differences in morphology, material compositions, and vegetation. In certain situations, separately calibrating channel and floodplain roughness may be possible (Winters and Baldys, 2011). Using a roughness coefficient that is too high or too low may result in flow being erroneously modeled as supercritical (Bodoque and others, 2015).
Roughness calibration data, typically a longitudinal profile or discrete locations of water surface elevations and associated discharge values, should be based on reliable systematic or historical data from large floods; however, these data may have uncertainties similar to PSIs, such as rating extrapolation as well as measurement uncertainties for HWMs and watersurface profiles.

Topographic uncertainty can be reduced by using highresolution lidar, Structure from Motion surveys, and digital topographic tools (Ostenaa, 2017). However, a substantial source of uncertainty may be channel and floodplain changes that have occurred between the time of the topography survey and the time of the paleoflood (Benito and O'Connor, 2013). Historical photographs, channel surveys, and maps may provide insights regarding substantial changes in channel geometry or channel and floodplain roughness that should be accounted for in the hydraulic model. Underlying topography and boundary conditions may need to be adjusted based on post-historical modifications such as large-scale land-use changes or the addition of roads, bridges, levees, or dams. Choosing a study reach with as little human modification as possible reduces these types of uncertainties.

If a pre-existing hydraulic model for a river reach is adopted for use in a paleoflood study, careful evaluation of model suitability is appropriate because many such models are designed for floods of lower stages than those of interest in a paleoflood study focused on rare and large magnitude floods. In particular, it may be necessary to extend model cross sections to higher elevations, extend the model domain to a longer reach, or add more reaches to achieve convergence on a normal-flow solution. Additionally, model roughness values may need to be recalibrated for flows that best represent the paleoflood record.

\section{Flood-Frequency Analysis}

A flood-frequency analysis is a statistical analysis used to estimate AEPs and characterize uncertainty for specific flood magnitudes. The analysis is based on the systematic peakstreamflow record combined with historical and paleoflood data. Analysis results are used in probabilistic flood-hazard assessment (PFHA) methods such as calibration of hydrologic models and scaling of hydrographs as discussed in appendix 2 . Flood-frequency analyses typically are conducted from an annual series of peak discharges measured at a streamgage. For most flood-frequency analyses, the annual peaks are assumed to be independent and identically distributed, and their probability distributions can be fit using parametric methods (Asquith and others, 2017). In other words, the peakflow series are assumed to be stationary, meaning that they can be described by a probability distribution with parameters (such as mean, variance, and skew) that do not change over 
time. These analyses are the basis for local flood recurrence estimates used for engineering design and regulation, such as the 0.01 and $0.002 \mathrm{AEP}$ floods, which also are termed the "100-year" and " 500 -year" floods, respectively.

A challenge in flood-frequency analysis has been to effectively incorporate specific characteristics of historical and paleoflood data and associated uncertainties (Stedinger and Baker, 1987; O'Connell and others, 2002). New statistical approaches, using concepts of censored observations, ${ }^{3}$ address these data characteristics, enabling effective use of paleoflood and historical data in flood-frequency analyses. Nevertheless, a consistent, widely adopted procedure was not available until the recent adoption of Bulletin 17C by the U.S. Advisory Committee on Water Information, Subcommittee on Hydrology (England and others, 2018).

Historical and paleoflood data are commonly sparse but often represent the large floods for which consideration will improve assessment of the frequency and magnitude of the largest floods. However, not all historical and paleoflood estimates are of the same quality. Many past flood-frequency analyses used point estimates for paleo and historical peaks, as these estimates could be readily incorporated in the analysis software. With the availability of improved software, paleoflood and historical flood-magnitude estimates can be expressed as interval estimates. In contrast to point estimates (for example, 10,000 $\mathrm{ft}^{3} / \mathrm{s}$ ), interval estimates are expressed as a range of values (for example, $8,000-12,000 \mathrm{ft}^{3} / \mathrm{s}$ ). Intervals are a more accurate way to express the uncertainties in the timing and magnitude of paleo and historical peaks compared to systematic gaged peaks. Where robust paleo and historical flood information is available, estimates of the magnitude and uncertainty of extreme events may be improved (Greenbaum and others, 2014; Harden and others, 2011; Ryberg and others, 2020). Paleo and historical flood information also can introduce and inform questions about nonstationarity 4 and separate peak flows into separate populations based on the dominant weather or climate processes that produced each peak (such as rare events caused by atmospheric rivers) that complicate flood-frequency analysis (Harden and others, 2015; Ryberg and others, 2020). For example, the interval and point estimates for paleofloods on the Escalante River near Escalante,

\footnotetext{
2 The use of such terms as the "100-year flood" can confuse or unintentionally mislead those unfamiliar with flood science. Because of the potential confusion, the U.S. Geological Survey, along with other agencies, is encouraging the use of the AEP terminology instead of the recurrence interval terminology (Holmes and Dinicola, 2010).

${ }^{3}$ Values less than a particular threshold, such as the minimum gage detection value; or values that are larger than a particular threshold, such as the value at which a streamgage is overtopped; or interval censored values that are known to be greater than some value, yet less than a maximum value (Leese, 1973) in conjunction with observations categorized with respect to precision and perception thresholds or bounds (for example, Stedinger and Cohn, 1986).

${ }^{4}$ A statistical description of a series with mean, variance, skew and (or) other parameters that change over time.
}

Utah, are large compared to the observed record and seem to create a discontinuity in the distribution of peak streamflow (fig. 25).

\section{Bulletin 17C}

The United States has been publishing flood-frequency guidelines since 1967 (Water Resources Council, 1967; Interagency Advisory Committee on Water Data, 1982). Current guidelines are provided in what is known as Bulletin 17C (England and others, 2018). The history of the development of such guidelines is noted in Bulletin 17C (Ryberg and others; 2020; Rumsey, 2015). Specifically, Bulletin 17C replaces Bulletin 17B (Interagency Advisory Committee on Water Data, 1982). Notable changes are the provision of a more generalized characterization of flood data, including a description of flood peaks as intervals; adoption of the expected moments algorithm (EMA; Cohn and others, 1997) to fit peak data to a parametric distribution; use of an improved low-outlier test, thus enabling better fits to the observations of large floods; and correction of the calculation procedure for determining accurate confidence intervals.

Bulletin $17 \mathrm{C}$ adopts the EMA to fit a log-Pearson Type III (LP3) statistical distribution (a distribution defined by a mean, variance, and a skew) to a series of peak flows at a gage. Software that implements Bulletin 17C analyses includes the USGS software PeakFQ (Flynn and others, 2006; Veilleux and others, 2014) and the U.S. Army Corps of Engineers HECSSP software (U.S. Army Corps of Engineers, 2019). Earlier methods that incorporated the use of paleoflood data include FLDFRQ3, a Bayesian method (O'Connell and others, 2002, and likelihood methods including Stedinger and Cohn (1986).

Other fitting methods and statistical distributions can be used in flood-frequency analysis and are commonly used outside the United States (such as the generalized extreme value [GEV] distribution in Europe; Archer, 2010). Bulletin $17 \mathrm{C}$ guidelines generally are used by U.S. Federal agencies, as well as by most U.S. State, local, and private organizations (England and others, 2018). Therefore, this report focuses on the Bulletin 17C approach of EMA and LP3 as the fitting method and distribution used for incorporating paleoflood and historical flood data in flood-frequency analyses.

\section{Distribution Choice and Fitting Methods}

The selection of appropriate distributions and fitting methods for flood-frequency analyses are two active areas of research in hydrology. The combination of LP3 and EMA methodologies, as described in Bulletin $17 \mathrm{C}$, have an important advantage in that interval estimates are incorporated in the analysis and software. The benefit of expressing historical and paleoflood peaks as interval estimates is that doing so incorporates the uncertainties of PSIs. 


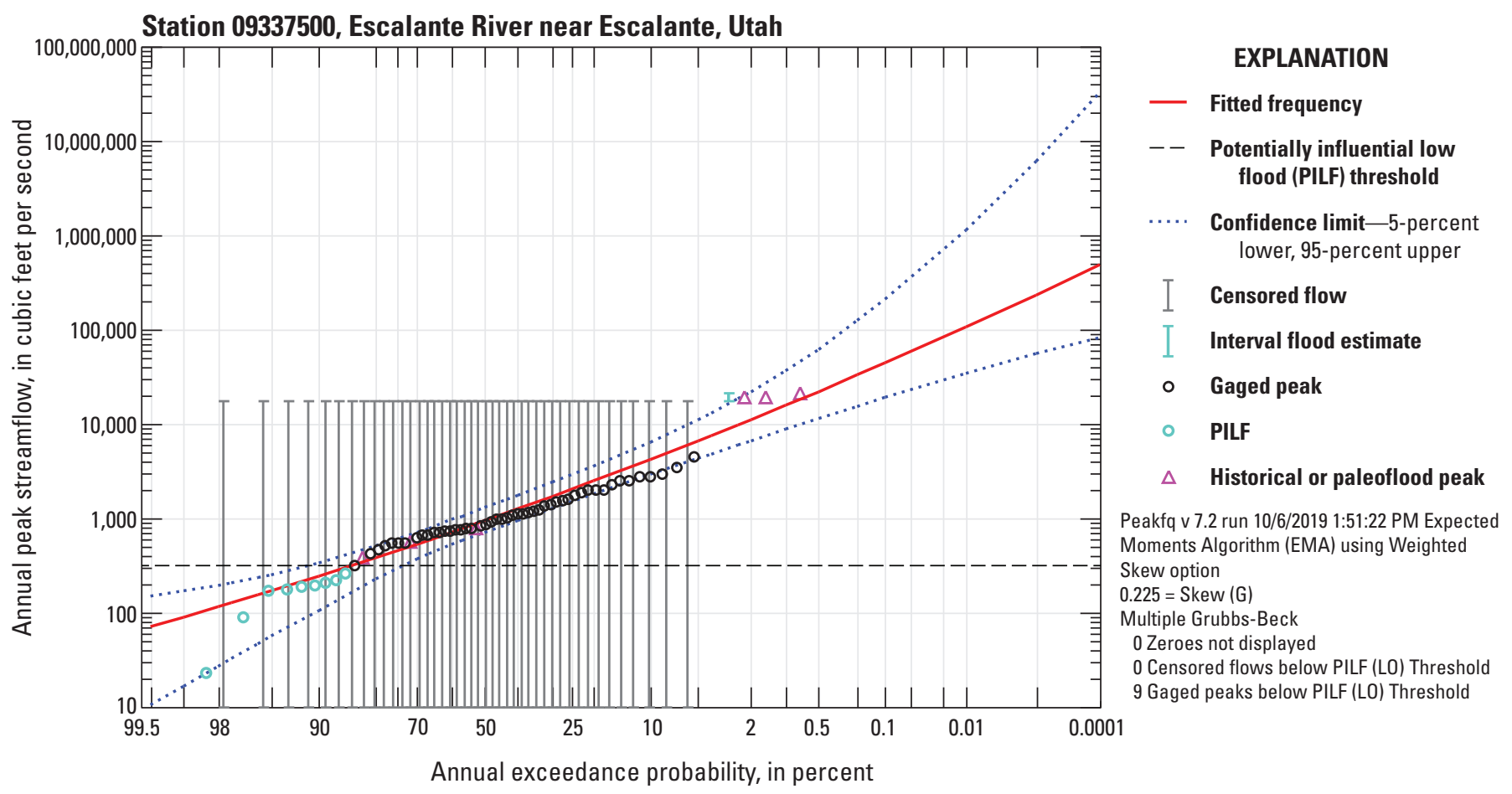

Figure 25. Annual exceedance probabilities using systematic, historical, and paleoflood peaks and thresholds for U.S. Geological Survey streamgage 09337500, Escalante River near Escalante, Utah. Modified from Ryberg and others (2020).

Analysts in countries outside the United States may have guidelines or experience using other distributions and do not necessarily prescribe a single distribution. For example, Australian guidelines state the following:

There is no universally accepted flood probability model. Many types of probability distributions have been applied to Flood Frequency Analysis. Unfortunately, it is not possible to determine the true form of distribution (for example, Cunnane, 1985), and there is no rigorous analytical proof that any particular probability distribution for floods is the correct theoretical distribution. Given these considerations, it is inappropriate to be prescriptive with regard to choice of flood probability model.

(Kuczera and Franks, 2019).

Furthermore, because the upper tails of the distribution, where paleoflood data usually lie, frequently have no gaged observations, goodness-of-fit methods may not differentiate between distributions. At those very low AEPs, model uncertainty begins to outweigh sampling uncertainty (Nathan and Weinmann, 2019). In such a case, when seeking design values at very low AEPs, multiple distributions might be weighted, as is practiced in seismic-hazard analysis (Xing and others, 2017).

A selected set of probability distributions should be consistent with available data. Because more than one set of curves may fit the data well, overall fit across a region could guide selection or weighting. L-moment diagrams, as shown in Asquith and others (2017), provide a visual way to select a set of curves. For discussion of other fitting methods, distributions, and examples using systematic data, see Asquith and others (2017).

\section{Identification of Perception Thresholds and Non-Exceedance Bounds}

The key change implemented by Bulletin 17C, as related to paleoflood and historical data, is the incorporation of typically less-precise historical and paleoflood data in the floodfrequency analysis. This is accomplished by allowing the flood observations to be quantified as interval data, where flood occurrence or non-occurrence for a particular year or series of years is characterized with respect to "perception thresholds." Perception thresholds describe the range of peak discharges that would be observed or recorded had they occurred during specific time periods (see example 3 sidebar). Therefore, in a Bulletin $17 \mathrm{C}$ analysis, all flood observations (gaged, historical, and paleoflood) are associated with perception thresholds and provide a continuous dataset for EMA fitting. Selection of perception thresholds requires careful integration of paleostage indicators, their chronology, and a hydraulic analysis (and associated uncertainties). Errors in defining perception thresholds (table 5) will directly, and sometimes substantially, affect resulting flood-frequency analyses. Much like reducing the uncertainty in the overall flood chronology of a reach, error owing to the selection of inappropriate perception thresholds 
(either too high or too low) can be reduced by investigating multiple sites at multiple elevations in the study area. Sensitivity analyses accomplished by running multiple perception threshold scenarios in the flood-frequency analyses can be used to characterize uncertainty (Harden and others, 2021). In Margo (2017), uncertainty in the value and time period of thresholds was represented by 25 combination scenarios. Results indicated little change in the mean curve but larger changes in confidence intervals.

For most gaging records derived from continuously recording streamflow measurement stations, the lower bound of the perception threshold likely is 0 . The USGS reports all annual peak discharges that are recorded, regardless of their magnitude, although there may be periods of no information in cases of interrupted gage operation. By assigning a lower perception threshold of 0 , the distribution fitting method has a continuous series, regardless of positive evidence of a peak flood magnitude.
The upper bound of the perception threshold represents the largest peak flow that could potentially be recorded. The upper bound generally is assigned a value of infinity, as the upper bound often is not definitively known because there are very few circumstances where a flood would be too large to leave a record. More detailed information about perception thresholds is provided in Bulletin 17C (England and others, 2018), including appendix 10 of that report, which provides examples with data from streamgages and paleoflood estimates.

Non-exceedance bounds (NEBs) are distinct from perception thresholds in that they are specific periods of time during which it is known that no flood has attained a specific discharge (Levish, 2002). Unlike perception thresholds, NEBs are not tied to specific flood observations. A common paleoflood example is the determination that a specific geomorphic surface, such as a stable terrace, has not been inundated for a defined period of time. The discharge required to inundate (and somehow leave a trace) on that terrace is an NEB.

\section{Example 3-Perception Thresholds and Non-Exceedance Bounds}

Note: Much of the material in this example is from the review of Benito and others, 2020.

Perception thresholds are stages that indicate the range of flows that would have been recorded had they occurred for any given year over a specified time span (England and others, 2018). For example, a high cave in the side of a river valley will only accumulate deposits from large floods high enough to inundate the cave and leave a deposit (fig. Ex3.1). In this instance, the perception threshold is the discharge (or stage) associated with inundation, assuming that each inundation results in an individual deposit. Thus, every year, the river of interest can be characterized as having a peak discharge either exceeding or not exceeding that perception threshold. In figure Ex3.1, perception thresholds 1 and 2 relate to the elevations of the two slack-water deposit sites. The time periods for the thresholds are defined by the time that the record begins at each site. Such perception thresholds commonly vary with time. For example, the cave might represent a perception threshold for recording extreme floods going back thousands of years, but the last several decades might be accounted for with a lower perception threshold consisting of flood marks on a bridge (fig. Ex3.1), assuming that each time flow stage reached the bridge, a mark was made. The end member condition is a typical streamgage, for which the perception threshold commonly is zero because the peak flow is recorded and thus precisely known every year. For example, in figure Ex3.1, perception threshold 4 is " 0 ," assuming that the streamgage records all peak flows since the time it was established. All perception thresholds critically rely on the assumption that all floods exceeding the threshold are recorded. In this manner, limits of flood magnitudes can be inferred for every year in the record. Knowledge of how many floods exceeded specified perception thresholds and the durations for which each perception threshold is valid as a flood recorder are more critical for flood-frequency analysis than exact flood dates. For example, the date of bridge construction could define the beginning of a perception threshold. For deposit accumulations, geochronologic evidence from sediment deposits could define the perception threshold. Perception thresholds can have upper bounds, indicating discharges so great that they would not be recorded. Although upper bounds may be defined for a single site, most comprehensive paleoflood analyses for flood-frequency applications do not rely on the information contained at only one site.

In comparison, "non-exceedance bounds" define intervals for specific discharges that have not been exceeded (Levish, 2002). Such bounds commonly are defined based on stable surfaces with no indicators of recent inundation or delicate landscape features unlikely to survive inundation, such as a fine-grained tephra preserved on an outcrop flanking a channel, as illustrated in figure Ex3.1. The non-exceedance bound associated with the volcanic tephra relies on the assumption that the tephra would be eroded away if inundated by floodwaters; thus, the lowest elevation of the tephra indicates the maximum possible flood stage since emplacement of the tephra. 

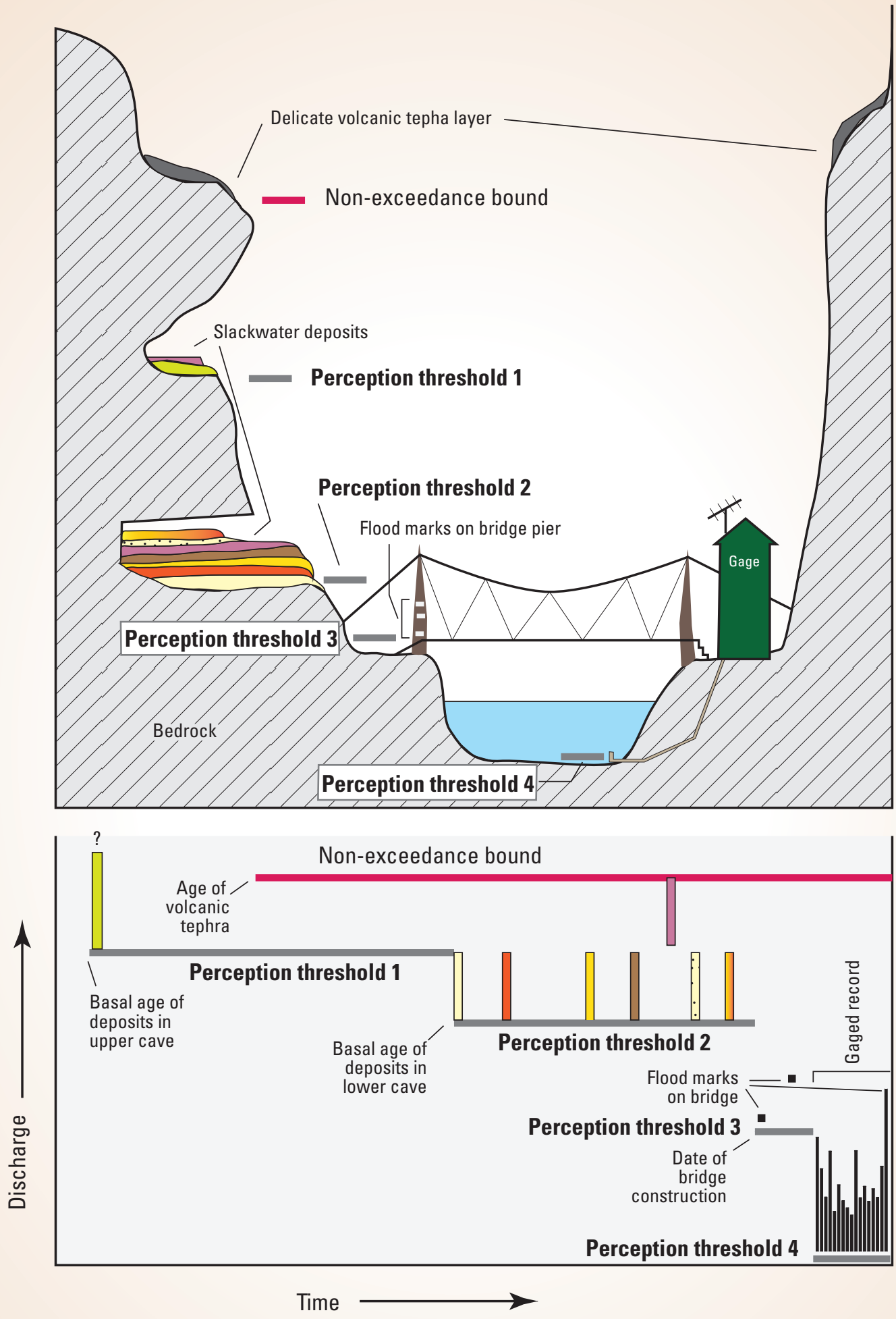

Figure Ex3.1. Concept of non-exceedance bounds and perception thresholds allowing for incorporation of paleoflood and historical information in statistical analyses of flood-frequency. Modified from Benito and others (2020). 

3

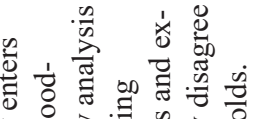

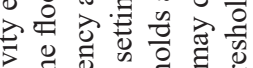

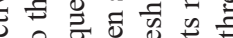

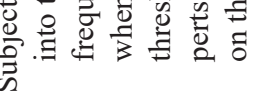

$\therefore$ :

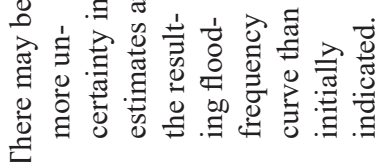

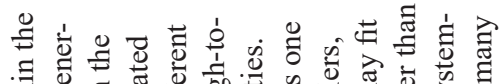

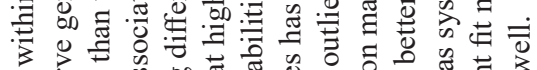

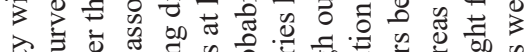

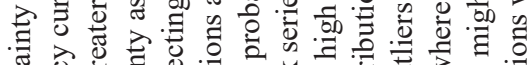

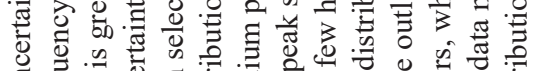

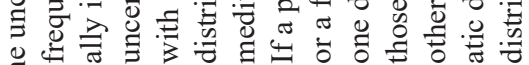
g 


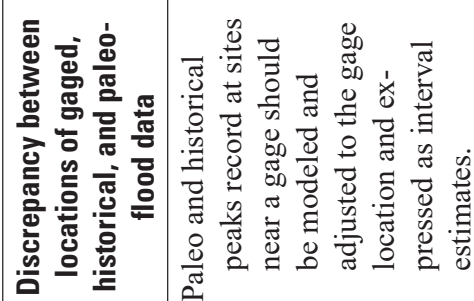

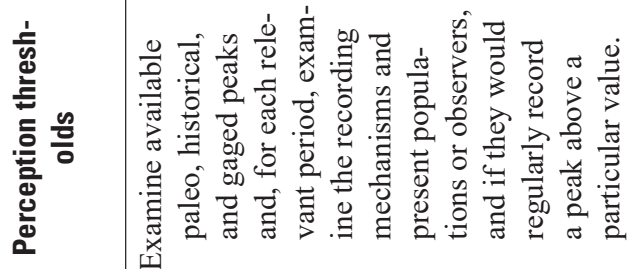

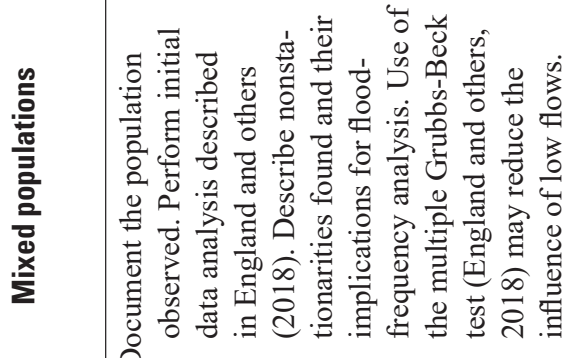

ค

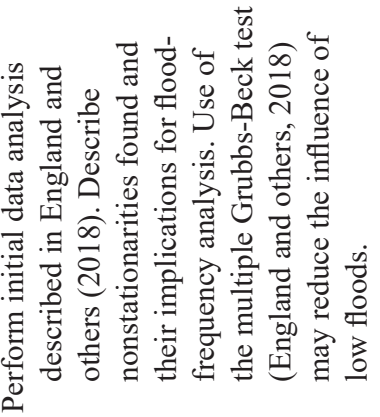

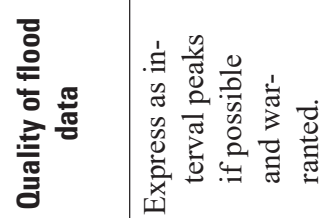

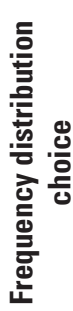

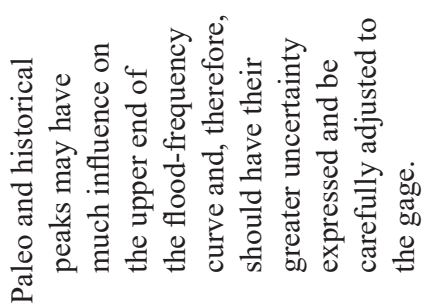

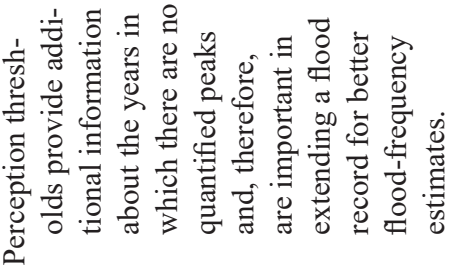

它战入

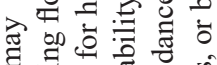

प

웅

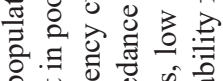

․․ㄹ छ

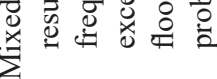

.

के छे उु

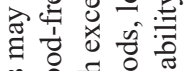

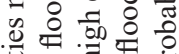

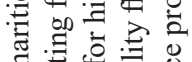

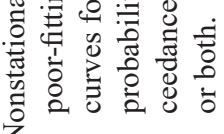

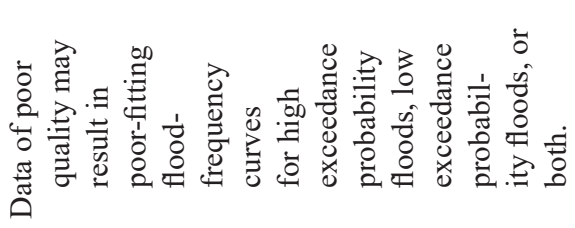

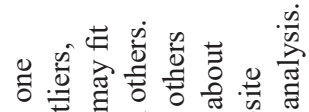

号

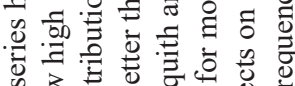

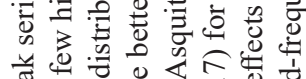

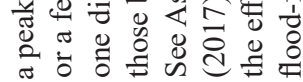

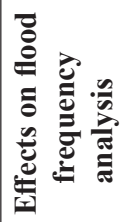




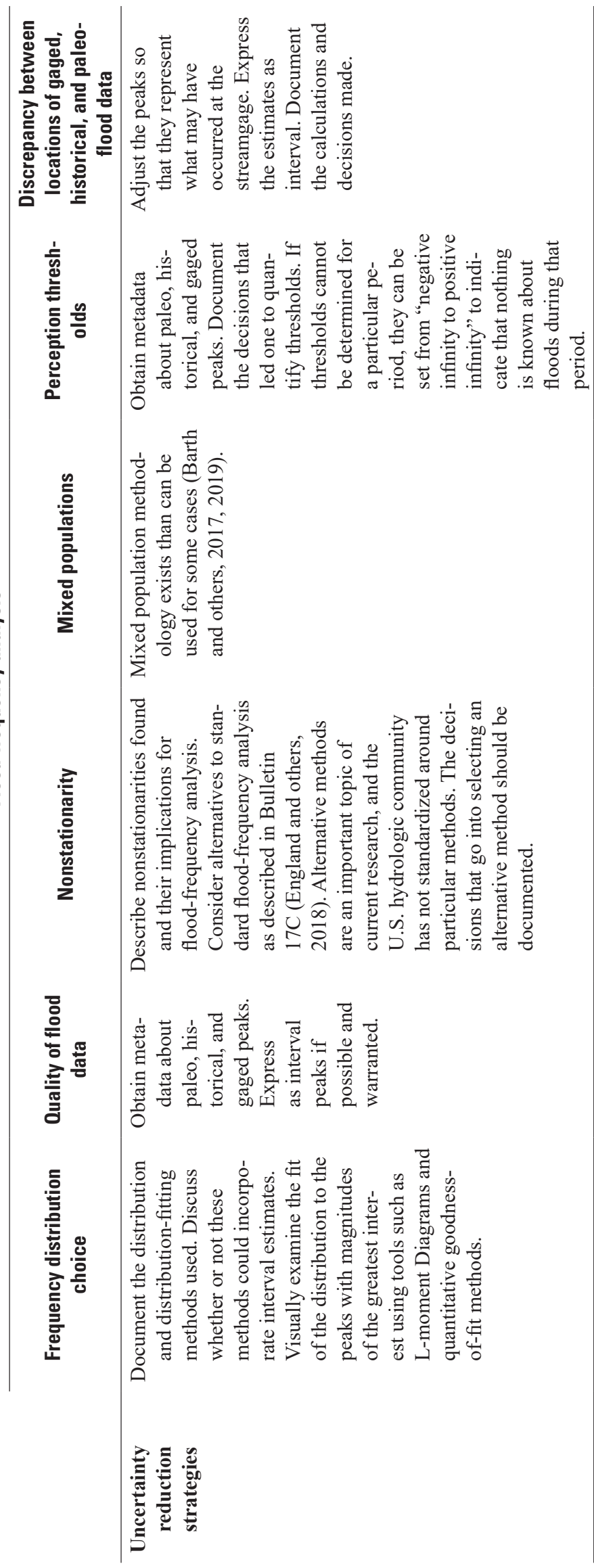


A historical example might be the knowledge that a bridge built in 1840 has never been overtopped. The discharge required to overtop the bridge would then be an NEB for the period of time from 1840 to present. Although NEBs differ from perception thresholds, they are treated the same by the EMA analysis, which can lead to errors in the flood-frequency analysis. By definition, floods (paleo, historical, or gaged) cannot have a magnitude that is less than the associated perception threshold for that location and time period (for example, the perception threshold for a streamgage at a specific site in operation over a specific time period). For NEBs, all floods have smaller magnitudes than their associated NEB. For example, the PeakFQ software uses perception thresholds; therefore, all paleoflood-discharge magnitudes must be greater than their associated perception threshold.

Perception thresholds can reduce substantially the uncertainty of the right-hand tail of flood-frequency distributions and, in many cases, lead to more robust frequency and magnitude estimates of rare and large floods ( $\mathrm{O}^{\prime}$ Connell and others, 2002). Moreover, multiple perception thresholds from various records (including paleoflood, historical, and systematic measurements) can be incorporated in a single flood-frequency analysis. Although application of perception thresholds can be statistically powerful, care in their application is warranted because they require certain knowledge of the completeness of the underlying records. For example, if a minimum perception threshold is defined for a certain period and the considered record does not include floods that surpassed the threshold, then the resulting flood-frequency assessment will be incorrect. This is an issue particularly when applied to geological records of flooding because of the variety of mechanisms by which large floods may fail to leave a recognizable depositional or erosional trace on a landform (Benito and O'Connor, 2013). Sensitivity analyses of plausible uncertainties of the perception thresholds developed for a specific study will quantify the uncertainties in the resulting flood-frequency analyses attributable to the uncertainty in the completeness of the input flow records. Such sensitivity analyses will provide important information on the effects of uncertainty in the analysis characterizing the quality of the source data and informing decision-makers of that uncertainty, which is not carried through in the standard Bulletin 17C confidence intervals.

Individual paleofloods used within the flood-frequency analysis should be considered interval or censored estimates, indicating that these floods typically have greater uncertainties than those that are part of a gaged record. Bulletin 17C guidelines recommend the use of flood-discharge intervals for flood magnitudes estimated by paleoflood or historical records, but not for flood-peak discharges computed by indirect methods that are estimated to be within 5-25 percent of the true magnitude (England and others, 2018). Quantification of such uncertainties generally arises from consideration of the uncertainties in the flow modeling.

\section{Peak-Streamflow Data Uncertainties and Assumptions}

To fully understand the uncertainties and assumptions in flood-frequency analysis, one must understand the underlying data. The next two sections describe uncertainty in gaged and historical point estimate data.

\section{Gaged Data}

Annual peak-streamflow series are available from several sources. The USGS provides annual peak-streamflow data in what is known as the peak-flow file (PFF), https://nwis .waterdata.usgs.gov/usa/nwis/peak, for more than 29,000 sites in the United States and its territories (U.S. Geological Survey, 2020a). The Bureau of Reclamation, the USACE, and State agencies also may have peak-streamflow information, but they are provided on a river basin, project, or regional basis (Advisory Committee on Water Information, 2018). The following discussion focuses on USGS flow data, but the concepts apply broadly.

Collection and interpretation of the data that result in the annual peak-streamflow series are described in Wagner and others (2017). The history of the peak-flow file is described in Ryberg and others (2017). Notably, peak-flow values were compiled and published in numerous USGS publications from 1906 to 1968 (Murphy, 1906; U.S. Geological Survey, 1952; Wells, 1955; Green, 1964; Speer and Gamble, 1964a, 1964b, 1965; Wiitala, 1965; Barnes and Golden, 1966; Patterson, 1966; Patterson and Gamble, 1968; Tice, 1968). The USGS began to systematically publish peak-flow values in the 1960s in annual Water Data Reports, such as U.S. Geological Survey (1962). In 1969, data contained in these publications were entered into a computer database that became known as the PFF (see Ryberg and others, 2017, app. 1). Annual peakstreamflow values continued to be entered manually each year as the annual peaks were determined. As with any database, these manual entries were prone to errors, many discovered during subsequent analyses of peak streamflow. The USGS undertook an effort to improve the quality of the PFF by using systematic screening methods that used comparisons to daily flows, logical checks, and statistical analyses to flag potential errors (Ryberg, 2008). The improvement of the PFF was documented in Ryberg and others (2017). This effort highlights a first step in the technical review of PFHAs. The source of the data must be documented and efforts, unless documented elsewhere, should be dedicated to quality assurance of the data.

Another issue documented in the USGS PFF that may or may not be documented in other sources is that not all peak-streamflow values at a site are the same in terms of the statistical population they represent (the flood-generating mechanism, regulated or unregulated conditions) or in their accuracy (some are based on estimates; table 6). As described in Ryberg and others (2017), the USGS PFF has qualification codes that provide additional information about the peaks. 
Metadata, to the extent available, should be compiled along with peak-streamflow values used in probabilistic flood-hazard assessment.

\section{Use of Historical Data in Flood-Frequency Analysis}

The PFF does not contain paleoflood data, but it does contain historical peaks that can bridge periods of systematic and paleoflood information. Historical and gaged peaks in the PFF also can be verified by paleoflood studies. In the PFF, historical peaks have a qualification code of 7 ; they are the quantification of nongaged peaks based on a search of archival material, such as historical newspaper accounts, for large floods. Code 7 is for peaks outside the systematic gaging record; that is, peaks determined before or after continuous data collection at a streamgage or during extended breaks. ${ }^{5}$ These types of peaks are qualified because they are biased toward large floods (table 6); they generally would not have been recorded had the magnitude of the flood not been large.

Code 7 peaks traditionally were excluded from PeakFQ (Veilleux and others, 2014) analyses using Bulletin 17B methods unless the user specified a Bulletin 17B (Interagency Advisory Committee on Water Data, 1982) historical record adjustment. Using the EMA fitting method (Cohn and others, 1997, 2001; England and others, 2018) in the USGS flood-frequency analysis software PeakFQ, historical peaks are included by default with a perception threshold and flow interval that the user can modify.

${ }^{5}$ For example, a nonsystematic peak would occur if a gap existed in the record of a streamgage because of a lack of funding, but a large flood occurred during that gap and the peak was determined and recorded in the database.

Table 6. Key uncertainties of paleoflood analysis and strategies for reducing them with respect to historical flood data and streamgage data.

\begin{tabular}{|c|c|c|}
\hline & Historical flood data & Streamgage data \\
\hline $\begin{array}{l}\text { Major issues (key } \\
\text { uncertainties) }\end{array}$ & $\begin{array}{l}\text { Historical peaks have greater uncertainty than gaged } \\
\text { peaks. Historical accounts may exaggerate floods } \\
\text { owing to perception. Datum inconsistencies. }\end{array}$ & $\begin{array}{l}\text { Not all peaks estimated at a streamgage have the same degree } \\
\text { of accuracy. If a very large flood prompts the extension of a } \\
\text { rating curve, the peak may have more uncertainty associ- } \\
\text { ated with it. Datum inconsistencies. }\end{array}$ \\
\hline $\begin{array}{l}\text { Likely } \\
\text { consequences }\end{array}$ & $\begin{array}{l}\text { Historical peaks are biased toward larger peaks } \\
\text { owing to perception bias, which may increase } \\
\text { magnitudes. If quantified as point estimates, this } \\
\text { implies that they have been measured/recorded } \\
\text { with the same degree of accuracy as gaged peaks, } \\
\text { which conceals actual uncertainty. }\end{array}$ & $\begin{array}{l}\text { Large peaks influence the flood-frequency curve and the prob- } \\
\text { ability estimates of low-frequency floods. }\end{array}$ \\
\hline $\begin{array}{l}\text { Approaches to } \\
\text { quantification } \\
\text { and evaluation of } \\
\text { uncertainty }\end{array}$ & $\begin{array}{l}\text { Historical peaks should be quantified as interval } \\
\text { estimates (see the Example } 4 \text { sidebar for an } \\
\text { example of an investigation and reinvestigation of } \\
\text { a historical peak). Historical peaks should be as- } \\
\text { sociated with a perception threshold; that is, some } \\
\text { knowledge that if peaks were above a particular } \\
\text { level during a particular historical period, they } \\
\text { would be recorded. }\end{array}$ & $\begin{array}{l}\text { Revisit large peaks, even if they were gaged. A better rating } \\
\text { curve may exist now if the peak was recorded some time } \\
\text { ago. If uncertainty can be quantified, quantify streamgaged } \\
\text { peaks as interval estimates in the flood-frequency analysis. }\end{array}$ \\
\hline $\begin{array}{l}\text { Effects on flood } \\
\text { frequency } \\
\text { analysis }\end{array}$ & $\begin{array}{l}\text { Large historical peaks can improve the estimates of } \\
\text { the upper end of the flood-frequency curve or they } \\
\text { possibly do not fit well in the distribution. }\end{array}$ & $\begin{array}{l}\text { Streamgage data provide the basis for flood-frequency } \\
\text { analysis curves. More streamgage data are likely to reduce } \\
\text { uncertainty in the flood-frequency analysis, provided the } \\
\text { gaged data come from the same population of peaks. If } \\
\text { there is a change in the population of peaks, such as they } \\
\text { are now regulated, one may need to separate the peaks } \\
\text { into different distributions for analysis or perform a mixed } \\
\text { population analysis. }\end{array}$ \\
\hline $\begin{array}{r}\text { Uncertainty } \\
\text { reduction } \\
\text { strategies }\end{array}$ & $\begin{array}{l}\text { Multiple lines of evidence should support the } \\
\text { historical peak. Additional historical peaks, or } \\
\text { information (for example, the peak in } 1858 \text { was } \\
\text { the largest since 1842) can provide additional } \\
\text { information about the frequency of large peaks. } \\
\text { Historical peaks should be evaluated as interval } \\
\text { estimates and can be used as historical perception } \\
\text { thresholds in the flood-frequency analysis. }\end{array}$ & $\begin{array}{l}\text { Obtain as much streamgage data as possible, examine the } \\
\text { largest peaks to determine if current rating curves would } \\
\text { provide the same estimate. Express peaks as interval } \\
\text { estimates if uncertainty can be quantified. Understand the } \\
\text { population or populations the peaks represent (they may be } \\
\text { a mix of snowmelt and rain-generated floods or a mix of } \\
\text { regulated and unregulated peaks). }\end{array}$ \\
\hline
\end{tabular}


Computer storage capacity was a severe limitation in 1969 and sources of information and uncertainty estimates were not stored to help document historical peaks. Additionally, the methods to include interval estimates in flood-frequency analyses are a recent development and historical (and paleo) flood information have been stored as point estimates, rather than interval estimates. Because these peaks have a lower degree of accuracy than those obtained through systematic streamgaging, they are better expressed as interval estimates when additional information is available to determine the interval estimates (table 6).

Analysts should examine historical peaks to determine whether there is sufficient information (some peaks have an unknown day or year, or little documentation) to include in flood-frequency analysis. Analysts should document other sources of information about these floods, such as newspaper accounts, USGS or other agency reports, and historical photographs. If enough information exists, point estimates from the USGS PFF should be replaced with an interval estimate.

Flood-frequency analysis performed with historical data should document the sources of the historical data and describe how that information was used to set perception thresholds within the flood-frequency analysis. The example 4 sidebar describes an investigation validating a historical peak.

\section{Examples of Flood-Frequency Analyses Performed with Historical and Paleoflood Data}

Bulletin $17 \mathrm{C}$ provides extensive examples of floodfrequency analyses in appendix 10 (England and others, 2018). These examples include the use of historical and paleoflood data. Ryberg and others (2020) also contained several examples of flood-frequency analyses with Bulletin 17C methods and historical and paleoflood data. Examples of paleoflood studies incorporating gaged, historical, and paleoflood data include O'Connor and others (1994), Hosman and others (2003), Benito and others (2004), Macdonald and Black (2010), Harden and others (2011), Greenbaum and others (2014), Lam and others (2017), and Harden and others (2021).

\section{Uncertainties Not Treated by Bulletin 17C}

Bulletin $17 \mathrm{C}$ does not include guidelines addressing several challenges to the appropriate application of floodfrequency analysis (table 5). These challenges include the analysis of peaks that come from mixed populations. Mixed populations are peak series that are not dominated by a single flood-generating mechanism; the peaks are instead the product of a mix of flood-generating mechanisms, such as mountain snowmelt, convective storms, and atmospheric rivers (Sando and McCarthy, 2018). Barth and others $(2017,2019)$ provided a statistical framework for mixed population analysis in the context of Bulletin 17C.
Bulletin 17C does not include analysis methods for nonstationary flood series (table 5). Many flood records indicate changing conditions, thereby violating the stationarity assumption common to most approaches of flood-frequency analysis. Such changes commonly have anthropogenic causes, such as regulation or urbanization, climate change, or naturally occurring climatic persistence and shifts in climate states (Potter, 1976; Cohn and Lins, 2005; Vecchia, 2008; Milly and others, 2008; Olsen and others, 2010; Hirsch, 2011; Kiang and others, 2011; Salas and others, 2012; Gül and others, 2014; Razavi and others, 2015; Kolars and others, 2016; Ryberg and others, 2020). Bulletin $17 \mathrm{C}$ outlines an exploratory analysis that should be conducted, at a minimum, to determine if a series is stationary, but does not indicate how sensitive a floodfrequency analysis is to violations of the stationary assumption. Furthermore, Bulletin 17C does not provide estimates of the uncertainties associated with nonstationary flood series, nor does it provide criteria for deciding if a different method should be used. A paleoflood study-based flood-frequency analysis should include an exploratory analysis of the series, a determination of stationarity of the system, or a description of the violation(s) of the stationarity assumption and a discussion of the implications of any violations. If an alternative floodfrequency analysis method is used, the analyst should describe why that method was selected. Bulletin $17 \mathrm{C}$ methods do not address nonstationarities, but other methods have successfully incorporated historical floods in time-varying models (Machado and others, 2015).

Changes causing nonstationarity of systematic records also affect paleo and historical flood records. Such factors (including climate change, watershed changes, and flow regulation) may affect the applicability of historical and paleoflood records for assessing future flood frequency. Issues to consider are the types of watershed changes, their plausible effects on floods of interest, and the timescales of interest in the floodfrequency analysis. For example, for situations in which the frequency of large flood-producing storms has changed during the last few thousand years because of quasi-periodic climate oscillations (for example, Harden and others, 2015), a floodfrequency analysis encompassing the period of climate change might not be appropriate for understanding the annual exceedance probability of a large flood within the next year or decade because of nonstationarity issues, but it could be appropriate for understanding the likelihood of floods over millennial time periods encompassing such climate cycles, as might be the case for evaluating the hazard to a nuclear waste repository. Watershed conditions, and the consequent relation between precipitation and runoff, also may have changed since the paleoflood deposits accumulated. Studies with paleoflood data should have some discussion of climate over the period of the paleoflood analysis and the gaged record. 


\section{Example 4-Validating a Historical Peak on the Colorado River at Lees Ferry, Arizona}

The annual peak-streamflow series for USGS streamgage 09380000, Colorado River at Lees Ferry, Arizona, includes a historical peak of 300,000 cubic feet per second on July 7, 1884 (fig. Ex4.1). This peak is qualified with peak streamflowqualification codes 2,7 , and $E$, indicating that (1) it is an estimate (code 2); (2) it is historical (outside the period of systematic record, code 7); and (3) that the maximum peak is the only streamflow available for that year (code E). The peak-flow file (PFF) was not designed to include additional background or metadata about the peak.

This measurement record has the additional complication that peaks from water years 1963-2014 are affected by regulation, as evident in the reduced peak magnitudes (fig. Ex4.1) and in the PFF by being attributed with qualification code " 6 ." If one were to perform a flood-frequency analysis using all the data from this site, the flow beginning in 1963 would need to be naturalized (the unregulated flow would need to be estimated) to have a record of peaks representing a single (unregulated) population or one would need to perform a flood-frequency analysis under regulated conditions, with only the regulated period. Assuming naturalized flows could be obtained, should the historical peak be used in flood-frequency analysis? Alternately, one could perform the flood-frequency analysis using only the unregulated period prior to 1963.

The first step should be to obtain additional information to verify this peak. Additional information is available in this case. The method for estimating the high-water mark is unique but does not preclude the ability to estimate a flood. Information about the 1884 Colorado River flood peak was documented in LaRue (1925, p.14):

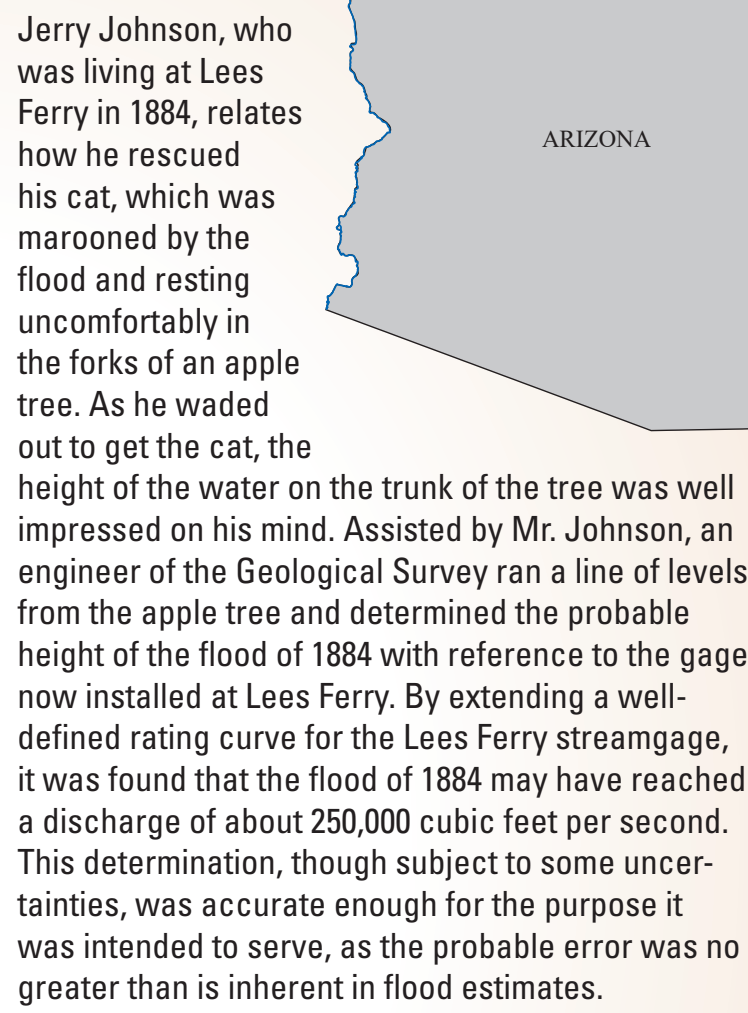

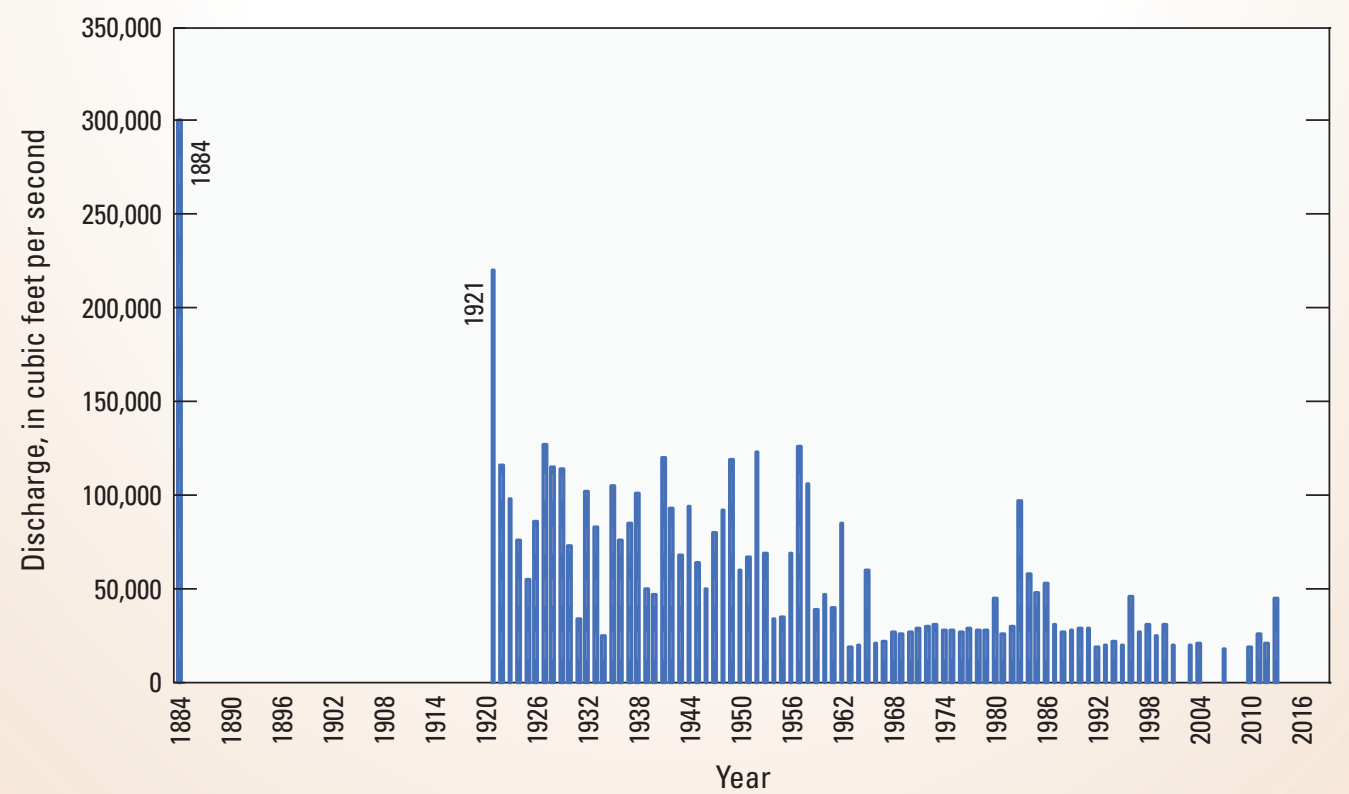

Figure Ex4.1. Annual peak streamflow, for U.S. Geological Survey (USGS) streamgage 09380000, Colorado River at Lees Ferry, Arizona (USGS, 2019). 
As shown in figure Ex4.1, the flood ultimately was entered in the PFF as 300,000 cubic feet per second $\left(\mathrm{ft}^{3} / \mathrm{s}\right)$ along with a corresponding stage of 31.5 feet (above local gage datum).

The flood has been reexamined and re-estimated several times, including by Topping and others (2003, p. 29-31):

Estimation of the peak discharge of the 1884 flood depends on accurate determination of maximum flood stage and appropriate extrapolation of stagedischarge rating curves to higher stages. The original unpublished estimate of the peak discharge of the 1884 flood at Lees Ferry was between 210,000 and $250,000 \mathrm{ft}^{3} / \mathrm{s}$ (G.C. Stevens, unpublished U.S. Geological Survey memorandum, May 28, 1925), and this estimate was revised by Gatewood and Hunter in 1938 to $300,000 \mathrm{ft}^{3} / \mathrm{s}$. They made this revision because they had revised the magnitude of the 1921 flood upward; this revision resulted in a change in the stage-discharge rating curve which, in turn, necessitated revision of the 1884 estimate. Reevaluation of stage-discharge data indicates that the probable range of the peak discharge of this [1884] flood was between 199,000 and 228,000 ft3/s. Based on the estimates at Lees Ferry [and] the revised estimate at the Grand Canyon gaging station...the peak discharge of the July 1884 flood, at two significant figures, was approximately $210,000 \pm 30,000 \mathrm{ft} 3 / \mathrm{s}$ at Lees Ferry and through Grand Canyon.

This example highlights an important issue. Historical peak estimates should not be considered chiseled in stone. They should be considered written in pencil, given the information available at the time. They often were calculated by extrapolation from a stage-discharge rating curve based on a short period of systematically observed peaks. If more recent discharge measurements have been made, the stagedischarge rating might be adjusted, and in the absence of reliable information on the stage-discharge relation at the time of the historical peak, the new rating curve might provide the best estimate of the historical peak.

\section{Outstanding Issues and Uncertainties}

One inherent issue in the development of paleoflood chronologies and associated hydraulic analyses is possible underestimation of the number and magnitude of floods (table 3). Stratigraphic records are seldom complete, and elevations of most PSIs provide only minimum indications of maximum flood stages. This underestimation bias is owing to the reliance on positive evidence for floods, although this bias is reduced using perception thresholds and non-exceedance bounds, which provide general information about flood magnitudes over a specified period of time. The investigation of multiple sites within each study reach in combination with specifying ranges of plausible flood magnitudes helps to minimize the bias of such factors, but the actual errors remain unknown.

A fundamental question is the applicability of the paleoflood record, which for most rivers spans thousands of years, to the present-day risk of flooding. Watershed conditions and the consequent relation between precipitation and runoff also may have changed in systematic, episodic, or cyclic manners for the period during which the paleoflood deposits accumulated. Long paleoflood records encompass past climate fluctuations and a range of watershed conditions that may or may not be representative of modern conditions. However, quantifying how rivers have responded to past climate variations helps to determine how they might respond to climate change in the future. Another important issue to consider when conducting paleoflood analyses is forest fire, which can enhance flood magnitudes (Elliott and Parker, 2001; Johansen and others, 2001). Applicability of study results to future watershed conditions is another important question. However, as stated in Greenbaum and others (2014, p. 5266-5267):

...[T]he question of climate and land-use change applies to all risk analyses based on all real-world flooding data, not merely to paleoflood data. [...] To assume that changes in climate or land-use will invalidate the role of long-term records [of flooding] for future, hazard designation presumes that there is little or no information on those changes. It is the goal of science to discover what those changes actually are, and to use resulting information to improve understanding... [of] how and why these changes arise.

Because of such issues and uncertainties, broad consideration of all factors and information likely will result in the most complete assessment of flood hazards. Results from comprehensive large-scale paleoflood analyses provide better physically based information to determine low-probability floods than the systematic and historical records alone, substantially improving estimates of the magnitude and frequency of large floods in basins and better characterizing associated uncertainty. 


\section{Paleoflood Analysis and Review Levels}

As paleoflood studies have become more common in assessing probabilistic flood risks to critical structures, the need emerges for guidelines to conduct and review such studies. In this section, we define three levels of paleoflood analyses and review for PFHAs (table 7). The boundaries between levels of analyses are purposefully ambiguous. The scope and complexity of individual studies will vary depending on project objectives, guidelines, and budgets. Nevertheless, this categorization helps determine levels of effort involved in conducting paleoflood studies as well as the degree of appropriate technical review. As the analysis and review level increases from 1 to 3, the number of reaches, sites, samples, and age dating methods increases, and more complex hydraulic models are used to estimate discharge, better quantifying uncertainty (England, 2011).

The selection of the appropriate analysis and review level depends on agency policy and project goals. Each increasing level of analysis will add complexity to the study, such as an increase in the number of sites in the study, the use of multiple dating methods, more complex hydraulic analyses, and more complex quantification of uncertainty (table 7). Review levels consider the size of project teams, planning efforts, budget, and study objectives. The application of a consistent and appropriate level of analysis and review, which correlates to project objectives, is key to a successful and high-quality study with reliable results.

Planning and logistics for a paleoflood study can range from one or two specialists to a much larger group of scientists, engineers, and technicians guided by a technical advisory board. Paleoflood studies may involve field reconnaissance, securing permits, gaining site access, and multiple field campaigns depending on the level of analysis required. Typical project teams may include one of more of the following specialists depending on the project methods and analysis level:

- Geologists and geomorphologists for site selection, stratigraphic analysis and interpretation, developing overall flood chronologies and plausible flood scenarios, gathering and interpreting any regional paleoflood information, and researching documented flood history;

- Dendrochronologists/ecologists/botanists for analysis of tree rings and other botanical data;
- Geochronologists for sample collection, processing, laboratory analysis, and results;

- Hydraulic engineers for hydraulic modeling and other flow computations;

- Surveyors for accurate channel geometry and site elevation data; and (or)

- Hydrologists, statisticians, or civil engineers for the flood-frequency analysis.

The numbers of team members will be larger for higher paleoflood study levels (table 7). For example, a single geomorphologist or geologist might be needed for a Level 1 study, but a Level 3 study might require a much larger team of geomorphologists, hydraulic modelers, hydrologists, and surveyors. Project staffing needs vary among projects depending on the specific methods applied and the expertise of each member (for example, a geomorphologist may also be able to survey site elevation and (or) develop the hydraulic model), as well as the scope of the study.

The degree of formal peer review is an important differentiation between the paleoflood study levels discussed in the sections that follow. Peer review is an essential part of scientific studies and ensures quality results. Data checks and policy reviews often are included in the review process, but not detailed here. Peer reviewers need to be qualified in the discipline and methods reviewed, but independent and not associated with the project. Peer reviewers may be internal or external to the agency conducting the study. They may review the study in-progress or the end-product, either independently or in a team setting. Reporting requirements for paleoflood analyses are similar for all levels, but higher-level studies will have more sites to report on and more components to the study than lower-level studies. Reporting requirements are discussed in section, "Documentation and Reporting."

\section{Level 1 Paleoflood Analysis and Review}

U.S. Federal agencies that conduct paleoflood studies, particularly for risk-based applications, similarly differentiate hydrologic hazard levels of study, with the first level (here, Level 1) as paleoflood reconnaissance-level studies. Paleoflood analysis and review for Level 1 is similar to the Bureau of Reclamation Dam Safety Program appraisals for Comprehensive Review and some Issue Evaluation studies (Bureau of Reclamation, 2013). 
Table 7. Summary table of paleoflood analysis and review levels for probabilistic flood-hazard assessments.

[Abbreviations and symbol: ${ }^{137} \mathrm{C}$, cesium-137; NRC, Nuclear Regulatory Commission; OSL, optically stimulated luminescence; 1D, one-dimensional; 2D, two-dimensional; +, plus]

\begin{tabular}{|c|c|c|c|}
\hline & Study level 1 & Study level 2 & Study level 3 \\
\hline Purpose & $\begin{array}{l}\text { Initial hazard screening. } \\
\text { Regional flood assessment. } \\
\text { Feasibility assessment. } \\
\text { Periodic review/update for } \\
\text { site hazard. }\end{array}$ & $\begin{array}{l}\text { Site-specific flood-frequency and } \\
\text { magnitude estimates. } \\
\text { Inspection finding Issue Evaluation } \\
\text { (NRC). } \\
\text { Site hazard assessment. } \\
\text { Hydroclimatic analysis. }\end{array}$ & $\begin{array}{l}\text { Regional and site-specific flood-frequency and } \\
\text { magnitude estimates. } \\
\text { Support siting, facility design, or retrofits of } \\
\text { critical infrastructure. } \\
\text { Broad-scale hydroclimatic analysis. }\end{array}$ \\
\hline Analysis effort & $\begin{array}{l}\text { Few personnel (1-2). } \\
\text { Minimal field campaign. } \\
\text { Site visit optional if regional } \\
\text { paleoflood information is } \\
\text { available. }\end{array}$ & $\begin{array}{l}\text { Multidisciplinary team }(2-5) \text {. } \\
\text { Single or multiple field campaigns } \\
(1-2) \text {. } \\
\text { Single or multiple reaches. }\end{array}$ & $\begin{array}{l}\text { Multidisciplinary team(s) }(3-6+) \\
\text { Multiple field campaigns }(2-3+) \text {. } \\
\text { Multiple reaches or river basins. }\end{array}$ \\
\hline $\begin{array}{l}\text { Concurrent } \\
\text { review and } \\
\text { project } \\
\text { modifica- } \\
\text { tion } \\
\end{array}$ & $\begin{array}{l}\text { Investigator determined in } \\
\text { accordance with project } \\
\text { purpose. }\end{array}$ & $\begin{array}{l}\text { In-process review and progress evalua- } \\
\text { tion by technical steering committee } \\
\text { of subject-matter experts. } \\
\text { Field review of critical study sites } \\
\text { and interpretations. }\end{array}$ & $\begin{array}{l}\text { In-process review by formally established } \\
\text { panel of subject-matter experts (such as } \\
\text { Consultant Review Board). } \\
\text { Field inspection and independent evaluation } \\
\text { of key sites. }\end{array}$ \\
\hline $\begin{array}{l}\text { Final technical } \\
\text { review }\end{array}$ & $\begin{array}{l}\text { Independent technical review } \\
\text { by general subject-matter } \\
\text { expert(s). }\end{array}$ & $\begin{array}{l}\text { Technical review by team of indepen- } \\
\text { dent subject-area experts, including } \\
\text { expertise for all study components } \\
\text { (that is, stratigraphy, dendrochronol- } \\
\text { ogy, hydraulics, flood-frequency } \\
\text { analysis). }\end{array}$ & $\begin{array}{l}\text { Technical review by formally established team } \\
\text { of independent and nationally or interna- } \\
\text { tionally recognized subject-area experts, } \\
\text { including expertise for all study components } \\
\text { (that is, stratigraphy, dendrochronology, } \\
\text { hydraulics, flood-frequency analysis). } \\
\text { Independent expert review of uncertainty } \\
\text { and sensitivity analyses. }\end{array}$ \\
\hline
\end{tabular}


Level 1 analyses typically are scoping- or

reconnaissance-level studies and commonly are the first step in almost all quantitative paleoflood analyses. The objectives of Level 1 studies vary, but typically include (1) providing an initial screening of a local flood-hazard issue; (2) supporting or verify existing flood studies; (3) serving as a feasibility assessment to use in assessing the need, appropriate methods, or probability of success for a higher-level analysis; (4) collecting information for a regional flood assessment; or (5) serving as a periodic review or update for site-specific flood-hazard information. Numerical dating techniques such as OSL and radiocarbon may be used if supported by the project objective and budget. However, relative dating methods such as soil development and general forest stand age may be used to constrain the age of the paleofloods, nonexceedance bounds, and (or) perception thresholds. Relative dating alone may be adequate for a Level 1 study. Hydraulic analyses for a Level 1 study are relatively simple approaches that establish a relation between paleo-stages and discharge and generally involve applying existing models, extending rating curves where appropriate, or simple calculations such as the Manning's equation at a single channel cross section. A typical Level 1 study might require two geomorphologists and involve one site visit to the study area. Flood stratigraphy generally is examined and recorded in detail and evaluated at about 1-3 sites, either in SWDs or terraces or a combination of the two. If using off-channel deposits, about 1-3 cores are analyzed. If using flood evidence from trees, only a few trees $(<5)$ might be cored. Relative or numerical age dating (about 1-3 samples analyzed) is used to determine the flood history. Discharge estimates are established by a single cross section or short 1D hydraulic model. If abundant and reliable regional paleoflood information is available for basins near the study area and basins are similar, Level 1 studies may not require a site visit. Because of the small number of sites studied, limited age control, and use of simple hydraulic calculations, uncertainties can be large and poorly defined. Results typically are considered to be preliminary. Depending on the data collected and project goals, a flood-frequency analysis may or may not be performed.

Preliminary scoping and project guidance are determined by the project lead in accordance with the project purpose. Independent technical review of Level 1 studies, although it may be minimal, is conducted by a subject-matter expert or experts external to the project. The review will encompass all aspects of the study. If field work was done, all field notes, photographs, and records should be retained for review. A field site visit for reviewers typically is not conducted.

Examples of Level 1 studies include the following:

1. Applicability of paleoflood surveys to the Black Hills of western South Dakota (O'Connor and Driscoll, 2007);

2. Assessing inundation hazards to nuclear powerplant sites using geologically extended histories of riverine floods, tsunamis, and storm surges (O'Connor and others, 2014);
3. Prehistoric floods on the Tennessee River-Assessing the use of stratigraphic records of past floods for improved flood-frequency analysis (Harden and O’Connor, 2017; see example 5 sidebar);

4. Regional interdisciplinary paleoflood approach to assess extreme flood potential (Jarrett and Tomlinson, 2000); and

5. Paleoflood investigations to improve peak-streamflow regional-regression equations for natural streamflow in eastern Colorado, 2015 (Kohn and others, 2016).

\section{Level 2 Paleoflood Analysis and Review}

Level 2 analyses generally aim to improve floodfrequency and magnitude estimates beyond those of a Level 1 study for a specific location, site hazard assessment, or hydroclimate analysis. Data from the Level 1 study are applied and expanded to better develop and ascertain flood scenarios and dates. Level 2 studies involve a multidisciplinary team ( $2-5$ persons) and one or more field campaigns to investigate paleoflood evidence at multiple sites on a single reach or multiple reaches of a river (table 7). Level 2 studies involve a team (2-3 persons) of geologists/geomorphologists investigating multiple sites (about 4-8 sites) at multiple elevations where flood deposits have been preserved on a single reach or multiple reaches. The stratigraphy of each site is described and recorded. Flood chronologies are supported by numerical dating, such as radiocarbon or OSL methods. To reduce uncertainty in the flood chronology, multiple geochronologic analyses per site (with replication) are used to constrain flood ages (fig. 26). Botanical analyses typically are based on systematic sampling of dozens of trees. The elevation of all floodevidence or non-exceedance bounds are surveyed using RTKGPS or methods with similar accuracy. Vertical error should be kept to a minimum $(<0.5 \mathrm{~m}$ if possible). Sophisticated flow calculations, such as step-backwater or 2D hydraulic modeling using high-resolution $(<1-\mathrm{m})$ topographic data (site or channel surveys, lidar, structure-from-motion) support hydraulic modeling to determine discharges associated with flood evidence or non-exceedance bounds. Hydraulic modeling results should account for uncertainty in the flood evidence; be quantified, at a minimum, by sensitivity analyses; and include model uncertainties (channel geometry data, roughness coefficient, boundary conditions, model calibration). Available historical flood information is gathered from archival evidence. Flood-frequency analyses incorporate gaged, historical, and paleoflood information, including flow intervals, identification of perception thresholds, and (or) non-exceedance bounds. Multiple flood scenarios encompassing the stratigraphic and hydraulic uncertainties are helpful to determine the sensitivity of the flood-frequency analysis to possible errors in stratigraphic interpretation, flood correlations, and discharge estimate uncertainties. 


\section{Example 5-Level 1 Example-Tennessee River near Chattanooga, Tennessee}

The Nuclear Regulatory Commission and U.S. Geological Survey cooperated on a Level 1 scoping study to assess the potential for paleoflood studies to improve estimates of the magnitude and frequency of past large floods on the Tennessee River near Chattanooga, Tennessee (fig. Ex5.1; Harden and O'Connor, 2017). The objectives of this study were to evaluate the presence and preservation of paleoflood deposits along the Tennessee River and the feasibility and necessary scope of a comprehensive paleoflood study that could potentially lead to measurably better estimates of flood risk-particularly for rare and large floods. The first objective, and one of the reasons that the Tennessee River was selected for this analysis, was to evaluate if deposit preservation and identification is possible in high-humidity environments (most paleoflood studies have been conducted in more arid environments), particularly because of the preponderance of nuclear power plants in the Eastern United States.

\section{The Tennessee River Gorge study area was selected for this study} because its stable bedrock

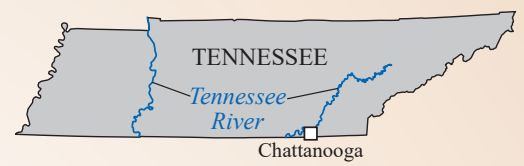
boundary constrains channel topography (fig. Ex5.2A), which provides well-defined and stable cross sections for hydraulic modeling. Large boulders (fig. Ex5.2B), bedrock ledges, alcoves, and small caves are present at multiple elevations along the Tennessee River Gorge, and in other locations where the channel narrows. Typically, these features can preserve paleoflood deposits for thousands of years. However, it was initially unclear if the high rates of bioturbation from dense vegetation, insects, and burrowing animals in the humid climate would obscure contacts between deposits. This study confirmed adequate preservation of flood deposits and that radiocarbon and optically stimulated luminescence (OSL) dating were viable geochronologic techniques for the Tennessee River.

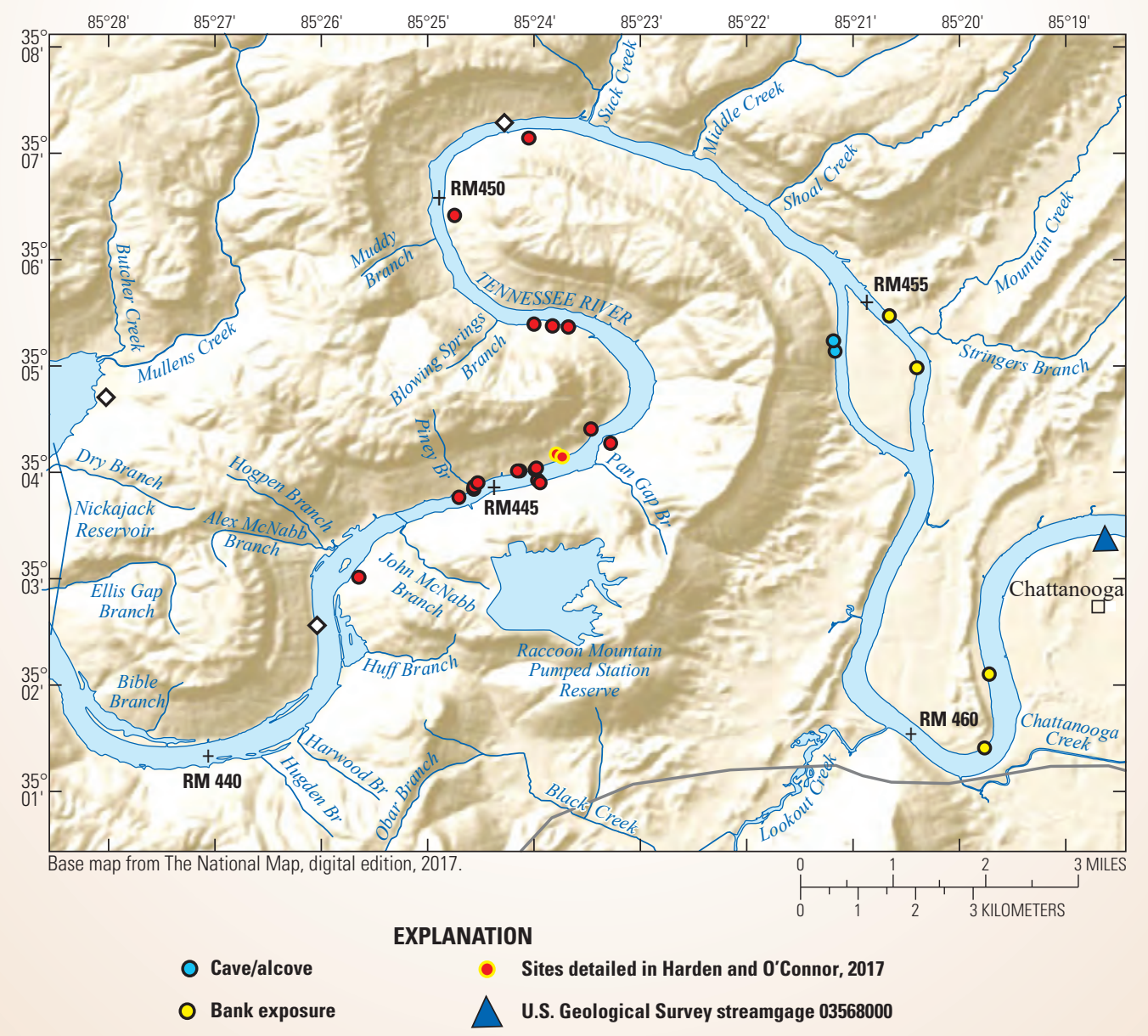

$\diamond$ Historical high-water mark

RM 440+ River mile

O Boulder shelter
Figure Ex5.1. Paleoflood feasibility study area on Tennessee River near Chattanooga, Tennessee, showing types of locations where flood deposits are preserved. Modified from Harden and O'Connor (2017). 

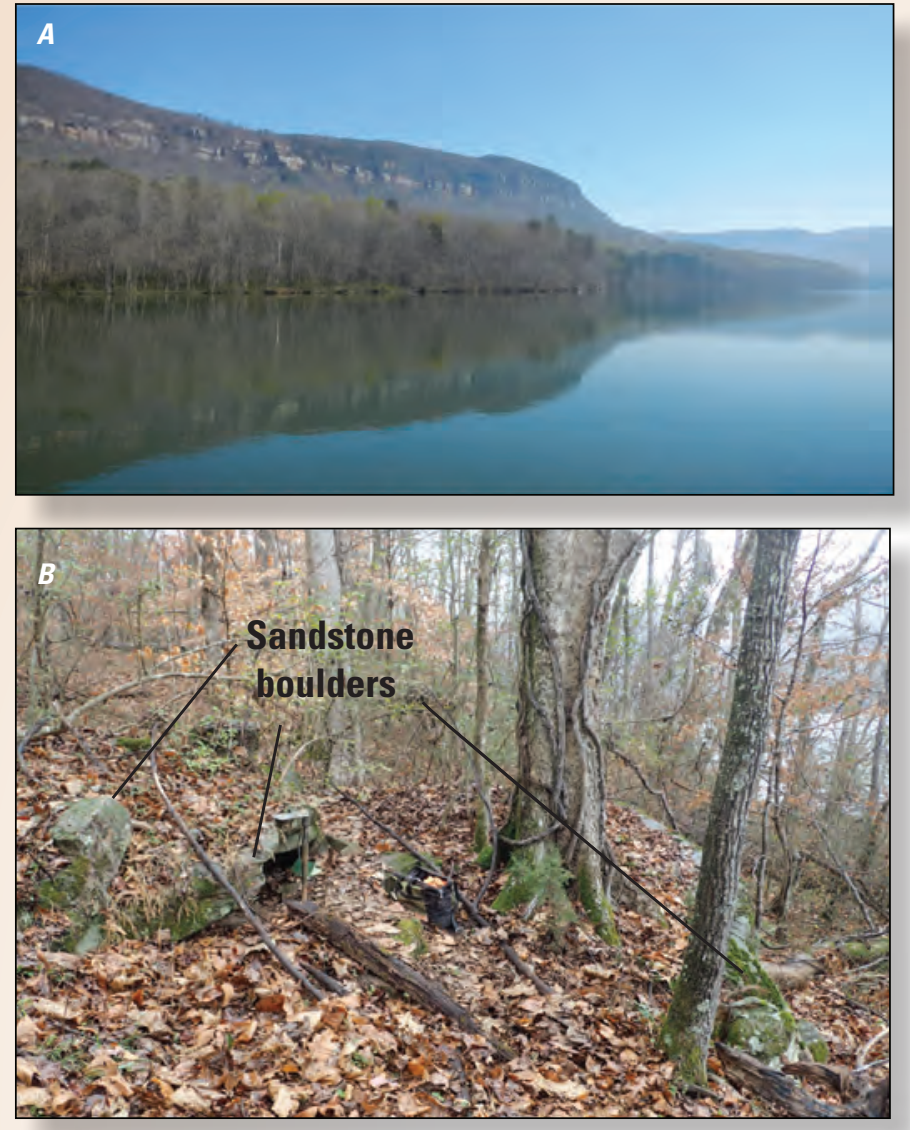

Figure Ex5.2. Bedrock cliffs $(A)$, slopes with colluvial boulders $(B)$, and pit exposure of a silty flood deposit surrounded by sandier local material $(C)$, on the Tennessee River Gorge of the Tennessee River near Chattanooga, Tennessee. Photographs by Tessa M. Harden, U.S. Geological Survey.

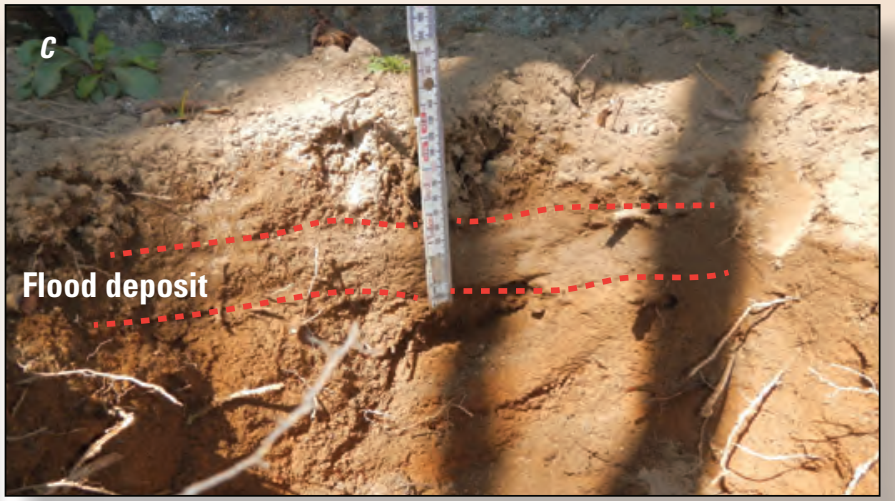

Results from two radiocarbon and three OSL analyses indicated that flood chronologies extended back more than 3,000 years using radiocarbon and 9,000 years using $0 S L$. The stage-discharge rating curve extrapolated from the largest historical and gaged floods was used to estimate the magnitude of the highest paleoflood deposits (fig. Ex5.3). These added data indicated that the largest flood on the Tennessee River near Chattanooga was more than twice as large as the 1867 historical peak that flooded much of the town of Chattanooga by several feet. This study, although a scoping study in nature, indicated that a comprehensive paleoflood study was feasible for the Tennessee River and that these methods likely would be applicable for many other areas of the humid Eastern United States. Additionally, the evidence of the exceptional flood preserved in the stratigraphic record indicated that paleofloodbased analyses likely would significantly improve the understanding of large and rare floods on the Tennessee River.

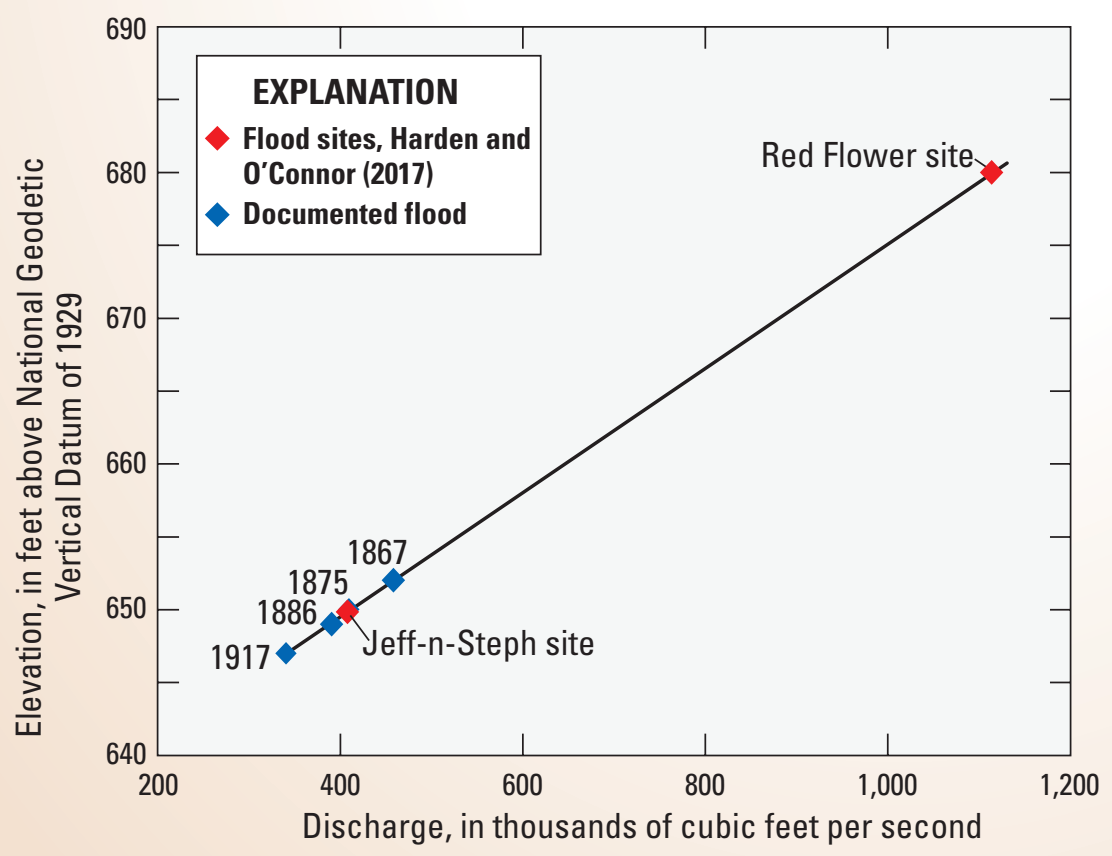

Figure Ex5.3. Largest documented floods (diamonds with only dates beside them) used to estimate magnitude of largest paleofloods (Jeff-n-Steph and Red Flower site diamonds) on the Tennessee River near Chattanooga, Tennessee. From Harden and O'Connor (2017). 


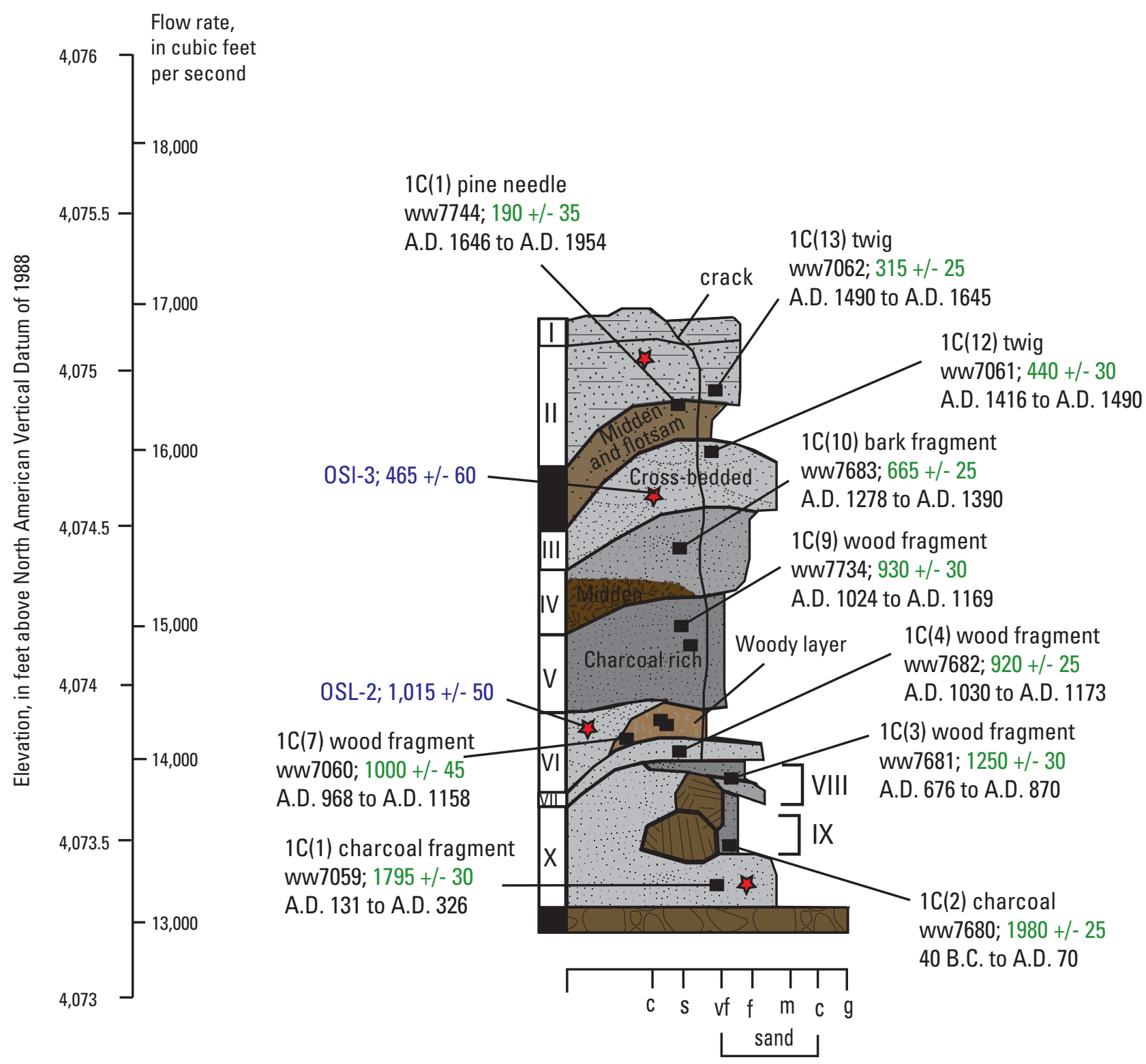

\section{EXPLANATION}

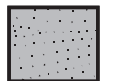

Boxelder Creek flood deposit

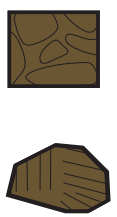

Rooffall and large rounded river cobbles

Local angular rooffall clasts Boxelder Creek flood deposit

Charcoal rich Boxelder Creek flood deposit

\section{Flood unit}

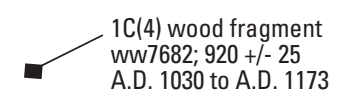

Radiocarbon samplelaboratory number (if analyzed), and analysis results

OSL sample - Result in years before present (if analyzed)

Figure 26. Schematic diagram showing stratigraphy, multiple dating methods, redundant dating of key units, and elevation of deposits in relation to discharge at Kitty's Corner pit C on Boxelder Creek, South Dakota. Modified from Harden and others (2011). See example 7 sidebar (Black Hills example) for more details of the study. 
If feasible, Level 2 studies may be guided by a small technical steering committee composed of subject-matter experts and stakeholders who can assist with project scoping and offer guidance in the initial planning stages of the paleoflood study. In-progress review may be overseen by a technical steering committee. Level 2 studies typically involve an in-field site visit by peer reviewers of the benchmark sites and accompanying interpretations. Care should be taken during the field campaign to preserve benchmark sites for the field review. Accurate, detailed record-keeping (field notes and interpretations, photographs, laboratory analyses, survey data) is particularly important if field review is limited.

Technical review of the final report for a Level 2 study typically involves a team of independent experts, including scientists and engineers with knowledge of study components (stratigraphy, dendrochronology, hydraulics, flood-frequency analysis). Comprehensive record-keeping (including field notes, photographs, and laboratory analyses) will aid the technical review.

Examples of Level 2 studies include the following:

1. Improving flood-frequency analysis with a 4,000-year record of flooding on the Tennessee River near Chattanooga, Tennessee (Harden and others, 2021);

2. Holocene paleoflood hydrology of the Lower Deschutes River, Oregon (Hosman and others, 2003; see example 6 sidebar); and

3. Paleoflood study on the Rio Chama near El Vado Dam, New Mexico (Godaire and Bauer, 2013).

\section{Level 3 Paleoflood Analysis and Review}

Level 3 studies are the most comprehensive. They typically support regional and site-specific flood-frequency and magnitude estimates to address broad flood-hazard or hydroclimate issues, large-scale flood risk management or transportation plans, or they may support review, siting, design, or retrofits of critical infrastructure such as dams, levees, and nuclear power plants. Level 3 studies also may be supported by or done in support of regional hydroclimate analyses to confirm reach- and basin-specific conclusions.

Project components for a Level 3 study include those associated with a Level 2 analysis - rigorous development of stratigraphic records, systematic surveys and analysis of botanical flood evidence, historical flood research, hydraulic modeling, and flood-frequency analysis involving all available information (systematic, historical, and paleo) including perception thresholds and non-exceedance bounds. Level 3 studies, however, generally are larger in geographic scale than Level 2 studies and involve multiple river reaches and possibly multiple river basins, and they are done for projects with substantial safety or economic consequences. A typical Level 3 study will involve a team of geologists/geomorphologists (2-4 persons), surveyors (1-2 persons), hydraulic modelers (1-2 persons), and a flood-frequency analyst. A Level 3-focused study will entail multiple field visits to identify deposits in the field, describe and report stratigraphy, and survey all flood evidence L RTK-GPS (vertical accuracy $<0.5 \mathrm{~m}$, if possible) or similar methods. If botanical evidence is used, dozens of trees and multiple stands are examined and recorded. Multiple numerical age-dating methods are used to establish flood chronology with redundant analyses of key deposits (fig. 26). Paleoflood sites on multiple reaches of a river are common and typically sites of stratigraphic investigation number $8-20$. The most comprehensive Level 3 studies will involve multiple sites on multiple rivers (for example, Harden and others, 2011).

As with Level 2 studies, sophisticated flow calculationssuch as step-backwater or 2D hydraulic modeling using highresolution $(<1-\mathrm{m})$ topographic data (site or channel surveys, lidar, structure-from-motion) - are used in Level 3 studies to determine discharge estimates associated with flood evidence and perception thresholds or non-exceedance bounds. Hydraulic modeling results should account for uncertainty estimates identified by sensitivity analyses and include model uncertainties (channel geometry data, roughness coefficient, boundary conditions, model calibration), as well as those deriving from uncertainties in the PSIs (elevation uncertainty, correlations between floods). Flood-frequency analyses incorporate gaged, historical, and paleoflood information, including flow intervals, perception thresholds, or nonexceedance bounds. Multiple flood scenarios encompassing the stratigraphic and hydraulic uncertainties (number of floods, correlation between floods, paleoflood-discharge estimates, range of possible discharge values associated with perception thresholds) are used to determine the sensitivity of the floodfrequency analysis to possible errors in stratigraphic interpretation or discharge estimates from the hydraulic modeling. Many Level 3 studies will include rigorous uncertainty assessments and sensitivity analyses encompassing all aspects of the paleoflood analysis, including PSIs, geochronology, hydraulic and statistical model analyses, and underlying assumptions.

The planning and review processes for Level 3 studies typically are more intensive than they are for the other 2 levels of study because of their large scope, cost, and safety consequences, especially for studies assessing hazards to critical facilities. For Level 3 reviews, a technical steering committee composed of national and (or) international subject-matter experts and stakeholders may be assembled during the initial planning stages of the project. Such a technical steering committee can offer specific guidance and help with project scoping and determination of formal reporting standards and datapreservation requirements. The technical steering committee also may conduct in-process reviews and field inspections at benchmark sites. Final technical reviews will be conducted by an established and independent team of experts for all study components (stratigraphy, dendrochronology, hydraulics, flood-frequency analysis). The final technical reviews also may involve a field review at the key sites. 


\section{Example 6-Level 2 Example—Lower Deschutes River, Oregon}

A Level 2-type study was completed in 2003 on the Deschutes River in north-central Oregon (fig. Ex6.1; Hosman and others, 2003) with the objective of determining the magnitude and frequency of late Holocene flooding and using that information to better inform a flood-frequency analysis. The stratigraphy at four sites along the lower Deschutes River was examined in detail in the field. The overall flood chronologies were different between sites, but all sites contained evidence of the largest floods in the last 5,000 years. A U.S. Army Corps of Engineers Hydrologic Engineering Center River Analysis System one-dimensional hydraulic model developed for this study was used to model discharges associated with individual floods at two benchmark sites (figs. Ex6.2-Ex6.3). These sites contained the longest and most complete record or large floods on the Deschutes River.

The paleoflood data, age estimates, and associated discharge interval estimates, were combined with the systematic record associated with USGS streamgage 14103000 (adjusted to remove the effects of regulation) to calculate long-term flood frequency. Flood-frequency calculations were based on maximum likelihood analysis with a Bayesian approach (0'Connell and others, 2002). This approach allows for the specification of the uncertainty of the magnitude and nonexceedance bounds of the paleofloods as well as uncertainty in flood magnitudes from the systematic record.

For this study, three paleoflood scenarios were developed based on the paleoflood data and were considered to help understand uncertainties in the stratigraphic record leading to the overall flood chronology. For the most plausible scenario, compared to analysis of the gage record alone, incorporating the paleoflood information increases flood quantile estimates by about 15-30 percent for rare, low annual exceedance probability floods. Perhaps more importantly, the paleoflood data significantly narrowed the confidence intervals for the rare floods compared to the gage record alone (fig. Ex6.4). This study also highlights the increased benefit and confidence in flood-frequency analysis gained from examining multiple sites in a paleoflood analysis.

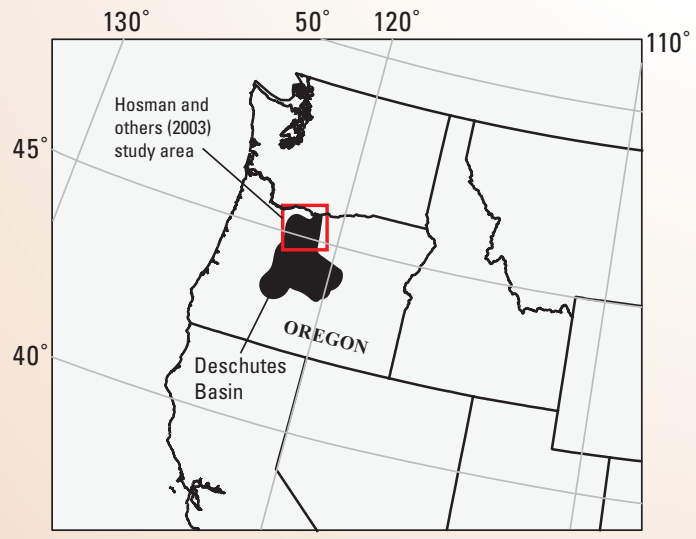

Figure Ex6.1. Location of Hosman and others (2003) paleoflood study and Deschutes River Basin, Oregon.

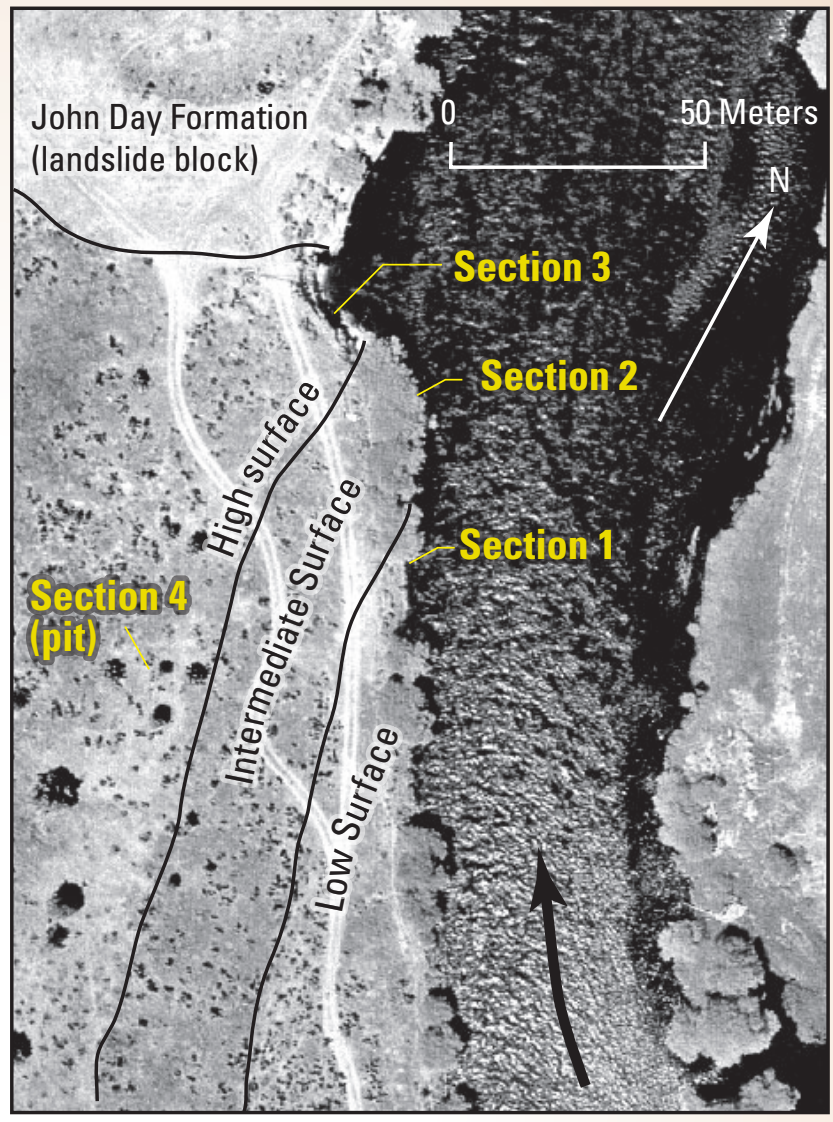

Figure Ex6.2. Axford study site, one of the two sites used in the flood-frequency analysis, showing three distinct surfaces composed of fine-grained slack-water deposits and sites of detailed stratigraphy (sections 1-4) described in Hosman and others (2003), Deschutes River Basin, Oregon. Flow is to the northwest.

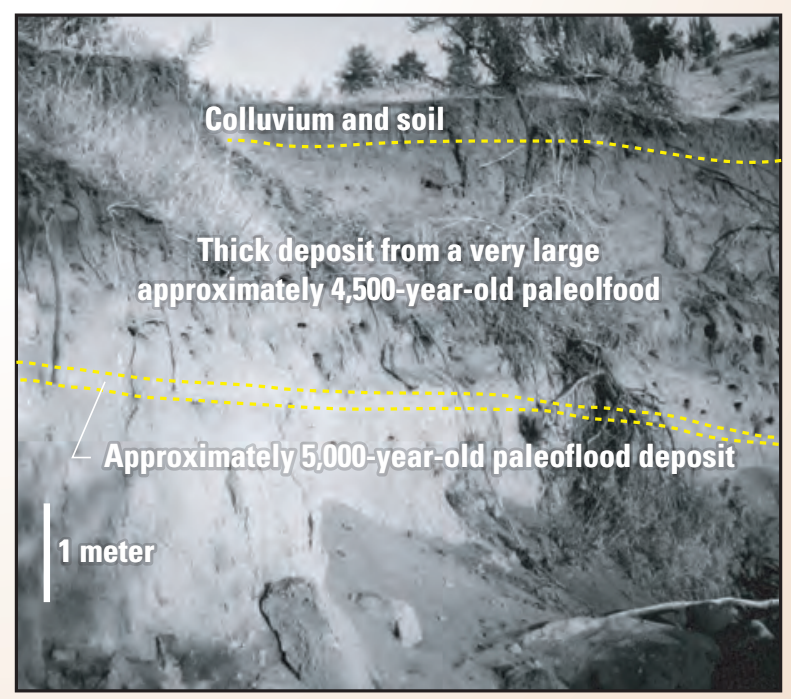

Figure Ex6.3. Section 3 of the Axford site showing two paleoflood deposits capped by colluvium and soil, Deschutes River Basin, Oregon. Modified from Hosman and others (2003). 


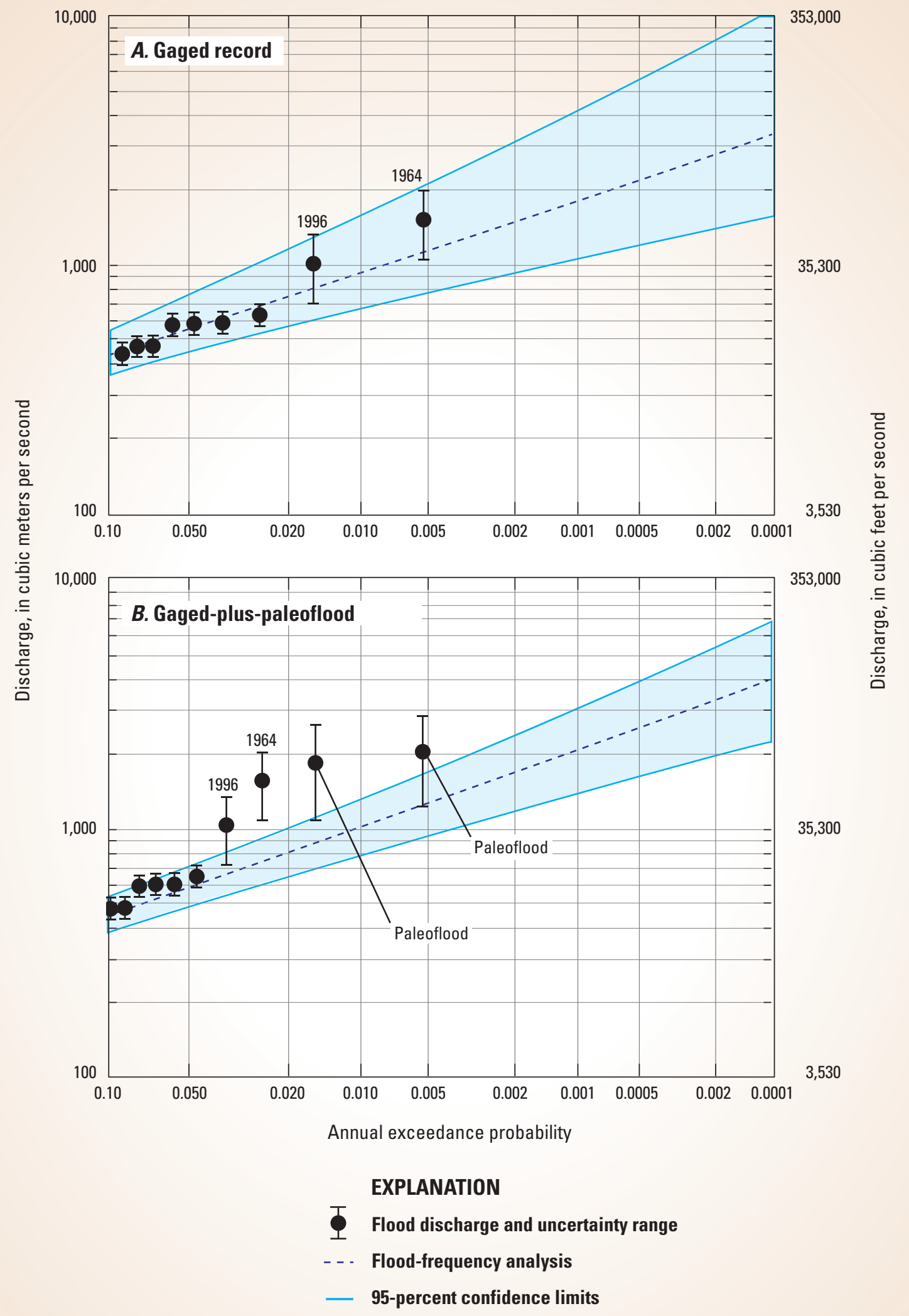

Figure Ex6.4. Flood-frequency curve of $(A)$ gaged-only record and $(B)$ gaged-plus-paleoflood record for the Deschutes River near the confluence with the Columbia River, Oregon. Modified from Hosman and others (2003). 
Examples of Level 3 studies include the following:

1. Flood-frequency analyses from paleoflood investigations for Spring, Rapid, Boxelder, and Elk Creeks, Black Hills, western South Dakota (Harden and others, 2011);

2. Flood-hazard analysis for Seminoe and Glendo Dams, Kendrick and North Platte Projects, Wyoming (Levish and others, 2003); and

3. Paleoflood-discharge reconstruction in Tatra Mountain streams (Ballesteros-Cánovas and others, 2016).

\section{Documentation and Reporting}

As for most science and engineering analyses, complete reporting of the foundational data and analyses of any floodfrequency study is essential, whether it involves paleoflood, historical, or systematic observations. Such reporting ensures repeatability, facilitates technical review, and enables reanalysis if new techniques and data become available. Reporting requirements for the typical components of a paleoflood analysis (including stratigraphy, discharge estimation, and geochronology) are likely to be similar for all study levels. For example, stratigraphic descriptions typically include location; site photographs; depth of exposure or pit; and details of stratigraphy including grain size, color, bedding features, sorting, and presence of organics, regardless of the study level. However, there will be less documentation for Level 1 studies compared to Level 3 studies because Level 1 studies involve fewer sites. Documenting all necessary site and stratigraphic or botanical information, analysis steps, laboratory analyses and results, modeling approaches, and associated uncertainty; and identifying assumptions allow for study transparency and more thorough and objective review.

The following is a list of information that typically would be documented and available for review in a paleoflood study of any level although all components might not be included at all levels. (Recommended information to include in paleoflood analyses is summarized in table 8.)

1. Site information analyses including general or geomorphic locations and nature of flood evidence, photographs, permit information, physical description of site and river reach.

2. Stratigraphic descriptions (deposit thickness, color, grain size, sorting, mineralogy, gravel content, structure, organic content, unit contacts, etc.), and site and stratigraphy photographs and (or) figures.

3. Locations of any tree-ring samples and machine-readable files of all tree-ring data.

4. Elevations and location of sites and methods of determination (hand level, total stations, RTK-GPS, etc.), including vertical and horizonal accuracy and datums.
5. Geochronology information including techniques and methods, stratigraphic and geographic location of the samples collected, sample material type, name of laboratory used to analyze the sample, and all raw measurements and calculation values.

6. Topographic data collection procedures for determinations of site elevations and hydraulic computations. Full documentation is appropriate in cases where adjustments are necessary to account for historical or prehistoric changes to channel and floodplain geometry or conditions.

7. Methods and underlying data used for flow estimation, including roughness coefficients, initial boundary conditions, or grain-size data for end-member modeling, and all associated uncertainties; documentation of model calibration procedures and results if using a hydraulic model. In many instances, it may be appropriate to include the hydraulic model or the data so that they could be rerun with the final report.

8. Range of flows (flow intervals) for each paleoflood and perception threshold or non-exceedance bound and time intervals within detection limits; includes uncertainty and justification of assigned flow ranges.

9. Flood-frequency analyses (when appropriate), including documentation of software; input data including paleo, historical, and gaged data; perception thresholds; interval information; and uncertainties. Documentation of methods for any adjustments to gaged flow data owing to regulation or drainage area.

10. Sufficient level of documentation to reproduce the flood-frequency results. For example, a description of the source of systematic streamgage records, as well as historical and paleoflood estimates.

11. Period of record, effects of any land-use changes, decisions regarding choice of flow intervals and perception thresholds, skew, record-extension methods, methods of combining two or more gage records, and any lowflow tests.

12. Comparisons of AEP estimates of flood quantiles to previously published estimates to understand the effect of the paleoflood data on the estimates. This information typically is not required in Level 1 studies.

The flood-frequency analyses may apply the initial data analyses described, including checking for autocorrelation, trends, and change points (or sudden shifts in the distribution). In 2020, there are no commonly accepted guidelines for how to conduct flood-frequency analysis in the presence of autocorrelation, trends, or change points; however, the implications may be discussed. 
Table 8. Suggested documentation for paleoflood analyses.

[Description: HWMs; high-water marks]

\begin{tabular}{|c|c|}
\hline Documentation type & Description \\
\hline \multicolumn{2}{|r|}{ Paleoflood study attributes } \\
\hline Site information & $\begin{array}{l}\text { Level 1: } \\
\text { Location and description of study area, map of area, simplistic description of hydrology, geomorphology and } \\
\text { geology of study area; stream/river length, slope, sinuosity, location (survey or Global Positioning System), } \\
\text { photograph or site sketch, comments. If using previously published regional paleoflood information, not all } \\
\text { information may be available. } \\
\text { Level 2: } \\
\text { Basin level: Location and description of study area, maps, lidar, existing inundation maps/models, land-use } \\
\text { maps, soil maps, general description of hydrology, geomorphology and geology of study. } \\
\text { Reach level: Reach location, photographs, stream information (width, confined or unconfined, slope, etc.), gen- } \\
\text { eral description of local geomorphology and geology. } \\
\text { Site level: Location data, surveying of landmark to link to lidar or aerial photography, aspect, land-cover, photo- } \\
\text { graphs, site sketch or annotated map, comments or observations. } \\
\text { Level 3: } \\
\text { Similar to Level 2, except for multiple basins and sites. Documentation may need to be standardized across } \\
\text { many field teams and simplified for tabulation. }\end{array}$ \\
\hline Botanical & $\begin{array}{l}\text { Level 1: } \\
\text { Trees: Species, condition, record of locations, scar location and height; may include limited cores or slabs at } \\
\text { chest height, observations and locations for recent HWMs, notes. } \\
\text { Levels } 2 \text { and 3: } \\
\text { Trees: Species, condition, sketches, photographs or annotated maps and locations of geomorphic and geo- } \\
\text { graphic positions (distance from trees to locations with respect to the thalweg, channel, bank, floodplain; straight } \\
\text { reaches, inside or outside bend, exposure), equipment and precision for distances and elevation, description of } \\
\text { geological characteristics, observations and locations for recent HWMs, notes. } \\
\text { Indicator: Scar or damage height, description, description of observed debris (boulders, woody), skeleton plots, } \\
\text { tilt description, aspect, angle to river, wedge, cross section or core location and elevation, photograph, equip- } \\
\text { ment used, comments. } \\
\text { Burial study information: Sediment depth, description, excavation method and details, tree species, condition, } \\
\text { slab locations, elevations and methods, method to link information with stratigraphic exposure, stratigraphic } \\
\text { information from exposure as above. }\end{array}$ \\
\hline
\end{tabular}

Geochronology

All levels:

All samples: Dating method, sample location, photograph, schematic diagram with sample location in exposure or core, stratigraphic unit: depth below surface, material, key observations and comments, laboratory results, uncertainty.

Soil development: Note characteristic soils and structures similar to nearby quantitatively dated studies, record: trimlines, soil characteristics, desert pavement, physical weathering of rocks and terraces, and vegetation. Dating anthropogenic evidence, unusual geological evidence.

Tree rings: Preparation methods, equipment, techniques, skeleton plots, criteria for, description of and measurements of growth anomalies, method of statistical evaluation of cross-dating with other samples/trees, software version, inputs and outputs, photographs, uncertainty estimates.

Radiocarbon: Organic material description, photograph, sample location and sampling collection method and storage, dating technique (accelerator mass spectrometry or conventional), results, corrections, uncertainties. Optically stimulated luminescence: Quartz or potassium feldspar, grain size used, measurement method, results, dose rate determination method. 
Table 8. Suggested documentation for paleoflood analyses.-Continued

[Description: HWMs; high-water marks]

Paleoflood study attributes-Continued

\begin{tabular}{ll}
\hline $\begin{array}{l}\text { Source information } \\
\text { for systematic, his- } \\
\text { torical, and other }\end{array}$ & Level 1: \\
existing data & Histematic records: Locations, recording agency, period of record. \\
& Levels 2 and 3: \\
& Systematic as in Level 1, may include more locations, more sources for gages, review of records if adjusted for \\
& regulation, trend tests, descriptions of corrections and raw stage measurements, uncertainty. \\
& Historical site: Source type, qualitative description of fidelity/uncertainty, photograph or reproduction of data, \\
& location, river, flood description, duration, cause, origin of information, meteorology, stage (location, original \\
& measurement, contemporary measurement/adjustment, datums), estimated discharge, description of damage, \\
& observation, comments. \\
& Historical aerial data: Aerial photograph and map dates, source, aspect, reference location, reference informa- \\
& tion. \\
& Existing studies: Reference, locations, time period of record, method of discharge determinations, dating meth- \\
& ods, relevance to current study, uncertainties. \\
\hline
\end{tabular}

Analyses methods and reproducibility

\begin{tabular}{|c|c|}
\hline $\begin{array}{l}\text { Flow estimation } \\
\text { methods }\end{array}$ & $\begin{array}{l}\text { May not conduct in botanical, land-use, or climate information study. } \\
\text { Level 1: } \\
\text { Hydraulic analysis: Equations, assumptions, input data, calibration information, results; modeling (if used), } \\
\text { software/algorithms with version, topography data, aerial photograph, or other geographic information system } \\
\text { layer metadata. } \\
\text { Paleostage indicator elevation estimation: Method, uncertainty, data used for correlation (for example, gage } \\
\text { location, years, events). } \\
\text { Levels } 2 \text { and 3: } \\
\text { Hydraulic model type: Model software and version, equations, and assumptions (full St. Venant, dispersion } \\
\text { wave, standard step, etc.), steady/unsteady flow, boundary conditions, initial conditions. } \\
\text { Model parameters and input/output: Geometric/bathymetric data source and resolution, mesh/section resolution } \\
\text { and development method and (or) software, Manning's } n \text { values and calibration, calibration data and source, } \\
\text { method or optimization routine, input and output files, sensitivity tests. }\end{array}$ \\
\hline $\begin{array}{l}\text { Flood-frequency } \\
\text { (hydraulic hazard } \\
\text { analysis) methods }\end{array}$ & $\begin{array}{l}\text { All Levels (Level } 1 \text { optional): } \\
\text { Flood-frequency analysis: Method, distribution(s), fitting method(s), goodness-of-fit or similar analyses, inter- } \\
\text { vals data, perception thresholds, outlier detection methods and identification, confidence intervals, software and } \\
\text { version, input and output files. }\end{array}$ \\
\hline $\begin{array}{l}\text { Uncertainty and non- } \\
\text { stationarity records } \\
\text { and methods }\end{array}$ & $\begin{array}{l}\text { All levels: } \\
\text { Uncertainty: Equipment measurement errors, method uncertainty estimates, test results, sensitivity analysis, } \\
\text { scenario analysis for model uncertainties or uncertainties not propagated through models. } \\
\text { Stationarity: Tests (for example, initial data analysis in England and others, 2018), land-use records, existing } \\
\text { local analyses, and evidence of aggradation/degradation. }\end{array}$ \\
\hline $\begin{array}{c}\text { Comparison with } \\
\text { other analyses }\end{array}$ & $\begin{array}{l}\text { All levels (when available): } \\
\text { References, comparative methods and metrics, results. }\end{array}$ \\
\hline
\end{tabular}




\section{Example 7-Level 3 Example-Black Hills, South Dakota}

A comprehensive paleoflood study in the eastern Black Hills, South Dakota (fig. Ex7.1), was initiated as a result of the region's high flood risk, expanding transportation infrastructure, and increasing pressure to develop flood-prone locations (Harden and others, 2011). Widespread flooding in June 1972 killed at least 238 people, indicating a considerable local flood hazard. The occurrence of the 1972 flood, coupled with the need for improved transportation infrastructure to accommodate the growing population and substantial pressure to develop the floodplain in Rapid City highlighted the need for more reliable flood-hazard assessments. Despite a gaged and historical flood record going back at least 60 years for most of the larger streams in the region, the 1972 flood is an outlier in a gaged record (fig. Ex7.2) that does not serve as a reliable basis for estimating flood frequency.

Multiple field visits to systematically identify and describe paleoflood deposits were conducted over a period of 3 years. The main project team consisted of three geomorphologists and an engineer. Additionally, a surveyor, two geochronologists, and two flood-frequency experts provided substantial project support.

Stratigraphic records at 29 individual study sites on four streams in four different basins (six total reaches) - supported by 99 radiocarbon, $11 \mathrm{OSL}$, and four ${ }^{137} \mathrm{Cs}$ age determinationsindicate multiple paleofloods during the last 2,000 years, some as large as, or larger than, the 1972 flood as indicated by deposit elevation and results from the hydraulic modeling (fig. Ex7.4). When combined with the

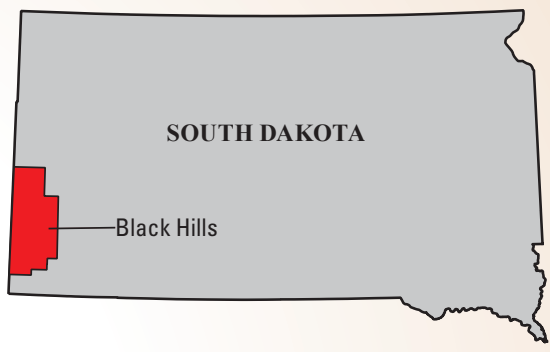
systematic and historical record in a flood-frequency analysis, the paleoflood data reduced the uncertainty in magnitude of large events with low annual exceedance probabilities on streams in the eastern Black Hills by as much as 99 percent (Harden and others, 2011).

This project was guided by a technical steering committee composed of engineers and decision-makers from the South Dakota Department of Transportation, the main stakeholder agency. The technical committee visited and reviewed key sites in the field (fig. Ex7.5). Several additional field trips to inspect and discuss key sites in each basin were taken by outside experts. Review of all documents generated in this project followed U.S. Geological Survey (USGS) protocol, with additional review by project component specialists. For example, the flood-frequency analysis underwent additional review by internal (USGS) and external (non-USGS) experts. 


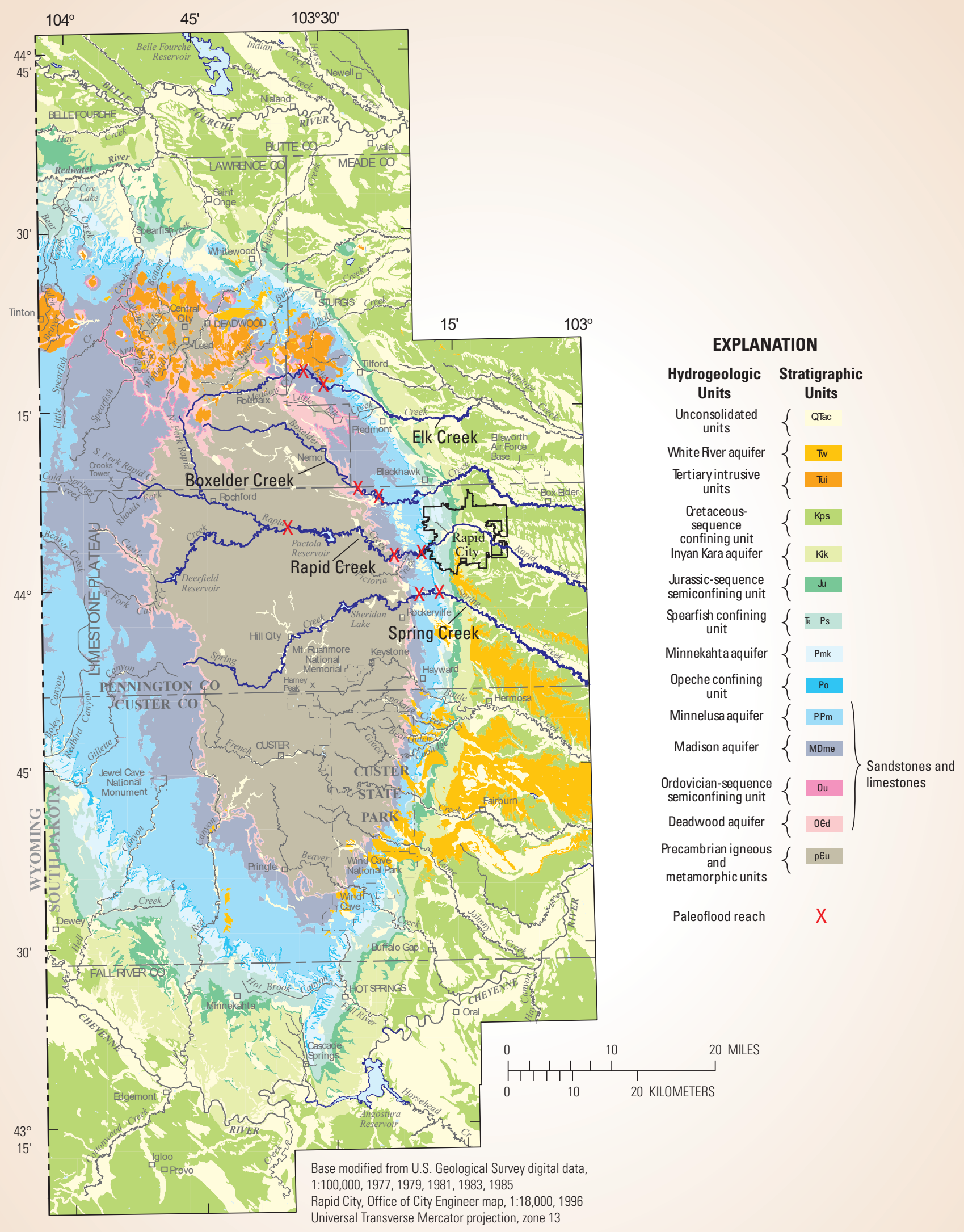

Figure Ex7.1. Hydrogeological units and paleoflood reaches of the Black Hills, South Dakota (modified from Strobel and others, 1999; and Harden and others, 2011). 


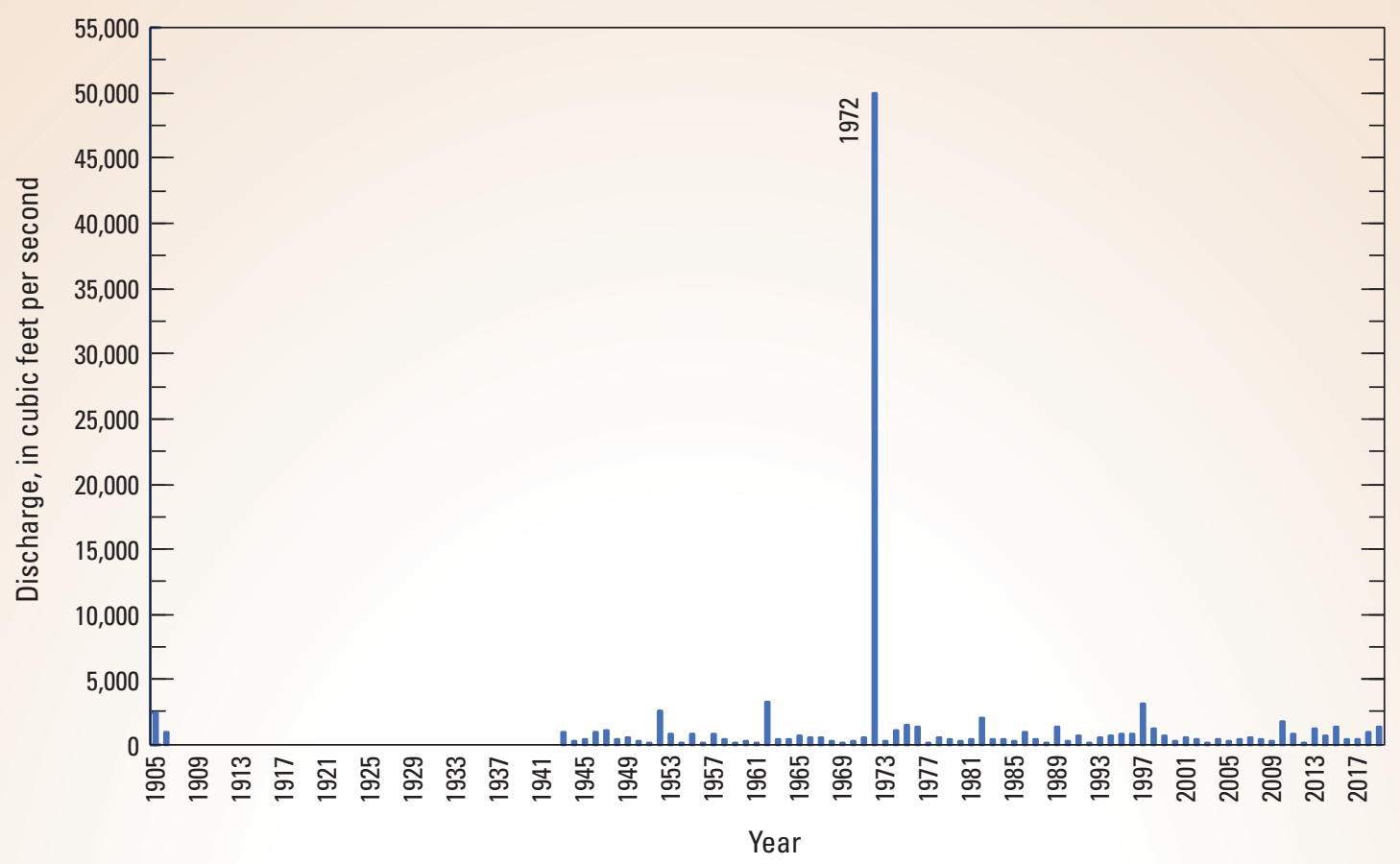

Figure Ex7.2. Discharge at U.S. Geological Survey streamgage 06414000, Rapid Creek at Rapid City, Black Hills, South Dakota, 1905-2020. The 1972 flood of record is more than an order of magnitude larger than any other peak in the systematic record.

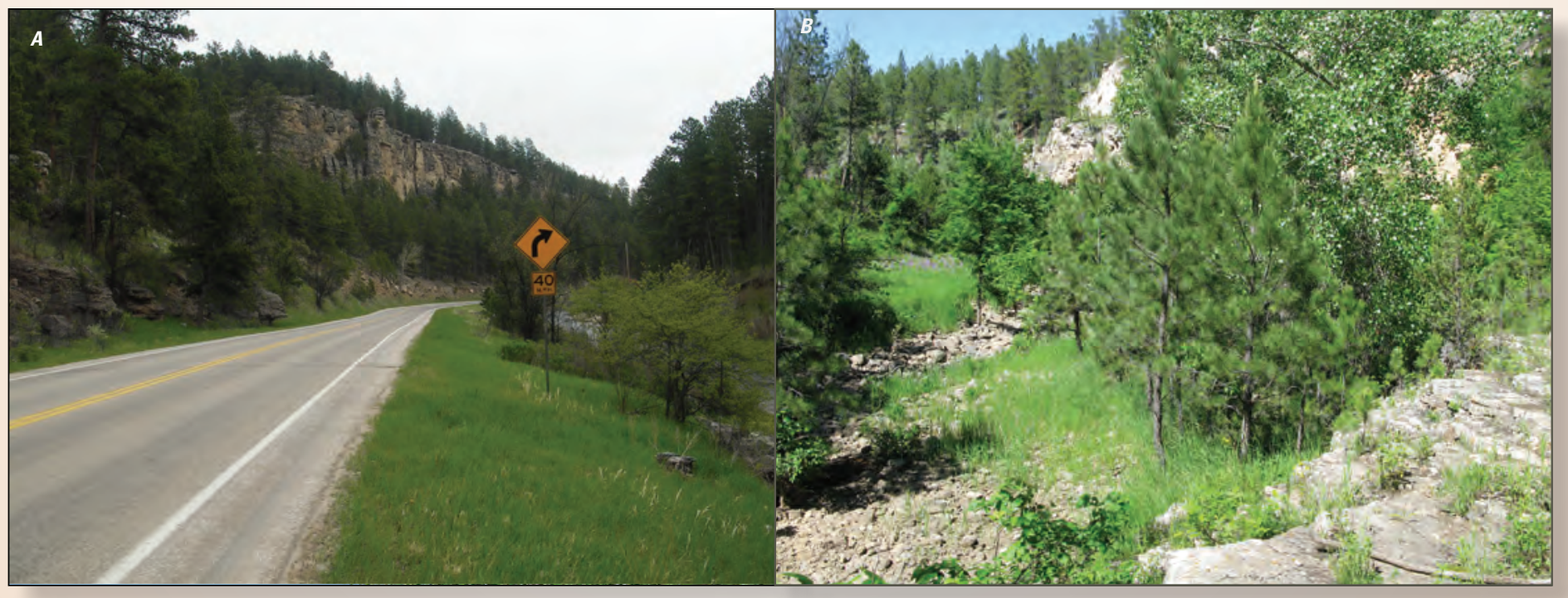

Figure Ex7.3. View looking downstream in limestone canyons of upper $(A)$ and lower $(B)$ Boxelder Creek, Black Hills, South Dakota. Photographs by Jim O'Connor, U.S. Geological Survey. 

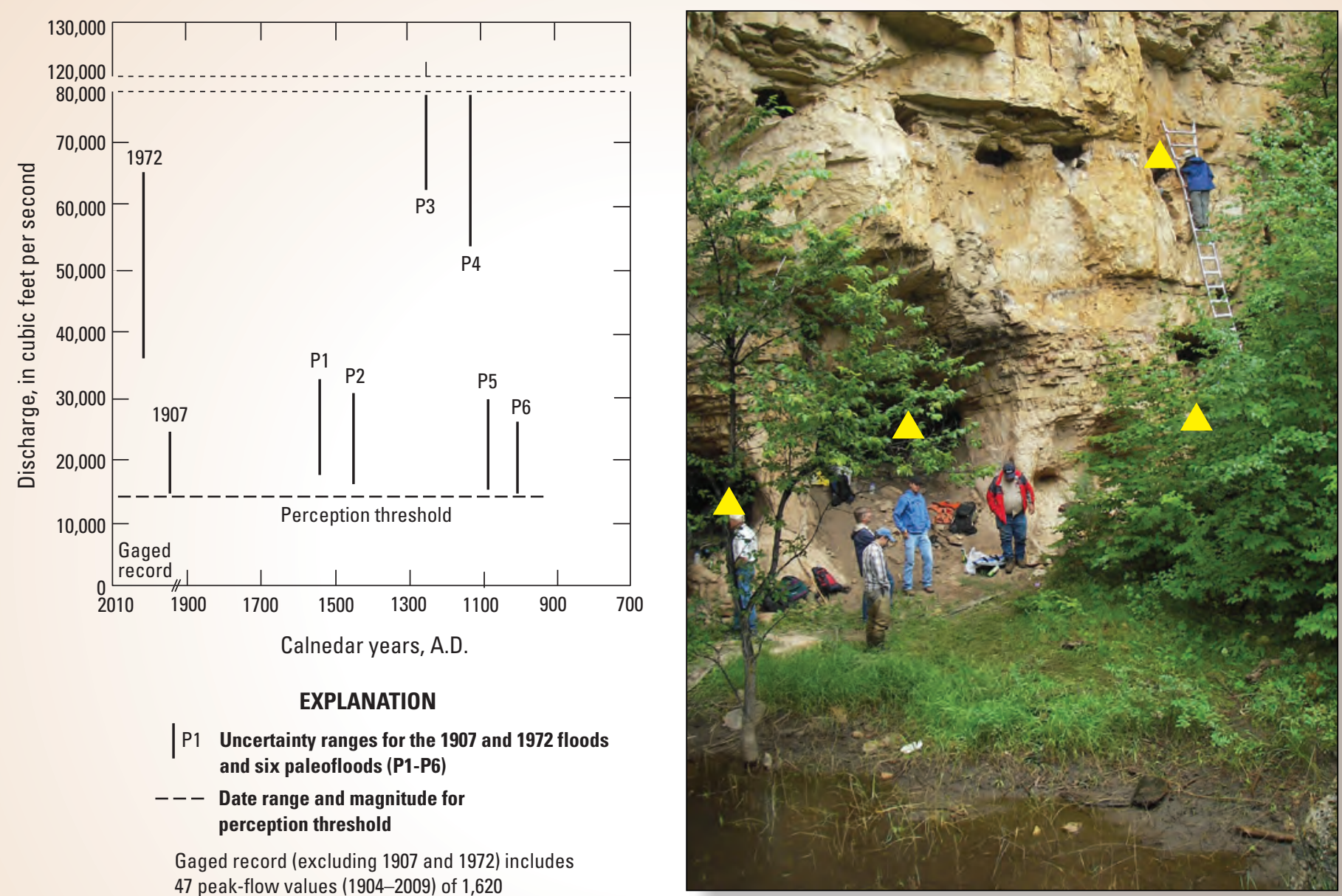

47 peak-flow values (1904-2009) of 1,620

cubic feet per second or smaller

Figure Ex7.4. Overall reach chronology of Lower Boxelder Creek, South Dakota, since about A.D. 700. Graph indicates six paleofloods, one perception threshold, and two large floods in the systematic record, including the large 1972 flood, along with uncertainty in disFigure Ex7.5. Technical committee members visiting key paleoflood sites (triangles) in the Black Hills, South Dakota paleoflood study. Paleoflood sites are from Harden and others (2011). Photograph by Jim O'Connor, U.S. Geological Survey. charge for all floods. 


\section{References Cited}

Aalto, R., and Nittrouer, C.A., 2012, 210Pb geochronology of flood events in large tropical river systems: Philosophical Transactions of the Royal Society A-Mathematical, Physical, and Engineering Sciences, v. 370, no. 1966, p. 2040-2074.

Advisory Committee on Water Information, 2018, Flood frequency resources-Data sources for flood frequency analysis, accessed April 18, 2019, at https://acwi.gov/hydrology/ Frequency/b17c/supplementary-materials/date-sources.html.

Aldridge, B.M., and Garrett, J.M., 1973, Roughness coefficients for stream channels in Arizona: U.S. Geological Survey Open-File Report 73-3, 87 p., https://doi.org/ $10.3133 /$ ofr 733 .

Alestalo, J., 1971, Dendrochronological interpretation of geomorphic processes: Fennia, v. 105, no. 1, p. 1-140.

Ali, A.M., Di Baldassarre, G., and Solomatine, D.P., 2015, Testing different cross-section spacing in 1D hydraulic modelling - A case study on Johor River, Malaysia: Hydrological Sciences Journal, v. 60, no. 2, p. 351-360, https://doi.org/10.1080/02626667.2014.889297.

Aitken, M.J., 1998, An introduction to optical dating-The dating of quaternary sediments by the use of photonstimulated luminescence: Oxford, United Kingdom, Oxford University Press, $280 \mathrm{p}$.

Arcement, G.J., Jr., and Schneider, V.R., 1989, Guide for selecting Manning's roughness coefficients for natural channels and flood plains: U.S. Geological Survey Water-Supply Paper 2339, 38 p.

Archer, D.R., 2010, Applying historical information to flood risk assessment in northeast England, British Hydrological Society Third International Symposium-Managing consequences of a changing global environment, Newcastle, United Kingdom, July 19-23, 2010: British Hydrological Society, $6 \mathrm{p}$.

Arnold, L.J., Roberts, R.G., Galbraith, R.F., and DeLong, S.B., 2009, A revised burial dose estimation procedure for optical dating of young and modern-age sediments: Quaternary Geochronology, v. 4, no. 4, p. 306-325.

Asquith, W.H., Kiang, J.E., and Cohn, T.A., 2017, Application of at-site peak-streamflow frequency analyses for very low annual exceedance probabilities: U.S. Geological Survey Scientific Investigations Report 2017-5038, 93 p., accessed December 2019, at https://doi.org/10.3133/sir20175038.
Astrade, L., and Bégin, Y., 1997, Tree-ring response of Populus tremula L. and Quercus robur L. to recent spring floods of the Saône River, France: Ecoscience, v. 4, no. 2, p. $232-239$.

Bahner, C., and Duren, A., 2019, Hydrologic risk analyses for Willamette River Basin dams, in Proceedings of the SEDHYD 2019 Conference on Sedimentation and Hydrologic Modeling (session 7B, Extreme floods and droughts II), June 24-28, 2019, Reno, Nevada: Federal Interagency Sedimentation and Hydrologic Modeling Conference, Reno, Nevada, June 27. 2019, session 7B-Extreme floods and droughts II: Federal Interagency Sedimentation and Hydrologic Modeling Conference, $12 \mathrm{p}$.

Bailey, R.M., Smith, B.W., and Rhodes, E.J., 1997, Partial bleaching and the decay form characteristics of quartz OSL: Radiation Measurements, v. 27, no. 2, p. 123-136.

Baker, V.R., 1987, Paleoflood hydrology and extraordinary flood events: Journal of Hydrology, v. 96, nos. 1-4, p. 79-99.

Baker, V.R., 1989, Magnitude and frequency of palaeofloods, in Beven, K., and Carling, P., eds., Floods-Their hydrological, sedimentological and gomorphological implications: Chichester, United Kingdom, Wiley, p. 171-183.

Baker, V.R., 2014, Paleohydrology_IAHS Benchmark Papers in Hydrology, 9: Wallingford, United Kingdom, International Association of Hydrological Sciences Press, $494 \mathrm{p}$.

Baker, V.R., and Kochel, R.C., 1988, Flood sedimentation in bedrock fluvial systems, in Baker, R.V., Kochel, R.C., and Patton, P.C., eds., Flood Geomorphology: New York, Wiley, p. 123-137.

Baker, V.R., Webb, R.H., and House, P.K., 2002, The scientific and societal value of paleoflood hydrology, in House, P.K., Webb, R.H., Baker, V.R., and Levish, D.R., eds., Ancient floods, modern hazards-Principles and applications of paleoflood hydrology, v. 5 of Water science and application series: Washington, D.C., American Geophysical Union, p. 127-146.

Ball, J., Babister, M., Nathan, R., Weeks, W., Weinmann, E., Retallick, M., and Testoni, I., eds., 2019, Australian rainfall and runoff-A guide to flood estimation: Barton, Australia, Geoscience Australia, 146 p.

Ballarini, M., Wallinga, J., Murray, A.S., van Heteren, S., Oost, A.P., Bos, A.J.J., and van Eijk, C.W.E., 2003, Optical dating of young coastal dunes on a decadal time scale: Quaternary Science Reviews, v. 22, nos. 10-13, p. 1011-1017. 
Ballesteros, J.A., Bodoque, J.M., Díez-Herrero, A., SanchezSilva, M., and Stoffel, M., 2011, Calibration of floodplain roughness and estimation of flood discharge based on tree-ring evidence and hydraulic modelling: Journal of Hydrology, v. 403, nos. 1-2, p. 103-115.

Ballesteros Cánovas, J.A., Eguibar, M., Bodoque, J.M., DiezHerrero, A., Stoffel, M., and Gutiérrez-Perez, I., 2010, Estimating flash flood discharge in an ungauged mountain catchment with 2D hydraulic models and dendrogeomorphic paleostage indicators: Hydrological Processes, v. 25, no. 6, p. $970-979$.

Ballesteros-Cánovas, J.A., Márquez-Peñaranda, J.F., SánchezSilva, M., Díez-Herrero, A., Ruiz-Villanueva, V., Bodoque, J.M., Eguibar, M.A., and Stoffel, M., 2015, Can tree tilting be used for paleoflood discharge estimations?: Journal of Hydrology, v. 529, p. 480-489.

Ballesteros-Cánovas, J.A., Stoffel, M., Spyt, B., Janecka, K., Kaczka, R.J., and Lempa, M., 2016, Paleoflood discharge reconstruction in Tatra Mountain streams: Geomorphology, v. 272 , p. $92-101$.

Ballesteros-Cánovas, J.A., Stoffel, M., St. George, S., and Hirschboeck, K., 2015, A review of flood records from tree rings: Progress in Physical Geography, v. 39, no. 6, p. $794-816$.

Barletta, F., St-Onge, G., Channell, J.E.T., and Rochon, A., 2010, Dating of Holocene western Canadian Arctic sediments by matching paleomagnetic secular variation to a geomagnetic field model: Quaternary Science Reviews, v. 29 , nos. $17-18$, p. $2315-2324$.

Barnes, H.H., 1967, Roughness characteristics of natural channels: U.S. Geological Survey Water Supply Paper $1849,213 \mathrm{p}$.

Barnes, H.H., and Golden, H.G., 1966, Magnitude and frequency of floods in the United States-Part 2-B, South Atlantic slope and Eastern Gulf of Mexico basins, Ogeechee River to Pearl River: U.S. Geological Survey Water Supply Paper 1674, 409 p., accessed May 23, 2019, at https ://pubs.er.usgs.gov/publication/wsp1674.

Barth, N.A., Villarini, G., Nayak, M.A., and White, K., 2017, Mixed populations and annual flood frequency estimates in the western United States-The role of atmospheric rivers: Water Resources Research, v. 53, no. 1, p. 257-269.

Barth, N.A., Villarini, G., and White, K., 2019, Accounting for mixed populations in flood frequency analysis-Bulletin $17 \mathrm{C}$ perspective: Journal of Hydrologic Engineering, v. 24, no. 3, p. 1-12.
Base de Données Historiques sur les Inondations, 2020, Database on historical floods: Ministry of Ecology, Sustainable Development and Energy, France, web page accessed July 2020, at https://bdhi.developpementdurable.gouv.fr/welcome.

Bates, P.D., and De Roo, A.P.J., 2000, A simple raster based model for flood inundation simulation: Journal of Hydrology, v. 236, nos. 1-2, p. 54-77.

Bauer, T.R., and Klinger, R.E., 2010, Evaluation of Paleoflood peak discharge estimates in hydrologic hazard studies: Denver, Colorado, Bureau of Reclamation, Dam Safety Technology Development Program, Report DSO-11-03, 19 p.

Bedinger, M.S., 1971, Forest species as indicators of flooding in the lower White River Valley, Arkansas: U.S. Geological Survey Professional Paper 750-C, p. C248-C253.

Benito, G., Brazdil, R., Herget, J., and Machado, M.J., 2015, Quantitative historical hydrology in Europe: Hydrology and Earth System Sciences, v. 19, no. 8, p. 3517-3539.

Benito, G., Harden, T.M., and O'Connor, J.E., 2020, Quantitative paleoflood hydrology, in Reference module in earth systems and environmental sciences: San Diego, Elsevier, $22 \mathrm{p}$.

Benito, G., Lang, M., Barriendos, M., Llasat, C., Francés, F., Ouarda, T., Varyl, R., Enzel, Y., and Bardossy, A., 2004, Use of systematic, palaeoflood and historical data for the improvement of flood risk estimation-Review of scientific methods: Natural Hazards, v. 31, no. 3, p. 623-643.

Benito, G., and O'Connor, J.E., 2013, Quantitative paleoflood hydrology, in Wohl, E. ed., Fluvial geomorphology, v. 9 of Treatise on geomorphology: San Diego, Elsevier, p. 459-474.

Benito, G., Sopeña, A., Sánchez-Moya, Y., Machado, M.J., and Pérez González, A., 2003, Palaeoflood record of the Tagus River (central Spain) during the late Pleistocene and Holocene: Quaternary Science Reviews, v. 22, nos. 15-17, p. $1737-1756$.

Benito, G., and Thorndycraft, V.R., 2005, Palaeoflood hydrology and its role in applied hydrological sciences: Journal of Hydrology, v. 313, nos. 1-2, p. 3-15.

Birkeland, P.W., 1984, Soils and geomorphology: New York, Oxford University Press, 372 p.

Blaauw, M., and Heegaard, E., 2012, Estimation of age-depth relationships, in Birks, H., Lotter, A., Juggins, S., and Smol, J., eds., Tracking environmental change using lake sediments, v. 5 of Developments in Paleoenvironmental Research: Dordrecht, The Netherlands, Springer, $p$. 379-413., https://doi.org/10.1007/978-94-007-2745-8_12. 
Blainey, J.B., Webb, R.H., Moss, M.E., and Baker, V.R., 2002, Bias and information content of paleoflood data in floodfrequency analysis, in House, P.K., Webb, R.H., Baker, V.R., and Levish, D.R., eds., Ancient floods, modern hazardsPrinciples and applications of paleoflood hydrology, v. 5 of Water and science application series: Washington, D.C., American Geophysical Union, p. 161-174.

Blong, R.J., and Gillespie, R., 1978, Fluvially transported charcoal gives erroneous ${ }^{14} \mathrm{C}$ ages for recent deposits: Nature, v. 271, no. 5647, p. 739-741, https://doi.org/ 10.1038/271739a0.

Bodoque, J.M., Díez-Herrero, A., Eguibar, M.A., Benito, G., Ruiz-Villanueva, V., and Ballesteros-Cánovas, J.A., 2015 , Challenges in paleoflood hydrology applied to risk analysis in mountainous watersheds-A review: Journal of Hydrology, v. 529, no. 2, p. 449-467, https://doi.org/ 10.1016/j.jhydrol.2014.12.004.

Bøtter-Jensen, L., Bulur, E., Duller, G.A.T., and Murray, A.S., 2000, Advances in luminescence instrument systems: Radiation Measurements, v. 32, nos. 5-6, p. 523-528. https://doi.org/10.1016/S1350-4487(00)00039-1.

Bradley, R.S., 1999, Paleoclimatology-Reconstructing climates of the Quaternary (2nd ed.): Burlington, Massachusetts, Harcourt Academic Press, p. 80-89.

British Historical Society, 2020, Chronology of British hydrological events: British Historical Society web page, accessed July 2020, at https://www.cbhe.hydrology.org.uk/.

Brunner, G.W., 2016b, HEC-RAS river analysis hydraulic reference manual (ver. 5.0): U.S. Army Corps of Engineers Institute for Water Resources Hydrologic Engineering Center, Davis, California. 205 p., accessed February 2020, at https://www.hec.usace.army.mil/software/hec-ras/ documentation.aspx.

Brunner, G.W., 2016a, HEC-RAS river analysis system 2D modeling user's manual (ver. 5.0): U.S. Army Corps of Engineers Institute for Water Resources, CPD-68A, 171 p., accessed February 2020, at https://www.hec.usace.army.mil/ software/hec-ras/documentation.aspx.

Bureau of Reclamation, 2002, Flood hazard analysisFolsom Dam, Central Valley Project, California: Bureau of Reclamation, Denver Technical Center, 128 p.

Bureau of Reclamation, 2013, Hydrologic considerations, chap. 2 of Design standards no. 14-Appurtenant structures for dams (spillways and outlet works): Bureau of Reclamation, Technical Service Center [variously paged].
Carolin, S.A., Cobb, K.M., Adkins, J.F., Clark, B., Conroy, J.L., Lejau, S., Malang, J., and Tuen, A., 2013, Varied response of Western pacific hydrology to climate forcings over the last glacial period: Science, v. 340 , no. 6140 , p. $1564-1566$.

Carr, M.L., Gaughan, S.P., George, C.R., and Mason, J.G., 2015, CRREL's ice jam database-Improvements and updates: Proceedings of the 18th workshop on the hydraulics of ice covered rivers, Quebec City, Quebec, Canada, August 18-20, 2015, 14 p., accessed May 2020, at http:// cripe.ca/docs/proceedings/18/20_Carr_et_al_2015.pdf.

Chow, V.T., 1959, Open-channel hydraulics: New York, McGraw-Hill, 680 p.

Clague, J.J., 2015, Paleolandslides, chap. 10 of Shroder, J.F. and Davies, Y., eds., Landslide hazards, risks, and disasters: Amsterdam, Elsevier, p. 321-344, https://doi.org/10.1016/ C2011-0-07015-1.

Cohn, T.A., Lane, W.L., and Baier, W.G., 1997, An algorithm for computing moments-based flood quantile estimates when historical flood information is available: Water Resources Research, v. 33, no. 9, p. 2089-2096.

Cohn, T.A., Lane, W.L., and Stedinger, J.R., 2001, Confidence intervals for expected moments algorithm flood quantile estimates: Water Resources Research, v. 37, no. 6, p. 1695-1706.

Cohn, T.A., and Lins, H.F., 2005, Nature's style-Naturally trendy: Geophysical Research Letters, v. 32, no. 23, 5 p.

Conyers, M., and Fonstad, M., 2005, The unusual channel resistance of the Texas Hill Country and its effect on flood flow predictions: Physical Geography, v. 26, no. 5, p. 379-395, https://doi.org/10.2747/0272-3646.26.5.379.

Copini, P., den Ouden, J., Robert, E.M.R., Tardif, J.C., Loesberg, W.A., Goudzwaard, L., and Sass-Klaassen, U., 2016, Flood-ring formation and root development in response to experimental flooding of young Quercus robur trees: Frontiers in Plant Science, v. 7, 14 p., https://doi.org/ 10.3389/fpls.2016.00775.

Costa, J.E., 1978, Holocene stratigraphy in flood frequency analysis: Water Resources Research, v. 14, no. 4, p. 626-632.

Costa, J.E., 1983, Paleohydraulic reconstruction of flashflood peaks from boulder deposits in the Colorado Front Range: Geological Society of America Bulletin, v. 94, no. 8, p. 986-1004. 
Costa, J.E., and Jarrett, R.D., 2008, An evaluation of selected extraordinary floods in the United States reported by the U.S. Geological Survey and implications for future advancement of flood science: U.S. Geological Survey Scientific Investigations Report 2008-5164, 232 p. [Also available at https://doi.org/10.3133/sir20085164.]

Cunge, J.A., Holly, F.M., and Verwey, A., 1980, Practical aspects of computational river hydraulics: London, Pitman, 420 p.

Cunnane, C., 1985, Factors affecting choice of distribution for flood series: Hydrological Sciences Journal, v. 30, no. 1, p. 25-36.

Cuven, S., Francus, P., and Lamoureux, S.F., 2010, Estimation of grain size variability with micro X-ray fluorescence in laminated lacustrine sediments, Cape Bounty, Canadian High Arctic: Journal of Paleolimnology, v. 44, no. 3, p. 803-817.

Dasgupta, S., Saar, M.O., Edwards, R.L., Shen, C., Cheng, H., and Alexander, E.C., Jr., 2010, Three thousand years of extreme rainfall events recorded in stalagmites from Spring Valley Caverns, Minnesota: Earth and Planetary Science Letters, v. 300, nos. 1-2, p. 46-54, https://doi.org/10.1016/ j.epsl.2010.09.032.

Davis, L., Lombardi, R., Sterart, C.L., Stinchcomb, G.E., Forman, S.L., Yaw, M., and Jawdy, C.M., 2019, Characterizing extreme floods on the middle Tennessee River, Alabama (USA) using a paleoflood chronology [abs.]: American Geophysical Union Annual Meeting, San Francisco, California, December 9-12, N44F-04. [Also available at https://agu.confex.com/agu/fm19/ meetingapp.cgi/Paper/528238.]

Dean, D.J., Scott, M.L., Shafroth, P.B., and Schmidt, J.C., 2011, Stratigraphic, sedimentologic, and dendrogeomorphic analyses of rapid floodplain formation along the Rio Grande in Big Bend National Park, Texas: Geological Society of America Bulletin, v. 123, nos. 9-10, p. 1908-1925.

Denlinger, R.P., O’Connell, D.R.H., and House, P.K., 2002, Robust determination of stage and discharge-An example form an extreme flood on the Verde River, Arizona, in House, P.K., Webb, R.H., Baker, V.R., and Levish, D.R., eds., Ancient floods, modern hazards - Principles and applications of paleoflood hydrology, v. 5 of Water science and application series: Washington, D.C., American Geophysical Union, p. 127-146.

Denniston, R.F., and Luetscher, M., 2017, Speleothems as high-resolution paleoflood archives: Quaternary Science Reviews, v. 170, p. 1-13.
Díez-Herrero, A., Ballesteros, J.A., Ruiz-Villanueva, V., and Bodoque, J.M., 2013, A review of dendrogeomorphological research applied to flood risk analysis in Spain: Geomorphology, v. 196, p. 211-220.

Digital Horizons, 2020, Digital horizons_-Life on the Northern Plains: Digital Horizons web page, accessed July 8, 2020, at http://digitalhorizonsonline.org.

Dorn, R.I., 1994, Surface exposure dating with rock varnish, in Beck, C., ed., Dating in exposed and surface contexts: Albuquerque, University of New Mexico Press, p. 77-113.

Dudek, D.M., McClenahen, J.R., and Mitsch, W.J., 1998, Tree growth responses of Populus deltoides and Juglans nigra to streamflow and climate in a bottomland hardwood forest in central Ohio: American Midland Naturalist, v. 140, no. 2, p. 233-244.

Duller, G.A.T., 2004, Luminescence dating of Quaternary sediments - Recent advances: Journal of Quaternary Science, v. 19, no. 2, p. 183-192.

Duller, G.A.T., and Murray, A.S., 2000, Luminescence dating of sediments using individual mineral grains: Geologos, v. 5, p. $87-106$.

Dunn, C., and Baker, P., 2010, A watershed modeling tool, HEC-WAT, in Potter, K.W., and Frevert, D.K., eds, Innovations in watershed management under land use and climate change-Proceedings of the 2010 Watershed Management Conference, Madison, Wisconsin, August 23-27, 2010: American Society of Civil Engineers, p. 1101-1112, https://doi.org/10.1061/41143(394)99.

Dunn, C., Baker, P., and Fleming, M., 2016, Flood risk management with HEC-WAT and the FRA compute option, in FLOODrisk 2016-Third European conference on flood risk management, v. 7 of E3S web of conferences, October 2016: Les Ulis, France, EDP Sciences, 11 p., https://doi.org/10.1051/e3sconf/20160711006.

Dury, G.H., 1976, Discharge prediction, present and former, from channel dimensions: Journal of Hydrology, v. 30, no. 3, p. 219-245.

Edmondson, J., Friedman, J., Meko, D., Touchan, R., Scott, J., and Edmondson, A., 2014, Dendroclimatic potential of plains cottonwood (Populus deltoides ssp. monilifera) from the northern Great Plains, USA: Tree-Ring Research, v. 70, no. 1, p. 21-30.

Elliott, J.G., and Parker, R.S., 2001, Developing a post-fire flood chronology and recurrence probability from alluvial stratigraphy in the Buffalo Creek watershed, Colorado, USA: Hydrological Processes, v. 15, no. 15, p. 3039-3051, https://doi.org/10.1002/hyp.390. 
Ely, L.L., and Baker, V.R., 1985, Reconstructing paleoflood hydrology with slackwater deposits - Verde River, Arizona: Physical Geography, v. 6, no. 2, p. 103-126.

Ely, L.L., Enzel, Y., Baker, V.R., and Cayan, D.R., 1993, A 5000 -yr record of extreme floods and climate change in the southwestern United States: Science, v. 262, no. 5132, p. $410-412$.

Ely, L.L., Webb, R.H., and Enzel, Y., 1992, Accuracy of postbomb $137 \mathrm{Cs}$ and $14 \mathrm{C}$ in dating fluvial deposits: Quaternary Research, v. 38, no. 2, p. 196-204.

Engeland, K., Wilson, D., Borsanyi, P., Roald, L., and Holmqvist, E., 2018, Use of historical data in flood frequency analysis - A case study for four catchments in Norway: Hydrology Research, v. 49, no. 2, p. 466-486.

England, J.F., Jr., 2011, Flood frequency and design flood estimation procedures in the United States-Progress and challenges: Australian Journal of Water Resources, v. 15, no. 1, p. 33-46.

England, J.F., Jr., Cohn, T.A., Faber, B.A., Stedinger, J.R., Thomas Jr., W.O., Veilleux, A.G., Kiang, J.E., and Mason, R.R., 2018, Guidelines for determining flood flow frequency-Bulletin 17C (ver. 1.1, 2019): U.S. Geological Survey Techniques and Methods, book 4, chap. B5, 148 p., accessed June 20, 2018, at https://doi.org/10.3133/tm4B5.

England, J.F., Jr., Godaire, J.E., Klinger, R.E., Bauer, T.R., and Julien, P.Y., 2010, Paleohydrologic bounds and extreme flood frequency of the Upper Arkansas River, Colorado, USA: Geomorphology, v. 124, nos. 1-2, p. 1-16.

England, J.F., Jr., Klawon, J.E., Klinger, R.E., and Bauer, T.R., 2006, Flood hazard study, Pueblo Dam, Colorado-Final report: Denver, Colorado, Bureau of Reclamation, $160 \mathrm{p}$.

England, J.F., and Stedinger, J.R., 2017, Peer review of TVA probabilistic flood hazard approach: Lakewood, Colorado, U.S. Army Corps of Engineers, Risk Management Center, Report RMS-TR-2017-06, 18 p.

Enzel, Y., Ely, L.L., Martinez-Goytre, J., and Vivian, R.G., 1994, Paleofloods comparable in magnitude to the catastrophic 1989 dam failure flood on the Virgin River, Utah and Arizona: Journal of Hydrology, v. 153, p. 291-317.

Everitt, B.L., 1968, Use of the cottonwood in an investigation of the recent history of a flood plain: American Journal of Science, v. 266, no. 6, p. 417-439.

Fanok, S.F., and Wohl, E.E., 1997, Assessing the accuracy of paleohydrologic indicators, Harpers Ferry, West Virginia: Journal of the American Water Resources Association, v. 33, no. 5, p. 1091-1102.
Flynn, K.M., Kirby, W.H., and Hummel, P.R., 2006, User's manual for program PeakFQ, annual flood-frequency analysis using Bulletin 17B guidelines: U.S. Geological Survey Techniques of Water Resources Investigations book 4, chap. B4, 42 p., accessed January 23, 2017, at https://pubs .usgs.gov/tm/2006/tm4b4/.

Frances, F., Salas, J.D., and Boes, D.C., 1994, Flood frequency analysis with systematic and historical or paleoflood data based on the two-parameter general extreme value models: Water Resources Research, v. 30, no. 6, p. 1653-1664.

Frappier, A.B., Pyburn, J., Pinkey-Drobnis, A.D., Wang, X., Corbett, D.R., and Dahlin, B.H., 2014, Two millennia of tropical cyclone-induced mud layers in a northern Yucatán stalagmite-Multiple overlapping climatic hazards during the Maya Terminal Classic "megadroughts": Geophysical Research Letters, v. 41, no. 14, p. 5148-5157. https://doi.org/10.1002/2014GL059882.

Friedman, J.M., and Lee, V.J., 2002, Extreme floods, channel change and riparian forests along ephemeral streams: Ecological Monographs, v. 72, no. 3, p. 409-425.

Friedman, J.M., Stricker, C.A., Csank, A.Z., and Zhou, H., 2019, Effects of age and environment on stable carbon isotope ratios in tree rings of riparian Populus: Palaeogeography, Palaeoclimatology, Palaeoecology, v. 524, p. $25-32$.

Friedman, J.M., Vincent, K.R., Griffin, E.R., Scott, M.L., Shafroth, P.B., and Auble, G.T., 2015, Processes of arroyo filling in northern New Mexico, USA: Geological Society of America Bulletin, v. 127, nos. 3-4, p. 621-640.

Friedman, J.M., Vincent, K.R., and Shafroth, P.B., 2005, Dating floodplain sediments using tree-ring response to burial: Earth Surface Processes and Landforms, v. 30, no. 9, p. 1077-1091.

Gennaretti, F., Arseneault, D., and Bégin, Y., 2014, Millennial stocks and fluxes of large woody debris in lakes of the North American taiga: Journal of Ecology, v. 102, no. 2, p. 367-380, https://doi.org/10.1111/1365-2745.12198.

Gibson, S., Ramos, K., Dahl, T., Webber, J.B., and Vuyovich, C., 2019, Comparing ice jam hindcasting models with tree scar data: Journal of Cold Regions Engineering, v. 33, no. 3, 11 p., https://doi.org/10.1061/(ASCE)CR.19435495.0000186 .

Godaire, J.E., and Bauer, T.R., 2012a, Paleoflood study of the North Fork Red River Basin near Altus Dam, Oklahoma: Denver, Colorado, Bureau of Reclamation, $55 \mathrm{p}$.

Godaire, J.E., and Bauer, T.R., 2012b, Paleoflood study, San Joaquin River near Friant Dam, California: Bureau of Reclamation, Technical Memorandum No. 86-68330-2012-24, $60 \mathrm{p}$. 
Godaire, J.E., and Bauer, T.R., 2013, Paleoflood study on the Rio Chama near El Vado Dam, New Mexico: Denver, Colorado, Bureau of Reclamation, $58 \mathrm{p}$.

Gottesfeld, A.S., 1996, British Columbia flood scarsMaximum flood-stage indicators: Geomorphology, v. 14, no. 4, p. 319-325.

Gottesfeld, A.S., and Johnson Gottesfeld, L.M., 1990, Floodplain dynamics of a wandering river, dendrochronology of the Morice River, British Columbia, Canada: Geomorphology, v. 3, no. 2, p. 159-179.

Grant, G.E., 1997, Critical flow constrains flow hydraulics in mobile-bed streams-A new hypothesis: Water Resources Research, v. 33, no. 2, p. 349-358.

Green, A.R., 1964, Magnitude and frequency of floods in the United States - Part 1-A, North Atlantic slope basins, Maine to Connecticut: U.S. Geological Survey WaterSupply Paper 1671, 260 p., accessed July 13, 2021, at https ://pubs.er.usgs.gov/publication/wsp1671.

Greenbaum, N., Harden, T.M., Baker, V.R., Weisheit, J., Cline, M.L., Porat, N., Halevi, R., and Dohrenwend, J., 2014, A 2000 year natural record of magnitudes and frequencies for the largest Upper Colorado River floods near Moab, Utah: Water Resources Research, v. 50, no. 6, p. 5249-5269.

Grimm, M.M., Wohl, E.E., and Jarrett, R.D., 1995, Coarsesediment distribution as evidence of an elevation limit for flash flooding, Bear Creek, Colorado: Geomorphology, v. 14, no. 3, p. 199-210, https://doi.org/10.1016/0169555X(95)00037-6.

Gül, G., Aşıkoğlu, Ö., Gül, A., Gülçem Yaşoğlu, F., and Benzeden, E., 2014, Nonstationarity in flood time series: Journal of Hydrologic Engineering, v. 19, no. 7, p. 1349-1360.

Gutiérrez, F., Zarroca, M., Castaneda, C., Carbonel, D., Guerrero, J., Linares, R., Roque, C., and Lucha, P., 2017, Paleoflood records from sinkholes using an example from the Ebro River floodplain, northeastern Spain: Quaternary Research, v. 88, no. 1, p. 71-88.

Gutsell, S.L., and Johnson, E.A., 2002, Accurately ageing trees and examining their height-growth rates-Implications for interpreting forest dynamics: Journal of Ecology, v. 90, no. 1 , p. 153-166.

Harden, T.M., 2013, Paleoflood study of Island Park Dam, ID: Denver, Colorado, Bureau of Reclamation, Technical Service Center, Technical Memorandum No. 86-68330-2013-4, 132 p.

Harden, T.M., and Bauer, T., 2014, Paleoflood Study for Little Panoche Detention Dam, CA: Denver, Colorado, Bureau of Reclamation, Technical Service Center, Technical Memorandum No. 86-68330-2014-36, 77 p.
Harden, T.M., and O'Connor, J.E., 2017, Prehistoric floods on the Tennessee River-Assessing the use of stratigraphic records of past floods for improved flood-frequency analysis: U.S. Geological Survey Scientific Investigations Report 2017-5052, 15 p., https://doi.org/10.3133/sir20175052.

Harden, T.M., O’Connor, J.E., Carr, M.L., and Keith, M., 2021, Improving flood-frequency analysis with a 4,000-year record of flooding on the Tennessee River near Chattanooga, Tennessee: U.S. Geological Survey Scientific Investigations Report 2020-5138, 64 p., https://doi.org/ $10.3133 / \operatorname{sir} 20205138$.

Harden, T.M., O’Connor, J.E., and Driscoll, D.G., 2015, Late Holocene flood probabilities in the Black Hills, South Dakota with emphasis on the Medieval Climate Anomaly: Catena, v. 130, p. 62-68, https://doi.org/10.1016/ j.catena.2014.10.002.

Harden, T.M., O’Connor, J.E., Driscoll, D.G., and Stamm, J.F., 2011, Flood-frequency analyses from paleoflood investigations for Spring, Rapid, Boxelder, and Elk Creeks, Black Hills, western South Dakota: U.S. Geological Survey Scientific Investigations Report 2011-5131, 136 p., https://doi.org/10.3133/sir20115131.

Harrison, S.S., and Reid, J.R., 1967, A flood-frequency graph based on tree-scar data: Proceedings of the North Dakota Academy of Science, v. 21, p. 23-33.

Helley, E.J., and LaMarche, V.C., Jr., 1968, 1964, a 400-year flood in northern California: U.S. Geological Survey Professional Paper 600-D, p. 34-37.

Henderson, F.M., 1966, Open channel flow: New York, MacMillan, 522 p.

Hereford, R., 1984, Climate and ephemeral-stream processes - Twentieth-century geomorphology and alluvial stratigraphy of the Little Colorado River, Arizona: Geological Society of America Bulletin, v. 95, no. 6, p. 654-668.

Hirsch, R.M., 2011, A perspective on nonstationarity and water management: Journal of the American Water Resources Association, v. 47, no. 3, p. 436-446.

Holliday, V.T., 1988, Genesis of a late-Holocene soil chronosequence at the Lubbock Lake archaeological site, Texas: Annals of the Association of American Geographers, v. 78, no. 4, p. 594-610.

Holmes, C.W., 1998, Short lived isotopic chronometers-A means of measuring decadal sedimentary dynamics: U.S. Geological Survey Fact Sheet 073-98, 1 p.

Holmes, R.L., 1983, Computer-assisted quality control in tree-ring dating and measurement: Tree-Ring Bulletin, v. 44, p. $69-78$. 
Holmes, R.R., Jr., and Dinicola, K., 2010, 100-Year floodIt's all about chance: U.S. Geological Survey General Information Product 106, 1 p.

Hosman, K.J., Ely, L.L., and O'Connor, J.E., 2003, Holocene paleoflood hydrology of the lower Deschutes River, Oregon, in O'Connor, J.E., and Grant, G.E., eds., A peculiar riverGeology, geomorphology, and hydrology of the Deschutes River, Oregon, v. 7 of Water science and application series: American Geophysical Union, p. 121-146.

House, P.K., and Baker, V.R., 2001, Paleohydrology of flash floods in small desert watersheds in western Arizona: Water Resources Research, v. 37, no. 6, p. 1825-1839.

Hupp, C.R., 1988, Plant ecological aspects of flood geomorphology and paleoflood history, in Baker, V.R., Kochel, R.C., and Patton, P.C., eds., Flood geomorphology: New York, Wiley, p. 335-356.

Hupp, C.R., and Simon, A., 1991, Bank accretion and the development of vegetated depositional surfaces along modified alluvial channels: Geomorphology, v. 4, no. 2, p. 111-124.

Interagency Advisory Committee on Water Data, 1982, Guidelines for determining flood flow frequency-Bulletin 17B: U.S. Geological Survey Interagency Advisory Committee on Water Data, accessed February 21, 2017, at https://water.usgs.gov/osw/bulletin17b/dl_flow.pdf.

Jacobs, Z., Li, B., Jankowski, N., and Soressi, M., 2015, Testing of a single grain OSL chronology across the Middle to Upper Palaeolithic transition at Les Cottés (France): Journal of Archaeological Science, v. 54, p. 110-122.

Jacobson, R.B., O’Connor, J.E., and Oguchi, T., 2016, Surficial geological tools in fluvial geomorphology, in Kondolf, M., and Piegay, H., eds., Tools in fluvial geomorphology (2nd ed.): Chichester, United Kingdom, Wiley, p. 15-39.

Jacoby, Y., Grodek, T., Enzel, Y., Porat, N., McDonald, E.V., and Dahan, O., 2008, Late Holocene upper bounds of flood magnitudes and twentieth century large floods in the ungauged, hyper-arid alluvial Nahal Arava, Israel: Geomorphology, v. 95, nos. 3-4, p. 274-294.

Jarrett, R.D., 1984, Hydraulics of high-gradient streams: Journal of Hydraulic Engineering, v. 110, no. 11, p. 1519-1539, https://doi.org/10.1061/(ASCE)0733-94 29(1984)110:11(1519).
Jarrett, R.D., 1985, Determination of roughness coefficient for streams in Colorado: U.S. Geological Survey WaterResources Investigations Report 85-4004, 54 p., https://pubs .usgs.gov/wri/1985/4004/report.pdf.

Jarrett, R.D., and England, J.F., Jr., 2002, Reliability of paleostage indicators for paleoflood studies, in House, P.K., Webb, R.H., Baker, V.R., and Levish, D.R., eds., Ancient floods, modern hazards - Principles and applications of paleoflood hydrology, v. 5 of Water science and application series: Washington, D.C., American Geophysical Union, p. 91-109.

Jarrett, R.D., and Tomlinson, E.M., 2000, Regional interdisciplinary paleoflood approach to assess extreme flood potential: Water Resources Research, v. 36, no. 10, p. 2957-2984.

Jenny, J.P., Wilhelm, B., Arnaud, F., Sabatier, P., GiguetCovex, C., Mélo, A., Fanget, B., Malet, E., Ployon, E., and Perga, M.E., 2014, A 4D sedimentological approach to reconstructing the flood frequency and intensity of the Rhône River (Lake Bourget, NW European Alps): Journal of Paleolimnology, v. 51, no. 4, p. 469-483.

Jeter, H.W., 2000, Determining the ages of recent sediments using measurements of trace radioactivity: Terra et Aqua, v. 78 , p. $21-28$.

Johansen, M.P., Hakonson, T.E., and Breshears, D.D., 2001, Post-fire run-off and erosion from rainfall simulationContrasting forests with shrublands and grasslands: Hydrological Processes, v. 15, no. 15, p. 2953-2965, https://doi.org/10.1002/hyp.384.

Jones, A.F., Macklin, M.G., and Brewer, P.A., 2012, A geochemical record of flooding on the upper River Severn, UK, during the last 3750 years: Geomorphology, v. 179, p. $89-105$.

Kämpf, L., Brauer, A., Swierczynski, T., Czymzik, M., Mueller, P., and Dulski, P., 2014, Processes of floodtriggered detrital layer deposition in the varved Lake Mondsee sediment record revealed by a dual calibration approach: Journal of Quaternary Science, v. 29, no. 5, p. 475-486, https://doi.org/10.1002/jqs.2721.

Karlstrom, T.N.V., 1988, Alluvial chronology and hydrologic change of Black Mesa and nearby regions, in Gumerman, G.J., ed., The Anasazi in a changing environment: Cambridge, United Kingdom, Cambridge University Press, p. 45-91.

Keim, R.F., and Amos, J.B., 2012, Dendrochronological analysis of baldcypress (Taxodium distichum) responses to climate and contrasting flood regimes: Canadian Journal of Forest Research, v. 42, no. 3, p. 423-436. 
Kelson, K.I., Hall, B., Harden, T., Mahan, S., and Duren, A., 2017a, Late Holocene paleofloods on the Middle Fork Willamette River-Improving hydrologic loading input for USACE dam safety evaluations [abs.], Geological Society of America annual meeting, Seattle, Washington, October 24, 2017: Geological Society of America Abstracts with Programs, v. 49, no. 6, https://doi.org/10.1130/abs/ 2017 AM-306129.

Kelson, K.I., Hall, B.M., Sasaki, R., Leonard, C.M., and Potts, S., 2017b, Paleoflood analysis for Ball Mountain Dam: Lakewood, Colorado, U.S. Army Corps of Engineers, Risk Management Center, Report RMC-TR-2017-08, 74 p.

Kelson, K.I., Hall, B.M., Walters, G.S., Duren, A.M., and Leonard, C.M., 2018, Paleoflood analysis for Lookout Point Dam: Lakewood, Colorado: U.S. Army Corps of Engineers, Risk Management Center, Report RMC-TR-2018-02, 80 p.

Kelson, K.I., Pearce, J.T., and Kinder, D.S., 2018, Paleoflood analysis for Proctor Dam: Lakewood, Colorado, U.S. Army Corps of Engineers, Risk Management Center, Report RMC-TR-2018-09, 36 p.

Kelson, K.I., Saski, R., and Hall, B.M., 2020, Paleoflood analysis - Carbon Canyon Dam, Orange County, California: Lakewood, Colorado, U.S. Army Corps of Engineers, Institute for Water Resources, Risk Management Center, Technical Report RMC-TR-2020-02, 79 p.

Kiang, J.E., Olsen, J.R., and Waskom, R.M., 2011, Introduction to the featured collection on "Nonstationarity, hydrologic frequency analysis, and water management": Journal of the American Water Resources Association, v. 47, no. 3, p. 433-435, https://doi.org/10.1111/j.17521688.2011.00551.x.

Kjeldsen, T.R., Macdonald, N., Lang, M., Mediero, L., Albuquerque, T., Bogdanowicz, E., Braźdil, R., Castellarin, A., David, V., Fleig, A., Onuşluel, G.G., Kriauciuniene, J., Kohnová, S., Merz, B., Nicholson, O., Roald, L.A., Salinas, J.L., Sarauskiene, D., Šraj, M., and Wilson, D., 2014, Documentary evidence of past floods in Europe and their utility in flood frequency estimation: Journal of Hydrology, v. 517, p. 963-973, https://doi.org/10.1016/j.jhydrol.2 014.06.038.

Knox, J.C., 1985, Responses of floods to Holocene climatic change in the upper Mississippi Valley: Quaternary Research, v. 23, no. 3, p. 287-300, https://doi.org/10.1016/ 0033-5894(85)90036-5.

Knox, J.C., and Daniels, J.M., 2002, Watershed scale and the stratigraphic record of large floods, in House, P.K., Webb, R., Baker, V.R., and Levish, D.R., eds., Ancient floods, modern hazards - Principles and applications of paleoflood hydrology, v 5 of Water science and application series: Washington, D.C., American Geophysical Union, p. 237-255.
Knuepfer, P.L., 1994, Use of rock weathering rinds in dating geomorphic surfaces, in Beck, C., ed., Dating in exposed and surface contexts: Albuquerque, University of New Mexico Press, p. 15-28.

Kochel, R.C., and Baker, V.R., 1982, Paleoflood hydrology: Science, v. 215, no. 4531, p. 353-361.

Kochel, R.C., and Baker, V.R., 1988, Paleoflood analysis using slack water deposits, in Baker, R.V., Kochel, R.C., and Patton, P.C., eds., Flood geomorphology: New York, Wiley, p. 357-376.

Kochel, R.C., Baker, V.R., and Patton, P.C., 1982, Paleohydrology of southwestern Texas: Water Resources Research, v. 18, no. 4, p. 1165-1183.

Koenig, T.A., Bruce, J.L., O’Connor, J.E., McGee, B.D., and Holmes, R.R., Hollins, R., Forbes, B.T., Kohn, M.S., Schellekens, M.F., Martin, Z.W., and Peppler, M.C., 2016, Identifying and preserving high-water mark data: U.S. Geological Survey Techniques and Methods, book 3, chap. A24, 47 p., https://doi.org/10.3133/tm3A24.

Kohn, M.S., Stevens, M.R., Harden, T.M., Godaire, J.E., Klinger, R.E., and Mommandi, A., 2016, Paleoflood investigations to improve peak-streamflow regional-regression equations for natural streamflow in eastern Colorado, 2015: U.S. Geological Survey Scientific Investigations Report 2016-5099, 58 p., https://doi.org/10.3133/sir20165099.

Kolars, K.A., Vecchia, A.V., and Ryberg, K.R., 2016, Stochastic model for simulating Souris River Basin precipitation, evapotranspiration, and natural streamflow: U.S. Geological Survey Scientific Investigations Report 2015-5185, 55 p., accessed June 29, 2017, at https://doi.org/ $10.3133 / \operatorname{sir} 20155185$.

Komar, P.D., 1996, Entrainment of sediments from deposits of mixed grain sizes and densities, in Carling, P.A., and Dawson, M.R., eds., Advance in fluvial dynamics and stratigraphy: Chichester, United Kingdom, Wiley, p. 107-134.

Kuczera, G., and Franks, S., 2019, At-site flood frequency analysis, chap. 2 of book 3 (Peak flow estimation) of Ball, J., Babister, M., Nathan, R., Weeks, W., Weinmann, E., Retallick, M., and Testoni, I., eds., Australian rainfall and runoff-A guide to flood estimation: Symonston, Commonwealth of Australia, Australia, [unpaginated], accessed June 30, 2021, at http://book.arr.org.au.s3-websiteap-southeast-2.amazonaws.com/.

Kutija, V., 2003, Hydraulic modelling of floods, in Thorndycraft, V.R., Benito, G., Barriendos, M., and Llasat, M.C., eds., Palaeofloods, historical data and climatic variability-Applications in flood risk assessment: Madrid, Consejo Superior de Investigaciones Científicas, p. 163-169. 
Lai, Y.G., 2008, SRH-2D theory and user's manual, sedimentation and river hydraulics-Two-dimensional river flow modeling, version 2: Denver, Colorado, Bureau of Reclamation, 97 p., https://www.usbr.gov/tsc/ techreferences/computer\%20software/models/srh2d/ index.html.

Lai, Y.G., 2009, Two-dimensional depth-averaged flow modeling with an unstructured hybrid mesh: Journal of Hydraulic Engineering, v. 136, no. 1, p. 12-23.

Lam, D., Thompson, C., Croke, J., Sharma, A., and Macklin, M., 2017, Reducing uncertainty with flood frequency analysis - The contribution of paleoflood and historical flood information: Water Resources Research, v. 53, no. 3, p. $2312-2327$.

Lang, M., Fernandez Bono, J.F., Recking, A., Naulet, R., and Grau Gimeno, P., 2004, Methodological guide for paleoflood and historical peak discharge estimation, in Benito, G., and Thorndycraft, V.R., eds., Systematic, palaeoflood and historical data for the improvement of flood risk estimation-Methodological guidelines: Madrid, Consejo Superior de Investigaciones Científicas, p. 43-53.

LaRue, E.C., 1925, Water power and flood control of Colorado River below Green River, Utah: U.S. Geological Survey Water-Supply Paper 556, 176 p.

Leese, M.N., 1973, Use of censored data in the estimation of Gumbel distribution parameters for annual maximum flood series: Water Resources Research, v. 9, no. 6, p. 1534-1542.

Leigh, D.S., 2018, Vertical accretion sand proxies of gaged floods along the upper Little Tennessee River, Blue Ridge Mountains, USA: Sedimentary Geology, v. 364, p. 342-350.

Levish, D.R., 2002, Paleohydrologic bounds-Nonexceedance information for flood hazard assessment, in House, P.K., Webb, R.H., Baker, V.R., and Levish, D.R., eds., Ancient floods, modern hazards-Principles and applications of paleoflood hydrology, v. 5 of Water science and application series: Washington, D.C., American Geophysical Union, p. 175-190.

Levish, D.R., England, J.F., Jr., Klawon, J.E., and O'Connell, D.R.H., 2003, Flood hazard analysis for Seminoe and Glendo Dams, Kendrick and North Platte Projects, Wyoming-Final report: Denver, Colorado, Bureau of Reclamation, $126 \mathrm{p}$.

Levish, D.R., Ostenaa, D.A., and O'Connell, R.H., 1996, Paleohydrologic bounds and the frequency of extreme floods on the Santa Ynez River, California, in A Prehistoric look at California rainfall and floods - California weather symposium, June 29, 1996: Sierra College, Rocklin, California, p. 61-78. [Also available at https://cepsym.org/ Sympro1996/Levish.pdf.]
Liu, T., Ji, L., Baker, V.R., Harden, T.M., and Cline, M.L., 2020, Holocene extreme paleofloods and their climatological context, Upper Colorado River Basin, USA: Progress in Physical Geography, v. 44, no. 5, p. 727-745, https://doi.org/10.1177/0309133320904038.

Macdonald, N., and Black, A.R., 2010, Reassessment of flood frequency using historical information for the River Ouse at York, UK (1200-2000): Hydrological Sciences Journal, v. 55, no. 7, p. 1152-1162.

Machado, M.J., Botero, B.A., Lopez, J., Frances, F., Diez-Herrero, A., and Benito, G., 2015, Flood frequency analysis of historical flood data under stationary and non-stationary modelling: Hydrology and Earth System Sciences, v. 19, no. 6, p. 2561-2576.

Maizels, J.K., 1983, Palaeovelocity and palaeodischarge determination for coarse gravel deposits, in Gregory, K.J., ed., Background to palaeohydrology: Chichester, United Kingdom, John, p. 101-139.

Manners, R.B., Schmidt, J.C., and Scott, M.L., 2014, Mechanisms of vegetation-induced channel narrowing of an unregulated canyon river-Results from a natural field-scale experiment: Geomorphology, v. 211, p. 100-115.

Margo, D.A., 2017, Flood hazard analysis for Cherry Creek Dam (CO01280): Lakewood, Colorado, U.S. Army Corps of Engineers, Risk Management Center, Report RMCTR-2017-11, 39 p.

Markewich, H.W., Pavich, M.J., and Wysocki, D.A., 2017, Soils as relative age-dating tools, in Richardson, D., and others, eds., The international encyclopedia of geography: Chichester, United Kingdom, Wiley, 14 p.

Martens, D.M., 1993, Hydrologic inferences from tree-ring studies on the Hawkesbury River, Sydney, Australia: Geomorphology, v. 8, nos. 2-3, p. 147-164.

McCarroll, D., and Loader, N.J., 2004, Stable isotopes in tree rings: Quaternary Science Reviews, v. 23, nos. 7-8, p. 771-801.

McCord, V.A.S., 1990, Augmenting flood frequency estimates using flood-scarred trees: Tucson, University of Arizona, Department of Geosciences, Ph.D. dissertation, 182 p. [Also available at https://repository.arizona.edu/handle/ 10150/185017.]

McCord, V.A.S., 1996, Fluvial process dendrogeomorphology-Reconstruction of flood events from the southwestern United States using flood-scarred trees, in Dean, J.S., Meko, D.M., and Swetnam, T.W., eds., Tree rings, environment and humanity, special issue: Tucson, Arizona, Radiocarbon, p. 689-699. 
McQueen, K.C., Vitek, J.D., and Carter, B.J., 1993, Paleoflood analysis of an alluvial channel in the south-central Great Plains-Black Bear Creek, Oklahoma: Geomorphology, v. 8, nos. 2-3, p. 131-146.

Meko, D.M., Friedman, J.M., Touchan, R., Edmondson, J.R., Griffin, E.R., and Scott, J.A., 2015, Alternative standardization approaches to improving streamflow reconstructions with ring-width indices of riparian trees: The Holocene, v. 25 , no. 7 , p. 1093-1101.

Merigliano, M.F., Friedman, J.M., and Scott, M.L., 2013, Tree-ring records of variation in flow and channel geometry. in: Shroder, J.F., Butler, D.R. and Hupp, C.R., eds., Ecogeomorphology, v. 12 of Treatise on geomorphology: San Diego, Elsevier, p. 145-164.

Miller, J.R., and Friedman, J.M., 2009, Influence of flow variability on floodplain formation and destruction, Little Missouri River, North Dakota: Geological Society of America Bulletin, v. 121, nos. 5-6, p. 752-759.

Merz, R., and Blöschl, G., 2008, Flood frequency hydrology - 1, Temporal, spatial, and causal expansion of information: Water Resources Research, v. 44, no. 8, 17 p., https://doi.org/10.1029/2007WR006744.

MGS Software LLC, 2018, Stochastic event flood model (SEFM)-Technical support manual: Olympia, Washington, MGS Software LLC, [variously paged]. [Also available at http://www.mgsengr.com/SEFM/Download/SEFM_Tec hnicalSupportManual_March2018.pdf.].

Milly, P.C.D., Betancourt, J., Falkenmark, M., Hirsch, R.M., Kundzewicz, Z.W., Lettenmaier, D.P., and Stouffer, R.J., 2008, Stationarity is dead-Whither water management?: Science, v. 319, no. 5863, p. 573-574.

Montgomery, D.R., 2016, Emperor Yu's great flood: Science, v. 353 , no. 6299 , p. $538-539$.

Moseley, G.E., Richards, D.A., Smart, P.L., Standish, C.D., Hoffman, D.L., ten Hove, H., and Vinn, O., 2015, Early-middle Holocene relative sea-level oscillation events recorded in a submerged speleothem from the Yucatán Peninsula, Mexico: The Holocene, v. 25, no. 9, p. 1511-1521, https://doi.org/10.1177/0959683615585832.

Munoz, S.E., Giosan, L., Therrell, M.D., Remo, J.W.F., Shen, Z., Sullivan, R.M., Wiman, C., O'Donnell, M., and Donnelly, J.P., 2018, Climatic control of Mississippi River flood hazard amplified by river engineering: Nature, v. 556, no. 7699 , p. 95-98.
Munoz, S.E., Gruley, K.E., Massie, A., Fike, D.A., Schroeder, S., and Williams, J.W., 2015, Cahokia's emergence and decline coincided with shifts in flood frequency on the Mississippi River: Proceedings of the National Academy of Sciences of the United States of America, v. 112, no. 20, p. 6319-6324.

Murphy, E.C., 1906, Destructive floods in the United States in 1905, with a discussion of flood discharge and frequency and an index to flood literature: U.S. Geological Survey Water-Supply and Irrigation Paper 162, 105 p., accessed May 24, 2019, at https://doi.org/10.3133/wsp162.

Murray, A.S., and Wintle, A.G., 2000, Luminescence dating of quartz using an improved single-aliquot regenerative-dose protocol: Radiation Measurements, v. 32, no. 1, p. 57-73.

Nanson, G.C., and Beach, H.F., 1977, Forest succession and sedimentation on a meandering-river floodplain, northeast British Columbia, Canada: Journal of Biogeography, v. 4, no. 3, p. 229-251.

Nathan, R., and Weinmann, E., 2019, Very rare to extreme flood estimation, book 8 of Ball, J., Babister, M., Nathan, R., Weeks, W., Weinmann, E., Retallick, M., and Testoni, I., eds., Australian rainfall and runoff-A guide to flood estimation: Symonston, Commonwealth of Australia, [unpaginated], accessed August 5, 2020, at http://book.arr. org.au.s3-website-ap-southeast-2.amazonaws.com.

National Centers for Environmental Information, 2020, Paleoclimatology data: National Oceanic and Atmospheric Administration web page, accessed January, 2020, at https: //www.ncdc.noaa.gov/data-access/paleoclimatology-data.

National Research Council, 2014, Lessons learned from the Fukushima nuclear accident for improving safety of U.S. nuclear plants: Washington, D.C., The National Academies Press, $366 \mathrm{p}$.

Natural Resources Conservation Service, 2014, Soil survey technical note 10 - Buried soils and their effect on taxonomic classification: U.S. Department of Agriculture web page, accessed November 2020, at https: //www.nrcs.usda.gov/wps/portal/nrcs/detail/soils/ref/?cid= nrcs142p2_053568.

North Dakota State University Archives, 2020, Fargo, North Dakota-Its history and images: North Dakota State University web page, accessed July 8, 2020, at https ://library.ndsu.edu/fargo-history/?q=content/front-streetmain-avenue. 
Novembre, N.J., Sankovich, V., Caldwell, J., and Niehaus, J.P., 2012, Altus Dam hydrologic hazard and reservoir routing for corrective action study: Denver, Colorado, Bureau of Reclamation, $216 \mathrm{p}$.

O’Connell, D.R.H., Ostenaa, D.A., Levish, D.R., and Klinger, R.E., 2002, Bayesian flood frequency analysis with paleohydrologic bound data: Water Resources Research, v. 38, no. 5, p. 16-1-16-13, https://doi.org/10.1029/2000WR000028.

O’Connor, J.E., Atwater, B.F., Cohn, T.A., Cronin, T.M., Keith, M.K., Smith, C.G., and Mason, R.R., 2014, Assessing inundation hazards to nuclear powerplant sites using geologically extended histories of riverine floods, tsunamis, and storm surges: U.S. Geological Survey Scientific Investigations Report 2014-5207, 66 p., https://doi.org/ $10.3133 / \operatorname{sir} 20145207$.

O’Connor, J.E., and Driscoll, D.G., 2007 Applicability of paleoflood surveys to the Black Hills of western South Dakota-Executive summary: South Dakota Department of Transportation, Study SD2005-12, 9 p.

O’Connor, J.E., Ely, L.L., Wohl, E.E., Stevens, L.E., Melis, T.S., Kale, V.S., and Baker, V.R., 1994, A 4500-year record of large floods on the Colorado River in the Grand Canyon: The Journal of Geology, v. 102, no. 1, p. 1-9.

O’Connor, J.E., Hardison, J.H., III, and Costa, J.E., 2001, Debris flows from failures of neoglacial-age moraine dams in the Three Sisters and Mount Jefferson Wilderness Areas, Oregon: U.S. Geological Survey Professional Paper 1606, 93 p, 2 pls.

O’Connor, J.E., and Webb, R.H., 1988, Hydraulic modeling for palaeoflood analysis, in Baker, R.V., Kochel, R.C., and Patton, P.C., eds., Flood geomorphology: New York, Wiley, p. 393-403.

O’Connor, J.E., Webb, R.H., and Baker, V.R., 1986, Paleohydrology of pool-and-riffle pattern developmentBoulder Creek, Utah: Geological Society of America Bulletin, v. 97, no. 4, p. 410-420.

Olivia, F., Viau, A.E., Bjornson, J., Desrochers, N., and Bonneau, M.A., 2016, A 1300 year reconstruction of paleofloods using oxbow lake sediments in temperate southwestern Quebec, Canada: Canadian Journal of Earth Sciences, v. 53 , no. 4 , p. 378-386.

Olsen, J.R., Kiang, J.E., and Waskom, R., 2010, Workshop on nonstationarity, hydrologic frequency analysis, and water management, Boulder, Colorado, January 13-15, 2010: Fort Collins, Colorado State University, Colorado Water Institute Information Series No. 109, 304 p.
Orton, P.M., Hall, T.M., Talke, S.A., Blumberg, A.F., Georgas, N., and Vinogradov, S., 2016, A validated tropicalextratropical flood hazard assessment for New York Harbor: Journal of Geophysical Research-Oceans, v. 121, no. 12, p. 8904-8929, accessed July 7, 2020, at https://doi.org/ 10.1002/2016JC011679.

Ostenaa, D., 2017, Better characterizing uncertainty in geologic paleoflood analyses [abs.], Geological Society of America annual meeting, Seattle, Washington, October, 24, 2017: Geological Society of America Abstracts with Programs, v. 49, no. 6, https://gsa.confex.com/gsa/2017AM/ webprogram/Paper307601.html.

Ostenaa, D.A., Klinger, R.E., and O’Connell, D.H.R., 2001, Paleoflood study of the Cantua stream group, California: Denver, Colorado, Bureau of Reclamation, Seismotectonic and Geophysics Group, 220 p.

Osterkamp, W.R., and Hupp, C.R., 1984, Geomorphic and vegetative characteristics along three northern Virginia streams: Geological Society of America Bulletin, v. 95, no. 9, p. 1093-1101.

Oxford University Press, 2017, 'Historic' or 'historical'?: Oxford, United Kingdom, Oxford University Press-powered Lexico web page, accessed November 3, 2017, at http s://en.oxforddictionaries.com/usage/historic-or-historical.

Panshin, A.J., and de Zeeuw, C., 1980, Textbook of wood technology-Structure, identification, properties, and uses of the commercial woods of the United States and Canada, volume 1: New York, McGraw Hill, 722 p.

Parris, A.S., Bierman, P.R., Noren, A.J., Prins, M.A., and Lini, A., 2010, Holocene paleostorms identified by particle size signatures in lake sediments from the northeastern United States: Journal of Paleolimnology, v. 43, no. 1, p. 29-49.

Patterson, J.L., 1966, Magnitude and frequency of floods in the United States - Part 6-A, Missouri River Basin above Sioux City, Iowa: U. S. Geological Survey WaterSupply Paper 1679, 471 p., accessed May 24, 2019, at https://doi.org/10.3133/wsp1679.

Patterson, J.L., and Gamble, C.R., 1968, Magnitude and frequency of floods in the United States-Part 5, Hudson Bay and Upper Mississippi River Basins: U.S. Geological Survey Water-Supply Paper 1678, 546 p., accessed May 24, 2019, at https://doi.org/10.3133/wsp1678.

Pearce, J.T., 2017, Limited geomorphic investigation of paleoflooding for Cherry Creek Dam (CO01280): Lakewood, Colorado, U.S. Army Corps of Engineers, Risk Management Center, Report RMC-TR-2017-10, 26 p. 
Pockman, W.T., and Sperry, J.S., 2000, Vulnerability to xylem cavitation and the distribution of Sonoran Desert vegetation: American Journal of Botany, v. 87, no. 9, p. 1287-1299.

Porat, N., 2006, Use of magnetic separation for purifying quartz for luminescence dating: Ancient TL, v. 24, no. 2 , p. 33-36.

Potter, K.W., 1976, Evidence for nonstationarity as a physical explanation of the Hurst Phenomenon: Water Resources Research, v. 12, no. 5, p. 1047-1052.

Rannie, W.F., 1998, A survey of hydroclimate, flooding, and runoff in the Red River Basin prior to 1870: Geological Survey of Canada Open-File Report 3705, 189 p., accessed May 24, 2019, at https://digitalcollection.gov.mb.ca/awweb/ pdfopener?smd=1\&did=18421\&md=1.

Razavi, S., Elshorbagy, A., Wheater, H., and Sauchyn, D., 2015, Toward understanding nonstationarity in climate and hydrology through tree ring proxy records: Water Resources Research, v. 51, no. 3, p. 1813-1830.

Reily, P.W., and Johnson, W.C., 1982, The effects of altered hydrologic regime on tree growth along the Missouri River in North Dakota: Canadian Journal of Botany, v. 60, no. 11, p. 2410-2423.

Reimer, P.J., Baillie, M.G.L., Bard, E., Bayliss, A., Beck, J.W., Blackwell, P.G., Bronk Ramsey, C., Buck, C.E., Burr, G.S., Edwards, R.L., Friedrich, M., Grootes, P.M., Guilderson, T.P., Hajdas, I., Heaton, T.J., Hogg, A.G., Hughen, K.A., Kaiser, K.F., Kromer, B., McCormac, F.G., Manning, S.W., Reimer, R.W., Richards, D.A., Southon, J.R., Talamo, S., Turney, C.S.M., van der Plicht, J., and Weyhenmeyer, C.E., 2009, IntCal09 and Marine09 radiocarbon age calibration curves, 0-50,000 years cal BP: Radiocarbon, v. 51, no. 4, p. $1111-1150$.

Rhodes, E.J., 2011, Optically stimulated luminescence dating of sediments over the past 200,000 years: Annual Review of Earth and Planetary Sciences, v. 39, no. 1, p. 461-488.

Rico, M., Benito, G., and Barnolas, A., 2001, Combined palaeoflood and rainfall-runoff assessment of mountain floods (Spanish Pyrenees): Journal of Hydrology, v. 245, nos. 1-4, p. 59-72.

Rodnight, H., Duller, G.A.T., Wintle, A.G., and Tooth, S., 2006, Assessing the reproducibility and accuracy of optical dating of fluvial deposits: Quaternary Geochronology, v. 1, no. 2, p. 109-120.

Rubtsov, M.V., and Salmina, I.U.N., 1983, Use of buried Salix thickets for determination of the chronology of floodplain deposits: Lesovedinie, p. 69-70.
Ruiz-Villanueva, V., Diez-Herrero, A., Stoffel, M., Bollschweiler, M., Bodoque, J.M., and Ballesteros, J.A., 2010, Dendrogeomorphic analysis of flash floods in a small ungauged mountain catchment (central Spain): Geomorphology, v. 118, nos. 3-4, p. 383-392.

Rumsey, B., 2015, From flood flows to flood maps-The understanding of flood probabilities in the United States: Historical Social Research, v. 40, no. 2, p. 134-150.

Ryberg, K.R., 2008, PFReports-A program for systematic checking of annual peaks in NWISWeb: U.S. Geological Survey Open-File Report 2008-1284, 17 p.

Ryberg, K.R., Goree, B.B., Williams-Sether, T., and Mason Jr., R.R., 2017, The U.S. Geological Survey peak-flow file data verification project, 2008-16: U.S. Geological Survey Scientific Investigations Report 2017-5119, 76 p., accessed November 2, 2017, at https://doi.org/10.3133/sir20175119.

Ryberg, K.R., Kolars, K.A., Kiang, J.E., and Carr, M.L., 2020, Flood-frequency estimation for very low annual exceedance probabilities using historical, paleoflood, and regional information with consideration of nonstationarity: U.S. Geological Survey Scientific Investigations Report 2020-5065, 89 p.

Sabol, T.A., Griffiths, R.E., Topping, D.J., Mueller, E.R., Tusso, R.B., and Hazel, J.E., Jr., 2021, Strandlines from large floods on the Colorado River in Grand Canyon National Park, Arizona (ver. 1.1, September 2021): U.S. Geological Survey Scientific Investigations Report 2021-5048, 41 p., https://doi.org/10.3133/sir20215048.

Salas, J.D., Rajagopalan, B., Saito, L., and Brown, C., 2012, Special section on climate change and water resourcesClimate nonstationarity and water resources management: Journal of Water Resources Planning and Management, v. 138 , no. 5 , p. $385-388$.

Salas, J.D., Wohl, E.E., and Jarrett, R.D., 1994, Determination of flood characteristics using systematic, historical and paleoflood data, in Rossi, G., Harmancioğlu, N., and Yevjevich, V., eds., Coping with floods, v. 257 of NATO ASI Series: Dordrecht, The Netherlands, Springer, $\mathrm{p}$ 111-134, https://doi.org/10.1007/978-94-011-1098-3_7.

Sando, S.K., and McCarthy, P.M., 2018, Methods for peakflow frequency analysis and reporting for streamgages in or near Montana based on data through water year 2015: U.S. Geological Survey Scientific Investigations Report 2018-5046, 39 p., https://doi.org/10.3133/sir20185046.

Schillereff, D.N., 2015, Lake sediment records of flood frequency and magnitude: Liverpool, United Kingdom, University of Liverpool, Ph.D. thesis, 354 p. 
Schillereff, D.N., Chiverrell, R.C., MacDonald, N., and Hooke, J.M., 2014, Flood stratigraphies in lake sediments-A review: Earth-Science Reviews, v. 135, p. 17-37.

Schneuwly-Bollschweiler, M., Corona, C., and Stoffel, M., 2013, How to improve dating quality and reduce noise in tree-ring based debris-flow reconstructions: Quaternary Geochronology, v. 18, p. 110-118.

Schook, D.M., Friedman, J.M., and Rathburn, S.L., 2016, Flow reconstructions in the Upper Missouri River Basin using riparian tree rings: Water Resources Research, v. 52, no. 10 , p. 8159-8173, https://doi.org/10.1002/ 2016WR018845.

Schook, D.M., Rathburn, S.L., Friedman, J.M., and Wolf, J.M., 2017, A 184-year record of river meander migration from tree rings, aerial imagery, and cross sections: Geomorphology, v. 293, p. 227-239.

Scileppi, E., and Donnelly, J.P., 2007, Sedimentary evidence of hurricane strikes in western Long Island, New York: Geochemistry, Geophysics, Geosystems, v. 8, no. 6, 25 p., accessed July 7, 2020, at https://doi.org/10.1029/ 2006GC001463.

Scott, M.L., Auble, G.T., and Friedman, J.M., 1997, Flood dependency of cottonwood establishment along the Missouri River, Montana, USA: Ecological Applications, v. 7 , no. 2, p. 677-690.

Scott, M.L., Friedman, J.M., and Auble, G.T., 1996, Fluvial process and the establishment of bottomland trees: Geomorphology, v. 14, no. 4, p. 327-339.

Sheffer, N.A., Enzel, Y., Benito, G., and others, 2003, Historical and palaeofloods of the Ardeche River, France: Water Resources Research, v. 39, no. 12, p. 7-1-7-13.

Shroder, J.F., Jr., 1980, Dendrogeomorphology—Review and new techniques of tree-ring dating: Progress in Physical Geography, v. 4, no. 2, p. 161-188.

Sigafoos, R.S., 1964, Botanical evidence of floods and floodplain deposition: U.S. Geological Survey Professional Paper $485 \mathrm{~A}, 35 \mathrm{p}$.

Smith, H., Bartles, M., and Fleming, M., 2018a, Hydrologic hazard methodology for semi-quantitative risk assessments-An inflow volume-based approach to estimating stage-frequency curves for dams: Lakewood, Colorado, U.S. Army Corps of Engineers, Risk Management Center, Report RMC-TR-2018-03, 132 p.
Smith, H., and Doughty, M., 2020, RMC-BestFit quick start guide: Lakewood, Colorado, U.S. Army Corps of Engineers, Risk Management Center, Technical Report RMC-TR-2020-03, 99 p., accessed December 4, 2020, at https://www.iwrlibrary.us/\#/document/f1767e9f-714d-43b7cf74-ed1bd65f9dd9.

Smith, H., Sasaki, R., Karlovits, G.S., Hall, B.M., and Parola, A., 2018b, Hydrologic hazard curve analysis for Whittier Narrows Dam (CA10027), Rio Hondo and San Gabriel Rivers, California: Lakewood, Colorado, U.S. Army Corps of Engineers, Risk Management Center, Report RMCTR-2018-11, 145 p.

Speer, P.R., and Gamble, C.R., 1964a, Magnitude and frequency of floods in the United States, Part 2-A, South Atlantic slope basins, James River to Savannah River: U.S. Geological Survey Water-Supply Paper 1673, 329 p., accessed May 24, 2019, at https://doi.org/10.3133/wsp1673.

Speer, P.R., and Gamble, C.R., 1964b, Magnitude and frequency of floods in the United States, Part 3-B, Cumberland and Tennessee River Basins: U.S. Geological Survey Water-Supply Paper 1676, 340 p., accessed May 24, 2019, at https://doi.org/10.3133/wsp1676.

Speer, P.R., and Gamble, C.R., 1965, Magnitude and frequency of floods in the United States, Part 3-A, Ohio River Basin except Cumberland and Tennessee River Basins: U.S. Geological Survey Water-Supply Paper 1675, 630 p., accessed May 24, 2019, at https://doi.org/10.3133/wsp1675.

Stambaugh, M.C., and Guyette, R.P., 2009, Progress in constructing a long oak chronology from the central United States: Tree-Ring Research, v. 65 , no. 2, p. 147-156, https://doi.org/10.3959/2008-14.1.

Stedinger, J.R., and Baker, V.R., 1987, Surface water hydrology - Historical and paleoflood information: Reviews of Geophysics, v. 25, no. 2, p. 119-124, https://doi.org/ 10.1029/RG025i002p00119.

Stedinger, J.R., and Cohn, T.A., 1986, Flood frequency analysis with historical and paleoflood information: Water Resources Research, v. 22, no. 5, p. 785-793.

St. George, S., 2010, Tree rings as paleoflood and paleostage indicators, in Stoffel, M., Bollschweiler, M., Butler, D., and Luckman, B., eds., Tree rings and natural hazards, v. 41 of Advances in global change research: Dordrecht, The Netherlands, Springer, p. 223-239, https://doi.org/10.1007/ 978-90-481-8736-2 22. 
St. George, S., and Nielsen, E., 2002, Flood ring evidence and its application to paleoflood hydrology of the Red River and Assiniboine Rivers in Manitoba: Géographie Physique et Quaternaire, v. 56, nos. 2-3, p. 181-190, https://doi.org/ 10.7202/009104ar.

St. George, S., and Nielsen, E., 2003, Paleoflood records for the Red River, Manitoba, Canada, derived from anatomical tree-ring signatures: The Holocene, v. 13, no. 4, p. 547-555.

St. George, S., Nielsen, E., Conciatori, F., and Tardif, J., 2002, Trends in Quercus macrocarpa vessel areas and their implications for tree-ring paleoflood studies: Tree-Ring Research, v. 58 , p. $3-10$.

Stoffel, M., and Bollschweiler, M., 2008, Tree-ring analysis in natural hazards research-An overview: Natural Hazards and Earth System Sciences, v. 8, no. 2, p. 187-202.

Stokes, M.A., and Smiley, T.L., 1968, An introduction to tree-ring dating: Chicago, Illinois, University of Chicago Press, 73 p.

Strobel, M.L., Jarrell, G.J., Sawyer, J.F., Schleicher, J.R., and Fahrenbach, M.D., 1999, Distribution of hydrogeologic units in the Black Hills area, South Dakota: U.S. Geological Survey Hydrologic Investigations Atlas HA-743, 3 sheets, scale 1:100,000. [Also available at https://pubs.usgs.gov/ ha/ha743/.]

Strunk, H., 1997, Dating of geomorphological processes using dendrogeomorphological methods: Catena, v. 31, nos.. 1-2, p. 137-151.

Strupczewski, W.G., Kochanek, K., and Bogdanowicz, E., 2014, Flood frequency analysis supported by the largest historical flood: Natural Hazards and Earth System Sciences, v. 14 , no. 6 , p. 1543-1551.

Sutcliffe, J.V., 1987, The use of historical records in flood frequency analysis: Journal of Hydrology, v. 96, no. 1-4, p. 159-171, https://doi.org/10.1016/0022-1694(87)90150-8.

Sutton, A., and Tardif, J., 2005, Distribution and anatomical characteristics of white rings in Populus tremuloides: International Association of Wood Anatomists Journal, v. 26, p. 221-238.

Swain, R.E., England, J.F., Jr., Bullard, K.L., and Raff, D.A., 2006, Guidelines for evaluating hydrologic hazards: Bureau of Reclamation, $83 \mathrm{p}$.
Talke, S.A., and Jay, D.A., 2017, Archival water-level measurements - Recovering historical data to help design for the future: U.S. Army Corps of Engineers Institute for Water Resources Civil Works Technical Series CWTS 2017-02, 45 p., accessed June 4, 2019, at https://usace.contentdm.oclc.org/digital/collection/ p266001coll1/id/5102.

Talke, S.A., Kemp, A.C., and Woodruff, J., 2018, Relative sea level, tides, and extreme water levels in Boston Harbor from 1825 to 2018: Journal of Geophysical Research-Oceans, v. 123 , no. 6 , p. 3895-3914.

Talke, S.A., Orton, P., and Jay, D.A., 2014, Increasing storm tides in New York Harbor, 1844-2013: Geophysical Research Letters, v. 41, no. 9, p. 3149-3155.

Tardif, J., and Bergeron, Y., 1997, Ice-flood history reconstructed with tree-rings from the southern boreal forest limit, western Québec: The Holocene, v. 7, no. 3, p. 291-300.

Tennessee Valley Authority, 1940, Flood profiles, Tennessee River-Mile 350-370 (Engineering drawing 1K112R), Flood control investigations: Knoxville, Tennessee, Tennessee Valley Authority, Water Control Planning Department, 1 pl.

Tennessee Valley Authority, 1961, Floods and flood control: Knoxville, Tennessee, Tennessee Valley Authority, Technical Report 26, 302 p.

Therrell, M.D., and Bialecki, M.B., 2015, A multi-century tree-ring record of spring flooding on the Mississippi River: Journal of Hydrology, v. 529, p. 490-498.

Therrell, M.D., Meko, D., Bialecki, M., and Remo, J.W., 2017, Assessment of methods to determine tree ring response to large magnitude Mississippi River floods [abs.]: American Geophysical Union, Fall Meeting 2017, Abstract, no. PP31A-1268.

Thomson, M.T., Gannon, W.B., Thomas, M.P., Hayes, G.S., and others, 1964, Historical floods in New England: U.S. Geological Survey Water Supply Paper 177-M, 105 p.

Thorndycraft, V., Benito, G., Rico, M., Sopena, A., SanchezMoya, Y., and Casas, M., 2005, A long-term flood discharge record derived from slackwater flood deposits of the Llobregat River, NE Spain: Journal of Hydrology, v. 313, nos. 1-2, p. 16-31. 
Tice, R.H., 1968, Magnitude and frequency of floods in the United States-Part 1-B, North Atlantic slope basins, New York to York River: U.S. Geological Survey WaterSupply Paper 1672, 585 p., accessed May 24, 2019, at https://doi.org/10.3133/wsp1672.

Toonen, W.H.J., Kleinhans, M.G., and Cohen, K.M., 2012, Sedimentary architecture of abandoned channel fills: Earth Surface Processes and Landforms, v. 37, no. 4, p. 459-472.

Toonen, W.H.J., Winkels, T.G., Cohen, K.M., Prins, M.A., and Middelkoop, H., 2015, Lower Rhine historical flood magnitudes of the last 450 years reproduced from grain-size measurements of flood deposits using end member modelling: Catena, v. 130, p. 69-81.

Topping, D.J., Schmidt, J.C., and Vierra, L.E., Jr., 2003, Computation and analysis of the instantaneous-discharge record for the Colorado River at Lees Ferry, Arizona-May 8, 1921, through September 30, 2000: U.S. Geological Survey Professional Paper 1677, 118 p.

Turzewski, M.D., Huntington, K.W., and LeVeque, R.J., 2019, The geomorphic impact of outburst floods - Integrating observations and numerical simulations of the 2000 Yigong Flood, Eastern Himalaya: Journal of Geophysical Research—Earth Surface, v. 124, no. 5, p. 1056-1079.

U.S. Army Corps of Engineers, 2016, HEC-RAS river analysis system hydraulics reference manual CPD-68, version 5.0: Davis, California, U.S. Army Corps of Engineers Hydrologic Engineering Center, 962 p., https://www .hec.usace.army.mil/software/hec-ras/documentation.aspx.

U.S. Army Corps of Engineers, 2019, HEC-SSP statistical software package user's manual CPD-86, version 2.2: Davis, California, U.S. Army Corps of Engineers, Hydrologic Engineering Center, 81 p., https://www .hec.usace.army.mil/software/hec-ssp/documentation.aspx.

U.S. Army Corps of Engineers, 2020b, Developing paleoflood information for flood frequency analysis: U.S. Army Corps of Engineers Technical Letter No. 1100-2-4, 34 p.

U.S. Army Corps of Engineers, 2020a, 308 reports series: U.S. Army Corps of Engineers Institute for Water Resources, web page, accessed November 2020, at https://www .iwr.usace.army.mil/Library/IWR-Library/308-ReportsProgram-Series/.

U.S. Geological Survey, 1952, Floods of 1950 in the Red River of the North and Winnipeg River Basins: U.S. Geological Survey Water Supply Paper 1137-B, accessed July 7, 2020, at https://pubs.er.usgs.gov/publication/wsp1137B.
U.S. Geological Survey, 1962, Surface water records of Colorado: U.S. Geological Survey Water Data Report CO-62-1, 335 p. [Also available at https://pubs.er.usgs.gov/ publication/wdrCO621.]

U.S. Geological Survey, 2019, Peak streamflow for ArizonaUSGS 09380000 Colorado River at Lees Ferry, Arizona: U.S. Geological Survey National Water Information System-Web interface database, accessed April 18, 2019 , at https://nwis.waterdata.usgs.gov/az/nwis/peak/?site no= 09380000 and https://doi.org/10.5066/F7P55KJN.

U.S. Geological Survey, 2020c, Colorado flood database: Denver, Colorado, U.S. Geological Survey Colorado Water Science Center database, accessed May 2020, at https://cwscpublic2.cr.usgs.gov/projects/coflood/ COFloodMap.html.

U.S. Geological Survey, 2020d, Flood database for Oklahoma: Oklahoma City, Oklahoma, U.S. Geological Survey Oklahoma Water Science Center database, accessed April 2020, at https:/webapps.usgs.gov/dbflood/.

U.S. Geological Survey, 2020a, Peak streamflow for the Nation: U.S. Geological Survey National Water Information System-Web interface database, accessed July 6, 2020, at https://nwis.waterdata.usgs.gov/usa/nwis/peak and https://doi.org/10.5066/F7P55KJN.

U.S. Geological Survey, 2020b, Water-year summary for site USGS 05054000: U.S. Geological Survey National Water Information System - Web interface database, accessed July 8, 2020, at https://nwis.waterdata.usgs.gov/nd/nwis/ wys_rpt/?site_no $=05054000 \&$ agency_cd $=$ USGS and https://doi.org/10.5066/F7P55KJN.

Van Hateren, J.A., Prins, M.A., and van Balen, R.T., 2017, On the genetically meaningful composition of grain-size distributions - A comparison of different end-member modelling algorithms: Sedimentary Geology, v. 375, p. 49-71.

Vecchia, A.V., 2008, Climate simulation and flood risk analysis for 2008-40 for Devils Lake, North Dakota: U.S. Geological Survey Scientific Investigations Report 2008-5011, 36 p., accessed March 2020, at https://doi.org/ $10.3133 /$ sir20085011.

Veilleux, A.G., Cohn, T.A., Flynn, K.M., Mason, R.R., and Hummel, P.R., 2014, Estimating magnitude and frequency of floods using the PeakFQ 7.0 program: U.S. Geological Survey Fact Sheet 2013-3108, 2 p., accessed September 30, 2016, at https://doi.org/10.3133/fs20133108. 
Vigicrues, 2020, National collaborative platform of flood sites and landmarks: Ministry of Ecological Transition, France, web page, accessed May 2020, at https://www.reperesde crues.developpement-durable.gouv.fr.

Vogel, J.S., Southon, J.R., Nelson, D.E., and Brown, T.A., 1984, Performance of catalytically condensed carbon for use in accelerator mass spectrometry: Nuclear Instruments and Methods in Physics Research, Section B-Interactions with Materials and Atoms, v. 5, no. 2, p. 289-293.

Wagner, D., Kiang, J.E., and Asquith, W.H., 2017, U.S. Geological Survey streamgaging methods and annual peak streamflow, app. 1 of Application of at-site peak-streamflow frequency analyses for very low annual exceedance probabilities: U.S. Geological Survey Scientific Investigation Report 2017-5038, p. 52-66.

Walker, M., 2005, Quaternary dating methods: Chichester, United Kingdom, Wiley, 286 p.

Wallinga, J., and Cunningham, A.C., 2014, Luminescence dating, uncertainties, and age range, in Rink, W., and Thompson, J., eds., Encyclopedia of scientific dating methods: Dordrecht, The Netherlands, Springer, 9 p.

Wang, L., and Leigh, D.S., 2012, Late-Holocene paleofloods in the Upper Little Tennessee River Valley, Southern Blue Ridge Mountains, USA: The Holocene, v. 22, no. 9, p. 1061-1066.

Water Resources Council, 1967, A uniform technique for determining flood flow frequencies: U.S. Water Resources Council Hydrology Committee Bulletin No. 15, accessed January 23, 2017, at https://water.usgs.gov/osw/bulletin17b/ Bulletin_15_1967.pdf.

Waterhouse, J.S., Barker, A.C., Carter, A.H.C., Agafonov, L.I., and Loader, N.J., 2000, Stable carbon isotopes in scots pine tree rings preserve a record of flow of the river $\mathrm{Ob}$ : Geophysical Research Letters, v. 27, no. 21, p. 3529-3532.

Waythomas, C.F., and Jarrett, R.D., 1994, Flood geomorphology of Arthurs Rock Gulch, Colorado-Paleoflood history: Geomorphology, v. 11, no. 1, p. 15-40.

Webb, R.H., Blainey, J.B., and Hyndman, D.W., 2002, Paleoflood hydrology of the Paria River, southern Utah and Northern Arizona, USA, in House, P.K., Webb, R.H., Baker, V.R., and Levish, D.L., eds., Ancient floods, modern hazards - Principles and applications of paleoflood hydrology, v. 5 of Water science and application series: Washington, D.C., American Geophysical Union, p. 295-310.
Webb, R.H., and Jarrett, R.D., 2002, One-dimensional estimation techniques for discharges of paleofloods and historical floods, in House, P.K., Webb, R.H., Baker, V.R., and Levish, D.L., eds., Ancient floods, modern hazards-Principles and applications of paleoflood hydrology, v. 5 of Water science and application series: Washington, D.C., American Geophysical Union, p. 111-125.

Webb, R.H., O’Connor, J.E., and Baker, V.R., 1988, Paleohydrologic reconstruction of flood frequency on the Escalante River, south-central Utah, in Baker, V.R., Kochel, R.C., and Patton, P.C., eds., Flood Geomorphology: New York, Wiley, p. 403-418.

Wells, J.V.B., 1955, Floods of 1952 in the basins of the upper Mississippi River and Red River of the North: U.S. Geological Survey Water Supply Paper 1260-C, accessed July 13, 2021, at http://pubs.er.usgs.gov/publication/ wsp1260C.

Wertz, E.L., St. George, S., and Zeleznik, J.D., 2013, Vessel anomalies in Quercus macrocarpa tree rings associated with recent floods along the Red River of the North, United States: Water Resources Research, v. 49, p. 630-634, https://doi.org/10.1029/2012WR012900.

Wiitala, S.W., 1965, Magnitude and frequency of floods in the United States - Part 4, St. Lawrence River Basin: U.S. Geological Survey Water-Supply Paper 1677, 357 p., accessed July 13, 2012, at https://doi.org/10.3133/wsp1677.

Wilhelm, B., Ballesteros Cánovas, J.A., Macdonald, N., Toonen, W.H., Baker, V., Barriendos, M., Benito, G., Brauer, A., Corella, J.P., Denniston, R., Glaser, R., Ionita, M., Kahle, M., Liu, T., Luetscher, M., Macklin, M., Mudelsee, M., Munoz, S., Schulte, L., St. George, S., Stoffel, M., and Wetter, O., 2018, Interpreting historical, botanical, and geological evidence to aid preparations for future floods: Wiley Interdisciplinary Reviews - Water, v. 6, no. 1, 22 p., https://doi.org/10.1002/wat2.1318.

Wilhelm, B., Canovas, J.A.B., Aznar, J.P.C., Kämpf, L., Swierczynski, T., Stoffel, M., Støren, E., and Toonen, W., 2018, Recent advances in paleoflood hydrology-From new archives to data compilation and analysis: Water Security, v. 3, p. 1-8.

Williams, G.P., 1984, Paleohydrological methods and some examples from Swedish fluvial environments, II, River meanders: Geografiska Annaler, v. 66A, p. 89-102. 
Williams, G.P., 1988, Paleofluvial estimates from dimensions of former channels and meanders, in Baker, V.R., Kochel, R.C., and Patton, P.C., eds., Flood geomorphology: New York, Wiley, p. 321-334.

Williams, G.P., and Costa, J.E., 1988, Geomorphic measurements after a flood, in Baker, R.V., Kochel, R.C., and Patton, P.C., eds., Flood geomorphology: New York, Wiley, p. 65-77.

Winters, K.E., and Baldys, S., 2011, Assessment of channel changes, model of historical floods, and effects of backwater on flood stage, and flood mitigation alternatives for the Wichita River at Wichita Falls, Texas: U.S. Geological Survey Scientific Investigations Report 2011-5175, 28 p.

Wintle, A.G., and Murray, A.S., 2006, A review of quartz optically stimulated luminescence characteristics and their relevance in single-aliquot regeneration dating protocols: Radiation Measurements, v. 41, no. 4, p. 369-391.

Wohl, E., 2010, Mountain rivers revisited, v. 19 of Water Resources Monograph: Washington, D.C., American Geophysical Union, 574 p.

Wolman, M.G., and Gerson, R., 1978, Relative scales of time and effectiveness of climate in watershed geomorphology: Earth Surface Processes, v. 3, no. 2, p. 189-208.

Wright, J.M., Sankovich, V., and Niehaus, J.P., 2013, Friant Dam hydrologic hazard for issue evaluation: Denver, Colorado, Bureau of Reclamation, 225 p.
Xing, J., Parry, G., Presley, M., Forester, J., Hendrickson, S., and Dang, V., 2017, An integrated human event analysis system (IDHEAS) for nuclear power plant internal events at-power application_-Volume 1: Nuclear Regulatory Commission NUREG-2199, accessed August 5, 2020, at https://www.nrc.gov/docs/ML1707/ML17073A041.pdf.

Yamaguchi, D.K., Atwater, B.F., Bunker, D.E., Boyd, E.B., and Reid, M.S., 1997, Tree-ring dating the 1700 Cascadia earthquake: Nature, v. 389, no. 6654, p. 922-923.

Yanosky, T.M., 1983, Evidence of floods on the Potomac River from anatomical abnormalities in the wood of floodplain trees: U.S. Geological Survey Professional Paper 1296, 42 p.

Yanosky, T.M., and Jarrett, R.D., 2002, Dendrochronologic evidence for the frequency and magnitude of paleofloods, in House, P.K., Webb, R.H., Baker, V.R., and Levish, D.R., eds., Ancient floods, modern hazards - Principles and applications of paleoflood hydrology, v. 5 of Water science and application series: Washington, D.C., American Geophysical Union, p. 77-89.

Zhu, C., Zheng, C., Ma, C., Sun, Z., Zhu, G., Wang, H., Gao, H., Wang, P., and Huang, R., 2005, Identifying paleoflood deposits archived in Zhongba Site, the Three Gorges reservoir region of the Yangtze River, China: Chinese Science Bulletin, v. 50, no. 21, p. 2493-2504.

Zio, E., and Pedroni, N., 2012, Risk-informed decisionmaking processes - An overview, report number 2012-10: Toulouse, France, Cahiers de la Sécurité Industrielle, Foundation for an Industrial Safety Culture, 48 p. 


\section{Appendix 1. Development of a Framework for Technical Review of Paleoflood Information Workshop}

As part of this project, a workshop was held during May 29-30, 2019, at the Nuclear Regulatory Commission in Rockville, Maryland. The purpose of the workshop was to gather technical input and guidance from experts in the field for the benefit of this Techniques and Methods Report.

Panels of experts on probabilistic flood-hazard assessment, paleohydrology and geomorphology, historical and botanical evidence for past floods, and levels of review shared their expertise on paleoflood data collection, interpretation, and use. Partner agencies and academics were invited to provide technical input and guidance. Time was included for questions and input from the participants. We thank the participants for their time, knowledge, and enthusiasm for the subject.

\section{Panels}

Individuals gave presentations and participated in panel discussion on the following topics:

1. Uses of systematic, historical, and paleoflood data in PFHA —Probabilistic flood-hazard assessment;

2. Historical peak-flow data;

3. Determining floods from botanical evidence;

4. Sedimentological, stratigraphic, geochronological data;

5. Flow reconstruction;

6. Levels of review; and

7. Flood databases.

\section{Participants}

Following is a list of the participants in the workshop:

- Ralph Klinger, Bureau of Reclamation

- Robert Jarrett, Flood and Paleoflood Science, LLC

- Will Thomas, Michael Baker International

- David Jay, Portland State University

- Stefan Talke, Portland State University
- John England, Jr., U.S. Army Corps of Engineers

- Keith Kelson, U.S. Army Corps of Engineers

- William Asquith, U.S. Geological Survey

- Jonathan Friedman, U.S. Geological Survey

- Tessa Harden, U.S. Geological Survey

- Julie Kiang, U.S. Geological Survey

- Robert Mason, U.S. Geological Survey

- Peter McCarthy, U.S. Geological Survey

- Jim O'Connor, U.S. Geological Survey

- Greg Pederson, U.S. Geological Survey

- Karen Ryberg, U.S. Geological Survey

- Andrea Veilleux, U.S. Geological Survey

- Hosung Ahn, Nuclear Regulatory Commission

- Laurel Bauer, Nuclear Regulatory Commission

- Meredith Carr, Nuclear Regulatory Commission

- Yuan Cheng, Nuclear Regulatory Commission

- Mark Fuhrmann, Nuclear Regulatory Commission

- Joseph Kanney, Nuclear Regulatory Commission

- Michael Lee, Nuclear Regulatory Commission

- Lisa Davis, University of Alabama

- Rachel Lombardi, University of Alabama

- Matthew Therrell, University of Alabama

- Victor Baker, University of Arizona

- Danielle Thomas, University of Iowa

- Judith Avila, University of Minnesota

- Amanda Hefner, University of Minnesota

- Scott St. George, University of Minnesota

- Joseph Giacinto, Nuclear Regulatory Commission

- Jeanne Godaire, Bureau of Reclamation 


\section{Appendix 2. Incorporating Historical and Paleoflood Information in Probabilistic Flood-Hazard Analysis}

\section{By Meredith L. Carr, Nuclear Regulatory Commission}

Risk informed decision-making (RIDM) supports "high impact, complex decisions involving multiple objectives in the presence of uncertainty" (Zio and Pedroni, 2012, abstract). RIDM is used in many industries, including energy, security, environmental protection, regulation, and disaster preparedness. In flood analysis, RIDM primarily is used to assess critical infrastructure, such as dam safety and nuclear power, although environmental and ecological impacts also have been considered. Probabilistic risk assessment is a method that considers the likelihood of an event (for example, hydraulic hazard load in dam safety or an initiating event in nuclear safety), the fragility of the system, and the consequences. In dam safety, this risk is expressed by the equation (Smith and others, 2018a).

$$
\begin{aligned}
& \text { Risk }=P(\text { Hazard }) \times P(\text { FailurelHazard }) \\
& \times \text { Consequences } \mid \text { Failure }
\end{aligned}
$$

Multiple methods and combinations of methods may be used for probabilistic flood-hazard assessment (PFHA)/HHA. Statistical methods, such as the flood-frequency analysis, fit gaged and non-systematic data to parametric distributions to extend the flood-hazard curves to relevant annual exceedance probabilities. Stochastic, or full probabilistic watershed model, methods use precipitation data or streamflow inputs while allowing for sampling of different hydrologic and operations factors in the watershed response to provide a probabilistic hazard for input to risk models (for example, U.S. Army Corps of Engineers [USACE] Hydrologic Engineering Center Watershed Analysis Tool, HEC-WAT; Dunn and Baker, 2010). Many events can be simulated to produce a set of output hydrographs or peak elevations that provide a mean and uncertainty. One class of models focuses on sampling the hydrometeorological inputs and uses a deterministic watershed model (for example, Stochastic Event Flood Model (SEFM): MGS Software LLC, 2018). A peer review team for the Tennessee Valley Authority Stochastic Precipitation Frequency-Based Model concluded that watershed characteristics contributing the most to uncertainty are site-specific. They recommended reviewing watershed specifics and even conducting a study using a flow/ volume-based model with paleoflood data to improve confidence in the results for use in decision-making (England and Stedinger, 2017).

Paleoflood information directly informs many of the stochastic models through flood-frequency inputs (for example, scaling of hydrographs), calibration (for example, floodfrequency analysis quantiles inform calibration for extreme flood response), or comparison and combination with precipitation-based models. Some of the methods for PFHA/HHA that use paleoflood information are presented in table 2.1.

Examples of paleoflood/historical data applied in PFHA/ HHA studies are as follows:
- Flood-frequency analysis: See examples for the Paleoflood Analysis and Review Levels.

- Scaled hydrographs:

- Glendo Dam, Wyoming, and Folsom Dam, California-Design modifications at Folsom and Glendo Dams used flood-frequency analysis (informed by paleoflood data) to scale several hydrographs to assess risks of modifications (Bureau of Reclamation, 2002; Levish and others, 2003).

- Calibration of watershed models:

- Friant Dam, California-The peak discharge annual exceedance probability curve was calculated downstream from Redinger Dam, California, using an expected moments algorithm (EMA) with a logPearson Type III statistical distribution to incorporate paleoflood and historical data (Wright and others, 2013). These curves were used to calibrate the annual peak discharge curve downstream from Redinger Dam generated by SEFM.

- Alberche River, Spain-Ballesteros and others (2011) demonstrated the use of tree-ring-derived paleoflood data in an ungaged catchment to calibrate roughness for a distributed rainfall-runoff model.

- Combination with stochastic event models or confirmation:

- Altus Dam, Oklahoma-For the Altus Dam Corrective Action Study, EMA-based floodfrequency analysis with thresholds based on paleofloods and non-exceedance bounds (Godaire and Bauer, 2012a) was compared with a stochastic model (SEFM; MGS Software LLC, 2018). The paleoflood data-informed flood-frequency curve was used to select the input precipitation frequency curve for production hydrologic hazard curves for risk analysis from the SEFM model (Novembre and others, 2012).

- Cherry Creek Dam, Colorado-In support of the dam safety modification study, flood frequency was analyzed using Bulletin 17C methods in Hydrologic Engineering Center Statistical Software Package with paleoflood and historical data (Pearce, 2017). The flood frequency was used in inflow volume calculations; hydrograph shapes and initial reservoir levels were modeled in the USACE Risk Management Center- Reservoir Frequency Analysis tool to combine their uncertainties and produce the stage frequency curve for assessing overtopping risk (Margo, 2017). 
- Stochastic flow frequency-based watershed models:

- The Willamette River Basin study (Oregon) used 70 years of hydrologic data (that is, flows and forecasts) to generate 16 synthetic floods to run a HEC-WAT model on the Columbia River. Studies on tributaries of the Willamette River incorporated in the larger model included paleoflood data (Dunn and others, 2016; Bahner and Duren, 2019).
- Stochastic precipitation frequency-based models:

- The Whittier Dam (California) hydrologic hazard curve was developed from peak-streamflow data (including historical event data) and rainfall data (Smith and others, 2018b).

Table 2.1. Methods for probabilistic flood-hazard assessments or hydrological hazard assessments that can incorporate historical and paleoflood data.

[Abbreviations: AEP, annual exceedance probability; HEC-WAT, Hydrologic Engineering Center Watershed Analysis Tool; SEFM, Stochastic Event Flood Model]

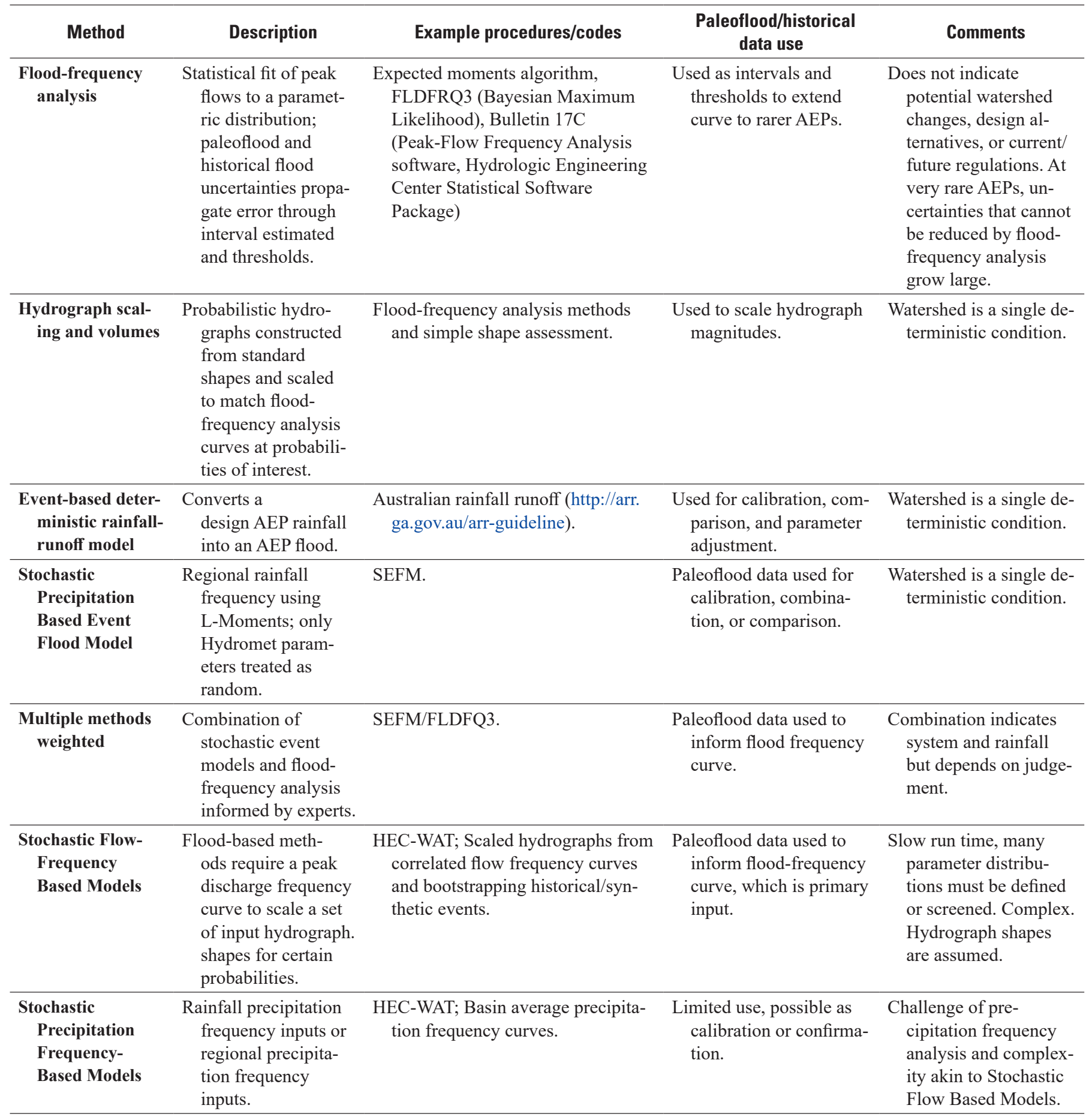



Publishing support provided by the U.S. Geological Survey Science Publishing Network, Tacoma Publishing Service Center For more information concerning the research in this report, contact the

Director, Oregon Water Science Center

U.S. Geological Survey

2130 SW 5th Avenue

Portland, Oregon 92701

https://www.usgs.gov/centers/or-water 

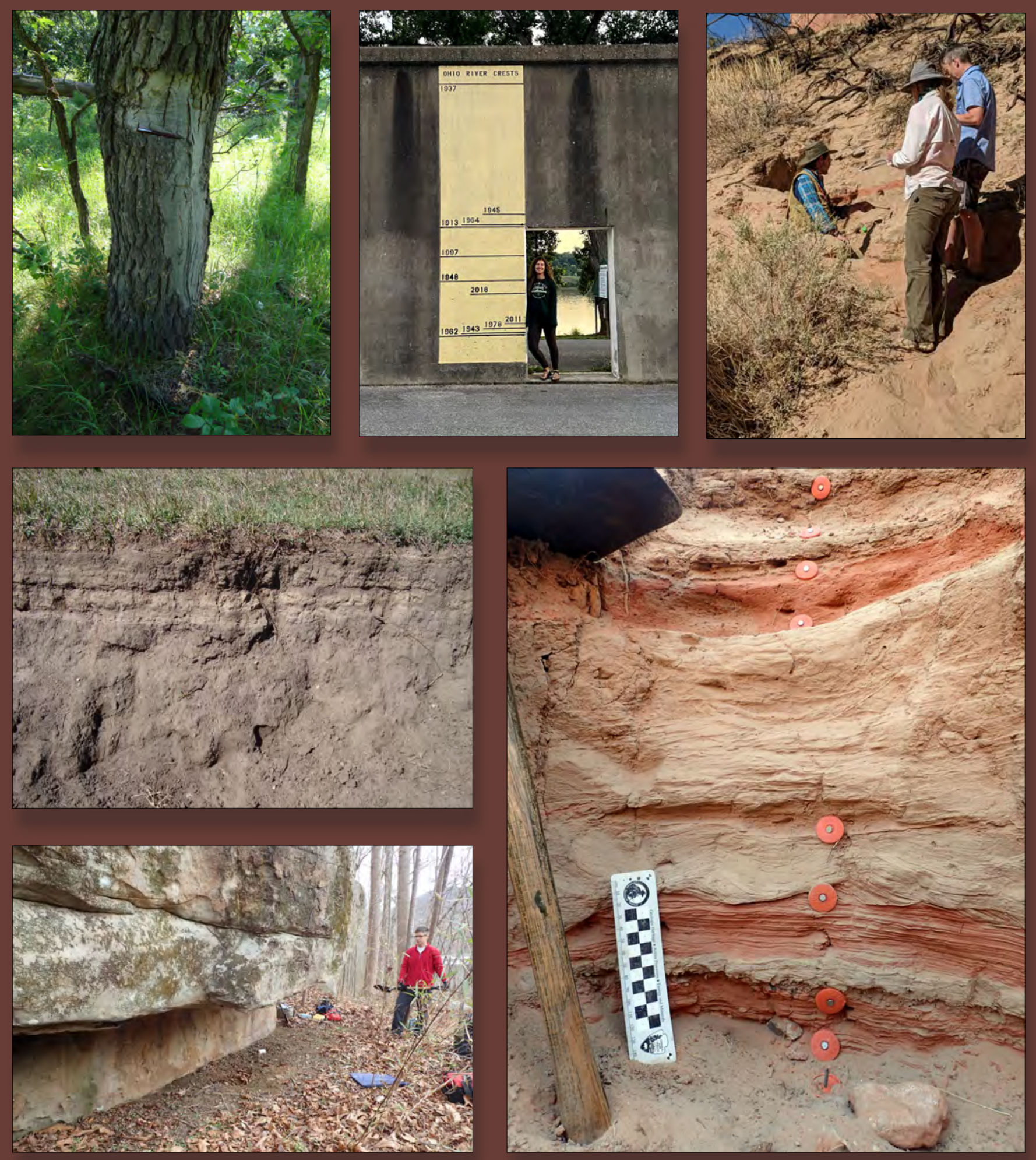